SDPS-001-0

June 2013

VOLUME 1

U.S. Department of Energy

Space and Defense Power Systems Program

TEN-YEAR GTRA TEGIE PLAN

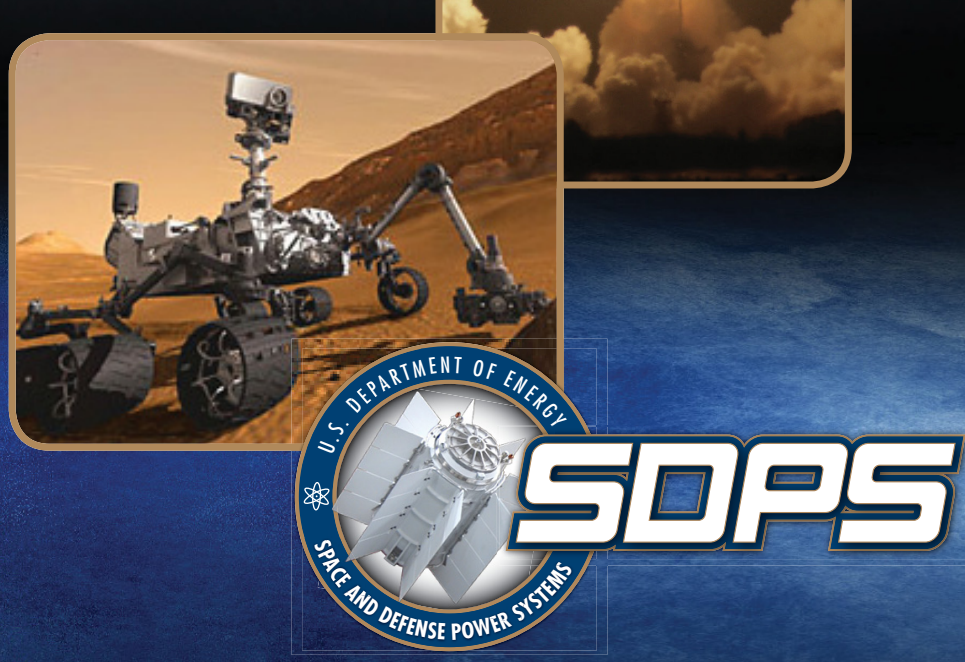


SDPS-001-0

June 2013

VOLUME 1

U.S. Department of Energy

Space and Defense Power Systems Program TEN-YEAR STRATECIC PLAN

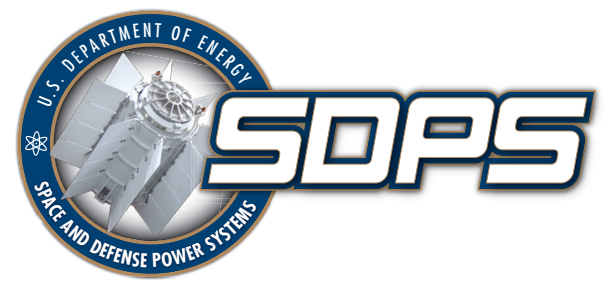




\title{
Space and Defense Power Systems
}

\section{Ten-Year Strategic Plan}

\author{
INL/MIS-13-29522 \\ SDPS-001-0 \\ Volume 1 \\ June 2013 \\ Prepared for: \\ Department of Energy \\ Office of Nuclear Energy \\ Space and Defense Power Systems (NE-75) \\ Prepared by: \\ Idaho National Laboratory \\ Radioisotope Power Systems \\ Technical Integration Office \\ Idaho Falls, ID
}




\section{FOREWORD}

$\mathrm{T}$

The Department of Energy's Space and

Defense Power Systems program provides

a unique capability for supplying power systems

that function in remote or hostile environments.

This capability has been functioning since the early

1960s and counts the National Aeronautics and

Space Administration as one of its most prominent

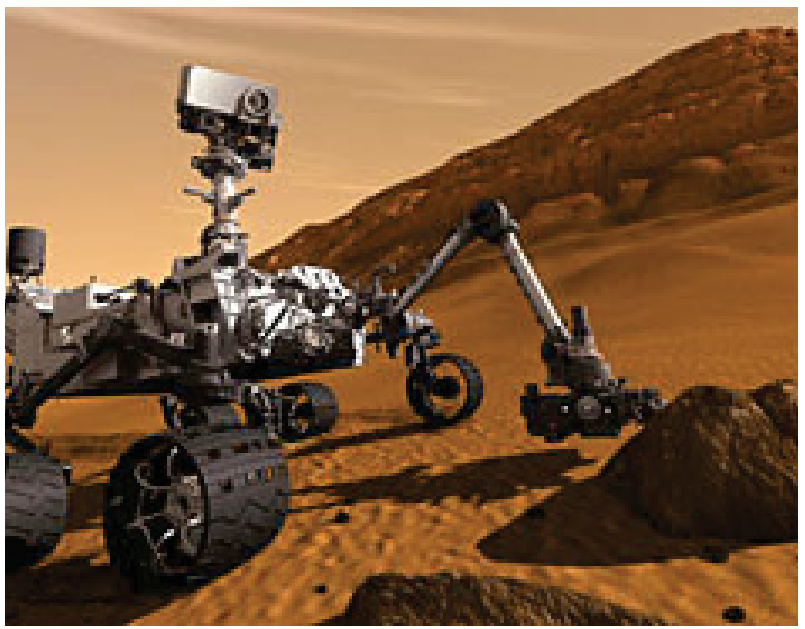

customers. This enabling technology has assisted

the exploration of our solar system including the

planets Jupiter, Saturn, Mars, Neptune, and soon

Pluto. This capability is one-of-kind in the world

in terms of its experience (over five decades),

breadth of power systems flown (over two dozen

to date) and range of power levels (watts to hun-

dreds of watts). This document describes the

various components of that infrastructure, work

scope, funding needs, and its strategic plans going

forward. 
TEN-YEAR STRATEGIC PLAN 


\section{TABLE OF CONTENTS}

1. INTRODUCTION

2. TECHNICAL OVERVIEW.

3. CURRENT PROGRAM PARTICIPANTS

AND ROLES........................

3.1 Oak Ridge National Laboratory...........8

3.2 Los Alamos National Laboratory............11

3.3 Idaho National Laboratory .............. 12

3.4 Sandia National Laboratories. ............. 14

4. HISTORICAL SUMMARY AND

ACCOMPLISHMENTS......................15

5. STRATEGIC PATH FORWARD AND GOALS ...... 18

5.1 Radioisotope Power System

Infrastructure....................18

5.1.1 Oak Ridge National Laboratory ....... 18

5.1.2 Los Alamos National Laboratory ....... 18

5.1.3 Idaho National Laboratory........... 19

5.2 DOE-Funded Infrastructure versus

Operations in a Campaign Mode for

Radioisotope Power System Production ..... 19

5.3 Path Forward for Radioisotope Power System Infrastructure.................20

5.4 Pu-238 Supply Project .................22

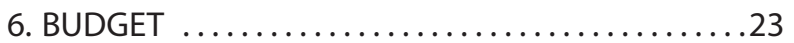

\section{Figures}

Figure X. Pu-238 dioxide pressed pellet prior to encapsulation into iridium alloy cladding. ......................

Figure 1. General purpose heat source module. ... 4

Figure 2. Multimission radioisotope thermoelectric generator. ............5

Figure 3. Advanced Stirling Radioisotope Generator. ....................6

Figure 4. Department of Energy role in National Aeronautics and Space Administration launches with radioisotope power systems and radioisotope heater units. . . .8

Figure 5. Iridium alloy clad vent set............9

Figure 6. Light weight radioisotope heater unit components. ................... 9

Figure 7. Carbon bonded carbon fiber components. 10

Figure 8. Aqueous processing gloveboxes at Los Alamos National Laboratory and pressed Pu-238 dioxide fuel pellets ready for encapsulation into iridium alloy clads. ...11

Figure 9. Preparing to fuel the multimission radioisotope thermoelectric generator in the Inert Atmosphere Assembly Chamber. .12

Figure 10. Graphite modules at the Engineering Development Laboratory prior to insertion of $\mathrm{Pu}-238$ fuel clads and radioisotope power system fueling................12 
Figure 11. Radioisotope thermoelectric generator transportation system trailer for 9904 casks in the Radioisotope Systems Training and Servicing Facility. ..................12

Figure 12. Hot fit check of the multimission radioisotope thermoelectric generator with the Mars Science Laboratory Curiosity rover.....................13

Figure 13. Fuel clad after a safety verification test. ............................14

Figure 14. High Flux Isotope Reactor at Oak Ridge National Laboratory.............20

Figure 15. Pu-238 production summary process flow.......................21

\section{Tables}

Table 1. U.S. missions using radioisotope power systems and light-weight radioactive heater units. ......................16

Table 2. Radioisotope power system infrastructure summary budget $(\$ K)$, FY12 through FY18............................23

Table 3. Pu-238 supply project annual infrastructure operating budget (beginning FY16)...................23

ACRONYMS AND ABBREVIATIONS ..............24 


\section{INTRODUCTION}

$\mathrm{T}$ he Atomic Energy Act of 1954 (as amended) ${ }^{1}$ establishes the unique responsibilities of the Department of Energy (DOE) for handling special nuclear material, maintaining national nuclear infrastructure, and developing nuclear systems. This includes responsibility for building and maintaining the capability to produce the radioisotope power system and radioisotope heater unit, both powered by the radioactive decay of plutonium-238 (Pu-238) for the U.S. space program, as well as national security missions. Within the DOE Office of Nuclear Energy (NE), the Office of Space and Defense Power Systems (SDPS) (NE75) funds and maintains this capability in a ready status. SDPS conducts and manages the production activities for user agencies, with the user funding the incremental costs of the production. As required by law, DOE retains ownership and accountability for the $\mathrm{Pu}-238$ and maintains close liaison with users.

\section{SDPS conducts and manages}

\section{the production activities for user}

\section{agencies, with the user funding the incremental costs of the} production.

Before 1989, DOE produced Pu-238 at the Savannah River Site (SRS) in South Carolina in nuclear reactors that are now decommissioned. From 1989 through 2009, existing DOE inventories of Pu-238 were supplemented by quantities of $\mathrm{Pu}-238$ purchased from Russia; however, supplies available for purchase from Russia are limited. DOE must

\section{DOE's SDPS Program}

Program Focus:

- Provides unique-in-the-world capabilities critical to space exploration, pioneered by the United States, the world's only current radioisotope power system producer.

- Conducts and manages production activities for NASA and other user agencies through a collaboration of agencies, national laboratories and industrial partners; as required by law, however, DOE retains ownership and accountability for all nuclear materials involved.

- Has enabled the United States to accomplish critical national missions by improving navigation, weather forecasting, communication, and exploration of the solar system, as well as maintaining national security.

- Has successfully fulfilled NASA's space power needs for decades, but requires some new capabilities as well as upgrades to others that are seriously underperforming.

- Needs to pursue the following areas of work aggressively to provide (1) what is necessary but missing (isotope production and power conversion system development); (2) improve what is present but underperforming (heat source production) for the radioisotope power system production pipeline; and (3) maintain that which is operational and reliable (component production, fueling and testing of radioisotope power system units). 
now restore domestic production to meet future demand; otherwise, the National Aeronautics and Space Administration (NASA) will be in danger of not being able to use radioisotope power systems in future missions. Congress approved funding to restart domestic production in 2011, and the DOE SDPS established the Pu-238 Supply Project to provide the technologies, logistical pathways, and capabilities to produce $\mathrm{Pu}-238$ oxide powder at a rate of 1.5 to 2 kilograms/year.

NE-75 operates complex process development and production facilities at three national laboratories - Los Alamos National Laboratory (LANL), Oak Ridge National Laboratory (ORNL), and Idaho National Laboratory (INL) - and maintains material and staff assets to support NASA launch activities for radioisotope power system- and/or radioisotope heater unit-equipped missions. Sandia National Laboratories (SNL) also has a significant role in SDPS for planning safety verification tests for specific heat sources, and for performing safety analyses for specific NASA missions. DOE also performs a number of activities to support successful launches for NASA missions, such as National Environmental Policy Act (NEPA) analyses, radiological contingency planning, nuclear safety and security, and risk communications. Given the scope of the operations and the capital investment at the facilities, a Ten-Year Strategic Plan ${ }^{2}$ is considered appropriate. NE-75 developed this TenYear Strategic Plan, and will continue to maintain it. The primary purpose of this Plan is to inform the annual budget process, and to serve as a reference for SDPS participants and interested parties.

2. Modeled on the 10-Year site planning process described in DOE Order 430.1B, Real Property Asset Management.

\section{DOE's SDPS Program}

Program Goals:

1. Re-establish a reliable means of providing usable Pu-238 for manufacturing into heat sources for NASA and national security customers.

2. Increase reliability and dependability of heat source production.

3. Re-establish a prototype development and testing capability for new power conversion systems.

4. Reinvigorate the existing safety verification test program to provide for an enhanced database to support the previous goals.

This Plan provides additional discussion about the role of DOE and each participating laboratory in supporting the radioisotope power system infrastructure and the Pu-238 Supply Project, as well as a historical summary of radioisotope power system and radioisotope heater unit use since their inception in 1954. Volume 1 focuses on the strategic path forward and goals for SDPS, followed by projected budget needs for the next 10 years. Volume 2 provides more detail about each laboratory, various historical aspects, and basic information about $\mathrm{Pu}-238$.

This Plan does not address national security radioisotope power system missions or space reactor technology development. 


\section{TECHNICAL OVERVIEW}

$\mathrm{T}$

he production of radioisotope power sys-

tems has been an ongoing endeavor for the DOE and its predecessor agencies for the past 5 decades. The overall mission of the radioisotope power system program is to develop, demonstrate, and deliver compact, safe nuclear power systems and related technologies for use in remote, harsh environments (i.e., space) where it is impractical to provide the fuel and maintenance that more conventional electrical power sources require.

The heart of the radioisotope power system is a ceramic consisting of sintered $\mathrm{Pu}-238$ oxide
Radioisotope Generator (ASRG) (Figure 3), will use only two GPHS modules while providing the same power output as the MMRTG due to an increase in the efficiency of the conversion of heat to electricity. Once assembled, the radioisotope power system units are subjected to various test conditions, including vibration, mass properties, magnetics, and thermal vacuum. Once tested, the radioisotope power system units are stored until they are transported to Kennedy Space Center (KSC) in Florida for integration with the spacecraft, or other client-specified location.

\section{The overall mission of the radioisotope power system Program is to develop, demonstrate, and deliver compact, safe nuclear power systems and related technologies for use in remote, harsh environments...}

encapsulated in an iridium alloy. Other heat source schemes may also be used. Through spontaneous radioactive decay of $\mathrm{Pu}-238,0.56$ watts of thermal energy per gram of isotope $\mathrm{Pu}-238$ are produced. Heat produced is either used directly in the form of heat or used to power a converter that produces electricity. $\mathrm{Pu}-238$ oxide is processed and assembled into fuel clads, and then assembled into the standard building blocks used in today's radioisotope power systems, the General Purpose Heat Source (GPHS) (see Figure 1).

The required number of modules needed to provide the mission's electrical power are then assembled into the converter to make up the radioisotope power system. For the latest NASA mission that just landed on Mars, the multi-mission radioisotope thermoelectric generator (MMRTG) used eight GPHS modules to provide electricity and heat to the rover Curiosity (Figure 2). The next generation radioisotope power system, the Advanced Stirling

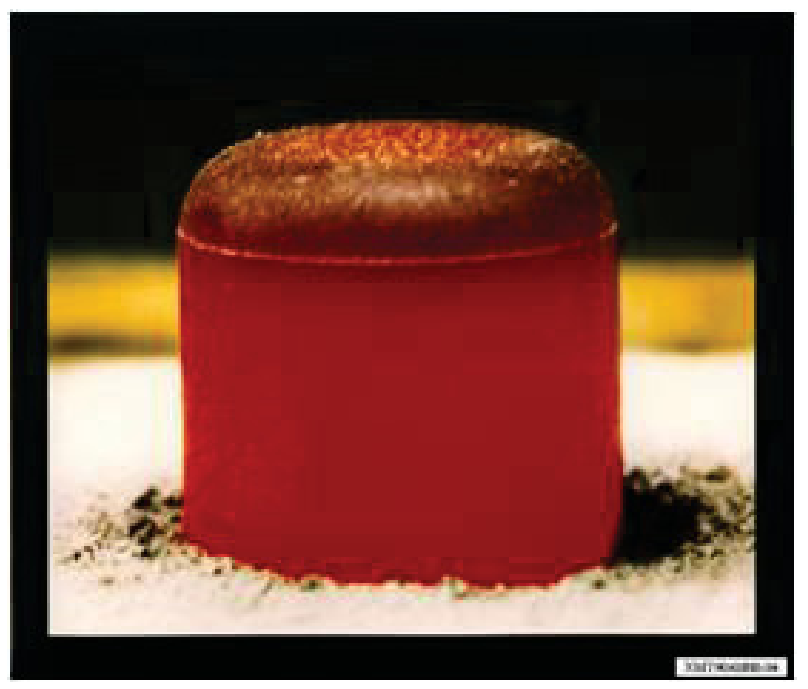

Figure X. Pu-238 dioxide pressed pellet prior to encapsulation into iridium alloy cladding. 


\section{GENERAL PURPOSE HEAT SOURCE (GPHS) MODULE}

$R_{\text {that continuously convert heat into electricity. The GPHS }}^{\text {adioisotope power systems are essentially nuclear batteries }}$ module is the "building block" of current U.S. designs of radioisotope power systems for space science and exploration missions.

The modules contain the heat-producing ceramic nuclear material — plutonium dioxide in a ceramic form. The principal isotope is Pu-238 that gives off heat as it naturally decays.

\section{Key Features}

- Mass: 3.5 lb (1.6 kg)

- Dimensions: $2 \times 4 \times 4$ inches $(6 \times 9 \times 10 \mathrm{~cm})$

- Thermal (heat) output: 250 Watts

- 4 fuel clads per module

- Fuel is assembled into GPHS

- Pu-238 is used for fuel

- Half life of 87.7 years

- Requires 1.8 grams to produce1-thermal watt of power

- Each GPHS Module contains $\sim 600$ grams plutonium dioxide in 4 Fuel Clads

- Pellet surface temp: $\sim 2700^{\circ} \mathrm{F}$

- Fuel Clad surface temp: $\sim 1600^{\circ} \mathrm{F}$

- Module surface temp: $1000^{\circ} \mathrm{F}$

- Fuel Clad dimensions

$\sim 1$ inch tall $x 1$ inch diameter

\section{Key Safety Features}

\section{Ceramic nuclear material (Pu-238 dioxide)}

- Formed into rugged pellets

- Robust to high temperatures

- Primarily fractures into large particles that cannot be inhaled

- Does not move easily through the environment

\section{Metal cladding surrounding the nuclear} material (iridium alloy)

- Protects against high temperature impacts

- Compatible with fuel and graphitics

\section{GPHS modules (graphite)}

- Protects fuel and cladding

- Insulate against high temperatures

- Provide impact protection

- Aeroshell protects against threat of atmospheric re-entry.

GENERAL PURPOSE HEAT SOURCE

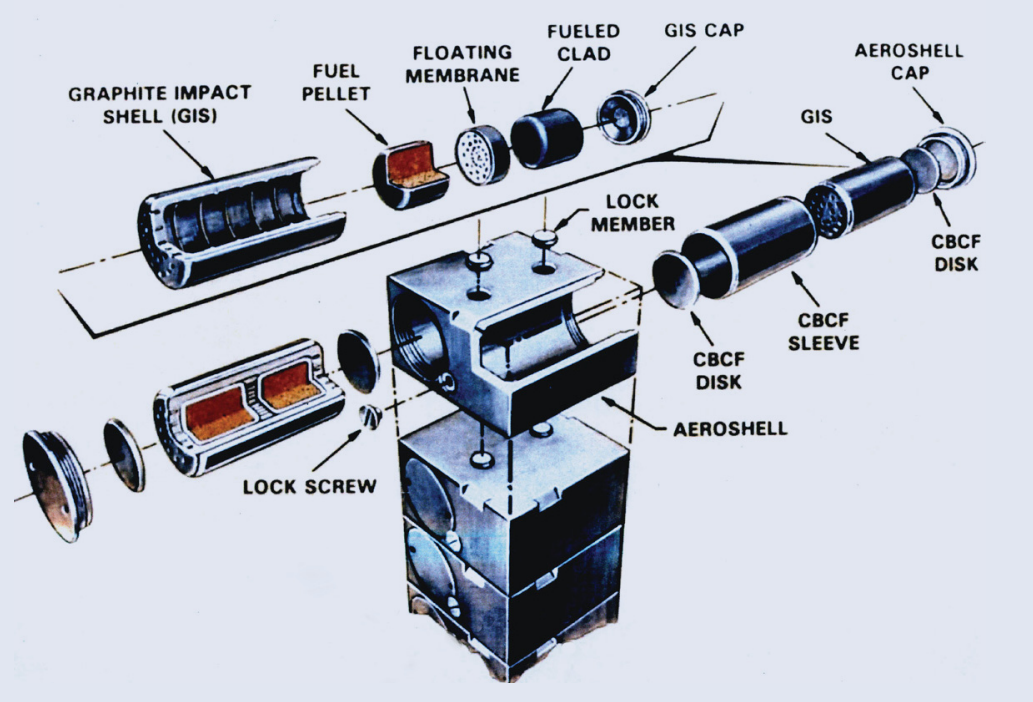




\section{MULTI-MISSION RADIOISOTOPE THERMOELECTRIC GENERATOR (MMRTG)}

The MMRTG is essentially a nuclear battery. The MMRTG is fueled with plutonium dioxide in a ceramic form. The principal isotope is Pu-238 that gives off heat as it naturally decays. No moving parts are required to convert this heat into electricity. The system uses thermocouples to reliably create an electrical current from the temperature difference between the nuclear material and the cold of space or the surface of Mars.

\section{Key Features}

- Mass of MMRTGS: $94 \mathrm{lb}(45 \mathrm{Kg})$

- Length: 26 in $(67 \mathrm{~cm})$

- Diameter: 25 in $(64 \mathrm{~cm})$

- Electrical output: 110 watts
- Thermal (heat) output: 2000 Watts

- MMRTG design lifetime: 14 years

- Mass of nuclear material: 10.6 lb $(4.8 \mathrm{Kg})$ contained in - 8 GPHS modules - 32 fuel clads

- Dimensions $~ 26$ inches tall $\times 25$ inches diameter

- MMRTG contains 8 GPHS Modules

- MMRTG thermal (heat) output 2000 watts

- MMRTG electrical output at beginning of mission 110 watts

- System conversion efficiency 7\%

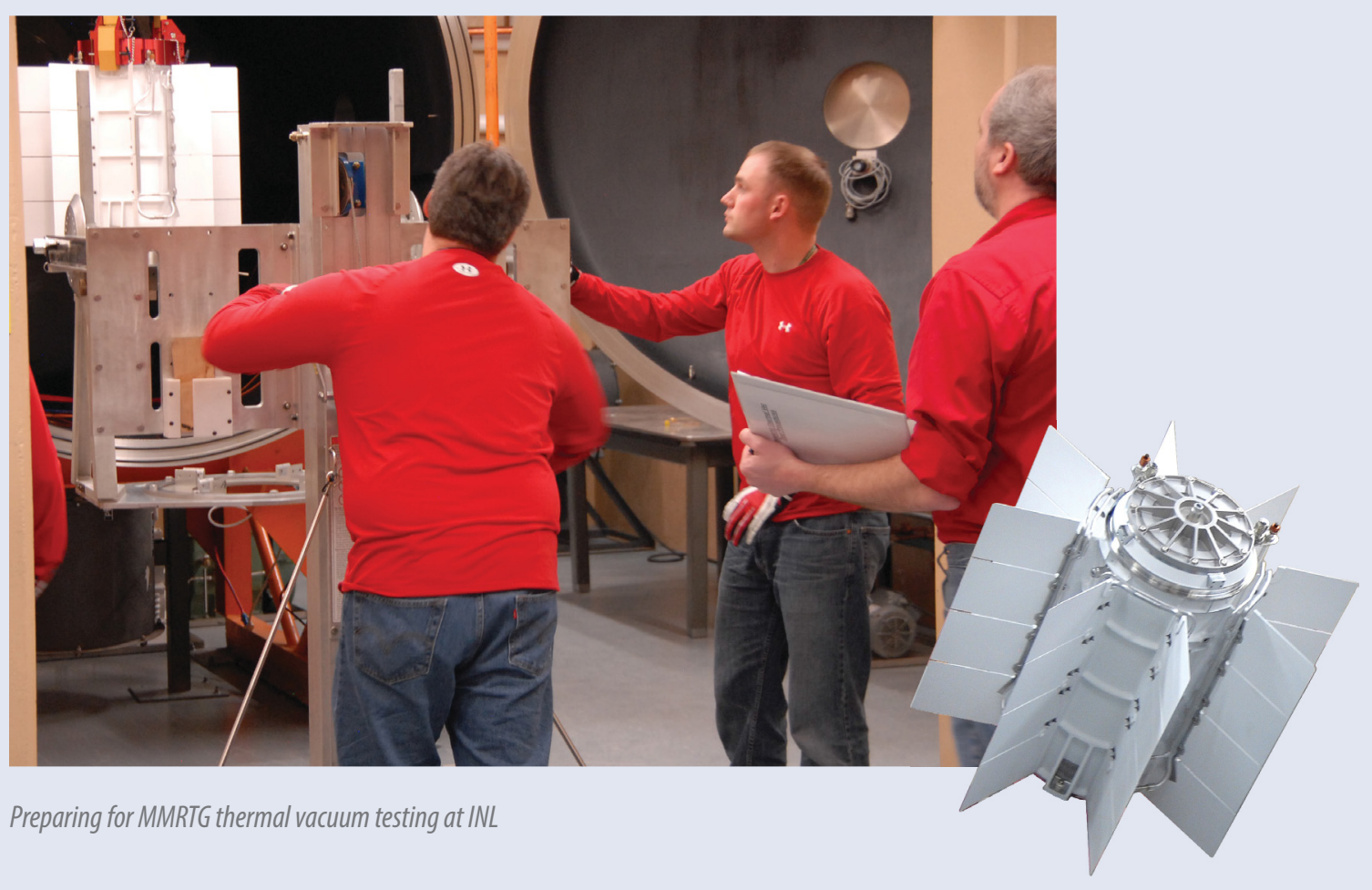

Figure 2. Multi-Mission radioisotope thermoelectric generator. 


\section{ADVANCED STIRLING RADIOISOTOPE GENERATOR (ASRG)}

For nearly 50 years, RTGs have provided safe, reliable electric Although RTGs have performed with exceptional reliability over very long mission durations, they are limited by the low conversion efficiency of thermoelectric materials, with system efficiencies typically ranging from about $5-7 \%$. Because Pu-238 is an extremely limited resource, for which the United States currently has no production capacity, DOE and NASA are pursuing higher-efficiency systems such as the ASRG that would reduce the amount of Pu-238 required for a given electric power output. Each ASRG is projected to produce 130-140 Watts of power using less than $1 \mathrm{Kg}$ of Pu-238 fuel. This is less than 25\% of the Pu-238 that would be required for a comparable RTG.

The ASRGs advancements are made possible by the use of highly efficient Stirling engines coupled with linear alternators (together known as Advanced Stirling Convertors, or ASCS) to convert the natural radioactive decay heat of Pu-238 into electricity. Although Stirling engines have been in use since the early 1800s, they pose some challenges that must be overcome before they can be used in spacecraft. Unlike RTGs, the ASRG is a complex thermodynamic system with moving parts. Their level of complexity is manageable and will be worth accepting to gain the benefits offered by the ASRG, once it has been proven to offer the high reliability demanded of spacecraft power systems. Before the ASRG can be considered as an alternative to RTGs for NASA missions, a flight-like system must be built and demonstrated, and its reliability must be well understood. These are the primary near-term goals of the ASRG Project.

The ASRG builds on years of Stirling convertor technology development and reliability testing. A flight-like engineering unit ASRG was tested during the first part of 2008. The generator underwent a series of tests to characterize its performance in a variety of environments, including vibration, shock and thermal vacuum tests that simulate the environments the system must survive during launch and in space. After qualification, a flight generator could be available for NASA mission use as early as 2015.
The ASRG is being developed by Lockheed Martin Space Systems Company, under contract to DOE. It has been designed to meet a generic "multi-mission" requirements set that includes both deep space and Mars surface environments.

It is designed as a modular, self-contained unit. The heat input to the ASRG is provided by two GPHS modules, which generate heat through the radioactive decay of Pu-238. Each GPHS module will produce roughly 250 thermal watts at launch, decaying to approximately 224 watts by the end of a 14-year mission. This heat is converted to electricity by the ASC, developed by Sunpower, Inc. under a NASA Research Announcement award with GRC. Sunpower and GRC are also implementing improvements to the ASC that allow it to operate at a higher temperature. Higher temperature operation will increase the power output for the same amount of radioisotope fuel. 


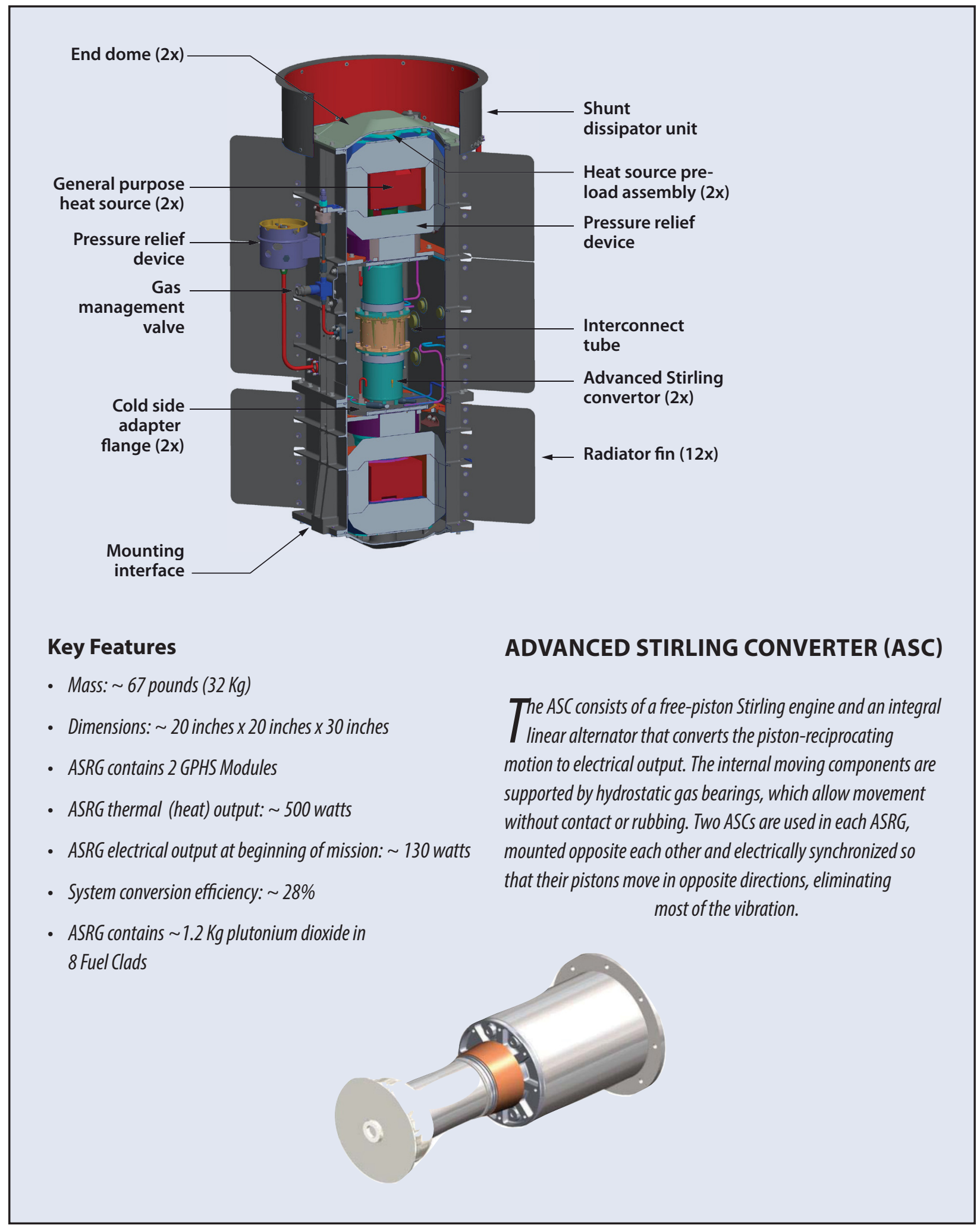




\section{CURRENT PROGRAM PARTICIPANTS AND ROLES}

$\mathrm{T}$

he radioisotope power system infrastructure can be characterized as a geographically dispersed collection of equipment and highly trained technical staff at DOE and several national laboratories (i.e., ORNL, LANL, INL, and SNL) organized to perform a sequential process with no redundancy of key functions. The following subsections briefly describe each site and its role. Figure 4 depicts the critical roles that DOE and its contractors play in a successful nuclear launch for NASA.

\subsection{Oak Ridge National Laboratory}

As part of the radioisotope power system infrastructure, ORNL produces the special iridium-alloy metal containment, or cladding, for the Pu-238 fuel pellets manufactured at LANL (called clad vent sets in their final configuration, as shown in Figure 5). ORNL then ships these sets to LANL, where they are used to encapsulate the Pu-238 fuel pellets. LANL then ships the resulting encapsulated pellets (GPHS fuel clads) to INL where they are inserted into graphite components to form GPHS modules. The modules are then inserted into converters to form radioisotope power systems.

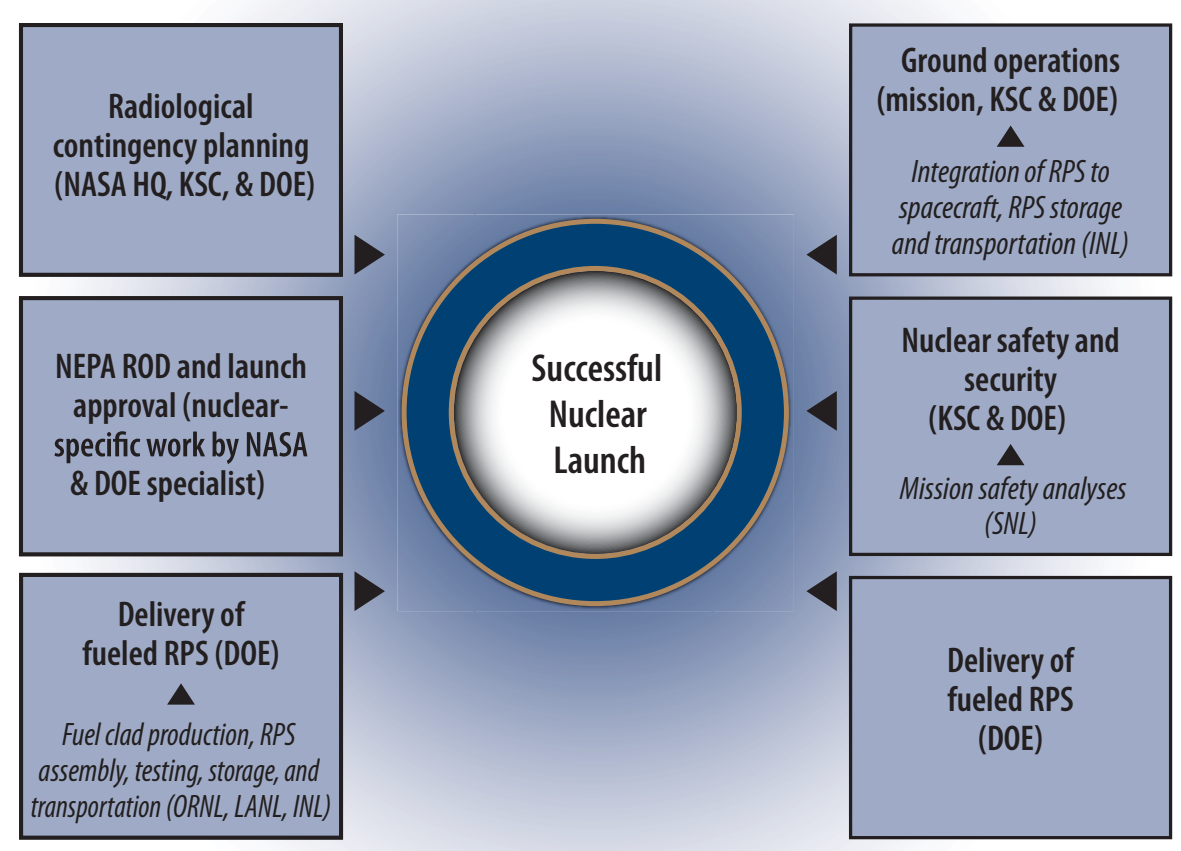

Figure 4. Department of Energy role in National Aeronautics and Space Administration launches with radioisotope power systems and radioisotope heater units. 
DOE SPACE AND DEFNESE

POWER SYSTEMS PROGRAM
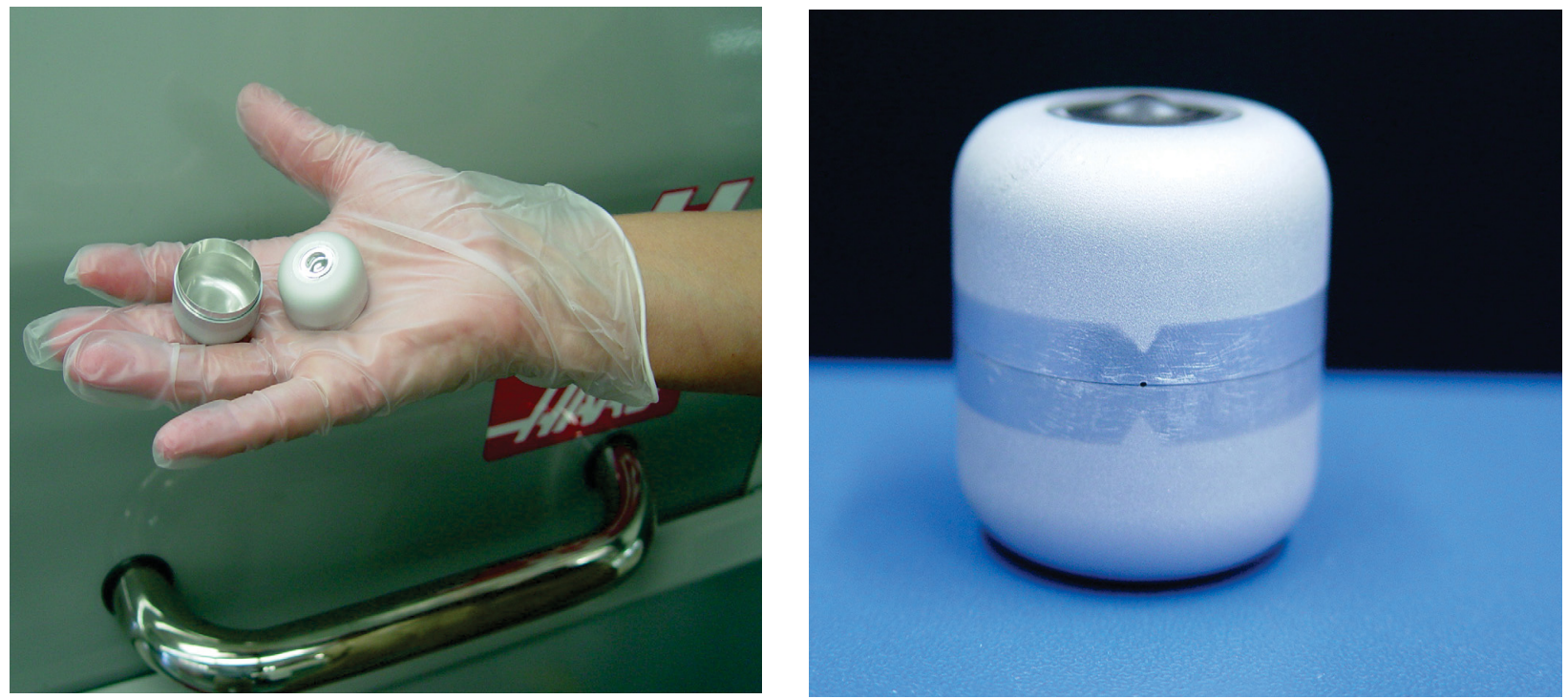

Figure 5. Iridium alloy clad vent set.
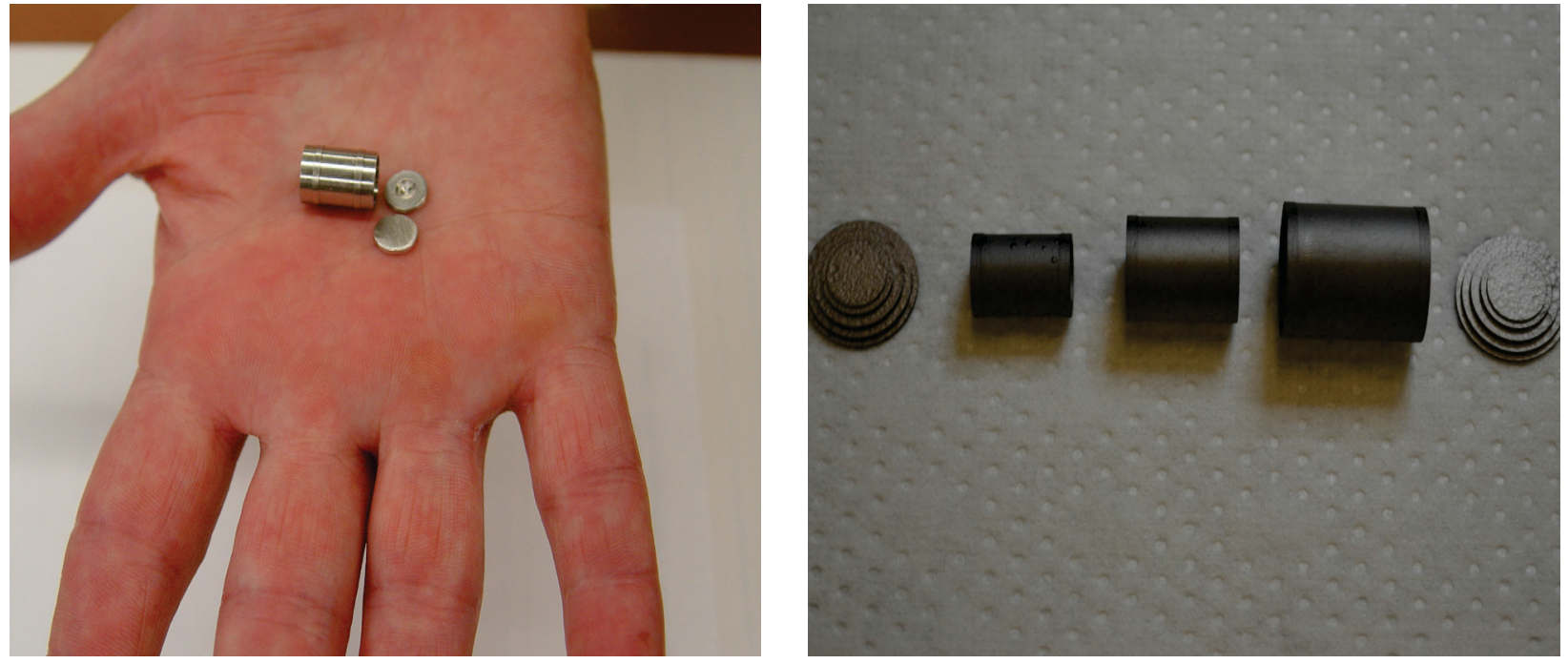

Figure 6. Light weight radioisotope heater unit components. 
ORNL also produces special platinum-rhodium alloy metal clads and ships them to LANL for use in encapsulating very small $\mathrm{Pu}-238$ pellets, which are ultimately used to fabricate the Light Weight Radioisotope Heater Unit (LWRHU). The LWRHU components are shown in Figure 6. NASA uses the LWRHUs for warming critical components, instrumentation, lubricating fluids, and thruster fuel during planetary space exploration missions and some Earth orbit missions.

ORNL also produces carbon-bonded/carbon-fiber (CBCF) insulator sleeves, which provide thermal insulation for the GPHS fuel clads installed in the GPHS modules. The CBCF components are shown in Figure 7.

\section{ORNL is the lead materials development laboratory for the DOE SDPS Program.}

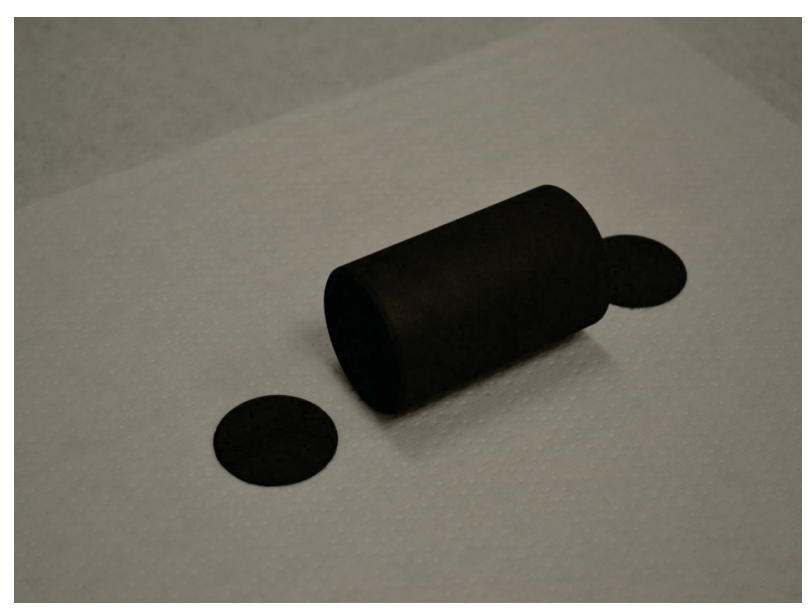

ORNL is the lead materials development laboratory for the SDPS Program. DOE supports a total of 10 full-time equivalents (FTEs) at ORNL in a base capability mode, which allows them to maintain key functions/facilities for the radioisotope power system program that would otherwise be difficult to duplicate or to stand up upon demand. These unique facilities, equipment, and trained personnel provide:

- Development, testing, welding, characterization, and production of materials for high-temperature heat source applications

- Expertise in iridium alloys, a capability that is a unique national asset

- Refractory and other high-temperature metal/ materials compatibility and mechanical properties testing (i.e., tensile, creep, and pressure burst)

- Expertise in $\mathrm{CBCF}$ insulator production, which is also a unique capability.

ORNL also serves as the project management organization, primary separation location for $\mathrm{Pu}-238$, and one of two irradiation facilities for neptunium targets (the precursor material for $\mathrm{Pu}-238$ ), for the DOE SDPS Pu-238 Supply Project. 


\subsection{Los Alamos National Laboratory} solution and precipitation purification process; it is then converted into a ceramic form, pressed into pellets, and encapsulated in clad vent sets supplied by ORNL. All processing of $\mathrm{Pu}-238$ oxide must take place in tightly sealed gloveboxes maintained under negative pressure to ensure no leaks of fuel into the workspaces.

Figure 8 shows an example of the size and complexity of the LANL glovebox installations required for fuel clad and radioisotope heater unit production. The SDPS gloveboxes are housed in the Plutonium Facility at LANL Technical Area 55 (TA-55). DOE supports a total of 45 FTEs at LANL in a base capability mode, which allows them to maintain key functions/facilities for the radioisotope power system program that would otherwise be difficult to duplicate or to stand up upon demand. LANL provides the following capabilities for the radioisotope power system program:
At LANL, Pu-238 oxide powder undergoes a dis-

- Purification of $\mathrm{Pu}-238$ feedstreams

- Ceramic heat source production

- Experimental facilities for safety verification impact tests

- Analytical chemistry and material science capabilities in support of heat source production

- Radiography of heat sources

- Production of LWRHU

- Safe and secure storage of Pu-238 stockpile.

LANL also participates in the Pu-238 Supply Project, providing technical consulting services for the $\mathrm{Pu}-238$ oxide that will be produced by ORNL - the starting material for heat source production at LANL.

\section{LANL supports the DOE SDPS Program as the lead for Pu-238 oxide processing and fuel clad fabrication.}
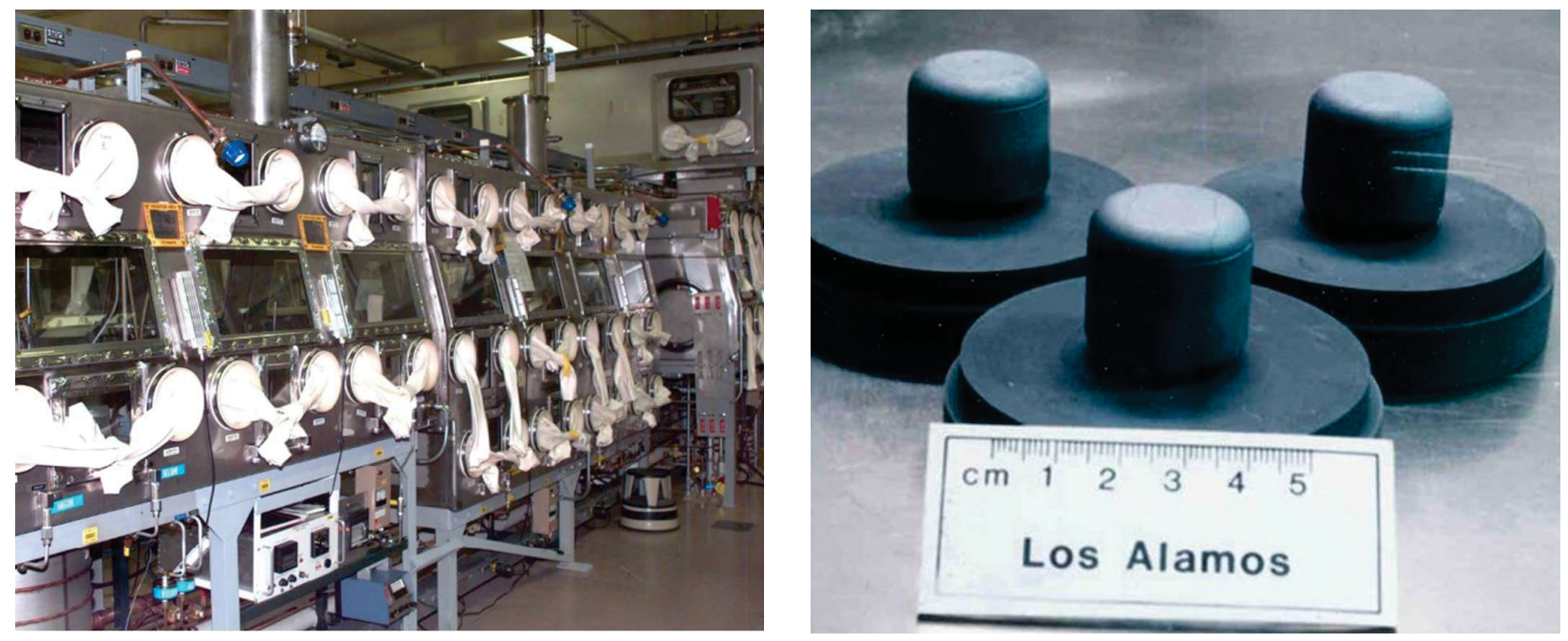

Figure 8. Aqueous processing gloveboxes at Los Alamos National Laboratory (left) and pressed Pu-238 dioxide fuel pellets ready for encapsulation into iridium alloy clads (right). 


\subsection{Idaho National Laboratory}

INL is responsible for assembly, testing, storage, and transportation of radioisotope power systems to user destinations and ground support at KSC in Florida. At the Space and Security Power Systems Facility (SSPSF), INL receives fuel clads from LANL and assembles them into graphite module components (Figure 9) to form the GPHS fuel modules (Figure 10). The modules are then assembled into converters to become radioisotope power systems. The radioisotope power system units are tested and stored after assembly until they are transported to KSC. The SSPSF is dedicated solely to SDPS activities.

A total of 35 FTEs are supported at INL in a base capability mode by DOE, which allows them to maintain key functions/facilities for the radioisotope power system program that would otherwise be difficult to duplicate or to stand up upon demand. These capabilities include:

- High-temperature bake-out of key components in the Engineering Development Laboratory.

- The only radioisotope power system fueling capability outside of Russia in the world. This facility has fueled radioisotope power system units of several designs and is now preparing to fuel the Stirling engine-based radioisotope power system unit under development.

\section{INL is responsible for}

\section{assembly, testing, storage, and transportation of radioisotope power systems.}

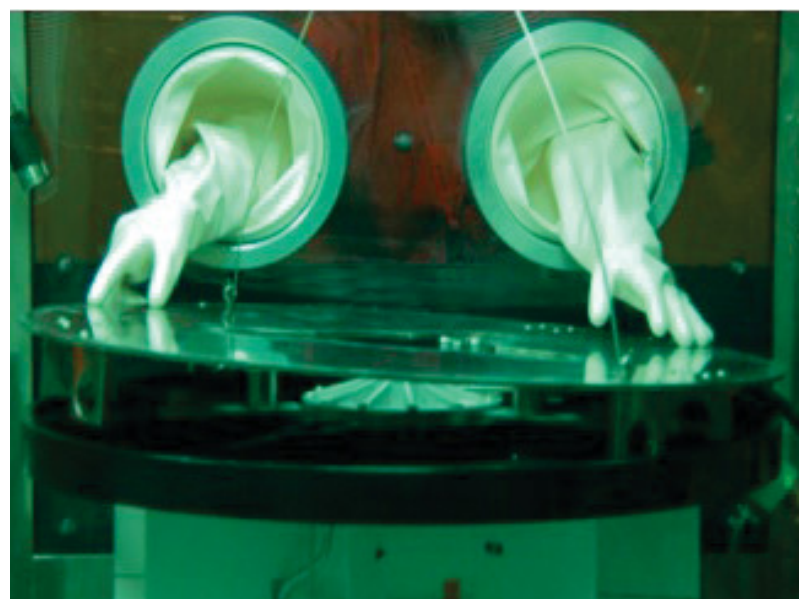

Figure 9. Preparing to fuel the Multi-Mission Radioisotope Thermoelectric Generator in the Inert Atmosphere Assembly Chamber.

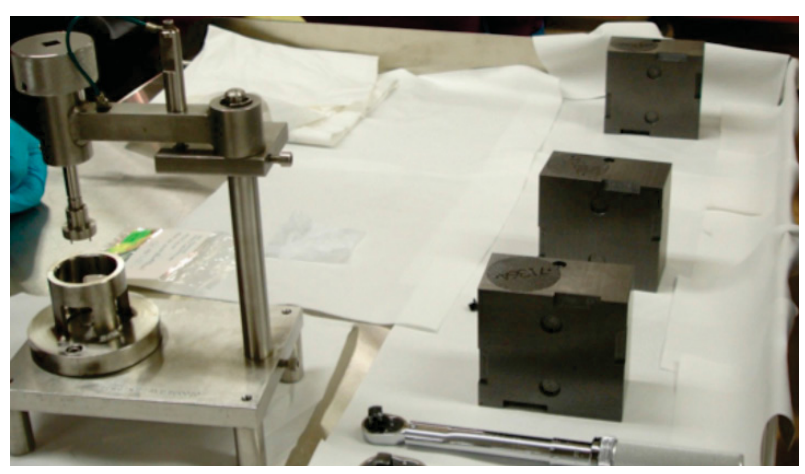

Figure 10. Graphite modules at the Engineering Development Laboratory prior to insertion of Pu-238 fuel clads and radioisotope power system fueling.

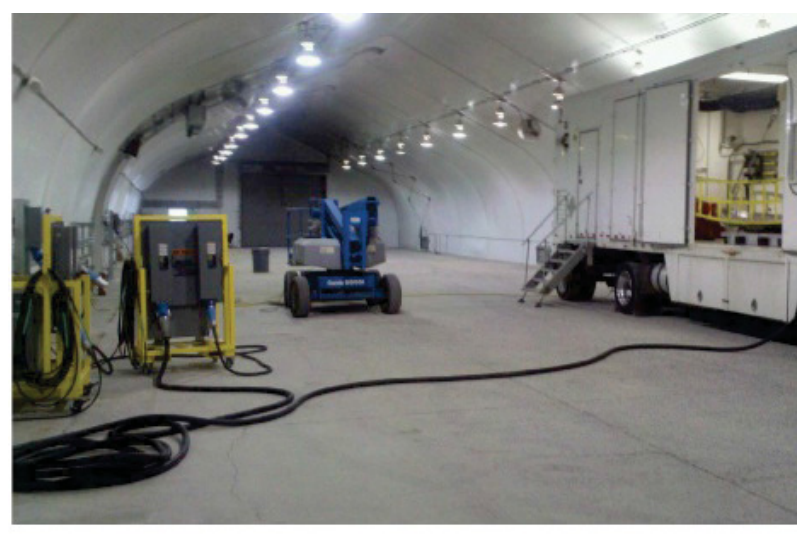

Figure 11. Radioisotope thermoelectric generator transportation system trailer for 9904 casks in the Radioisotope Systems Training and Servicing Facility. 
- A most complete acceptance testing facility for radioisotope power system units that allows for testing fully $\mathrm{Pu}-238$ fuel radioisotope power system units for vibration, magnetic properties, mass properties, and thermal vacuum power performance.

- A collection of 9904 type-B shipping containers for transporting radioisotope power system units for NASA or national security customers. These casks have active cooling and are matched with a dedicated set of trailers (radioisotope thermoelectric generator transportation system [RTGTS]) for transporting the radioisotope power system units to locations such as KSC.

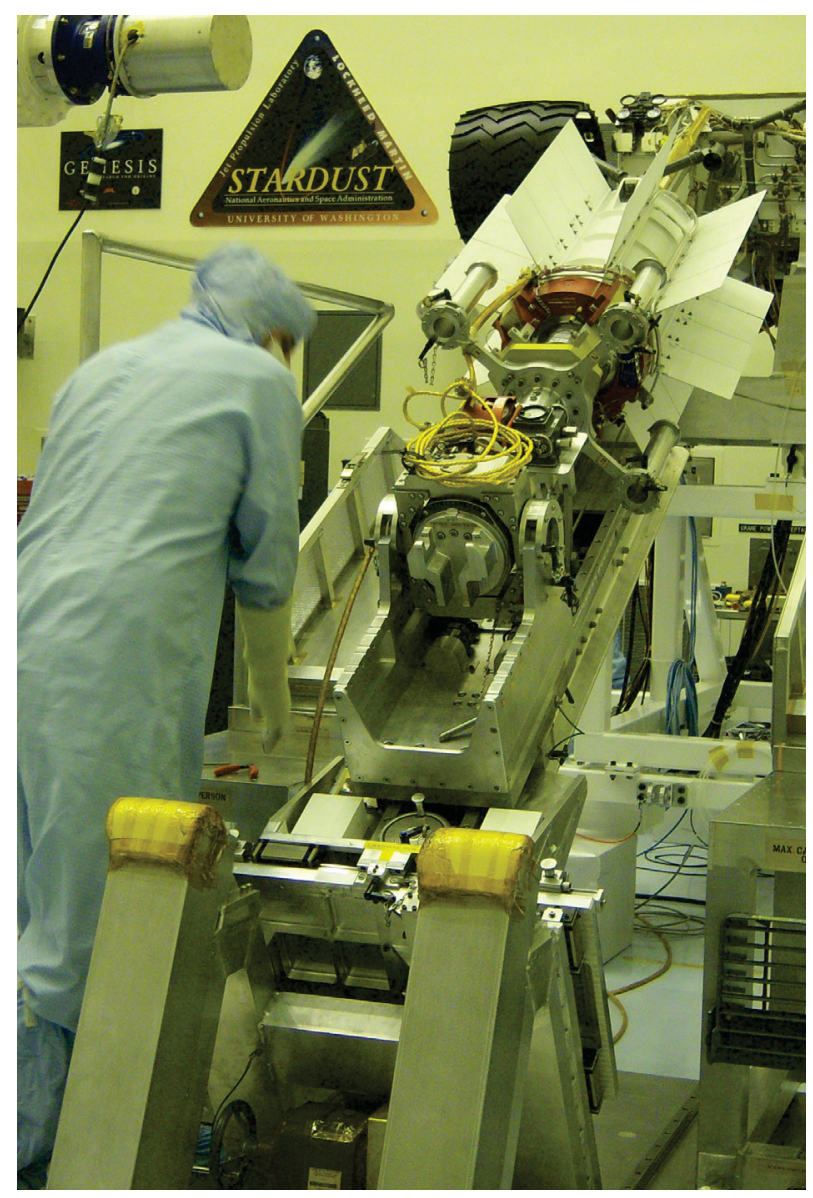

Figure 12. Hot fit check of the Multi-Mission Radioisotope Thermoelectric Generator with the Mars Science Laboratory Curiosity rover at Kennedy Space Center.
- Storage of the 9904 containers and RTGTS in a specialized building at INL, the Radioisotope Systems Training and Servicing Facility (see Figure 11).

- A fleet of internationally certified-type shipping containers (9516) that are used for movement of powdered $\mathrm{Pu}-238$ oxide or heat sources. This cargo has included Russian plutonium dioxide on occasion.

- Support at KSC for ground operations from the time of radioisotope power system arrival through integration with NASA spacecraft and launch (Figure 12).

- Lead laboratory for SDPS, providing technical integration and coordination of material reviews and configuration control reviews for the radioisotope power system infrastructure.

For the Pu-238 Supply Project, INL is principally responsible for transfer of neptunium oxide from INL to ORNL for target fabrication. Also, INL is responsible for the design of neptunium targets that will be irradiated in the Advanced Test Reactor (ATR) at INL, irradiation of neptunium targets in ATR, and shipment of the irradiated targets from INL to ORNL for processing.

\section{In addition to providing ground} support operations, INL serves as the lead laboratory for DOE'S SDPS Program providing technical integration and

\section{coordination.}




\subsection{Sandia National Laboratories}

SNL supports the DOE SDPS Program as the lead for safety analysis capabilities. DOE supports a total of six FTEs at SNL in a base capability mode, which allows them to maintain key functions/facilities for the radioisotope power system program that would otherwise be difficult to duplicate or to stand up upon demand. These capabilities include the following:

- Probabilistic risk analysis, accident scenarios and probabilities, and accident environments.

- Nuclear hardware response modeling, mechanical impact environments, solid propellant fire environments, reentry environments, source terms, radiological consequence analysis, atmospheric transport and dispersion modeling, exposure pathway modeling, technical feasibility analysis, materials analysis, and thermal analysis.

- Safety analyses and supporting safety verification tests (see Figure 13) to support radioisotope power system fuel qualification and for NASA missions to support the launch approval process.

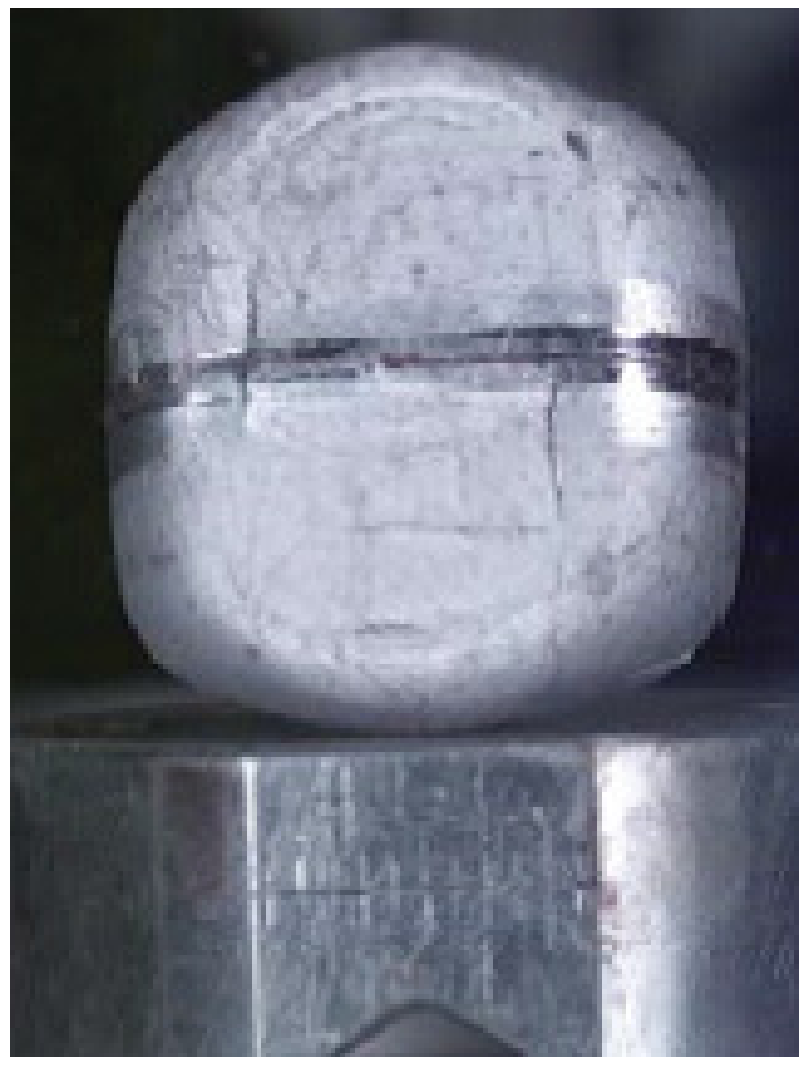

Figure 13. Fuel clad after a safety verification test.

\section{SNL supports the DOE SDPS \\ Program as the lead for safety analysis capabilities.}




\section{HISTORICAL SUMMARY AND ACCOMPLISHMENTS}

$\mathrm{T}$ he role of the SDPS organization and its supporting contractors has evolved over the last 50 years. In the 1960s, it encompassed isotope production; heat source development and production; and radioisotope power system development, fueling, testing, and delivery.

The heat-source design changed frequently in the 1960 s and 1970 s as power demands increased and attitudes toward launch and flight safety evolved. These changes culminated in development of the GPHS in the late 1970s - an effort to provide a safe and well-tested heat source for NASA missions and minimize the number and frequency of premission safety verification tests. Because of the success of this effort, new heat-source designs are now considered only when there are specific mission requirements.

The development of new power conversion systems, which took place at both government and private entities during the 1960s and 1970s, has been completely outsourced to private industry via a competitive bid process. The part that the government institutions played historically was largely in building engineering systems and testing new models, many of which were never deployed (e.g., Space Nuclear Auxiliary Power [SNAP]-1, -5, -11, $-13,-15,-21,-23$, and -25$)$.
Isotope production has been, and shall remain, the sole domain of the government. Production took place primarily at SRS and Hanford sites since they possess that capability. There is evidence that production was considered at Hanford but not implemented in the early 1960s. Hanford did participate in studies, including irradiation of neptunium targets to provide low-Pu-236-content Pu-238 material for pacemakers in the early 1970s; it may have supplied some of the neptunium used at SRS as targets for $\mathrm{Pu}-238$ production. SRS alone produced $\mathrm{Pu}-238$ in the United States from the 1960 s until production ceased in the 1980s.

The success of the SDPS has enabled the United States to accomplish critical national missions by improving navigation, weather forecasting, communication, and exploration of the solar system, as well as maintaining national security. The program's capabilities, which DOE has developed and maintained, continue to be critical to these missions. Pioneered by the United States, the only current radioisotope power system producer, these capabilities are unique; if lost, recovering them would require at least a decade and major expenditures. Table 1 summarizes the US missions that have used radioisotope power systems and/ or radioisotope heater units since 1954 . Twentyseven missions have used 46 radioisotope power systems, and 10 have utilized radioisotope heater units through the latest mission, the Mars Science Laboratory launched in November 2011.

\section{The success of the SDPS has enabled the United States to accomplish critical national missions by improving navigation, weather forecasting, communication, and exploration of the solar system, as well as maintaining national security.}


Table 1. U.S. missions using radioisotope power systems and light weight radioactive heater units.

\begin{tabular}{|c|c|c|c|c|c|c|c|}
\hline No. & $\begin{array}{l}\text { Spacecraft/ } \\
\text { System }\end{array}$ & $\begin{array}{l}\text { Principal } \\
\text { Energy } \\
\text { Source (\#) }\end{array}$ & $\begin{array}{l}\text { LWRHU on } \\
\text { Mission }\end{array}$ & $\begin{array}{l}\text { Destination / } \\
\text { Application }\end{array}$ & $\begin{array}{l}\text { Launch } \\
\text { Date }\end{array}$ & $\begin{array}{l}\text { BOM } \\
\text { Power } \\
\text { (We) }\end{array}$ & Notes/Status \\
\hline 1 & Transit 4A & $\begin{array}{l}\text { SNAP-3B7 } \\
\text { RTG (1) }\end{array}$ & 0 & $\begin{array}{l}\text { Earth Orbit / } \\
\text { Navigation Satellite }\end{array}$ & $\begin{array}{l}29 \text { June } \\
1961\end{array}$ & 2.7 & $\begin{array}{l}\text { RTG operated for } 15 \text { yrs. Satellite now } \\
\text { shutdown. }\end{array}$ \\
\hline 2 & Transit 4B & $\begin{array}{l}\text { SNAP-3B8 } \\
\text { RTG (1) }\end{array}$ & 0 & $\begin{array}{l}\text { Earth Orbit / } \\
\text { Navigation Satellite }\end{array}$ & 15 Nov 1961 & 2.7 & $\begin{array}{l}\text { RTG operated for } 9 \text { yrs. Operation } \\
\text { intermittent after } 1962 \text { high altitude } \\
\text { test. Last signal in } 1971 .\end{array}$ \\
\hline 3 & Transit 5BN-1 & $\begin{array}{l}\text { SNAP-9A } \\
\text { RTG (1) }\end{array}$ & 0 & $\begin{array}{l}\text { Earth Orbit / } \\
\text { Navigation Satellite }\end{array}$ & 28 Sep 1963 & $>25$ & $\begin{array}{l}\text { RTG operated as planned. Non-RTG } \\
\text { electrical problems on satellite caused } \\
\text { failure after } 9 \text { months. }\end{array}$ \\
\hline 4 & Transit 5BN-2 & $\begin{array}{l}\text { SNAP-9A } \\
\text { RTG (1) }\end{array}$ & 0 & $\begin{array}{l}\text { Earth Orbit / } \\
\text { Navigation Satellite }\end{array}$ & 05 Dec 1963 & $>25$ & $\begin{array}{l}\text { RTG operated for over } 6 \text { yrs. Satellite lost } \\
\text { navigational capability after } 1.5 \text { yrs. }\end{array}$ \\
\hline 5 & Transit 5BN-3 & $\begin{array}{l}\text { SNAP-9A } \\
\text { RTG (1) }\end{array}$ & 0 & $\begin{array}{l}\text { Earth Orbit / } \\
\text { Navigation Satellite }\end{array}$ & 21 Apr 1964 & $>25$ & $\begin{array}{l}\text { Mission aborted because of launch } \\
\text { vehicle failure. RTG burned up on } \\
\text { reentry as designed. }\end{array}$ \\
\hline 6 & Nimbus B-1 & $\begin{array}{l}\text { SNAP-19B2 } \\
\text { RTG (2) }\end{array}$ & 0 & $\begin{array}{l}\text { Earth Orbit / } \\
\text { Meteorology Satellite }\end{array}$ & $\begin{array}{l}18 \text { May } \\
1968\end{array}$ & 28 ea. & $\begin{array}{l}\text { Mission aborted and destructed } \\
\text { because of an error in a guidance gyro } \\
\text { setting. The RTG fuel was recovered and } \\
\text { reused. }\end{array}$ \\
\hline 7 & Nimbus III & $\begin{array}{l}\text { SNAP-19B3 } \\
\text { RTG (2) }\end{array}$ & 0 & $\begin{array}{l}\text { Earth Orbit / } \\
\text { Meteorology Satellite }\end{array}$ & 14 Apr 1969 & 28 ea. & $\begin{array}{l}\text { RTGs operated for over } 2.5 \text { yrs. No data } \\
\text { taken after that. }\end{array}$ \\
\hline- & Apollo 11 & LWRHU & 2 & $\begin{array}{l}\text { Lunar Surface / } \\
\text { Science Station }\end{array}$ & $16 \mathrm{Jul} 1969$ & - & $\begin{array}{l}\text { Unqualified success. Apollo } 11 \text { splashed } \\
\text { down in the Pacific Ocean on } 24 \text { July } \\
\text { 1969, after Neil Armstrong's famous } \\
\text { "one small step for man, one giant leap } \\
\text { for mankind" on } 20 \text { July } 1969 .\end{array}$ \\
\hline 8 & Apollo 12 & $\begin{array}{l}\text { SNAP-27 } \\
\text { RTG (1) }\end{array}$ & 0 & $\begin{array}{l}\text { Lunar Surface / } \\
\text { Science Station }\end{array}$ & 14 Nov 1969 & $>70$ & $\begin{array}{l}\text { RTG operated to provide power for } \\
\text { the ALSEP that was left behind on the } \\
\text { moon; it operated for about } 8 \text { years } \\
\text { until the station was shutdown. }\end{array}$ \\
\hline 9 & Apollo 13 & $\begin{array}{l}\text { SNAP-27 } \\
\text { RTG (1) }\end{array}$ & 0 & $\begin{array}{l}\text { Lunar Surface / } \\
\text { Science Station }\end{array}$ & 11 Apr 1970 & $>70$ & $\begin{array}{l}\text { Mission aborted. } \mathrm{RTG} \text { reentered intact } \\
\text { with no release of } \mathrm{Pu}^{238} \text {. Currently } \\
\text { located at bottom of Tonga Trench in } \\
\text { South Pacific Ocean. }\end{array}$ \\
\hline 10 & Apollo 14 & $\begin{array}{l}\text { SNAP-27 } \\
\text { RTG (1) }\end{array}$ & 0 & $\begin{array}{l}\text { Lunar Surface / } \\
\text { Science Station }\end{array}$ & 31 Jan 1971 & $>70$ & $\begin{array}{l}\text { RTG operated for over } 6.5 \text { years until } \\
\text { station was shutdown. }\end{array}$ \\
\hline 11 & Apollo 15 & $\begin{array}{l}\text { SNAP-27 } \\
\text { RTG (1) }\end{array}$ & 0 & $\begin{array}{l}\text { Lunar Surface / } \\
\text { Science Station }\end{array}$ & 26 July 1971 & $>70$ & $\begin{array}{l}\text { RTG operated for over } 6 \text { years until } \\
\text { station was shutdown. }\end{array}$ \\
\hline 12 & Pioneer 10 & $\begin{array}{l}\text { SNAP-19 } \\
\text { RTG (4) }\end{array}$ & 12 & $\begin{array}{l}\text { Planetary / Payload } \\
\& \text { Spacecraft }\end{array}$ & 02 Mar 1972 & 40 ea. & $\begin{array}{l}\text { Last signal in 2003. Spacecraft now well } \\
\text { beyond orbit of Pluto. }\end{array}$ \\
\hline 13 & Apollo 16 & $\begin{array}{l}\text { SNAP-27 } \\
\text { RTG (1) }\end{array}$ & 0 & $\begin{array}{l}\text { Lunar Surface / } \\
\text { Science Station }\end{array}$ & 16 Apr 1972 & $>70$ & $\begin{array}{l}\text { RTG operated for about } 5.5 \text { years until } \\
\text { station was shutdown. }\end{array}$ \\
\hline 14 & $\begin{array}{l}\text { Transit } \\
\text { (Triad-01-1X) }\end{array}$ & Transit- RTG (1) & 0 & $\begin{array}{l}\text { Earth Orbit / } \\
\text { Navigation Satellite }\end{array}$ & 02 Sep 1972 & 35 & RTG still operating. \\
\hline 15 & Apollo 17 & $\begin{array}{l}\text { SNAP-27 } \\
\text { RTG (1) }\end{array}$ & 0 & $\begin{array}{l}\text { Lunar Surface / } \\
\text { Science Station }\end{array}$ & 07 Dec 1972 & $>70$ & $\begin{array}{l}\text { RTG operated for almost } 5 \text { years until } \\
\text { station was shutdown. }\end{array}$ \\
\hline
\end{tabular}


Table 1. U.S. missions using radioisotope power systems and light weight radioactive heater units.

\begin{tabular}{|c|c|c|c|c|c|c|c|}
\hline No. & $\begin{array}{l}\text { Spacecraft/ } \\
\text { System }\end{array}$ & $\begin{array}{l}\text { Principal } \\
\text { Energy } \\
\text { Source (\#) }\end{array}$ & $\begin{array}{l}\text { LWRHU on } \\
\text { Mission }\end{array}$ & $\begin{array}{l}\text { Destination / } \\
\text { Application }\end{array}$ & $\begin{array}{l}\text { Launch } \\
\text { Date }\end{array}$ & $\begin{array}{l}\text { BOM } \\
\text { Power } \\
\text { (We) }\end{array}$ & Notes/Status \\
\hline 16 & Pioneer 11 & $\begin{array}{l}\text { SNAP-19 } \\
\text { RTG (4) }\end{array}$ & 12 & $\begin{array}{l}\text { Planetary / Payload } \\
\text { \& Spacecraft }\end{array}$ & 05 Apr 1973 & 40 ea. & $\begin{array}{l}\text { Last signal in } 1995 \text {. Spacecraft now well } \\
\text { beyond orbit of Pluto. }\end{array}$ \\
\hline 17 & Viking 1 & $\begin{array}{l}\text { SNAP-19 } \\
\text { RTG (2) }\end{array}$ & 0 & $\begin{array}{l}\text { Mars Surface / } \\
\text { Payload \& Spacecraft }\end{array}$ & 20 Aug 1975 & 42 ea. & $\begin{array}{l}\text { RTGs operated for over } 6 \text { years until } \\
\text { lander was shutdown. }\end{array}$ \\
\hline 18 & Viking 2 & $\begin{array}{l}\text { SNAP-19 } \\
\text { RTG (2) }\end{array}$ & 0 & $\begin{array}{l}\text { Mars Surface / } \\
\text { Payload \& Spacecraft }\end{array}$ & 09 Sep 1975 & 42 ea. & $\begin{array}{l}\text { RTGs operated for over } 4 \text { years until } \\
\text { relay link was lost. }\end{array}$ \\
\hline 19 & LES 8 & MHW-RTG (2) & 0 & $\begin{array}{l}\text { Earth Orbit/ } \\
\text { Communication } \\
\text { Satellites }\end{array}$ & 15 Mar 1976 & 154 ea. & $\begin{array}{l}\text { Both LES } 8 \text { and LES } 9 \text { were launched } \\
\text { on a single Titan IIIC rocket. LES } 8 \\
\text { shutdown in } 2004 \text { due to control issues. }\end{array}$ \\
\hline 20 & LES $9(2)$ & MHW-RTG & 0 & $\begin{array}{l}\text { Earth Orbit/ } \\
\text { Communication } \\
\text { Satellites }\end{array}$ & 14 Mar 1976 & 154 ea. & LES 9 RTG is still operating. \\
\hline 21 & Voyager 2 & MHW-RTG (3) & 9 & $\begin{array}{l}\text { Planetary / Payload } \\
\& \text { Spacecraft }\end{array}$ & 20 Aug 1977 & $\begin{array}{l}>156 \\
\text { ea. }\end{array}$ & $\begin{array}{l}\text { RTGs still operating. Spacecraft } \\
\text { successfully operated to Jupiter, Saturn, } \\
\text { Uranus, Neptune, and beyond. }\end{array}$ \\
\hline 22 & Voyager 1 & MHW-RTG (3) & 9 & $\begin{array}{l}\text { Planetary / Payload } \\
\& \text { Spacecraft }\end{array}$ & 05 Sep 1977 & $\begin{array}{l}>156 \\
\text { ea. }\end{array}$ & $\begin{array}{l}\text { RTGs still operating. Spacecraft } \\
\text { successfully operated to Jupiter, Saturn, } \\
\text { and beyond. }\end{array}$ \\
\hline 23 & Galileo & GPHS-RTG (2) & 120 & $\begin{array}{l}\text { Planetary / Payload } \\
\& \text { Spacecraft }\end{array}$ & 18 0ct 1989 & 287 ea. & $\begin{array}{l}\text { RTGs continued to operate until 2003, } \\
\text { when spacecraft was intentionally } \\
\text { de-orbited into Jupiter atmosphere. }\end{array}$ \\
\hline 24 & Ulysses & GPHS-RTG (1) & 0 & $\begin{array}{l}\text { Planetary / Payload } \\
\& \text { Spacecraft }\end{array}$ & 06 0ct 1990 & 282 & $\begin{array}{l}\text { RTG continued to operate until 2008, } \\
\text { when spacecraft was deactivated. }\end{array}$ \\
\hline- & $\begin{array}{l}\text { Mars Rover } \\
\text { Pathfinder }\end{array}$ & Solar & 3 & Mars / Surface Rover & 14 Dec 1996 & & $\begin{array}{l}\text { Outlived its design life by } 12 \text { times; last } \\
\text { data transmission to Earth was } 27 \text { Sept } \\
1997 .\end{array}$ \\
\hline 25 & Cassini & GPHS-RTG (3) & 117 & $\begin{array}{l}\text { Planetary / Payload } \\
\text { \& Spacecraft }\end{array}$ & 15 0ct 1997 & $\begin{array}{l}>290 \\
\text { ea. }\end{array}$ & $\begin{array}{l}\text { RTGs continue to operate successfully. } \\
\text { Scientific mission and operations still } \\
\text { continue. }\end{array}$ \\
\hline- & $\begin{array}{l}\text { Mars Rover } \\
\text { Spirit }\end{array}$ & Solar & 8 & Mars / Surface Rover & 10 Jun 2003 & & $\begin{array}{l}\text { Rover outlived its design life by many } \\
\text { years. Last communication from Spirit } \\
\text { was } 22 \text { Mar } 2010 \text {. }\end{array}$ \\
\hline- & $\begin{array}{l}\text { Mars Rover } \\
\text { Opportunity }\end{array}$ & Solar & 8 & Mars / Surface Rover & $07 \mathrm{Jul} 2003$ & & Rover is still operating. \\
\hline 26 & New Horizons & GPHS-RTG (1) & 0 & $\begin{array}{l}\text { Planetary / Payload } \\
\& \text { Spacecraft }\end{array}$ & 19 Jan 2006 & 246 & $\begin{array}{l}\text { RTG continues to operate successfully. } \\
\text { Spacecraft in transit to Pluto, expected } \\
\text { fly-by } 2015 .\end{array}$ \\
\hline 27 & $\begin{array}{l}\text { Mars Science } \\
\text { Lab }\end{array}$ & $\begin{array}{l}\text { Multi-Mission } \\
\text { RTG (1) }\end{array}$ & 0 & Mars / Surface Rover & 26 Nov 2011 & $>110$ & $\begin{array}{l}\text { Curiosity Rover with MMRTG landed } \\
\text { on Mars on } 05 \text { Aug 2012, for 2-year } \\
\text { mission. }\end{array}$ \\
\hline
\end{tabular}




\section{STRATEGIC PATH FORWARD AND GOALS}

$\mathrm{T}$

he arrangement of the current infrastructure supporting the SDPS mission provides power systems for the primary customers of DOE, NASA, and national security programs. Although this infrastructure usually supports production of radioisotope power system units for a single customer and a single type of radioisotope power system (i.e., GPHS-RTG, MMRTG) at a time, it has demonstrated the ability to serve more than one customer simultaneously with adequate advanced planning. The most recent example was in 20072009, when three power systems of two distinct designs were fueled and tested for NASA and national security missions. LANL processed and shipped the fuel for both to INL in the spring and summer of 2008. All three systems were fueled in 2008. This represents a combined effort of ORNL, LANL, and INL for cladding production, heat source production, and fueling/testing.

\subsection{Radioisotope Power System Infrastructure}

The radioisotope power system infrastructure can be characterized as a geographically dispersed collection of equipment and highly trained technical staff at several national laboratories (i.e., ORNL, LANL, INL, and SNL), organized to perform a sequential process with no redundancy of key functions. The current operational state of the infrastructure is mixed and is described below on a site-by-site basis. Certain capabilities are necessary but missing, and some are present but underperforming. DOE has a number of challenges to maintain success in the SDPS Program due to the unique facilities and capabilities at the DOE sites and industry contractors. These challenges include increased facility cost (primarily due to increasing overheads and wages), increasing age of equipment, lack of depth in critical personnel skills, investments in safety basis to ensure launch safety is not impacted, and niche manufacturing capabilities of specialized materials that must be sustained or replacement materials sought and qualified (e.g., fine weave pierced fabric and $\mathrm{CBCF}$ ). A strategic pathway to shore up these deficiencies is described here.

\subsubsection{Oak Ridge National Laboratory}

ORNL produces iridium alloy hardware and $\mathrm{CBCF}$ sleeves, both integral to production of the GPHS module. The production of iridium alloy hardware is greater than 10 years ahead of demand because of the large orders manufactured in the mid-2000s that have not yet been used. The annual production of several iridium alloy clad vent cup sets for maintenance production continues to keep stores ahead of demand.

The production of CBCF sleeves is also ahead of demand. ORNL improved its equipment between 2005 and 2012, bringing several significant pieces of equipment online to replace aging items; however, some equipment more than 40 years old is being kept operational by careful preventative maintenance. In summary, the infrastructure at ORNL is aging but should be able to support SDPS missions over the near term.

\subsubsection{Los Alamos National Laboratory}

LANL produces encapsulated heat sources and purifies the $\mathrm{Pu}-238$ oxide. The LANL equipment has continued to degrade at an accelerated pace over the past several years. This statement applies to every piece of equipment with the exception of the aqueous scrap-recovery line housed in the bench-scale glovebox. The hot presses are a matter of particular concern from a maintenance viewpoint because of their age (greater than 50 years). The same applies to the fuel clad welder and other pieces of equipment (i.e., the LWRHU welder). 
LANL support for the dual NASA and national security missions in 2007-2008 represents a level of performance that is unlikely to be repeated without significant investment.

\subsubsection{Idaho National Laboratory}

DOE transferred 20- to 40-year old equipment to INL from the Mound Site, although the SSPSF facility itself was new in 2004. Extensive maintenance activities, coupled with timely replacement of subsystems of many pieces of equipment, have improved the status from merely functional to dependably functional/updated/modernized. Modernization activities continue with planned environmental upgrades for several glovebox systems through 2014. Consistent annual efforts in upgrading or modernizing equipment with relatively modest sums (less than $\$ 1$ million/year) should continue to keep overall equipment status as maintained or further improved.

\subsection{DOE-Funded Infrastructure versus Operations in a Campaign Mode for Radioisotope Power System Production}

A topic that needs to be addressed for the SDPS Program is the issue of maintaining a standing infrastructure versus simply allowing it to "melt away" in between missions and then stood up again when required as new NASA or national security missions materialize. The current annual cost for maintaining facilities and staffing at the four national laboratories runs approximately $\$ 45$ to $\$ 50$ million/year. This will increase by approximately $\$ 10$ million/year when the $\mathrm{Pu}-238$ production capability comes on board later this decade. This DOE infrastructure funding maintains approximately 100 to 120 individuals at ORNL, LANL, INL, and SNL in key roles such as specialized one-of-a-kind production of hardware (i.e., iridium alloy cladding, $\mathrm{CBCF}$ ), specialized production of ceramic heat sources and safety testing, radioisotope power system fueling, testing and delivery, and sophisticated safety analysis in support of launch of nuclear materials into space for NASA. The breadth of knowledge in these areas is extremely diverse and is frequently maintained at the "one deep" level with current funding levels. Previous history from SRS would strongly counsel us to maintain a base level of infrastructure for production and delivery of radioisotope power system units rather than cycling the staffing and facility from "zero" to "production" status and back again.

\section{This DOE infrastructure funding maintains approximately 100 to 120 individuals at ORNL, LANL, INL, and SNL in key roles...}

The specific experience at SRS was that after the heat sources were produced for the Galileo and Ulysses missions in late 1983, the funding was drastically reduced so that staffing at the Plutonium Fuel Fabrication Facility went from 135 to approximately 3 FTEs in a very short time. SRS placed the equipment into a standby status without cleaning it because of the rapid (less than a month) change in funding status and the promise of additional funding for the next NASA mission, for which production would resume in fall 1984. This promise was repeated every year until funding finally resumed in 1990 as a prelude to the Cassini mission. Unfortunately, because the equipment had not been appropriately maintained, the onset of massive corrosion of all metallic processing equipment in the Plutonium Fuel Fabrication Facility and the cost and schedule involved to make it usable made the project untenable from the NASA mission perspective. The decision to move the heat source production operations to LANL was the only option available to support the Cassini 
mission. This painful experience led to the establishment of the current approach of DOE funding the basic infrastructure for the radioisotope power system production with NASA or national security customers funding any additional costs to produce the required power systems.

More specifically, DOE estimates that if existing highly specialized RPS-DOE facilities were allowed to go into "inactive standby" status between missions, bringing them back into production mode would require approximately 3 years. This estimate assumes that the following events would be required to occur:

- Hiring/transferring of staff with appropriate security clearances (LANL and INL)

- Very involved training in sophisticated techniques/methods (ORNL, INL, LANL, and SNL)

- Extensive DOE nuclear facility operational readiness reviews (INL and LANL)

- Extensive DOE programmatic readiness reviews (ORNL, INL, and LANL).

Three years is, in some respects, optimistic in that it assumes that at least some of the previous engineering, scientific, and operational staff is still available to train the new staff being brought on board.

\subsection{Pu-238 Supply Project}

The Pu-238 Supply Project will establish the dedicated facilities and equipment needed to support the goal of re-establishing the domestic capability for producing $\mathrm{Pu}-238$ in quantities needed to support future NASA space missions. The Project will procure and install new equipment to fabricate production targets in existing facilities, obtain qualified target designs, optimize irradiation production rates, and use existing hot cell facilities to process irradiated targets to recover unused neptunium and harvest the Pu-238 product. Enabling tasks include development work to determine the optimal irradiation target designs - one for the High Flux Isotope Reactor (HFIR) at ORNL (Figure 14), and the ATR at INL - and to select optimized chemical processes to (1) purify the neptunium prior to target pellet fabrication, (2) harvest the $\mathrm{Pu}-238$ from irradiated targets, and (3) recover unused neptunium for recycle into the feedstock for target pellet fabrication. Figure 15 provides a $\mathrm{Pu}-238$ production summary process flow diagram.

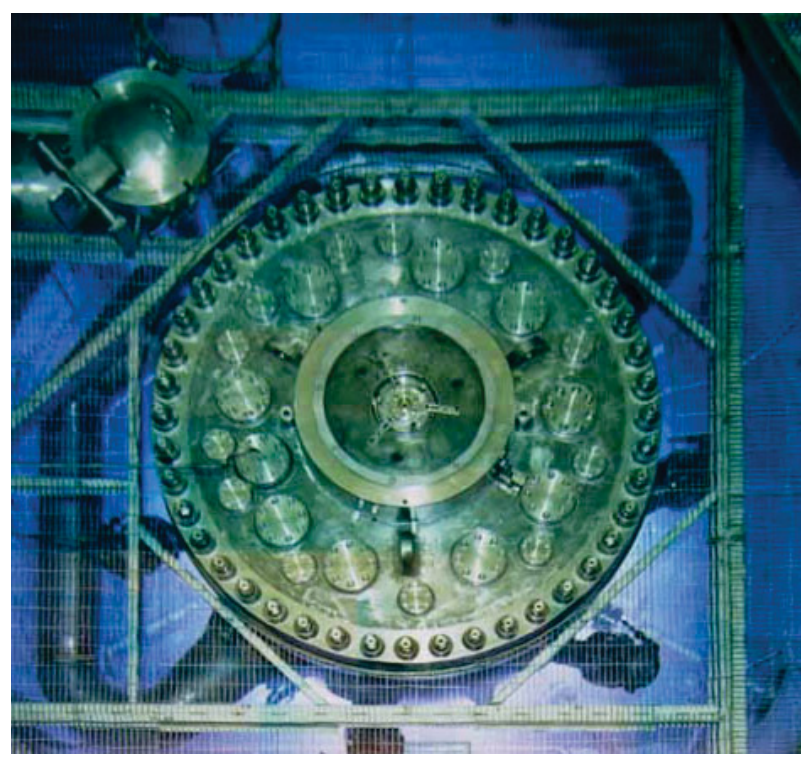

Figure 14. High Flux Isotope Reactor at Oak Ridge National Laboratory. 


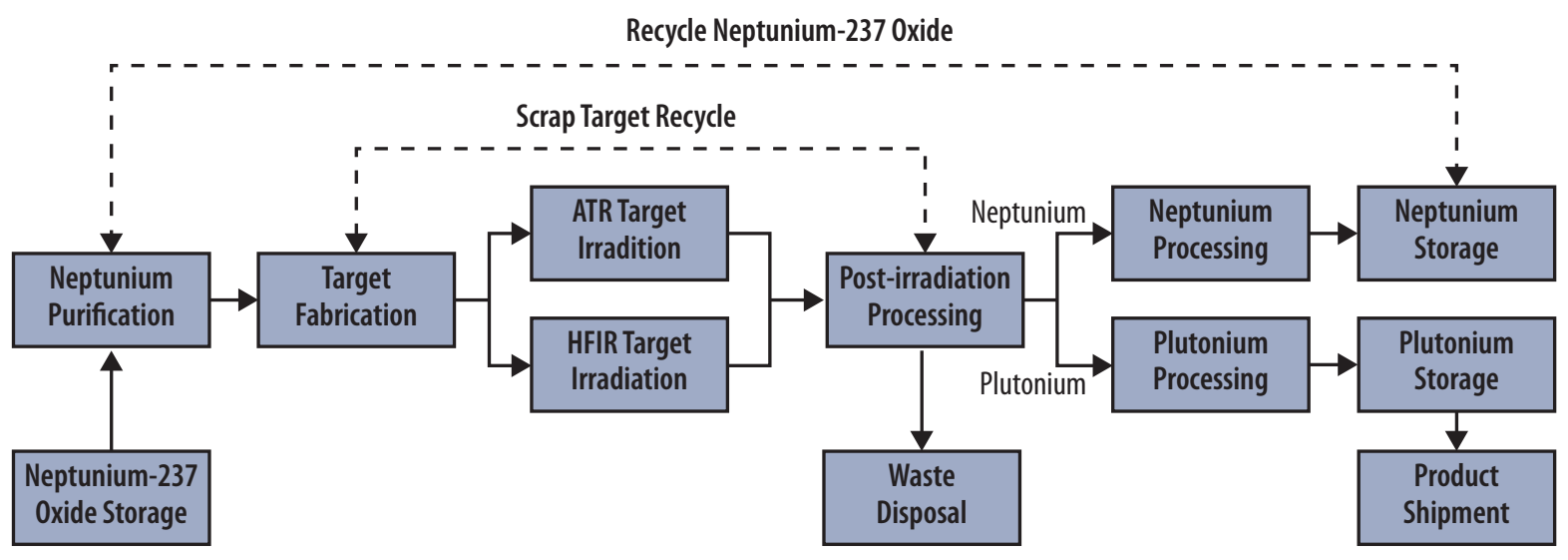

Figure 15. Pu-238 production summary process flow.

Three key decisions points have been identified for the Pu-238 Supply Project, when the project will be evaluated in regard to progress towards technical and project goals, and decisions will be made with regard to forward movement. These decision points are summarized as follows:

\section{- 4th Quarter Fiscal Year 2013(FY13): Go/No} Go on Project proceeding based on successful chemical processing experiments yielding data needed; final HFIR target designed; ATR target design initiated; NEPA Supplemental Analysis complete and approved; and glovebox design for neptunium oxide repackaging at INL approved

- 4th Quarter FY15: Determination on neptunium target fabrication laboratory equipment and integrated production demonstration number 2, based on: integrated production demonstration number 1 completed; hot cell improvements completed; cask approved for transport of full-length irradiated HFIR targets to the Radiochemical Engineering Development Complex (REDC); first neptunium oxide shipment ready to ship to ORNL from INL; preliminary ATR target design completed; preliminary ORNL neptunium target fabrication facility design completed; and study of $\mathrm{Pu}-238$ production capability extension completed

- Late FY17 or Early FY18: Go/No Go on transition to operations based on whether the ORNL target fabrication laboratory is operational; $\mathrm{Pu}-238$ manufacturing and purification process is operational; and shipment of $\mathrm{Pu}-238$ product to LANL is successfully demonstrated in approved container.

\begin{tabular}{|c|c|c|c|c|c|}
\hline FY2013 & FY2014 & FY2015 & FY2016 & FY2017 & FY2018 \\
\hline \multicolumn{2}{|c|}{$\begin{array}{l}\text { Go/no go on } \\
\text { project proceeding }\end{array}$} & \multicolumn{2}{|c|}{$\begin{array}{l}\text { Determination on neptunium target } \\
\text { fabrication laboratory equipment } \\
\text { and integrated production } \\
\text { demonstration number } 2\end{array}$} & \multicolumn{2}{|c|}{$\begin{array}{c}\text { Go/no go on } \\
\text { transition to operations }\end{array}$} \\
\hline
\end{tabular}




\subsection{Path Forward for Radioisotope Power System Infrastructure}

$\mathrm{F}^{\mathrm{e}}$ or the next 10 years, the DOE's SDPS program and its affiliated contractors should aggressively pursue specific areas of work. These include providing what is necessary but missing (e.g., isotope production and power conversion system development), improving what is present but underperforming (e.g., heat source production) for the radioisotope power system production pipeline, and maintaining that which is operational and reliable (e.g., component production, and fueling and testing of radioisotope power system units). The goals below are listed in order of priority:

1. Re-establish a reliable means of providing usable Pu-238 feedstock for manufacturing into heat sources for NASA and national security customers

2. Increase reliability and dependability of heat source production

3. Re-establish a prototype development and testing capability for new power conversion systems

4. Reinvigorate the existing safety verification test program to provide for an enhanced database to support goals 1 through 3 above.

Goal 1 should include all means of providing usable Pu-238 material, not just new production. Materials that can be recycled via chemical cleanup and made available as heat source feed stream material, albeit with less heat output for a given mass, should be developed after careful consultation with appropriate customers.

Goal 2 should entail a comprehensive look at the best available means of providing the functions currently residing at LANL in a robust production manner. These items are essential radioisotope power system building blocks and need to be available in a predictable manner without months to years of delay to established schedules. Splitting of responsibilities (i.e., scrap recovery, heat source fabrication, or impact testing) should be considered, within reason, with the end goal of providing a dependable production line for heat sources. Refurbishment of the facilities at LANL would also be considered as a means to the end of providing a reliable and dependable heat source production.

Goal 3 would recreate something that has not existed at a government institution for at least 2 decades - sharing work scope between several laboratories. This could include pairing laboratories with heat sources available for use with prototype or engineering systems (LANL or INL), but otherwise not well positioned for developing new power conversion systems, with a laboratory with technological capability (ORNL or the University of Dayton Research Institute [UDRI]) but without $\mathrm{Pu}-238$ heat sources for final prototype testing. It is likely that a partnership of either ORNL or UDRI with INL could provide the right combination for developing this system capability. For ORNL, this task could make use of some resources that, because of the substantial lead ORNL enjoys in iridium alloy hardware and $\mathrm{CBCF}$ production, could be reoriented on an as-available basis.

Finally, Goal 4 increases the emphasis on safety verification tests, which are currently administered by SNL and performed at LANL and other locations, as dictated by the nature of the test. Any changes to processes should have the final product subjected to safety verification tests to augment the database, which is used to support the launch approval process. 


\section{BUDGET AND INFRASTRUCTURE}

$\mathrm{T}$ able 2 provides general budget summaries for the SDPS radioisotope power system infrastructure and the Pu-238 Supply Project. The numbers are escalated 3\% per year from FY12.
Table 3 provides a summary of the facility and personnel infrastructure to support NASA and national security missions at the three main locations supported by SDPS.

Table 2. Radioisotope power system infrastructure summary budget (\$K), FY12 - FY18.

\begin{tabular}{|c|c|c|c|c|c|c|c|}
\hline Element & FY12 ${ }^{2}$ & FY13 ${ }^{3}$ & FY14 & FY15 & FY16 5 & FY1 $17^{5}$ & FY18 \\
\hline $\begin{array}{l}\text { INL } \\
\text { Radioisotope power system assembly, testing, transport, } \\
\text { ground support }\end{array}$ & 9,500 & 10,000 & 11,725 & 12,118 & 12,516 & 12,915 & 13,326 \\
\hline $\begin{array}{l}\text { INL } \\
\text { Neptunium storage, safeguards, and security }{ }^{6}\end{array}$ & 0 & 0 & 0 & 0 & 135 & 139 & 143 \\
\hline $\begin{array}{l}\text { LANL } \\
\text { Pu-238 oxide processing and fuel clad fabrication }\end{array}$ & 27,000 & 27,000 & 28,000 & 34,495 & 32,062 & 29,546 & 30,433 \\
\hline $\begin{array}{l}\text { ORNL } \\
\text { Heat source component fabrication }\end{array}$ & 4,514 & 4,649 & 4,976 & 5,125 & 5,279 & 5,437 & 5,601 \\
\hline $\begin{array}{l}\text { ORNL } \\
\text { Neptunium target fabrication and irradiated target } \\
\text { processing }^{6}\end{array}$ & 0 & 0 & 0 & 0 & 10,805 & 11,129 & 11,463 \\
\hline $\begin{array}{l}\text { SNL } \\
\text { Safety analyses and verification testing }\end{array}$ & 1,300 & 1,300 & 1,500 & 1,545 & 1,591 & 1,639 & 1,688 \\
\hline $\begin{array}{l}\text { OTHER }^{1} \\
\text { Risk assessment, materials studies, quality assurance } \\
\text { oversight }\end{array}$ & 4,592 & 3,100 & 2,500 & 2,575 & 2,652 & 2,732 & 2,814 \\
\hline Total & 46,906 & 46,049 & 48,701 & 55,858 & 65,040 & 63,538 & 65,468 \\
\hline
\end{tabular}

1. Other participants include direct contractors to DOE (Orbital Sciences Corporation, UDRI, and URS-Washington Safety Management Solutions).

2. FY12 based on SDPS Integrated Priorities List submitted March 2012 (Actual).

3. FY13 based on SDPS Integrated Priorities List submitted March 2012 (President's Budget).

4. FY14 based on SDPS Integrated Priorities List submitted March 2012 (Target Level).

5. FY15- FY18 based on SDPS Integrated Priorities List submitted March 2012 (Target Level), with values escalated 3.0\% beyond FY12.

6. Other tasks will be covered by user funds based on material needs (e.g., neptunium transport from INL to ORNL, target irradiation time in reactors, irradiated target

transport from ATR to ORNL, portion of irradiated target processing, and post-campaign facility maintenance).

Table 3. Facility and personnel infrastructure.

\section{Location}

Approximate Square Footage (Excluding Office Space)

Personnel Resources (FTE)

\begin{tabular}{l|c|c}
\hline INL (RPS assembly and testing) & 23,000 & 35 \\
\hline INL (neptunium management) & 100 & 0.5 \\
\hline LANL & 8,000 & 45 \\
\hline ORNL (heat source component fabrication) & xxxx & 10 \\
\hline ORNL (Pu-238 supply) & xxxx & $x x$
\end{tabular}


TEN-YEAR STRATEGIC PLAN 


\title{
ACRONYMS AND ABBREVIATIONS
}

\author{
ASRG Advanced Stirling Radioisotope \\ Generator \\ ATR Advanced Test Reactor (at INL) \\ CBCF carbon bonded carbon fiber \\ DOE Department of Energy \\ NEPA National Environmental Policy Act \\ ORNL Oak Ridge National Laboratory \\ Pu-238 plutonium-238 \\ REDC Radiochemical Engineering \\ Development Complex (at ORNL) \\ FTE full-time equivalent \\ RTG radioisotope thermoelectric generator \\ FY fiscal year \\ RTGTS RTG transportation system \\ GPHS general purpose heat source \\ SDPS Space and Defense Power Systems \\ Program (within DOE-NE) \\ HFIR High Flux Isotope Reactor (at ORNL) \\ INL Idaho National Laboratory \\ KSC Kennedy Space Center \\ LANL Los Alamos National Laboratory \\ LWRHU light weight radioisotope heater unit \\ SSPSF Space and Security Power Systems \\ Facility (at INL) \\ MMRTG multimission radioisotope \\ thermoelectric generator \\ TA-55 Technical Area 55 \\ UDRI University of Dayton Research \\ NASA National Aeronautics and Space \\ Institute \\ Administration \\ NE Office of Nuclear Energy (within \\ DOE) \\ SNAP space nuclear auxiliary power \\ SNL Sandia National Laboratories \\ SRS Savannah River Site
}


SDPS-001-0

June 2013

VOLUME 2

U.S. Department of Energy Space and Defense Power Systems Program TEN-YEAR STRATE[IE PLAN

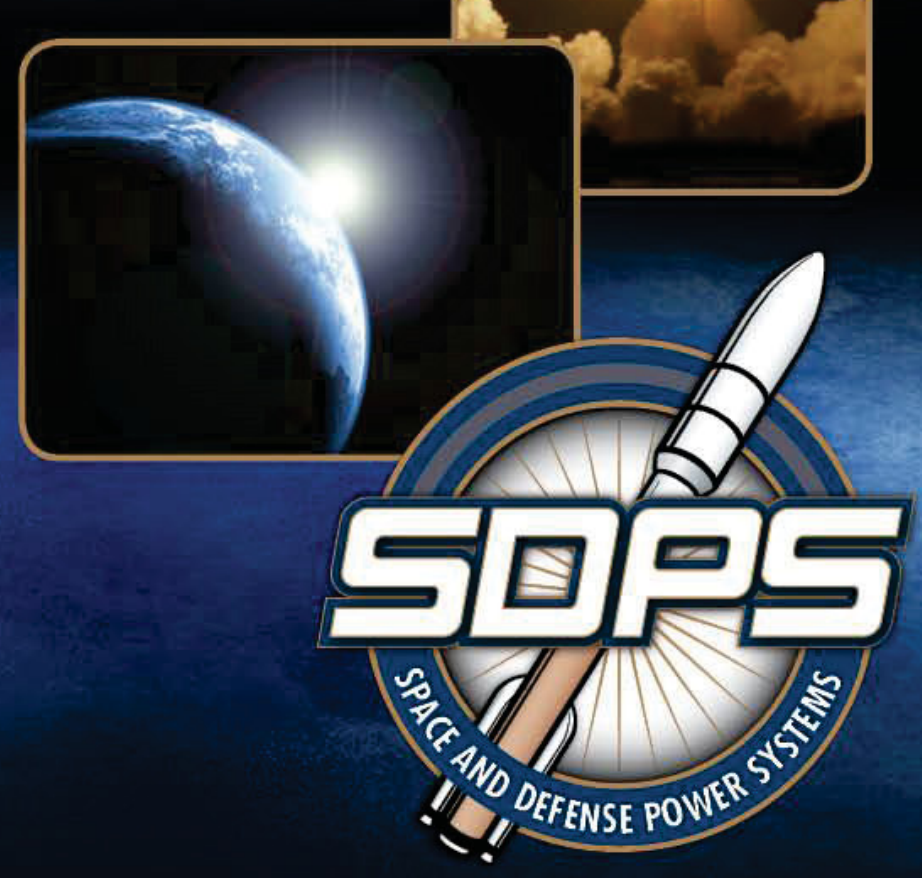


SDPS-001-0

June 2013

VOLUME 2

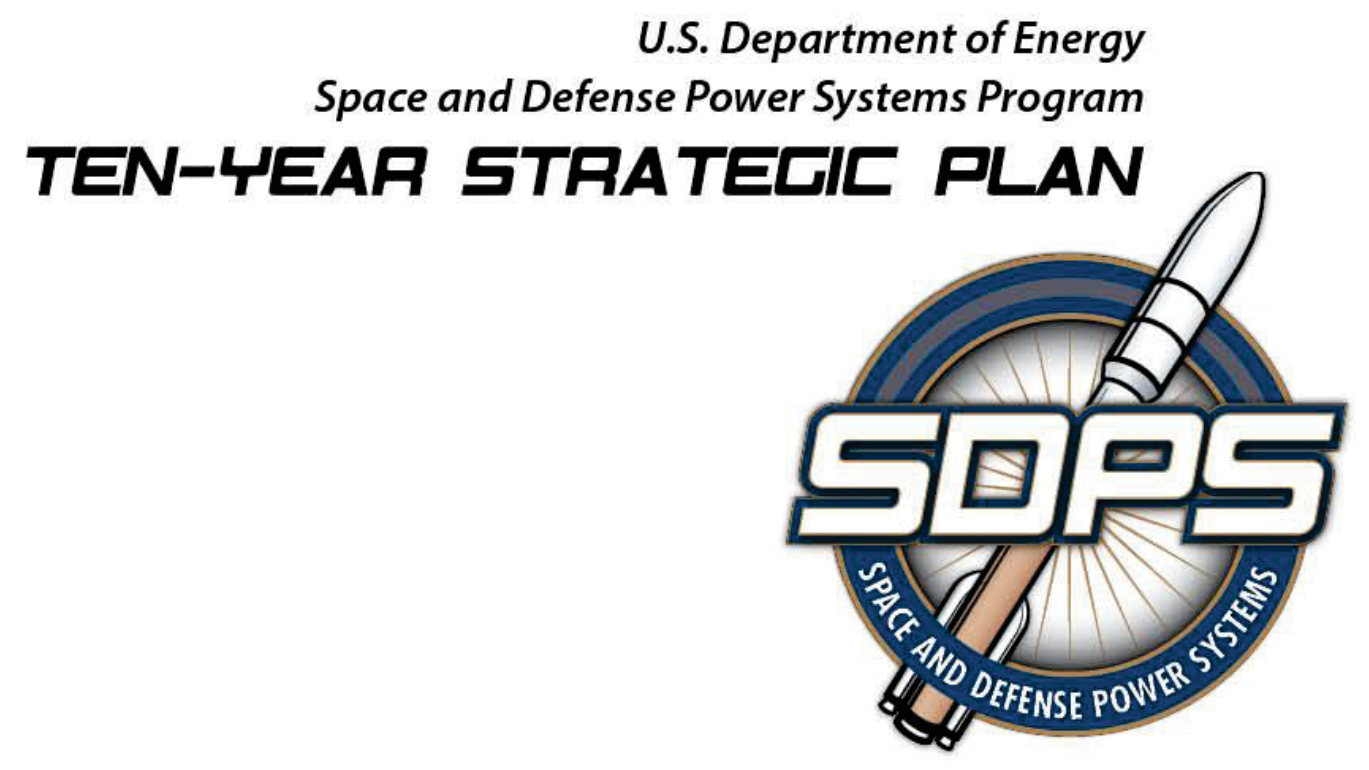




\title{
Space and Defense Power Systems
}

\section{Ten-Year Strategic Plan}

\author{
INL/MIS-13-29522 \\ SDPS-001-0 \\ Volume 2
}

June 2013

\author{
Prepared for: \\ Department of Energy \\ Office of Nuclear Energy \\ Space and Defense Power Systems (NE-75)
}

Prepared by:

Idaho National Laboratory Radioisotope Power Systems Technical Integration Office Idaho Falls, ID 


\section{FOREWORD}

The Department of Energy's Office of Nuclear Energy Space and Defense Power Systems (NE-75) program provides a unique capability for supplying power systems that function in remote or hostile environments. This capability has been functioning since the early 1960s and counts the National Aeronautics and Space Administration as one of its most prominent customers. This enabling technology has assisted the exploration of our solar system including the planets Jupiter, Saturn, Mars, Neptune, and soon Pluto. This capability is one-of-kind in the world in terms of its experience (over five decades), breadth of power systems flown (over two dozen to date) and range of power levels (watts to hundreds of watts). This document describes the various components and organizations that make up the infrastructure for the Radioisotope Power Systems program. This document provides more detail and historical perspective than its summary-level companion document, Volume 1.

This document was initially drafted by Lawrence Miller of DOE-NE-75, and updated by the Radioisotope Power Systems Program Technical Integration Office staff. Thanks to the many program participants who contributed information and photos for this Volume 2! 


\section{CONTENTS}

FOREWORD

1. INTRODUCTION

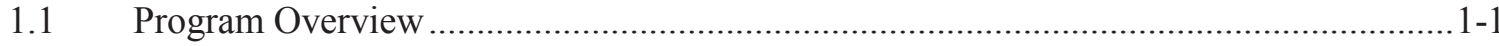

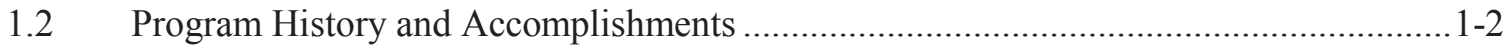

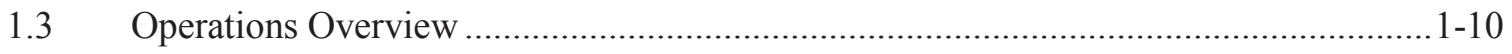

1.3.1 Heat Sources and Power Systems Production/Delivery ...................................1-10

1.3.2 Operations: Next steps ...........................................................................1-13

2. OAK RIDGE NATIONAL LABORATORY (ORNL) …................................................... 2-1

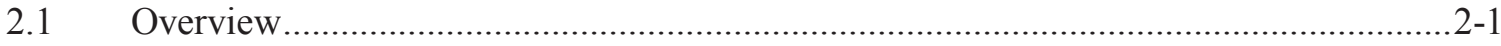

2.2 ORNL Mission for Space and Defense Power Systems ..............................................2-2

2.3 Iridium Alloy Clad Vent Set Production ...................................................................2-2

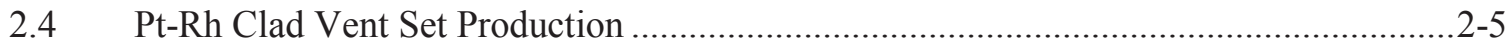

2.5 Procurement, Receipt Inspection, and Heat Treatment of Pyrolytic Graphite Insulator for

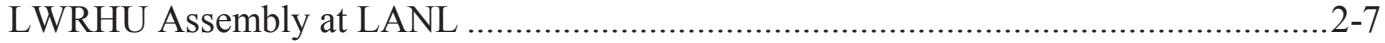

2.6 Manufacture of CBCF Insulation Sets at ORNL ............................................................

3. LOS ALAMOS NATIONAL LABORATORY (LANL) ….................................................... $3-1$

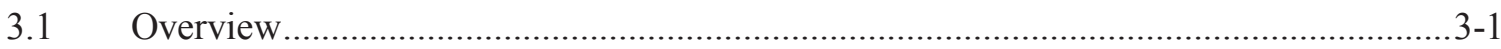

3.2 Aqueous Processing to Remove Impurities ...............................................................

3.2.1 Dissolving Fuel, Filtration, Oxalate Precipitation, and Calcination ....................3-4

3.2.2 Disposition of Waste from Aqueous Processing …........................................... 3-6

3.2.3 Fuel Accountability after Aqueous Processing...................................................

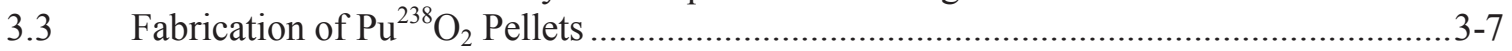

3.3.1 Ball Milling, Slugging, and Screening ...........................................................

3.3.2 Granule Seasoning and Oxygen 16 Exchange ................................................3-11

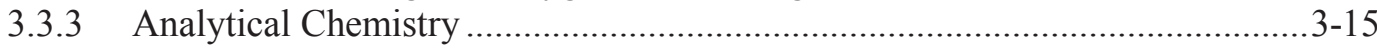

3.3.4 Hot Pressing Fuel into Ceramic Pellets ........................................................... 3-18

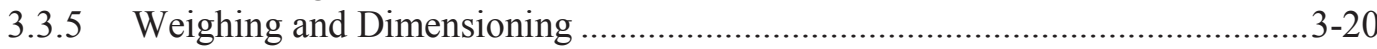

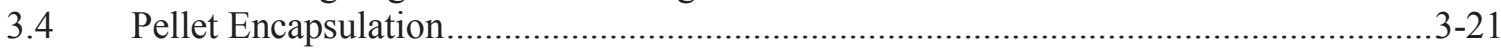

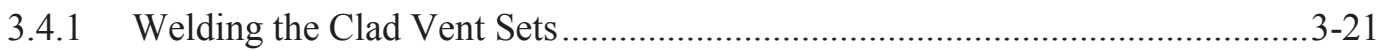




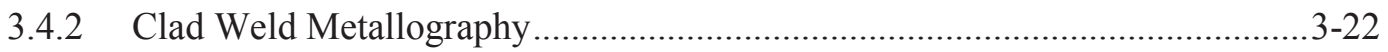

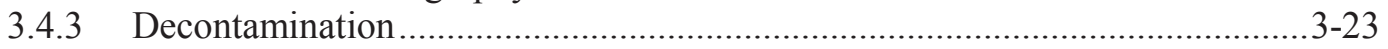

3.4.4 Non-Destructive Testing for FC Welds ..................................................... 3-23

3.4.5 Inserting LWRHU FCs into Insulators and Aeroshells to Make Flight Ready

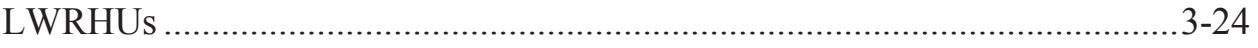

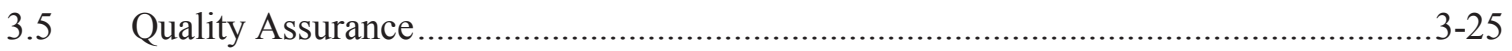

3.5.1 Inspections and Process Records Review .................................................. 3-25

3.5.2 Calorimetric Measurements of Thermal Power Output....................................3-25

3.5.3 Destructive Impact Testing on Selected FCs ............................................... 3-26

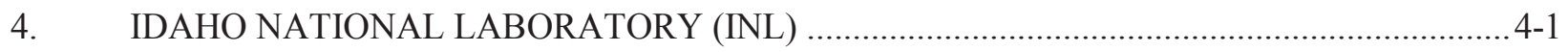

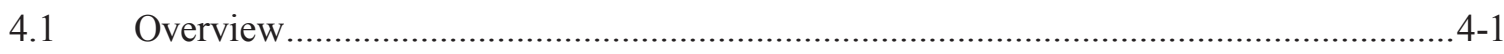

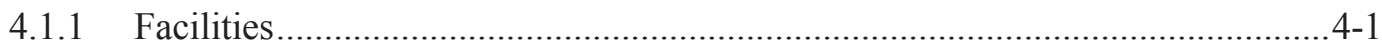

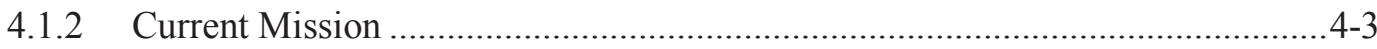

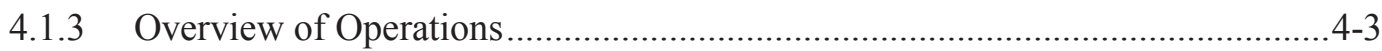

4.2 Preparation of GPHS Module Aeroshells in the EDL ............................................. $4-4$

4.3 Fueling and Assembly of RPSs at the SSPSF ..............................................................

4.3.1 SSPSF Facility ................................................................................ $4-5$

4.3.2 Production Material Requirements Provided from Off Site ..............................4-6

4.3.3 First Operation - Assembling a GPHS Module................................................4-7

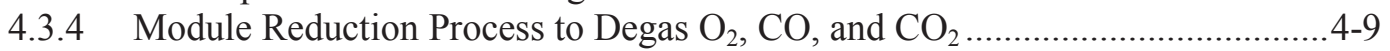

4.3.5 Second Operation - Fueling and Final Assembly of a MMRTG ....................4-10

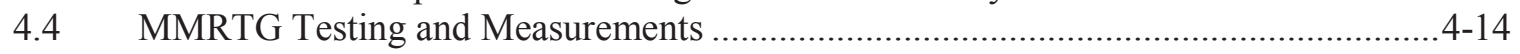

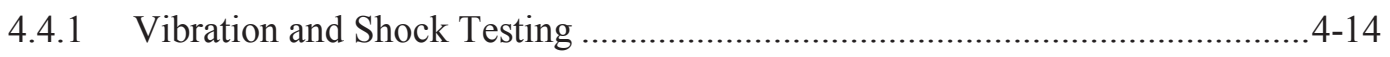

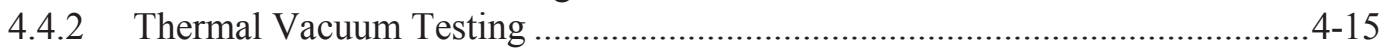

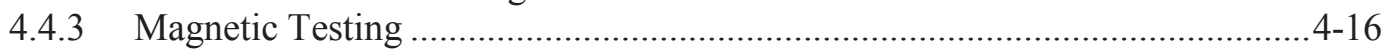

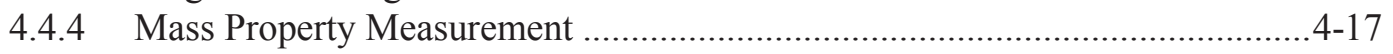

4.5 Planned ASRG Fueling and Final Assembly .......................................................... $4-18$

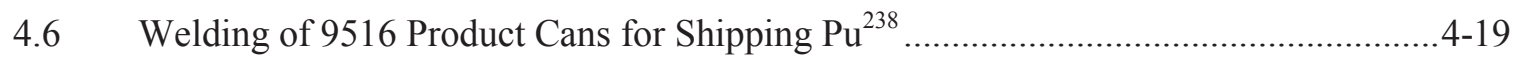

4.6.1 Vacuum/Inert Atmosphere Welding Glovebox ............................................4-19

4.6.2 Model 9516 Product Cans...........................................................................4-20

4.6.3 Model 9516 Shipping Packages............................................................ 4-20

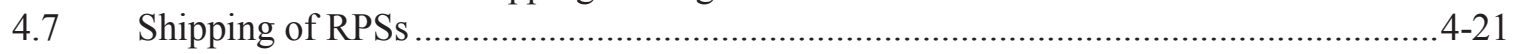

5. KENNEDY SPACE CENTER OPERATIONS ….......................................................... $5-1$

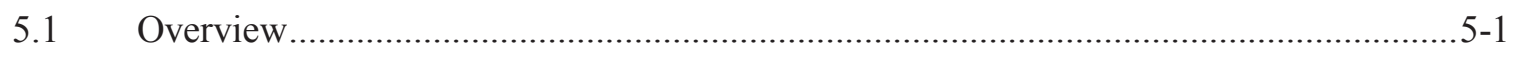

5.2 Activities Prior to Shipment to the KSC ....................................................................

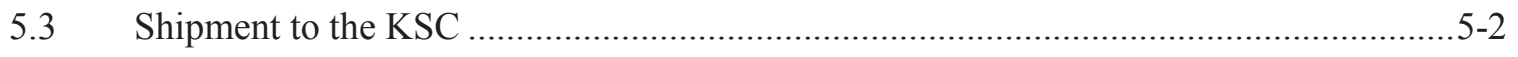




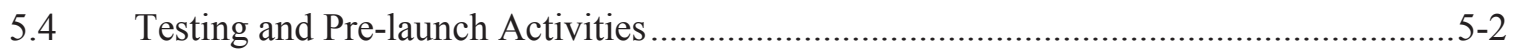

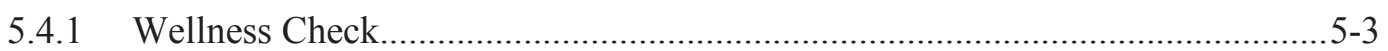

5.4.2 Hot Fit Check ......................................................................................... $5-3$

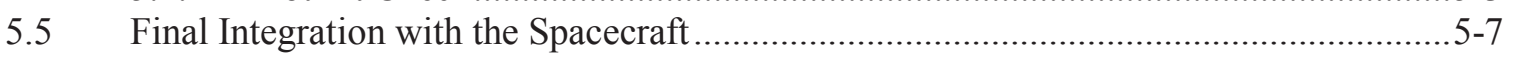

5.6 Recent Launches of NASA Missions Powered by RTGs ........................................... 5-11

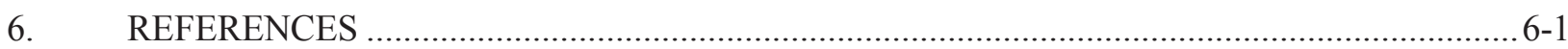

\section{FIGURES}

Figure 1-1. 2006 New Horizons Pluto flyby................................................................................. $1-1$

Figure 1-2. Nimbus III, NASA/Goddard meteorological, 1969; one SNAP 19B RTG shown

with white fins, lower center. $1-3$

Figure 1-3. Apollo landings 1969-1972; SNAP, 27 RTGs, five total for Apollo 12 and 14-16;

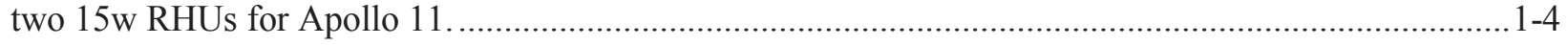

Figure 1-4. TRIAD Navy/APL navigation satellite 1972; one transit RTG. ........................................1-4

Figure 1-5. Pioneer 10 (1972) and 11 (1973) outer planets; four RTGs each (SNAP 19), 12

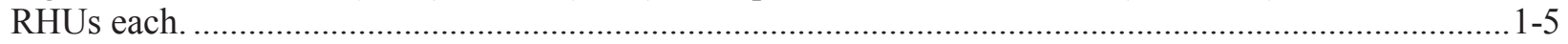

Figure 1-6. Viking 1 and 2 1975; Mars landers, two SNAP, 19 RTGs each mission.............................. 1-5

Figure 1-7. Lincoln Experimental Satellite (LES) 8 and 9, 1976; USAF/MIT Lincoln Laboratory,

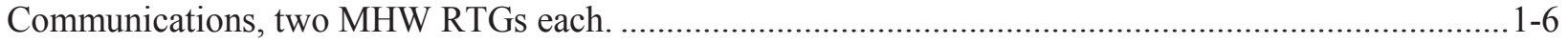

Figure 1-8. Voyager 1 and 2 1977, outer planets; 3 MHW RTGs each, 9 RHUs.................................. 1-6

Figure 1-9. Galileo 1989, Jupiter system, two GPHS RTGs, 120 RHUs............................................ 1-7

Figure 1-10. Ulysses, solar polar by way of Jupiter 1990; one GPHS RTG....................................... 1-7

Figure 1-11. Mars Rover Pathfinder 1996; three RHUs. .................................................................... 1-8

Figure 1-12. Cassini-Huygens 1997; Saturn system; three GPHS RTGs, 129 RHUs. ............................1-8

Figure 1-13. Mars Rovers Spirit and Opportunity. 2003; eight RHUs each......................................... 1-9

Figure 1-14. Mars Science Laboratory, Curiosity November 2011; one MMRTG................................1-9

Figure 1-15. RTG designs currently in production: MMRTG and ASRG......................................... 1-10

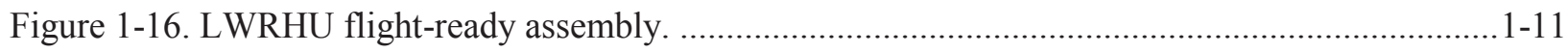

Figure 1-17. Geographic relationship of RPS/RHU production and delivery systems.........................1-12

Figure 1-18. Functions performed by national laboratories and supporting contractors in RPS/RHU production. $1-13$ 


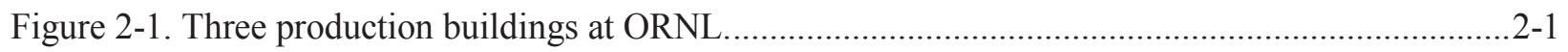

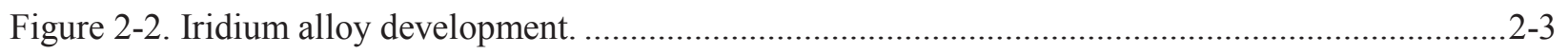

Figure 2-3. Frit vent on the vent clad assembly..........................................................................2-4

Figure 2-4. Nine major pieces of equipment used in Iridium GPHS clad vent set fabrication.................2-5

Figure 2-5. Parts and production process of the LWRHU clad vent set. .............................................2-6

Figure 2-6. Major pieces of equipment for manufacture of LWRHU clad vent sets...........................2-7

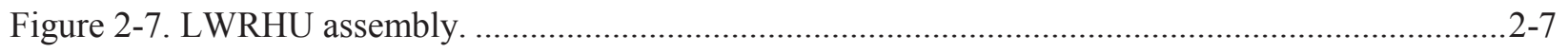

Figure 2-8. CBCF insulation sleeves production process at ORNL. ................................................. 2-8

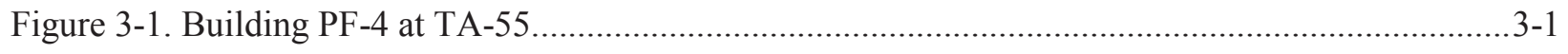

Figure 3-2. Heat sources produced at LANL using clad vent sets from ORNL. ................................... $3-2$

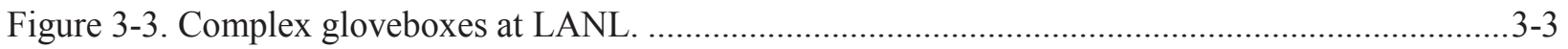

Figure 3-4. Flow Chart - Processing of $\mathrm{Pu}^{238} \mathrm{O}_{2}$ into FCs and LWRHUs. ............................................. -4

Figure 3-5. Glovebox line used for aqueous processing. ............................................................... $3-5$

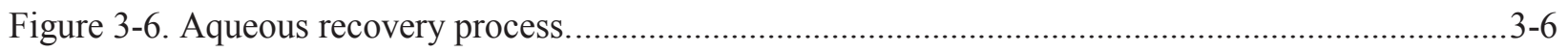

Figure 3-7. Disposal of hazardous waste from aqueous processing. …................................................ $3-6$

Figure 3-8. Weighing fuel between process steps for continuous accountability................................ 3-7

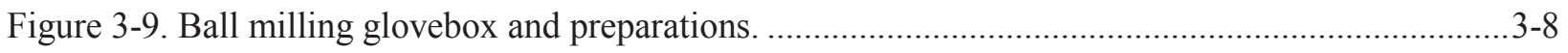

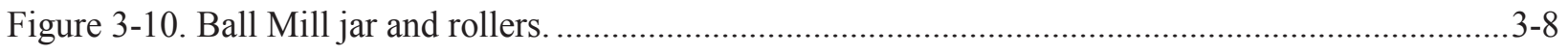

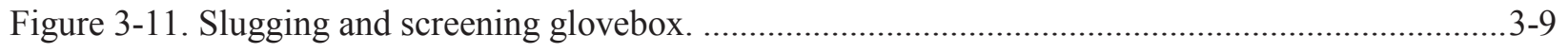

Figure 3-12. Transferring weighted fuel into the cold press die..........................................................

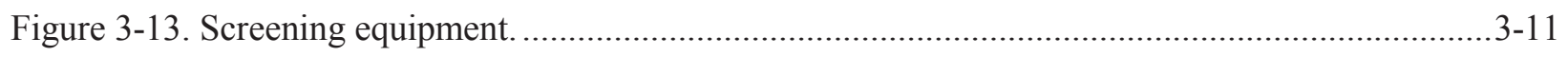

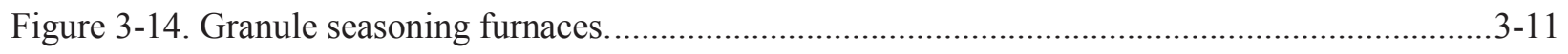

Figure 3-15. Flow path of argon gas mixed with $\mathrm{H}_{2} \mathrm{O}_{16}$ vapor for $\mathrm{O}_{16}$ exchange during

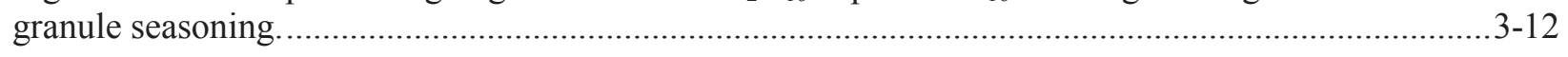

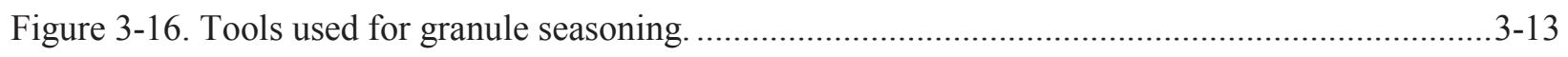

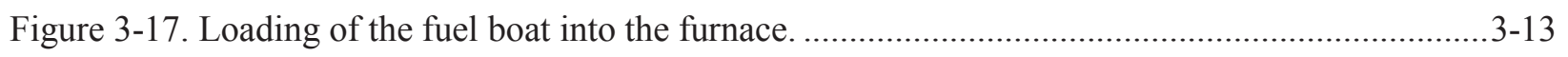

Figure 3-18. Ruler used to position platinum boat in the furnace.................................................... 3-14 
Figure 3-19. Inserting spacer to direct the heat within the furnace.

Figure 3-20. Analytical chemistry conducted to determine $\mathrm{Pu}^{238}$ content and levels of impurities in $\mathrm{Pu}^{238} 0_{2}$ fuel.

Figure 3-21. Tantalum sample vial.

Figure 3-22. Tantalum sample vial with press-fit lid (prior to welding)

Figure 3-23. AMET welder glovebox.

Figure 3-24. AMET welding machine in glovebox.

Figure 3-25. New gloveboxes under construction for $\mathrm{Pu}^{238}$ Facility. 3-18

Figure 3-26. Glovebox where low fired and high fired fuel is mixed $3-18$

Figure 3-27. Hot press gloveboxes.

Figure 3-28. Major equipment supporting hot press operation.

Figure 3-29. Pressed GPHS pellets awaiting encapsulation.

Figure 3-30. GPHS FC assembly.

Figure 3-31. GPHS welder and welder glovebox.

Figure 3-32. RHU assembly.

Figure 3-33. Metallography station

Figure 3-34. Decontamination glovebox.

Figure 3-35. GPHS and RHU radiography equipment.

Figure 3-36. LWRHU components.

Figure 3-37. Calorimetry measurement equipment.

Figure 3-38. Isotope fuels impact tester.

Figure 3-39. $\mathrm{Pu}^{238}$ GPHS fueled clad impact testing.

Figure 3-40. $\mathrm{Pu}^{238}$ Facility IFIT control room.

Figure 4-1. The SSPSF at INL.

Figure 4-2. EDL Facility and Radioisotope Training and Servicing Facility at INL

Figure 4-4. INL process flow for production and delivery of radioisotope power supplies. 


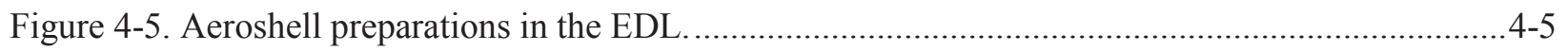

Figure 4-6. GPHS FC shipped to INL for assembly..................................................................

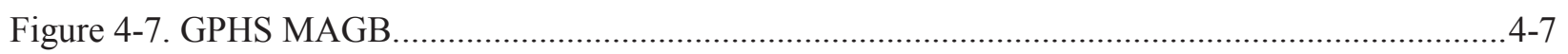

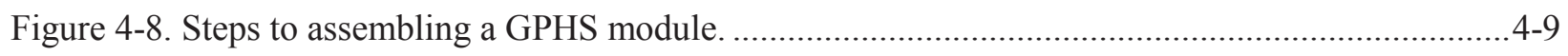

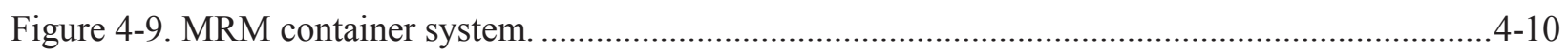

Figure 4-10. Decanning operations to remove GPHS module from the MRM container......................4-10

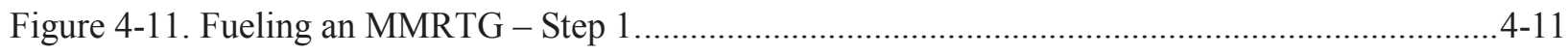

Figure 4-12. Fueling an MMRTG - Step 2 ...............................................................................

Figure 4-13. Fueling an MMRTG - Step 3 ............................................................................ $4-12$

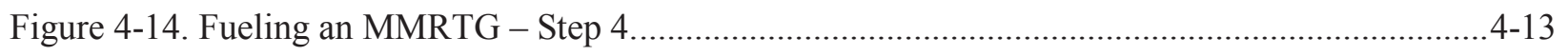

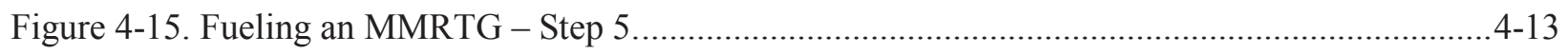

Figure 4-16. Final assembly of MMRTGs at the IAAC ................................................................ $4-14$

Figure 4-17. Vibration and shock testing table and facility..........................................................4-15

Figure 4-18. Thermal vacuum testing chamber. .................................................................................

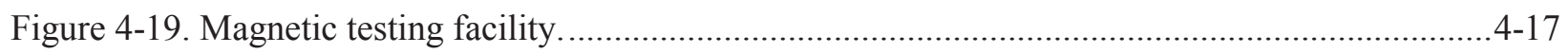

Figure 4-20. Mass Property Measurement Facility...................................................................... $4-18$

Figure 4-21. Fueling and final assembly of the ASRG in the MPFG. ................................................4-19

Figure 4-22. Vacuum/Inert Atmosphere Welding Glovebox............................................................4-20

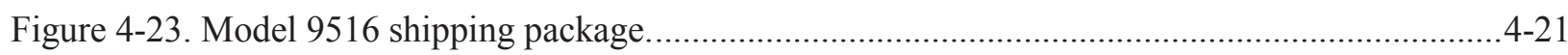

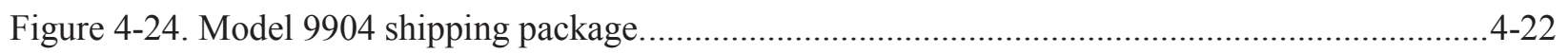

Figure 4-25. RTGTSs used to transport Model 9904 shipping packages. ............................................. $4-22$

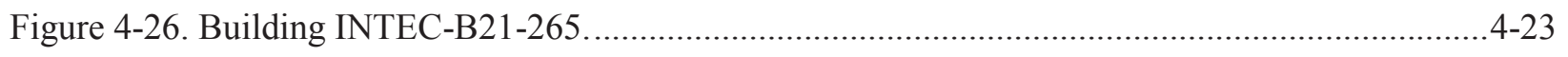

Figure 5-1. KSC operations for SDPS personnel........................................................................

Figure 5-2. Model 9904 shipping cask.................................................... Error! Bookmark not defined.

Figure 5-3. RTGF at KSC where RTGs are stored and serviced for 4 to 6 months prior to launch..........5-2

Figure 5-4. RTGTS trailers stored at INL that are used to deliver RTGs to the KSC......Error! Bookmark not defined. 
Figure 5-5. Inside the RTGF at KSC where cask is unloaded and stored (cooling lines run from the RTGTS) Error! Bookmark not defined.

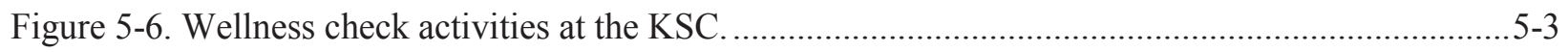

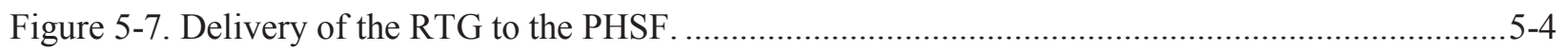

Figure 5-8. INL personnel assisting JPL technicians as they prepare for hot fit check..........................5-5

Figure 5-9. Training for spacecraft integration operations using the RIC ............................................5-5

Figure 5-10. Hot fit check for the MSL rover at the PHSF...............................................................

Figure 5-11. INL personnel assisting NASA in hot fit check for Pluto New Horizons spacecraft............5-6

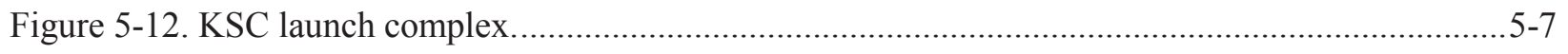

Figure 5-13. Delivery of MMRTG for MSL to the VIF Launch Complex 41....................................... $5-8$

Figure 5-14. Delivery of MMRTG to Level 6 of VIF................................................................................

Figure 5-15. Final preparations for inserting MMRTG into spacecraft inside the noise fairing conducted on Level 6 of VIF.

Figure 5-16. MMRTG being placed on the MSL rover using the RIC through rocket nose hatch on Level 5 of the VIF

Figure 5-17. Pluto New Horizons launch - January 19, 2006........................................................ 5-11

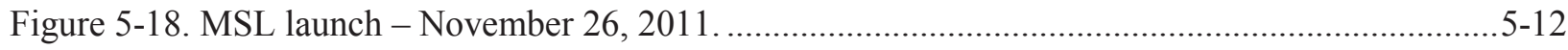

TABLES

Table 1-1. RTGs used on DOD and NASA space missions. ............................................................ $1-2$

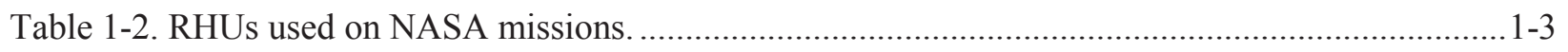




\section{ACRONYMS}

AMET Advanced Manufacturing Engineering Technologies

APL Applied Physics Laboratory

ASRG Advanced Stirling Radioisotope Generator

${ }^{\circ} \mathrm{C} \quad$ degrees Celsius

$\mathrm{CBCF} \quad$ carbon bonded carbon fiber

CFR Code of Federal Regulations

CMR Chemistry and Metallurgy Research

DA/SIC Design Agency/Systems Integration Contractor

DOD Department of Defense

DOE Department of Energy

DSA Documented Safety Analysis

EDL Engineering Development Laboratory

FC fueled clad

FMS facility monitoring system

FTE full-time equivalent

FWPF fine weave pierced fabric

FY fiscal year

GIS graphite impact shells

GPHS general purpose heat source

IAAC Inert Atmosphere Assembly Chamber

ID identification

IFIT Isotope Fuels Impact Tester

INL Idaho National Laboratory

INTEC Idaho Nuclear Technology and Engineering Center

JPL Jet Propulsion Laboratory 


\begin{tabular}{|c|c|}
\hline KSC & Kennedy Space Center \\
\hline LANL & Los Alamos National Laboratory \\
\hline LES & Lincoln Experimental Satellite \\
\hline LWRHU & light-weight radioisotope heater unit \\
\hline MAGB & Module Assembly Glovebox \\
\hline MEV & million electron volt \\
\hline MFC & Materials and Fuels Complex \\
\hline MHW & multi-hundred watt \\
\hline MMRTG & Multi-Mission Radioisotope Thermoelectric Generator \\
\hline MPFG & Multipurpose Fueling Glovebox \\
\hline MRM & module reduction monitoring \\
\hline MSL & Mars Science Laboratory \\
\hline NASA & National Aeronautics and Space Administration \\
\hline NE & Office of Nuclear Energy (DOE) \\
\hline NEPA & National Environmental Policy Act \\
\hline NER & neutron emission rate \\
\hline ORNL & Oak Ridge National Laboratory \\
\hline $\mathrm{PF}$ & Plutonium Facility \\
\hline PHSF & Payload Hazardous Servicing Facility \\
\hline psig & pounds per square inch, gauge \\
\hline QA & quality assurance \\
\hline RHU & Radioisotope Heater Unit \\
\hline RIC & RTG Integration Cart \\
\hline RPS & radioisotope power systems \\
\hline RPV & replacement plant value \\
\hline RTG & Radioisotope Thermoelectric Generator \\
\hline
\end{tabular}




$\begin{array}{ll}\text { RTGF } & \text { RTG Facility } \\ \text { RTGTS } & \text { RTG Transportation System } \\ \text { SARP } & \text { Safety Analysis Report Packaging } \\ \text { SDPS } & \text { Space and Defense Power Systems (NE-75) } \\ \text { SNAP } & \text { Systems for Nuclear Auxiliary Power } \\ \text { SSPSF } & \text { Space and Security Power Systems Facility } \\ \text { TA } & \text { Technical Area } \\ \text { TVC } & \text { thermal vacuum chamber } \\ \text { ULA } & \text { United Launch Alliance } \\ \text { USAF } & \text { United States Air Force } \\ \text { USN } & \text { United States Navy } \\ \text { USQ } & \text { Unreviewed Safety Question } \\ \text { VIF } & \text { Vertical Integration Facility }\end{array}$




\section{Space and Defense Power Systems Ten-Year Strategic Plan}

\section{INTRODUCTION}

\subsection{Program Overview}

The Atomic Energy Act of 1954 (as amended) ${ }^{1}$ establishes the unique responsibilities of the Department of Energy (DOE) for handling special nuclear material, maintaining national nuclear infrastructure, and developing nuclear systems. These responsibilities include building and maintaining the capability to produce radioisotope power systems (RPS) powered by the radioactive decay of plutonium-238 $\left(\mathrm{Pu}^{238}\right)$ for the U.S. space program, as well as for national defense and security missions.

Within the DOE Office of Nuclear Energy (NE), the Office of Space and Defense Power Systems (SDPS), or NE-75, funds and maintains this capability in a ready status. SDPS conducts the production activities for user agencies, with the user funding the incremental costs of production. As required by law, DOE retains ownership and accountability for $\mathrm{Pu}^{238}$ and maintains close liaison with users.

RPS provide electricity and heat to enable spacecraft to undertake scientific missions to environments beyond the capabilities of solar power, chemical batteries, and fuel cells. They include the Radioisotope Thermoelectric Generator (RTG), which provides power by converting radioactive decay heat into electricity using thermocouples, and the Advanced Stirling Radioisotope Generator (ASRG), which converts heat into electricity using a moving piston. A Radioisotope Heater Unit (RHU) generates direct heat for spacecraft instrumentation and maneuvering systems to ensure they function properly in the extreme cold of space.

Since 1961, SDPS has provided RTGs to:

1. National Aeronautics and Space Administration (NASA)

2. Department of Defense (DOD)

3. National security agencies.

In addition, the program has provided RHUs to NASA to heat critical components, instrumentation, lubricating agents, and thruster fuel for numerous exploratory space missions to the edge of the solar system (Figure 1-1) and beyond.

To fulfill these responsibilities, NE-75 operates complex process development and

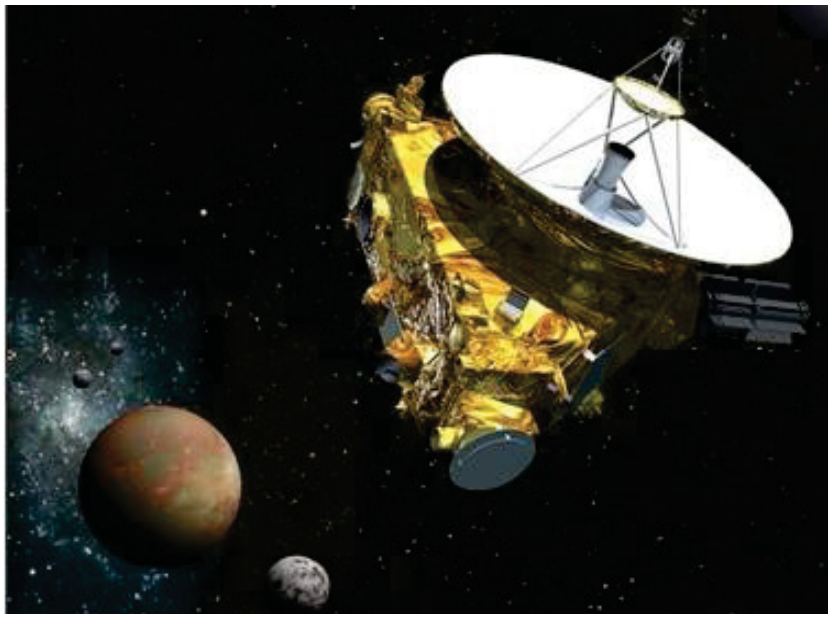

Figure 1-1. 2006 New Horizons Pluto flyby. production facilities at three national laboratories - Los Alamos National Laboratory (LANL), Oak Ridge National Laboratory (ORNL), and Idaho National Laboratory (INL) - and maintains material and staff assets to support NASA launch activities at the Kennedy Space Center (KSC) for RPS- and/or RHUequipped missions.

Given the scope of the operations and the capital investment at these facilities, a Ten-Year Program Plan ${ }^{2}$ is considered appropriate. NE-75 prepared this Plan to inform the annual budget process.

\footnotetext{
${ }^{1}$ P.L. 83-703.

${ }^{2}$ Modeled on the planning process described in DOE Order 430.1B, Real Property Asset Management.
} 


\subsection{Program History and Accomplishments}

Over the past 50 years, RPS technologies have proven they can produce electricity and heat under the harsh conditions of deep space without refueling. All these power systems, flown on dozen of missions since the 1960s, have operated for longer than they were originally designed. For example, the two Voyager spacecraft launched in 1977 are still in operation providing data from beyond the solar system.

Their success has enabled the United States to accomplish critical national missions, including improved navigation, weather forecasting, and communications, as well as exploration of the solar system. Table 1-1 identifies DOD and NASA space missions that have used RTGs; Table 1-2 lists NASA missions that have used RHUs. ${ }^{3}$

Table 1-1. RTGs used on DOD and NASA space missions.

\begin{tabular}{|c|c|c|c|c|c|}
\hline Spacecraft & Mission & User & Type of RTG & $\begin{array}{c}\text { Number of } \\
\text { RTGs }\end{array}$ & $\begin{array}{c}\text { Launch } \\
\text { Date }\end{array}$ \\
\hline Transit 4A & Navigation & USN & SNAP-3 & 1 & $06 / 29 / 61$ \\
\hline Transit 4B & Navigation & USN & SNAP-3 & 1 & $11 / 15 / 61$ \\
\hline Transit 5BN-1 & Navigation & USN & SNAP-9 & 10 & $9 / 28 / 63$ \\
\hline Transit 5BN-2 & Navigation & USN & SNAP-9 & 11 & $2 / 05 / 63$ \\
\hline Nimbus III & Meteorological & NASA & SNAP-19 & 2 & $04 / 14 / 69$ \\
\hline Apollo 12 & Lunar & NASA & SNAP-27 & 1 & $11 / 14 / 69$ \\
\hline Apollo 14 & Lunar & NASA & SNAP-27 & 1 & $01 / 31 / 71$ \\
\hline Apollo 15 & Lunar & NASA & SNAP-27 & 1 & $07 / 26 / 71$ \\
\hline Pioneer 10 & Outer Planets & NASA & SNAP-19 & 4 & $03 / 02 / 72$ \\
\hline Apollo 16 & Lunar & NASA & SNAP-27 & 1 & $04 / 16 / 72$ \\
\hline Triad & Navigation & USN & Transit-RTG & 1 & $09 / 02 / 72$ \\
\hline Apollo 17 & Lunar & NASA & SNAP-27 & 1 & $12 / 07 / 72$ \\
\hline Pioneer 11 & Outer Planets & NASA & SNAP-19 & 1 & $04 / 05 / 73$ \\
\hline Viking 1 & Mars Lander & NASA & SNAP-19 & 2 & $08 / 20 / 75$ \\
\hline Viking 2 & Mars Lander & NASA & SNAP-19 & 2 & $09 / 09 / 75$ \\
\hline LES-8 & Communications & USAF & MHW-RTG & 2 & $03 / 14 / 76$ \\
\hline LES-9 & Communications & USAF & MHW-RTG & 2 & $03 / 14 / 76$ \\
\hline Voyager 2 & Outer Planets & NASA & MHW-RTG & 3 & $08 / 20 / 77$ \\
\hline Voyager 1 & Outer Planets & NASA & MHW-RTG & 3 & $09 / 05 / 77$ \\
\hline Galileo & Jupiter System & NASA & GPHS-RTG & 2 & $10 / 18 / 89$ \\
\hline Ulysses & Solar Polar & NASA & GPHS-RTG & 1 & $10 / 06 / 90$ \\
\hline Cassini & Saturn System & NASA & GPHS-RTG & 3 & $10 / 15 / 97$ \\
\hline New Horizons & Pluto Flyby & NASA & GPHS-RTG & 1 & $01 / 19 / 06$ \\
\hline Curiosity (MSL) & Mars Rover & NASA & MMRTG & 1 & $11 / 26 / 11$ \\
\hline \multicolumn{3}{|c|}{$\begin{array}{l}\text { GPHS = general purpose heat source } \\
\text { LES = Lincoln Experimental Satellite } \\
\text { MHW = multi-hundred watt } \\
\text { MMRTG = Multi-Mission Radioisotope Thermoelectric Generator }\end{array}$} & \multicolumn{3}{|c|}{$\begin{array}{l}\text { NASA }=\text { National Aeronautics and Space Administration } \\
\text { SNAP }=\text { Systems for Nuclear Auxiliary Power } \\
\text { USAF }=\text { United States Air Force } \\
\text { USN }=\text { United States Navy }\end{array}$} \\
\hline
\end{tabular}

${ }^{3}$ Does not include national security missions, which are classified. 
Table 1-2. RHUs used on NASA missions.

\begin{tabular}{|c|c|c|}
\hline Mission & RHUs Used & Launch Date \\
\hline Apollo 11 & 2 & 07/16/69 \\
\hline Pioneer 10 & 12 & $03 / 02 / 72$ \\
\hline Pioneer 11 & 12 & $04 / 05 / 73$ \\
\hline Voyager 2 & 9 & 08/20/77 \\
\hline Voyager 1 & 9 & $09 / 15 / 77$ \\
\hline Galileo & 120 & $10 / 18 / 89$ \\
\hline Mars Rover - Pathfinder & 3 & $12 / 14 / 96$ \\
\hline Cassini & 117 & $10 / 15 / 97$ \\
\hline Mars Rover - Spirit & 8 & 06/10/03 \\
\hline Mars Rover - Odyssey & 8 & 07/07/03 \\
\hline
\end{tabular}

These capabilities, which DOE has developed and maintained throughout, continue to be critical to NASA space exploration. Pioneered by the United States, the only RPS producer, they are unique; if lost, recovering them would require at least a decade and major expenditures.

Advances in RTG technology have required continuous technology improvements. Figures 1-2 through 1-14 illustrate the variety, complexity, and engineering challenges associated with RTG development.

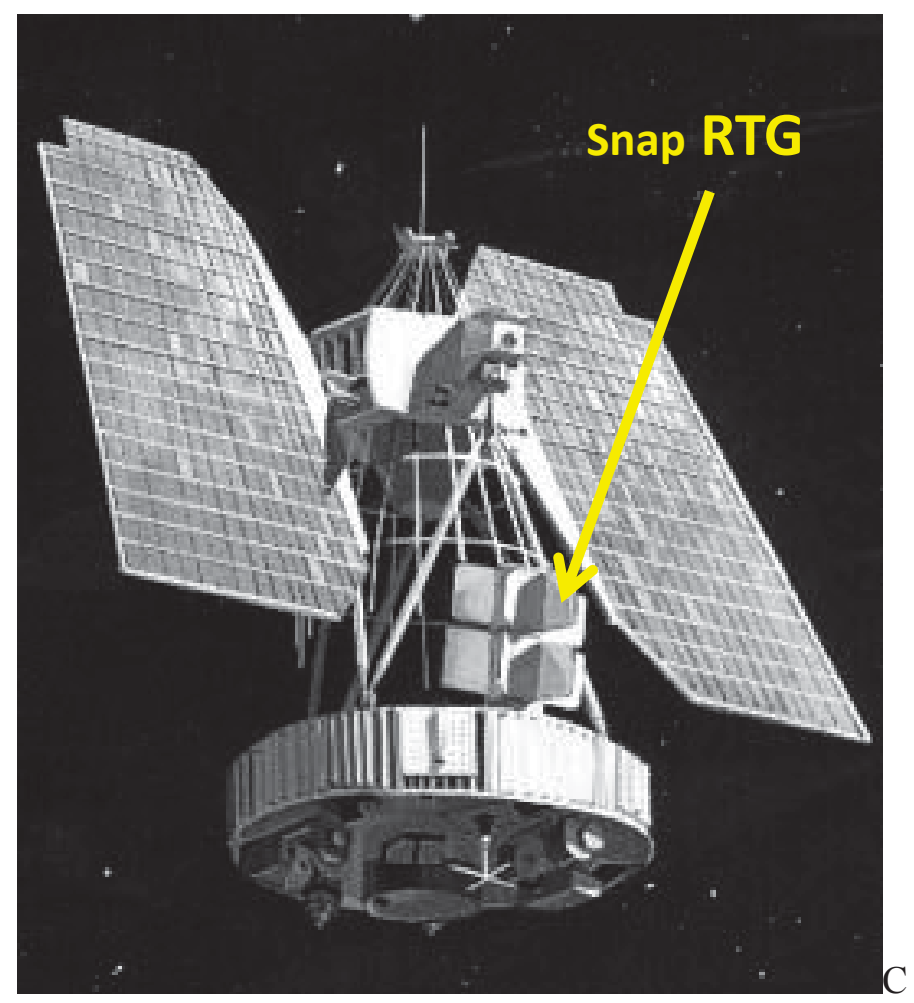

Figure 1-2. Nimbus III, NASA/Goddard meteorological, 1969; one SNAP 19B RTG shown with white fins, lower center. 


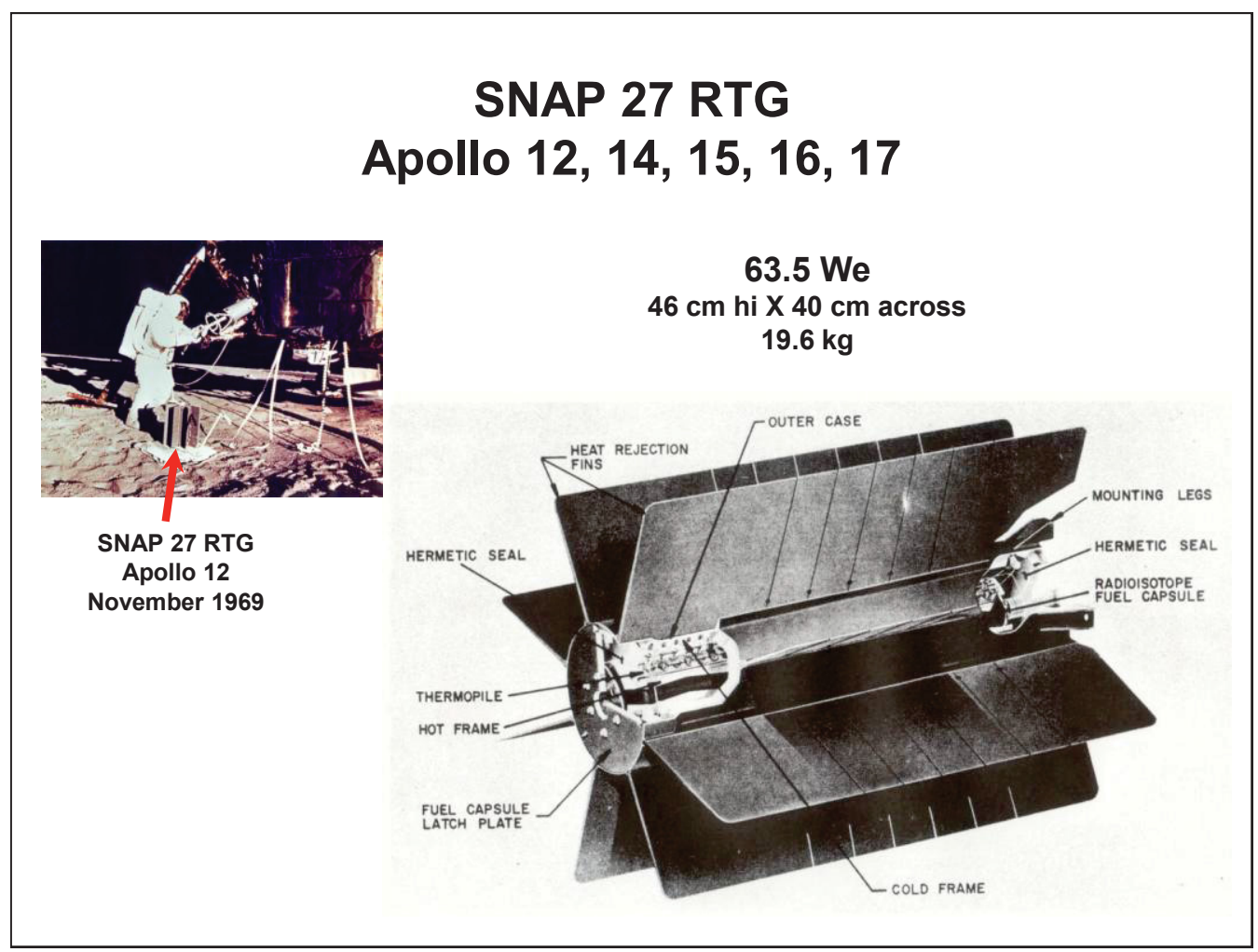

Figure 1-3. Apollo landings 1969-1972; SNAP, 27 RTGs, five total for Apollo 12 and 14-16; two 15w RHUs for Apollo 11.

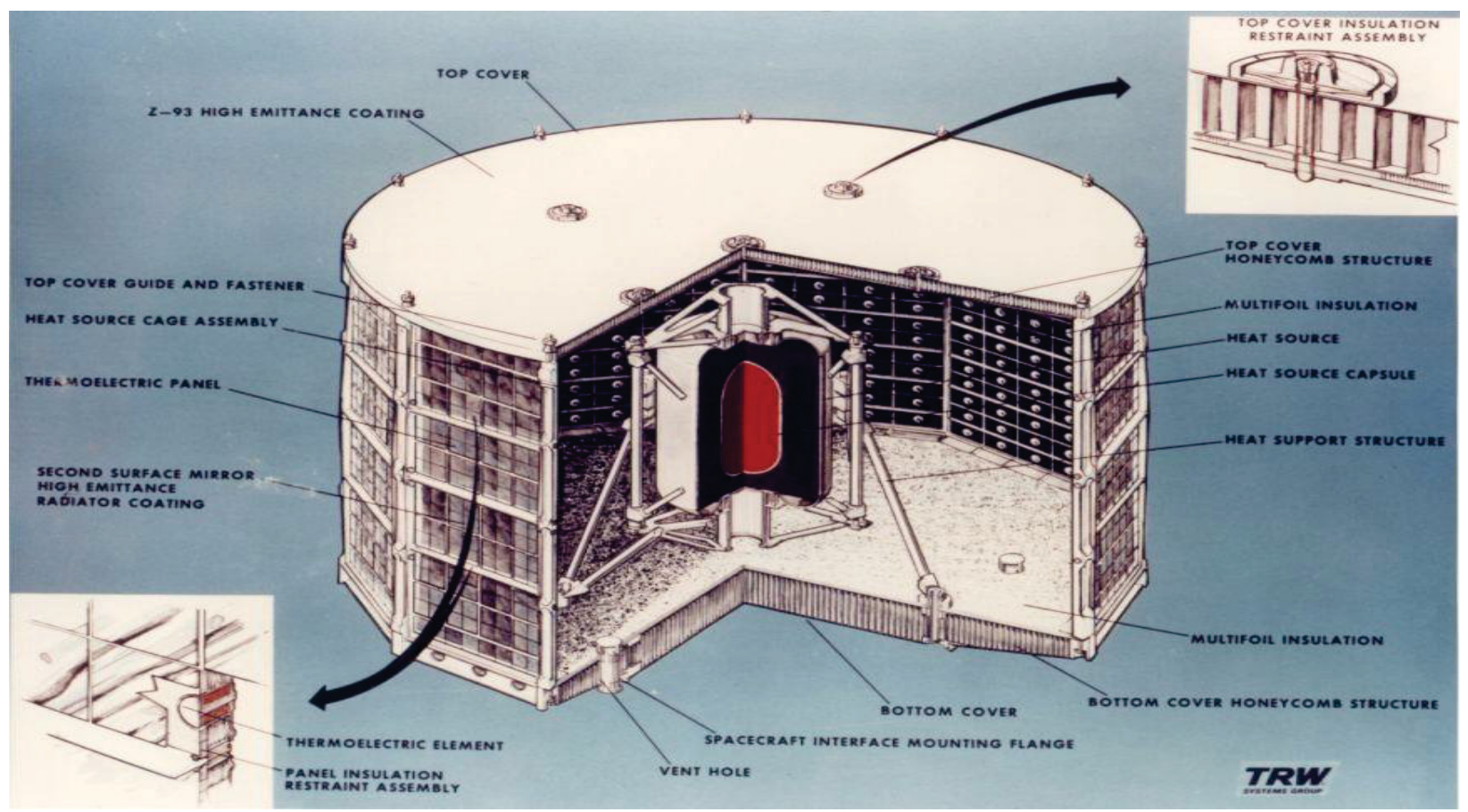

Figure 1-4. TRIAD Navy/APL navigation satellite 1972; one transit RTG. 


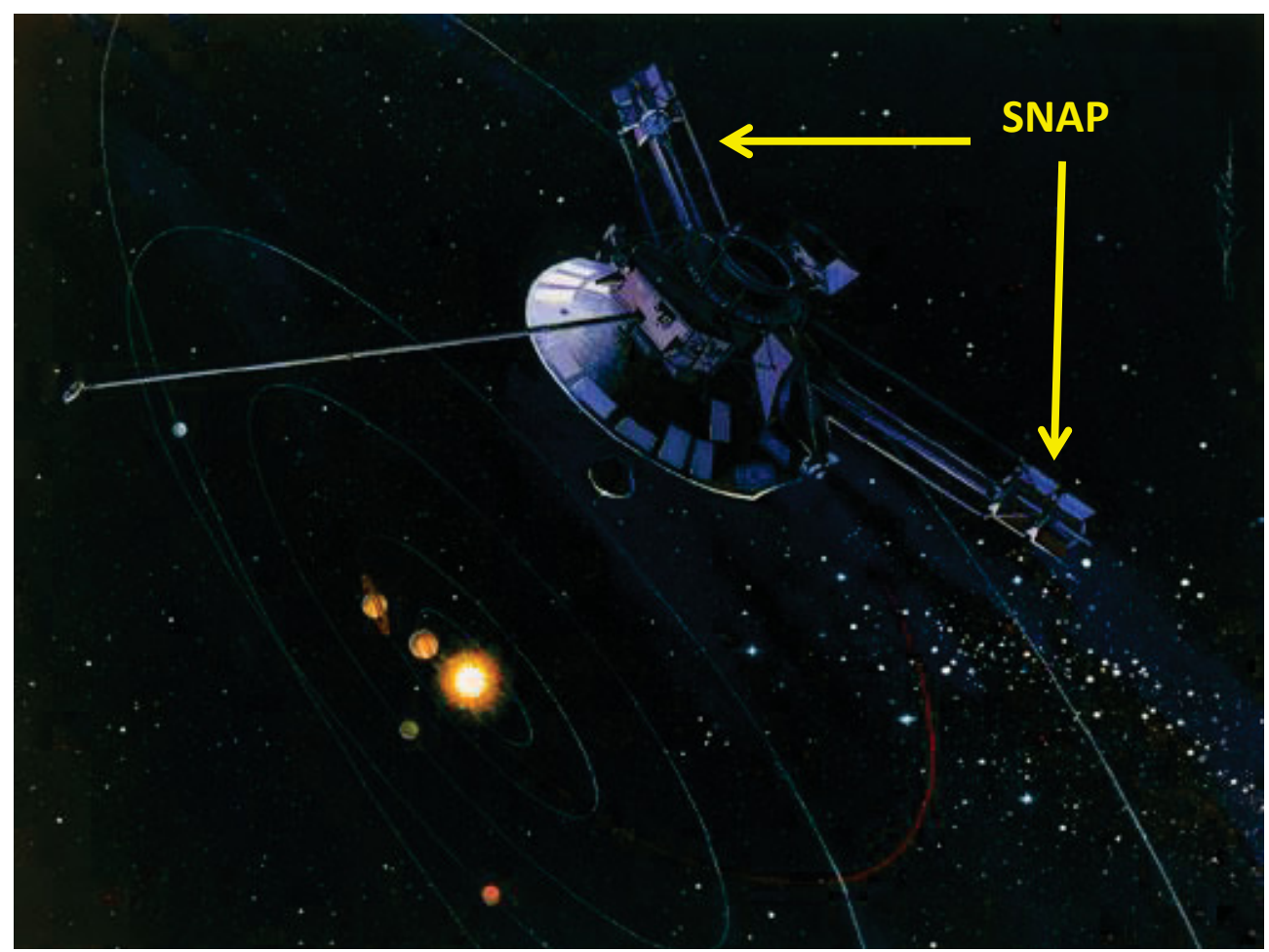

Figure 1-5. Pioneer 10 (1972) and 11 (1973) outer planets; four RTGs each (SNAP 19), 12 RHUs each.

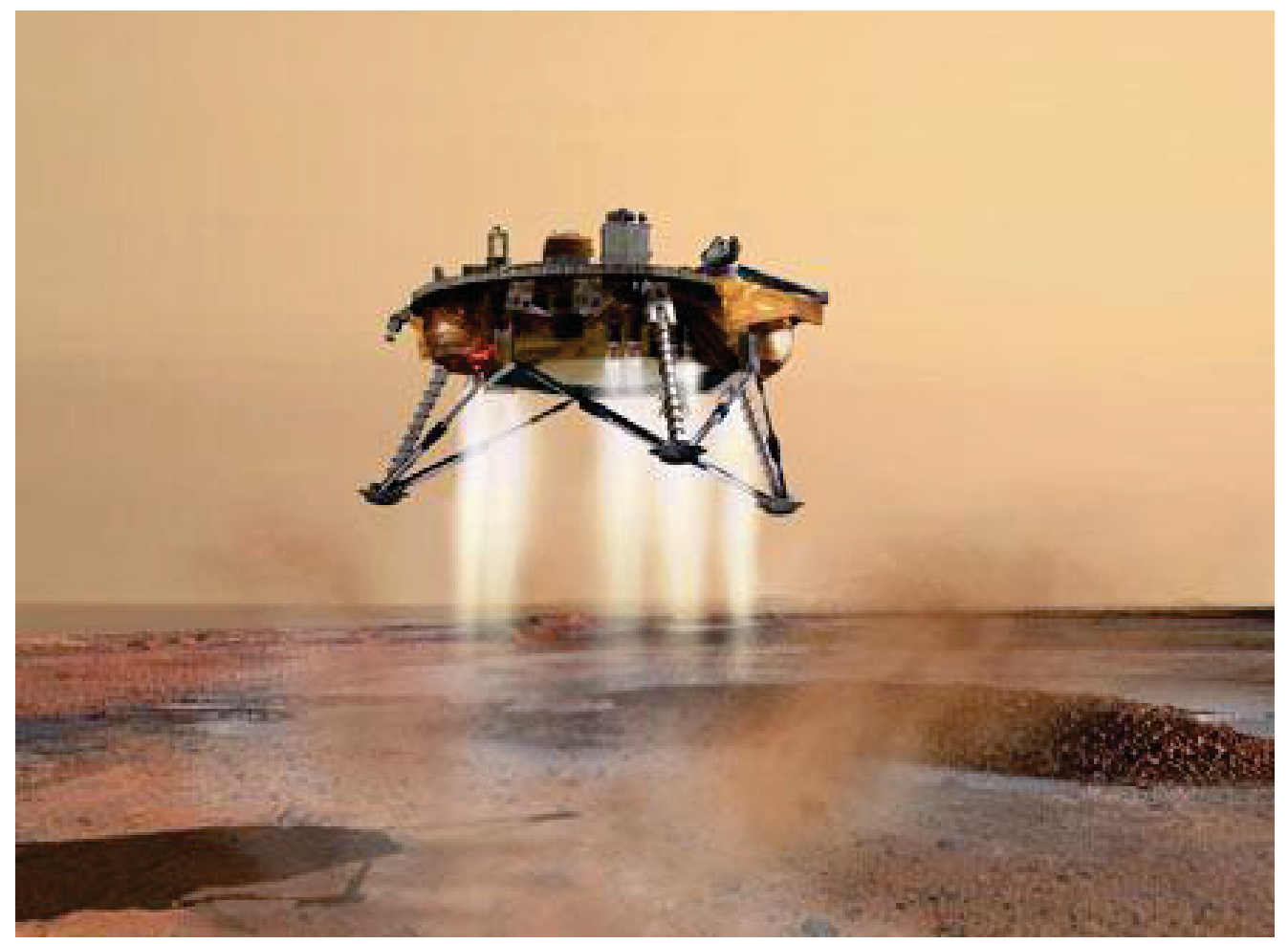

Figure 1-6. Viking 1 and 2 1975; Mars landers, two SNAP, 19 RTGs each mission. 


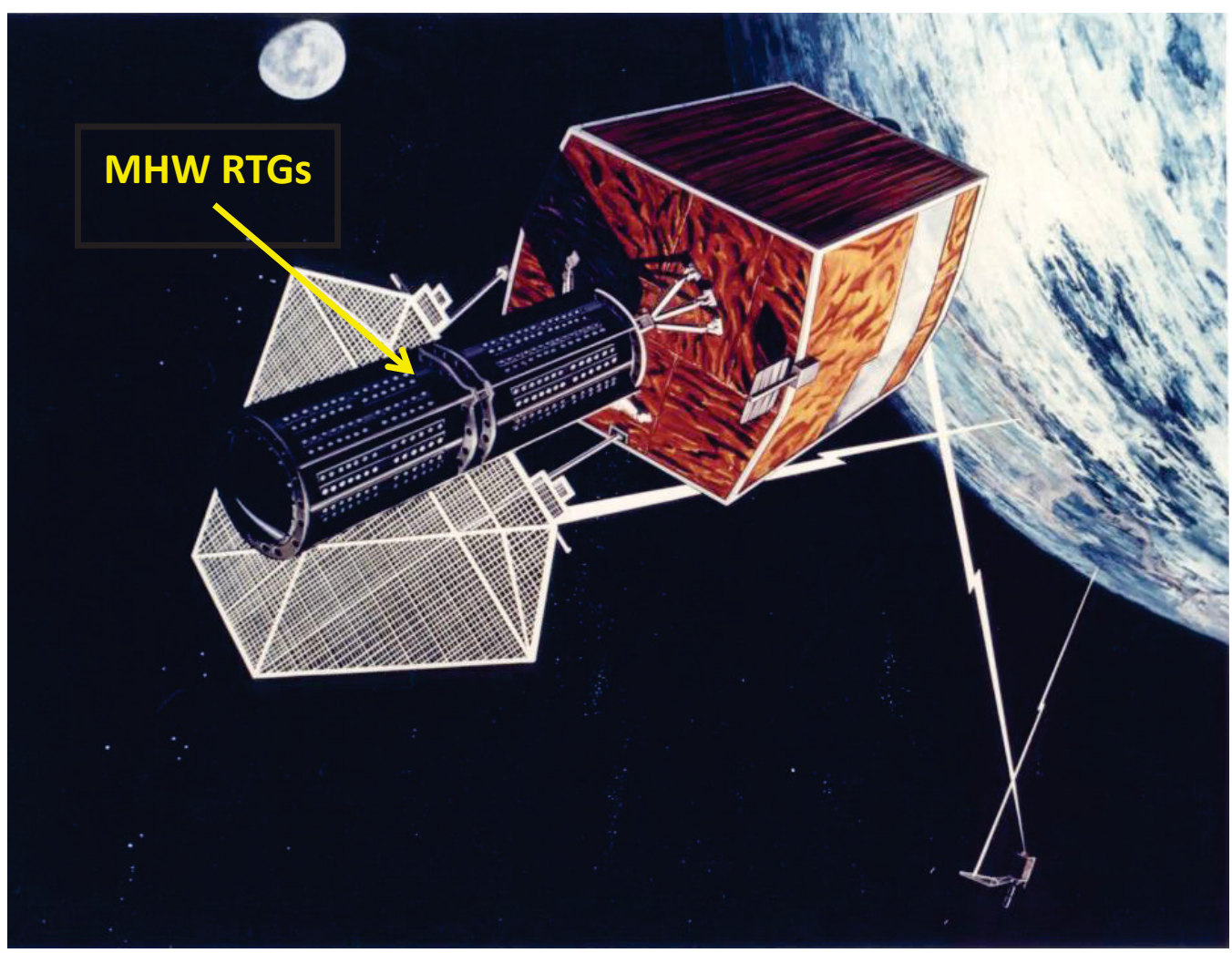

Figure 1-7. Lincoln Experimental Satellite (LES) 8 and 9, 1976; USAF/MIT Lincoln Laboratory, Communications, two MHW RTGs each.

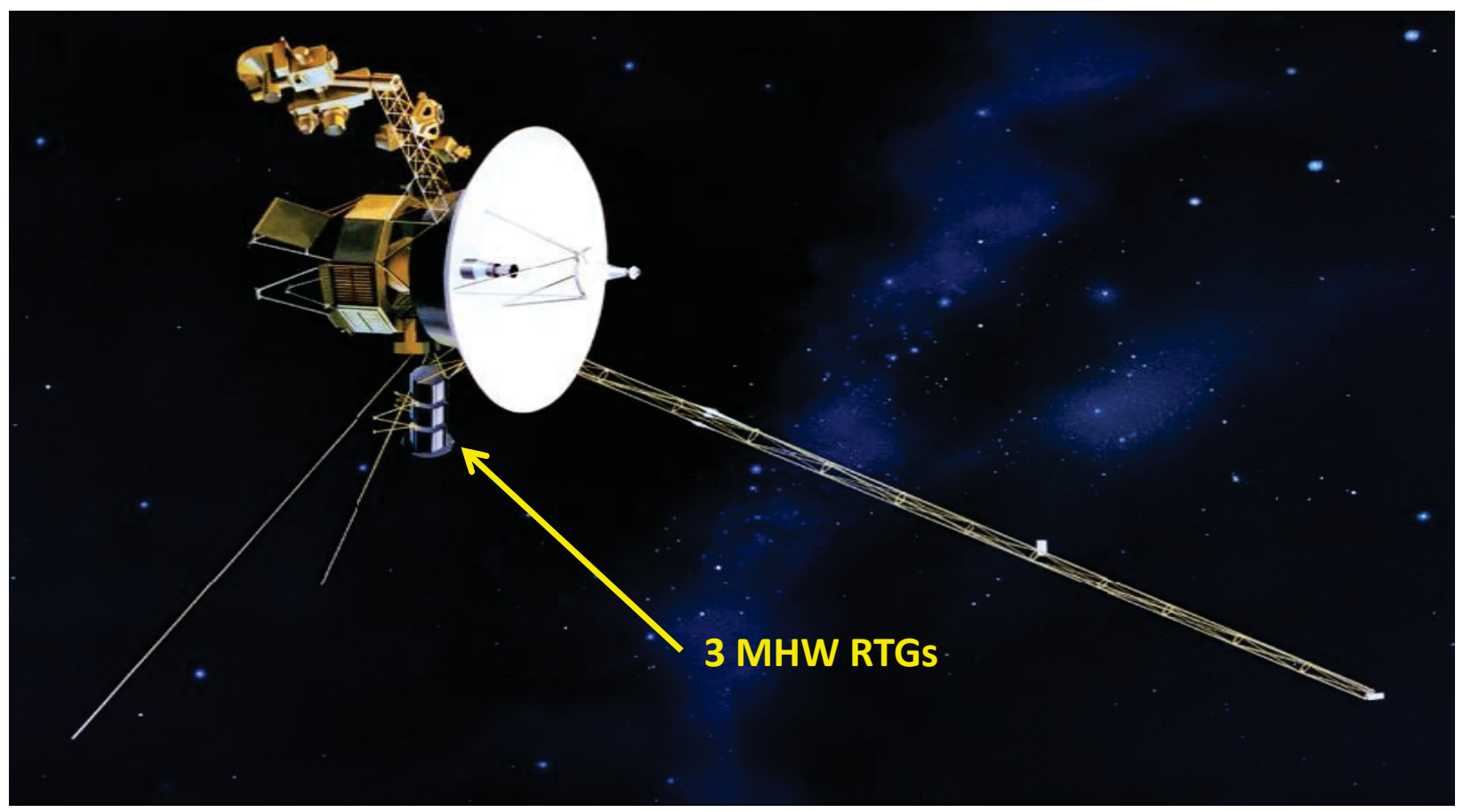

Figure 1-8. Voyager 1 and 2 1977, outer planets; 3 MHW RTGs each, 9 RHUs. 


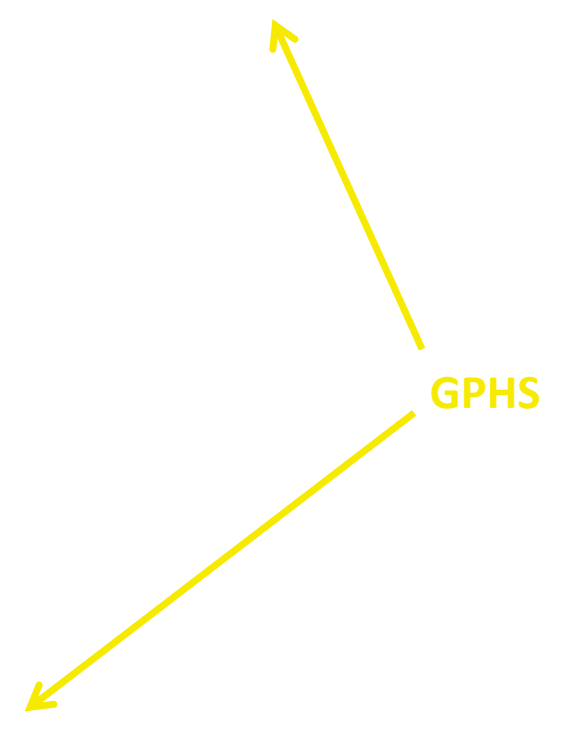

Figure 1-9. Galileo 1989, Jupiter system, two GPHS RTGs, 120 RHUs.

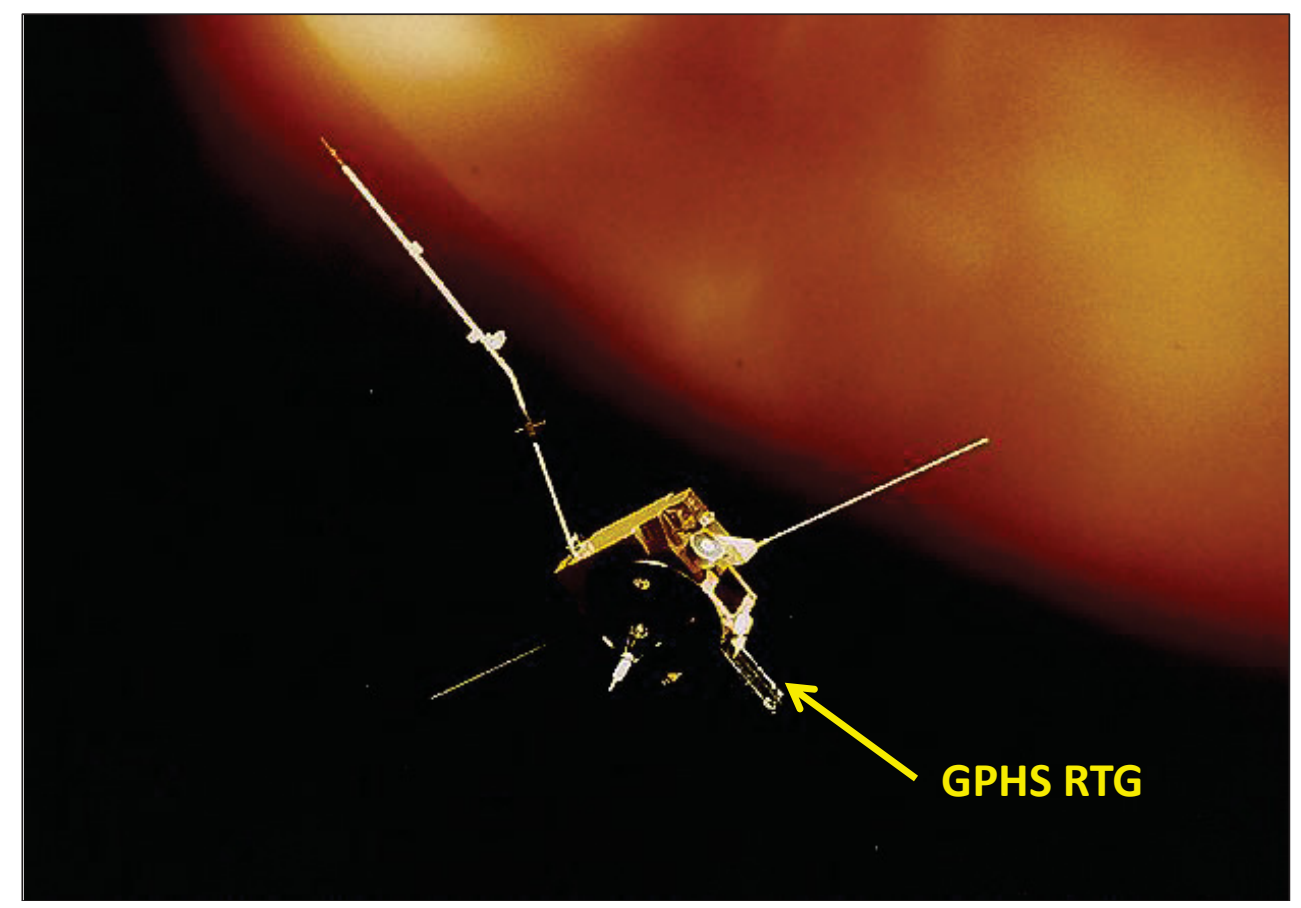

Figure 1-10. Ulysses, Jupiter 1990; one GPHS RTG. 


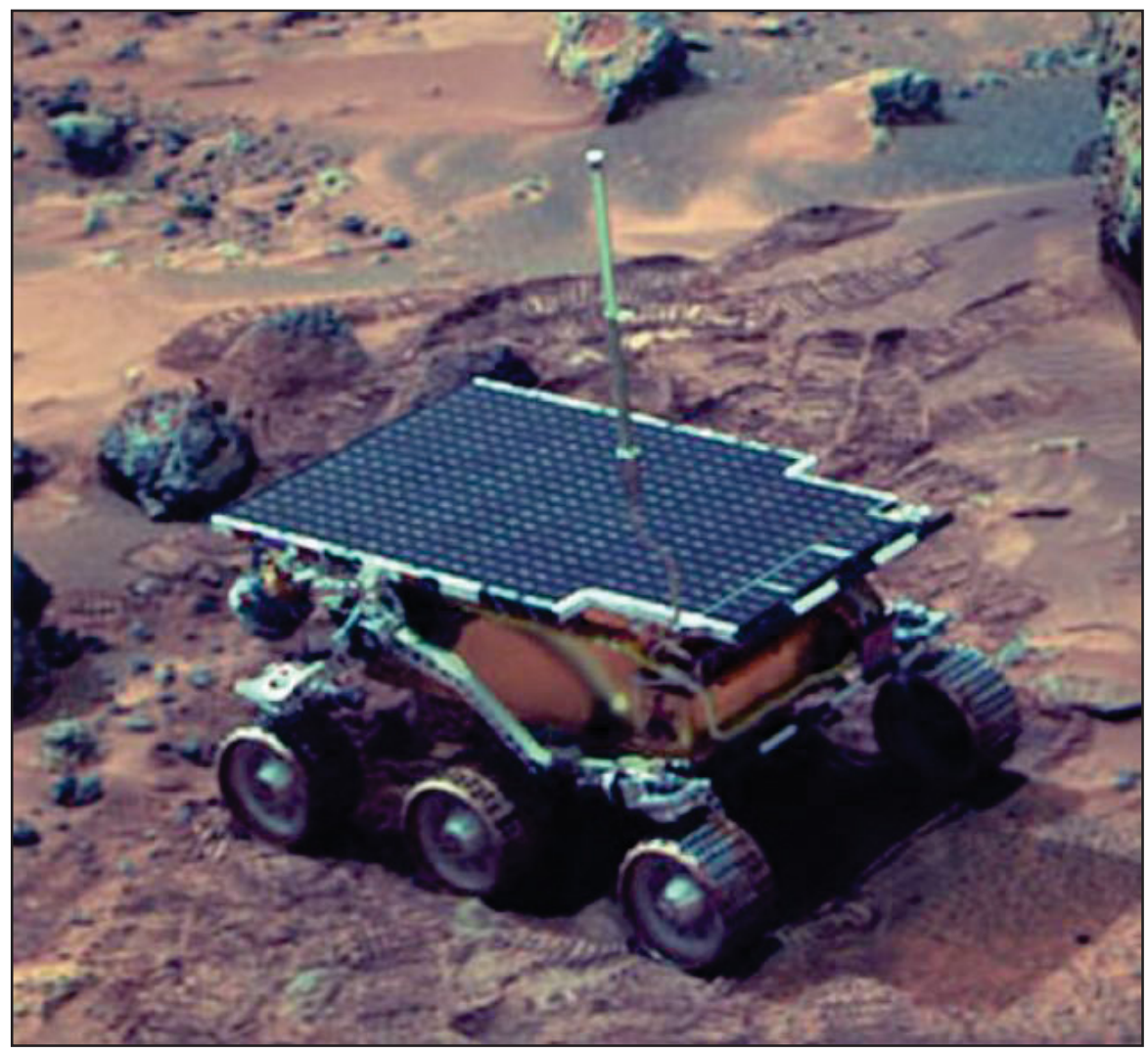

Figure 1-11. Mars Rover Pathfinder 1996; three RHUs.

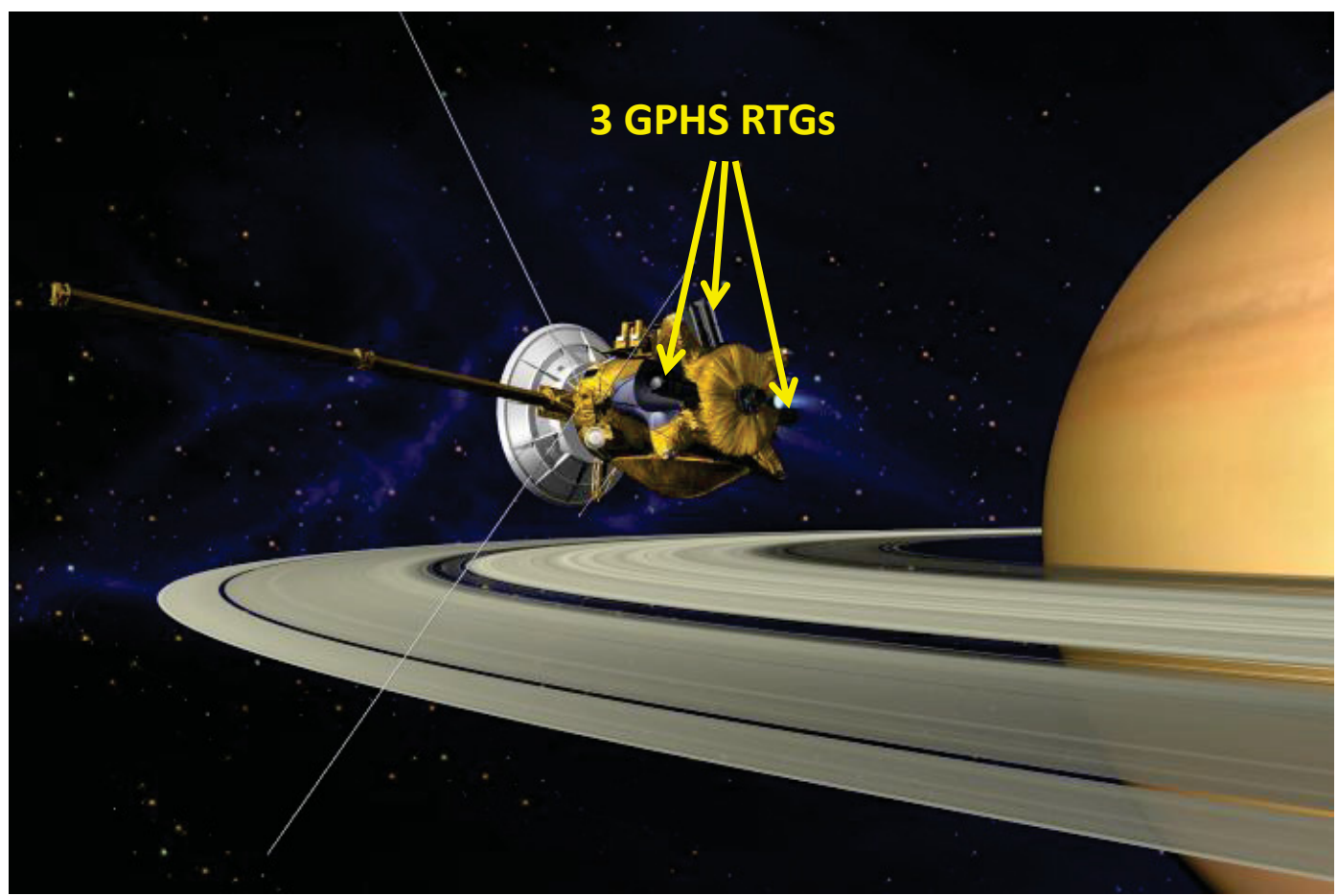

Figure 1-12. Cassini-Huygens 1997; Saturn system; three GPHS RTGs, 129 RHUs. 


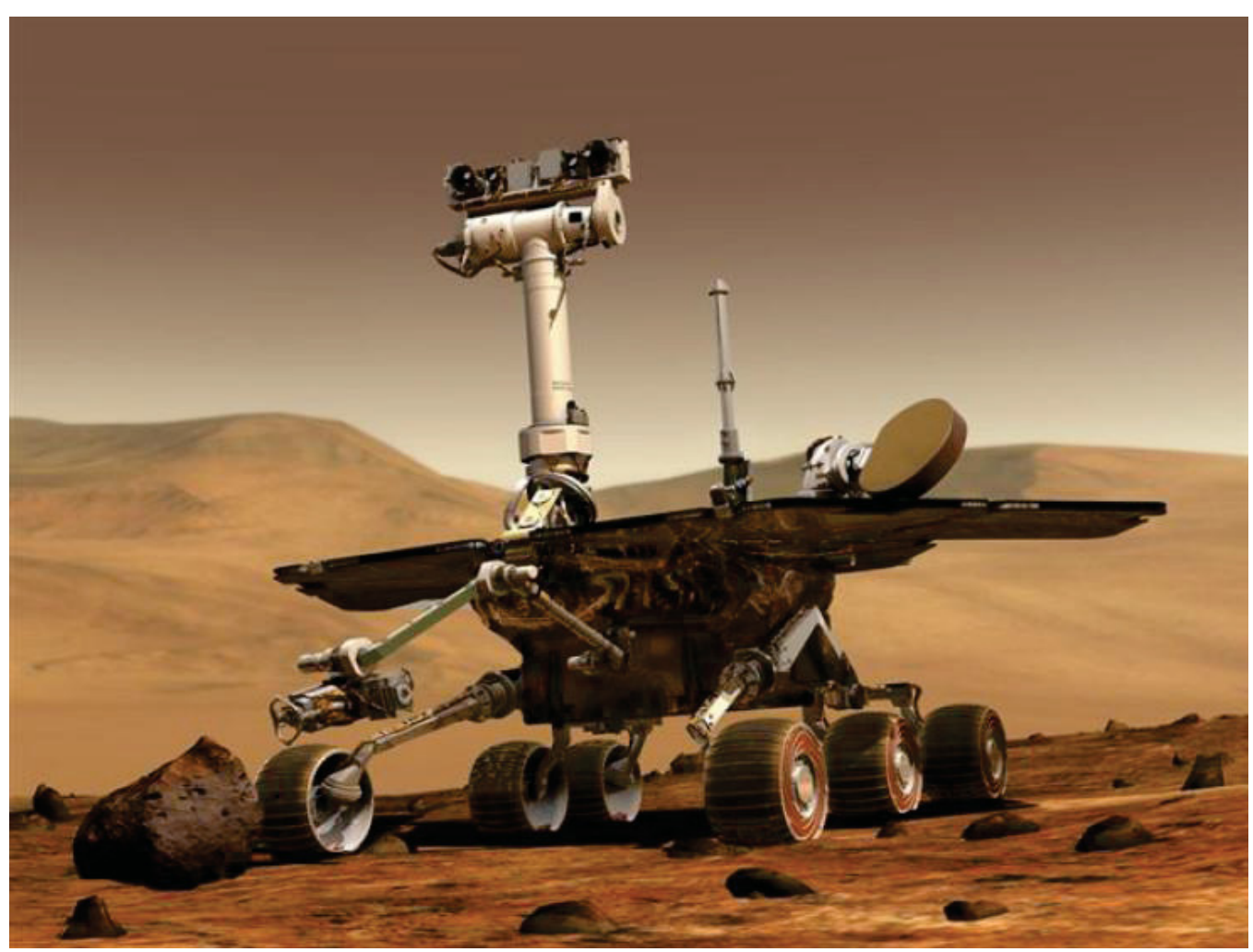

Figure 1-13. Mars Rovers Spirit and Opportunity. 2003; eight RHUs each.

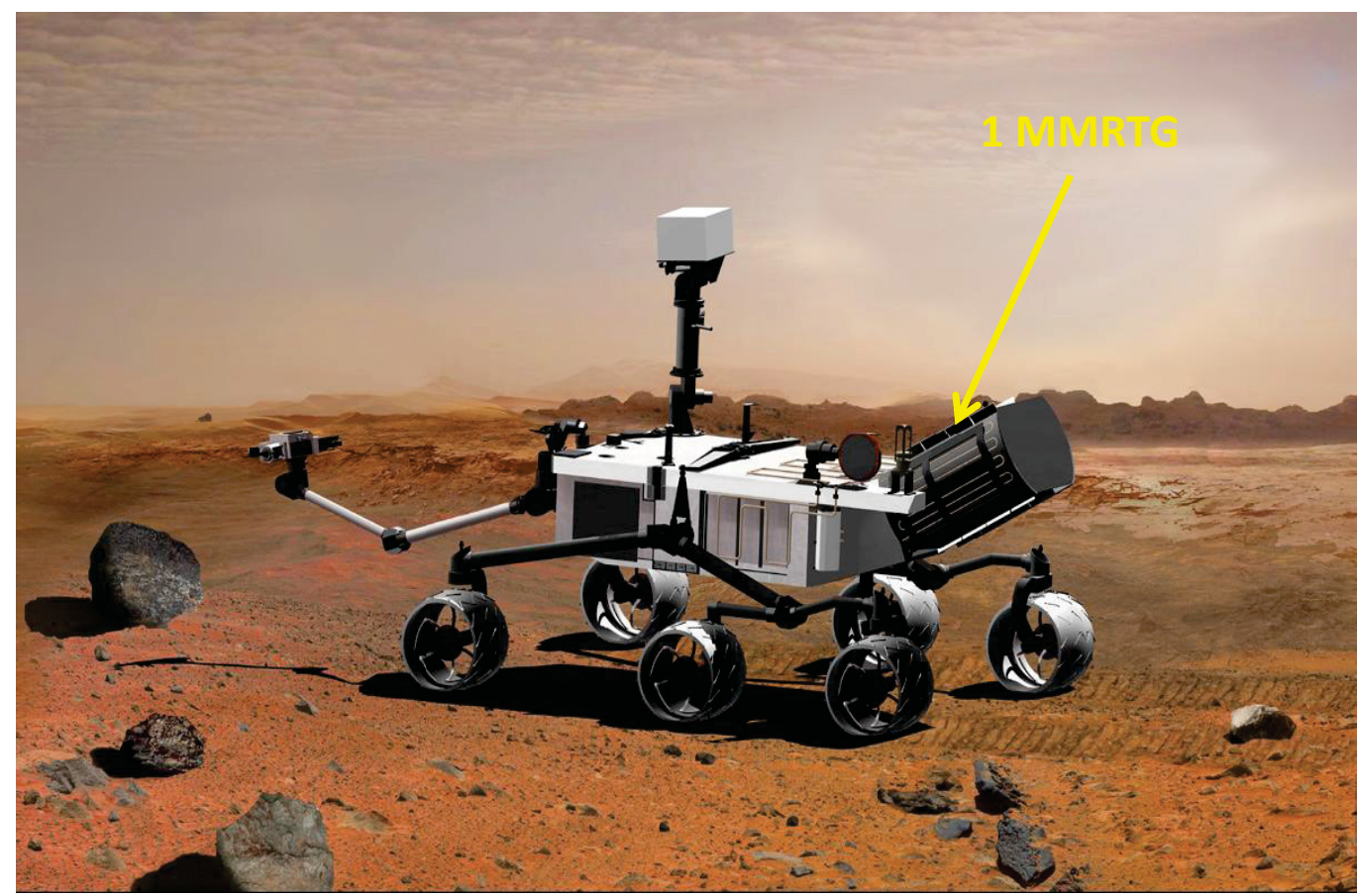

Figure 1-14. Mars Science Laboratory, Curiosity, November 2011; one MMRTG. 


\subsection{Operations Overview}

\subsubsection{Heat Sources and Power Systems Production/Delivery}

The SDPS program is responsible for the design and production of RTGs and RHUs using an oxide of $\mathrm{Pu}^{238}$. Actual production campaigns in support of specific NASA or national security missions are funded by the user in accordance with established cost reimbursement protocols.

The RTGs convert the heat of decay from the fuel to electric power for spacecraft operation. Designs currently in production are the Multi-Mission Radioisotope Thermoelectric Generator (MMRTG) and the ASRG (Figure 1-15).
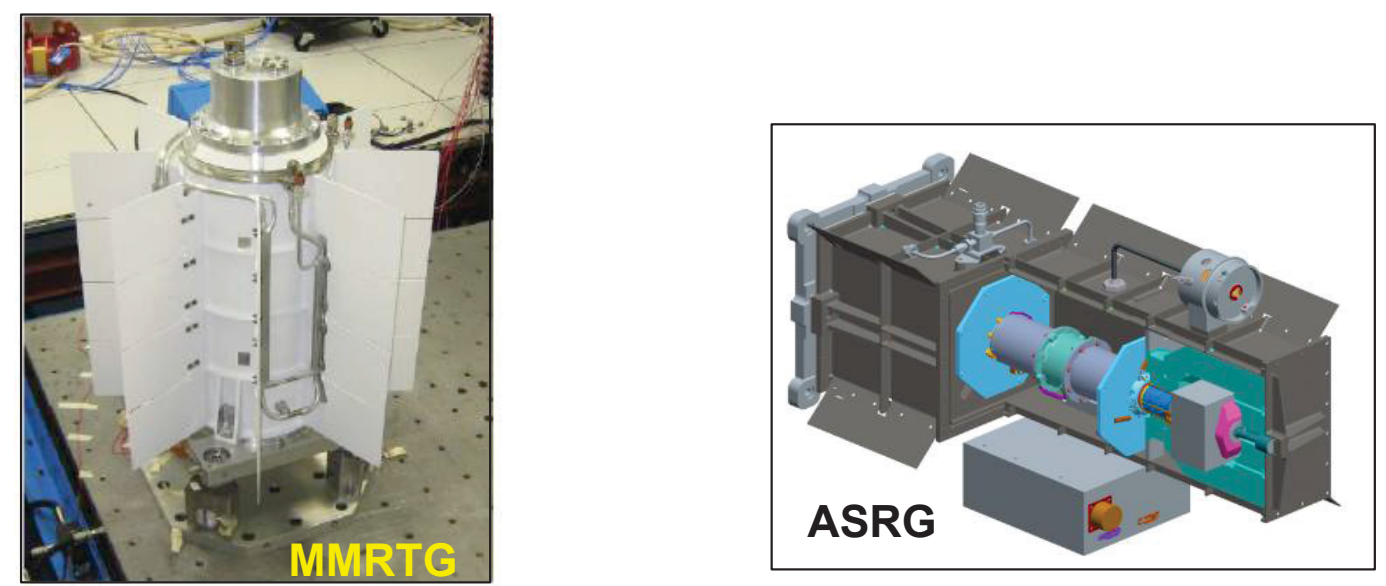

Figure 1-15. RTG designs currently in production: MMRTG and ASRG.

The $\mathrm{Pu}^{238}$ fuel is encapsulated at LANL in special cladding manufactured at ORNL to make two types of heat sources:

1. The general purpose heat source (GPHS) (Figure 1-16), the basic building block of the MMRTG and ASRG that provides heat for conversion to electricity and heat for spacecraft, satellite, or rover components.

2. The light-weight radioisotope heater unit (LWRHU) (Figure 1-17), a small heat source that provides heat for spacecraft, satellite, or rover components. 


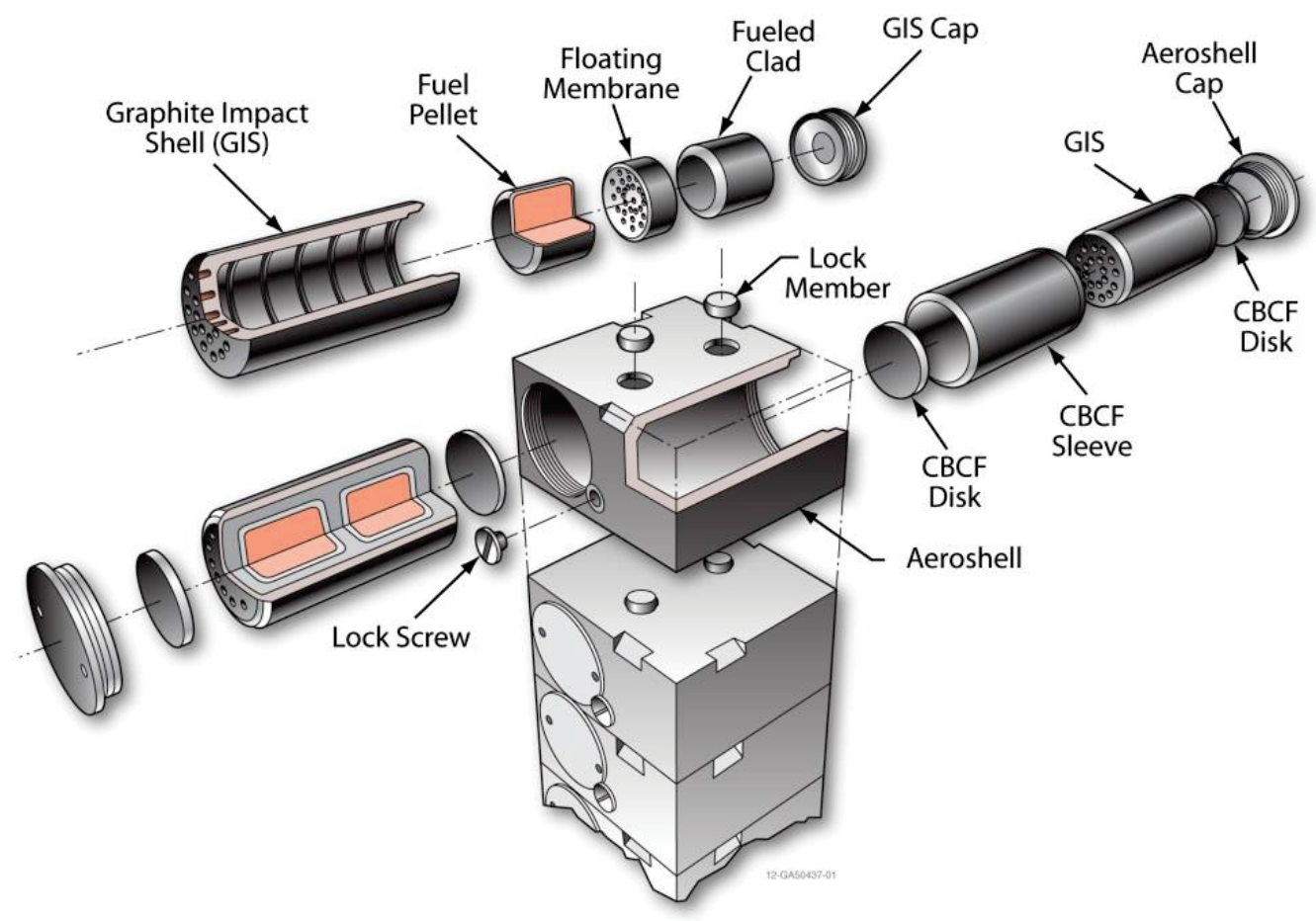

Figure 1-16. GPHS

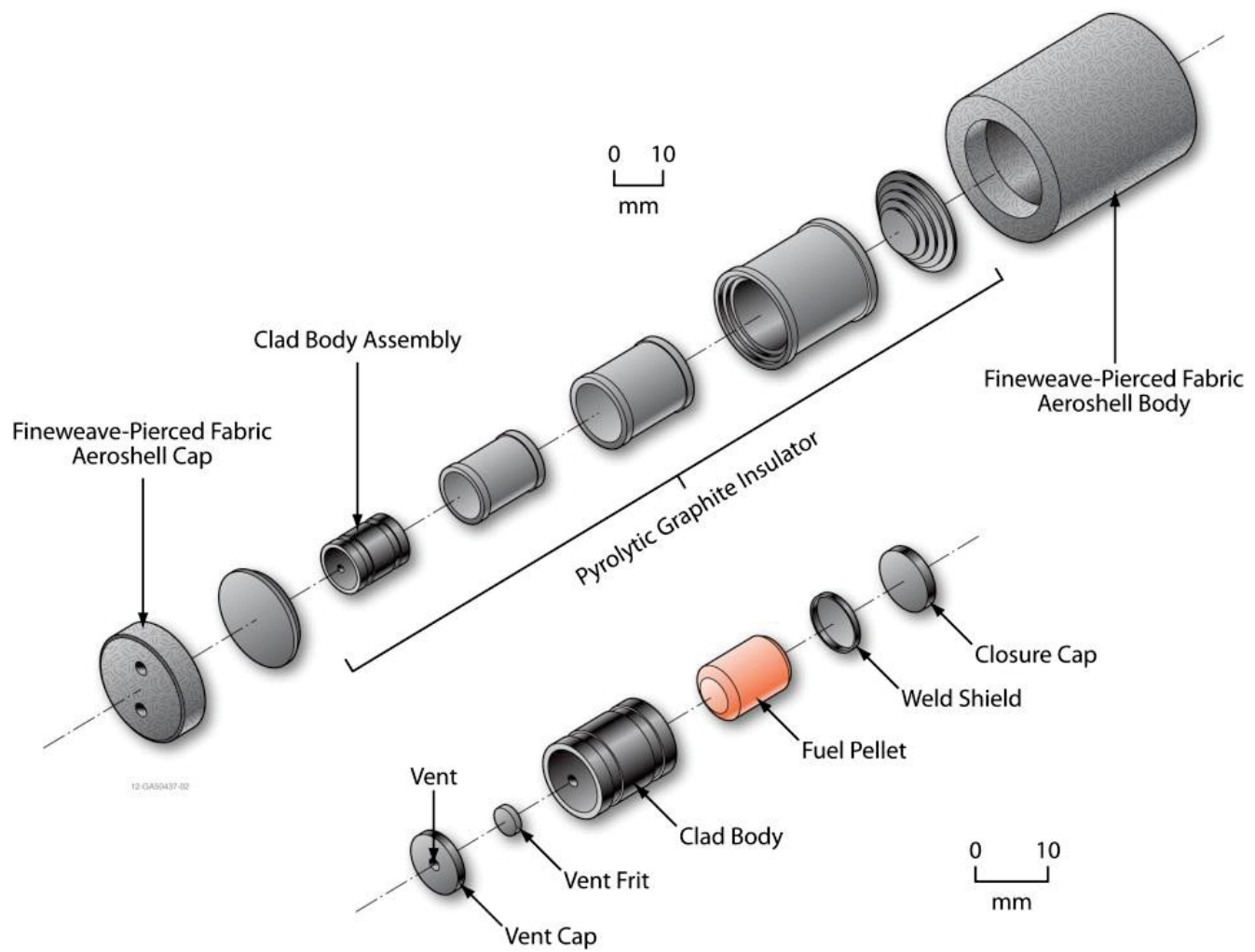

Figure 1-17. LWRHU 
Production of MMRTGs, ASRGs, and LWRHUs is a highly complex and technically challenging process. Maintaining this capability includes:

1. Ensuring adequate equipment and support infrastructure are in place at the three laboratories and are being maintained and revitalized properly

2. Ensuring a core staff of fully trained operators, engineers, and supervisors is in place

3. Providing effective SDPS Office oversight of the DA/SICs.

Figure 1-18 shows the interrelationship of the facilities geographically. Activities take place in eight states.

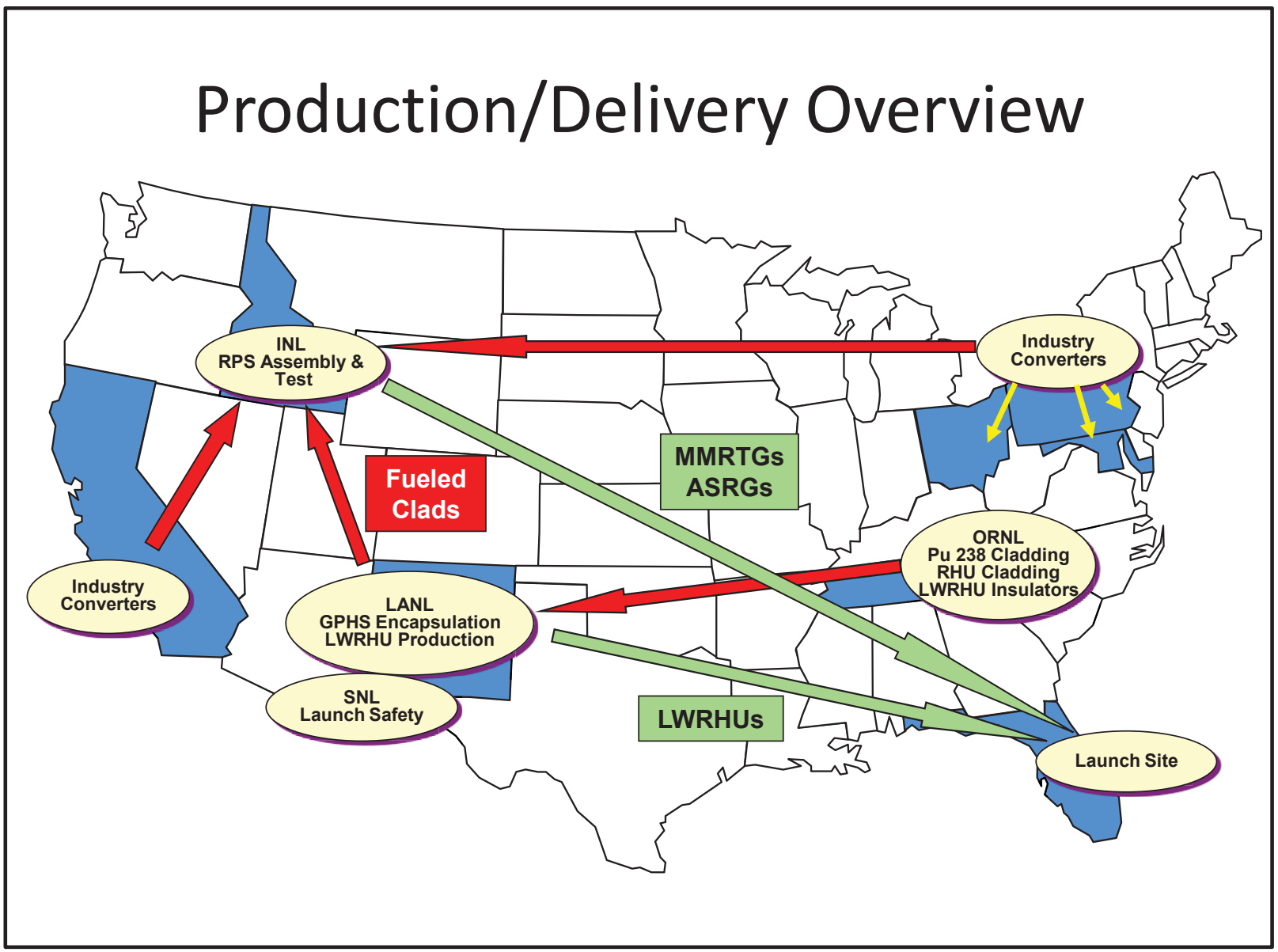

Figure 1-18. Geographic relationship of RPS/RHU production and delivery systems.

For NASA launch operations, DOE maintains control of the RTGs and LWRHUs at the KSC site during storage, onsite transport, and delivery to the launch vehicle integration facility. DOE provides major support to NASA's emergency preparedness program, which includes deployment of a large response team during the launch window, media interface, and public outreach. DOE conducts nuclear risk assessments for NASA's National Environmental Policy Act (NEPA) reviews and prepares Safety Analysis Reports for review by the Interagency Nuclear Safety Review Panel. Chapter 5 describes in detail launch support operations at the KSC. 
Figure 1-19 illustrates the functions performed by the three national laboratories and the supporting contractors. Sandia National Laboratories (SNL) also participates in the Program by performing launch safety analyses for DOE to support the presidential launch approval process.

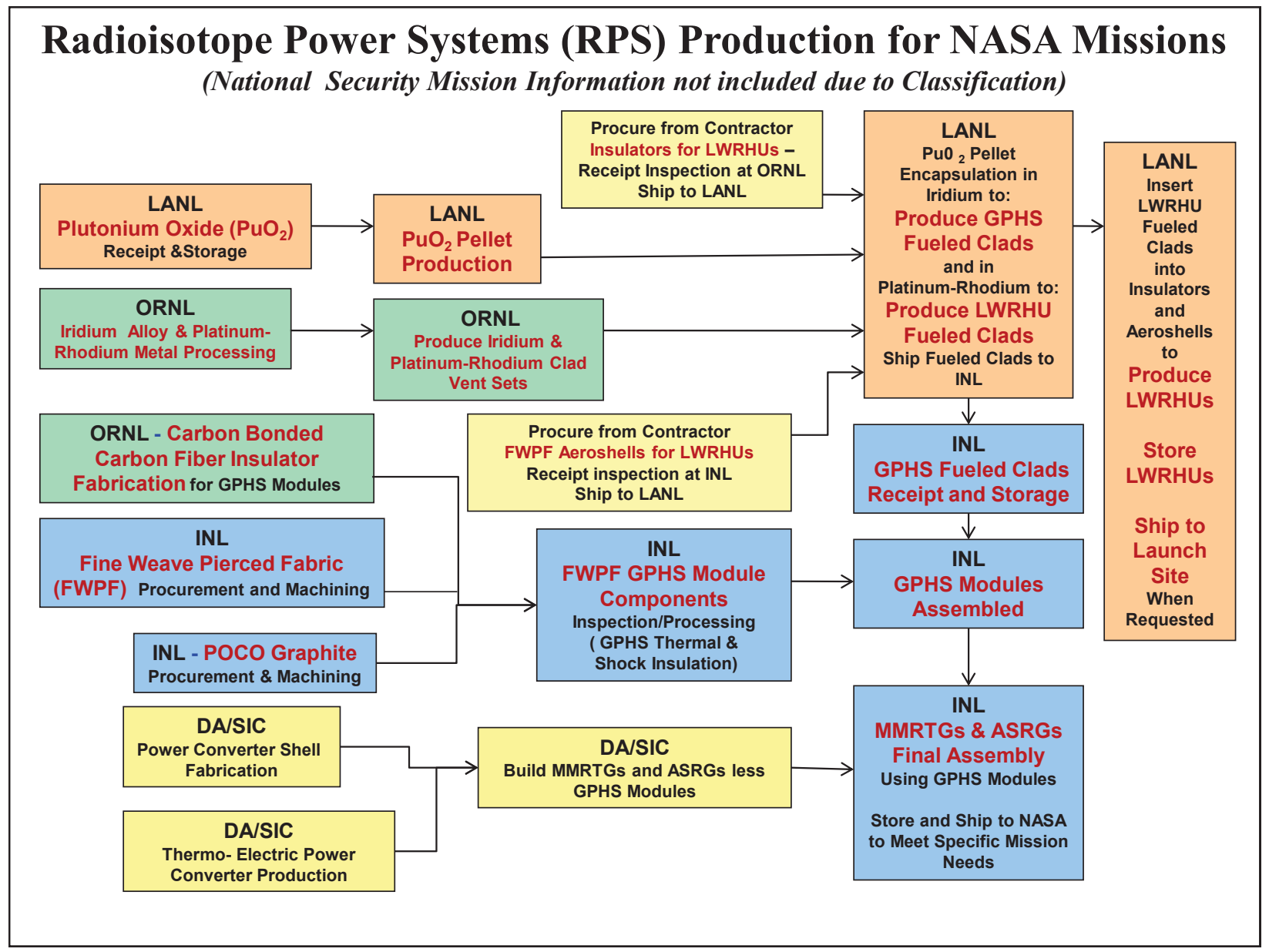

Figure 1-19. Functions performed by national laboratories and supporting contractors in RPS/RHU production.

\subsubsection{Operations: Next steps}

The success of DOE in delivering RPS technologies has enabled NASA to meet its needs for space power for many years. However, certain capabilities for the Program are necessary but missing, while others are present but seriously underperforming.

The SDPS Program should aggressively pursue the following areas of work:

- Provide essential, but missing, capabilities (e.g., isotope production and power conversion system development)

- Improve what is present but underperforming (heat source production) for the RPS production pipeline

- Maintain what is operational and reliable (i.e., component production, fueling, and testing of RPS units). 
The specific goals below are listed in order of priority:

1. Reestablish a reliable means of providing usable $\mathrm{Pu}^{238}$ for manufacturing into heat sources for NASA and national security customers

2. Increase reliability and dependability of heat source production

3. Reestablish a prototype development and testing capability for new power conversion systems

4. Reinvigorate the existing safety-verification test program to provide for an enhanced database to support goals 1-3 above. 


\section{OAK RIDGE NATIONAL LABORATORY (ORNL)}

\subsection{Overview}

The production plant at ORNL occupies significant space in three production buildings at ORNL (Figure 2-1). The NE SPDS funds its share of the infrastructure costs for the real property maintenance in accordance with Department Orders and Federal Acquisition Regulations.

\section{Oak Ridge National Laboratory (ORNL) Facilities}

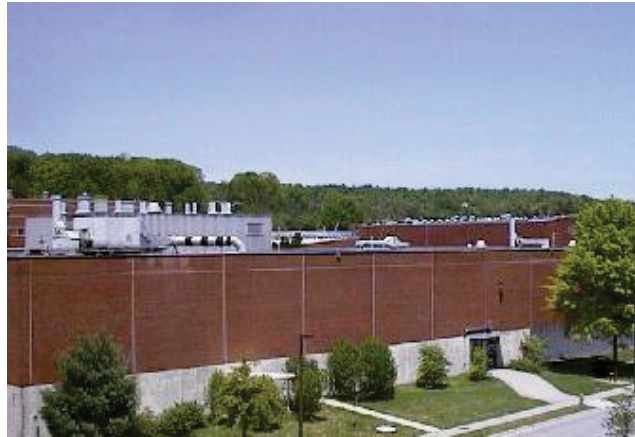

Bldg. 4508

- Production of Iridium and PlatinumRhodium Alloys

- Fabrication of Carbon Bonded Carbon Fiber Insulator Sets

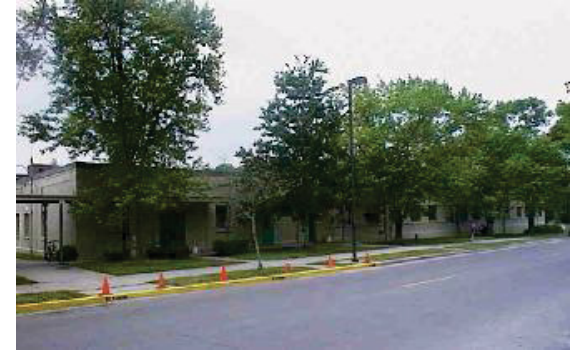

Bldg. 2525 - Fueled Clad Vent Set and Platinum-Rhodium RHU Clad Vent Set Production Area

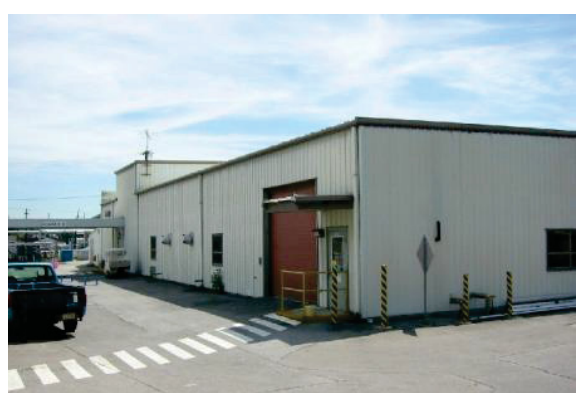

Bldg. 2547 - Clad Welding and Dimensional Inspections. LWRHU Insulators Receipt, Inspection, and Heat Treatment

Figure 2-1. Three production buildings at ORNL.

The ORNL production operation:

- Has 60 major pieces of equipment - replacement value of the equipment is estimated at over \$35 million

- Occupies a total of 13,500 square feet $\left(\mathrm{ft}^{2}\right)$ in three industrial buildings

- Has a staff of highly skilled and trained technicians and managers that includes 11 full-time equivalents (FTEs) directly charged in addition to approximately 10 FTEs charged under indirect charges. 


\subsection{ORNL Mission for Space and Defense Power Systems}

The mission for space and defense power systems at ORNL includes the following:

1. Produce the special iridium alloy metal containment for the $\mathrm{Pu}^{238}$ fuel pellets that are manufactured at LANL. This containment is called cladding, and in its final configuration it is called a clad vent set. These clad vent sets are shipped to LANL where they are then used to encapsulate the $\mathrm{Pu}^{238}$ fuel pellets. The encapsulated heat sources are called GPHS FCs. The finished GPHS FCs are shipped to INL where they are inserted into the RTGs assembled at INL. The heat from GPHS FCs is converted to electricity in MMRTGs or ASRGs for NASA outer planet space exploration missions.

2. Produce special platinum-rhodium (Pt-Rh) alloy metal clad vent sets. These clad vent sets are shipped to LANL where they are used to encapsulate very small $\mathrm{Pu}^{238}$ pellets to produce LWRHU FCs. The LWRHU FCs are encased in Pyrolytic Graphite Insulators and fine weave pierced fabric (FWPF) aeroshells at LANL to make LWRHUs. The LWRHUs are used by NASA for warming critical components, instrumentation, lubricating fluids, and thruster fuel during planetary space exploration missions and some Earth orbit missions.

3. Produce carbon bonded carbon fiber (CBCF) insulator sleeves. These special sleeves provide thermal insulation for the GPHS FCs installed in the GPHS modules manufactured at INL.

4. Procure, conduct quality assurance (QA) receipt inspections, and provide "bake out" heat processing for Pyrolytic Graphite Insulators. These are sent to LANL where they used in the assembly of LWRHUs.

ORNL is the lead materials development laboratory for the SDPS program. These unique facilities, equipment, and trained personnel provide:

- Development, testing, welding, and characterization of materials for high temperature heat source applications

- Expertise in iridium alloys - this capability is a unique national asset

- Refractory and other high temperature metal/materials compatibility and mechanical properties testing (i.e., tensile, creep, and pressure burst)

- Expertise in $\mathrm{CBCF}$ insulator production, which is a unique capability.

Much of the capital equipment at the ORNL facilities is obsolete, beyond useful life expectancy, and no longer has vendor support. Funding is necessary to revitalize the facility over the next 10 years.

\subsection{Iridium Alloy Clad Vent Set Production}

In order to maximize thermo-electric conversion efficiency, the GPHS FCs must be maintained at a very high temperature. Platinum alloys were initially used but were found to have inadequate strength and impact properties for the high temperature application. The switch was made to iridium and the subsequent alloy development led to the current DOP-26 alloy (Figure 2-2). 


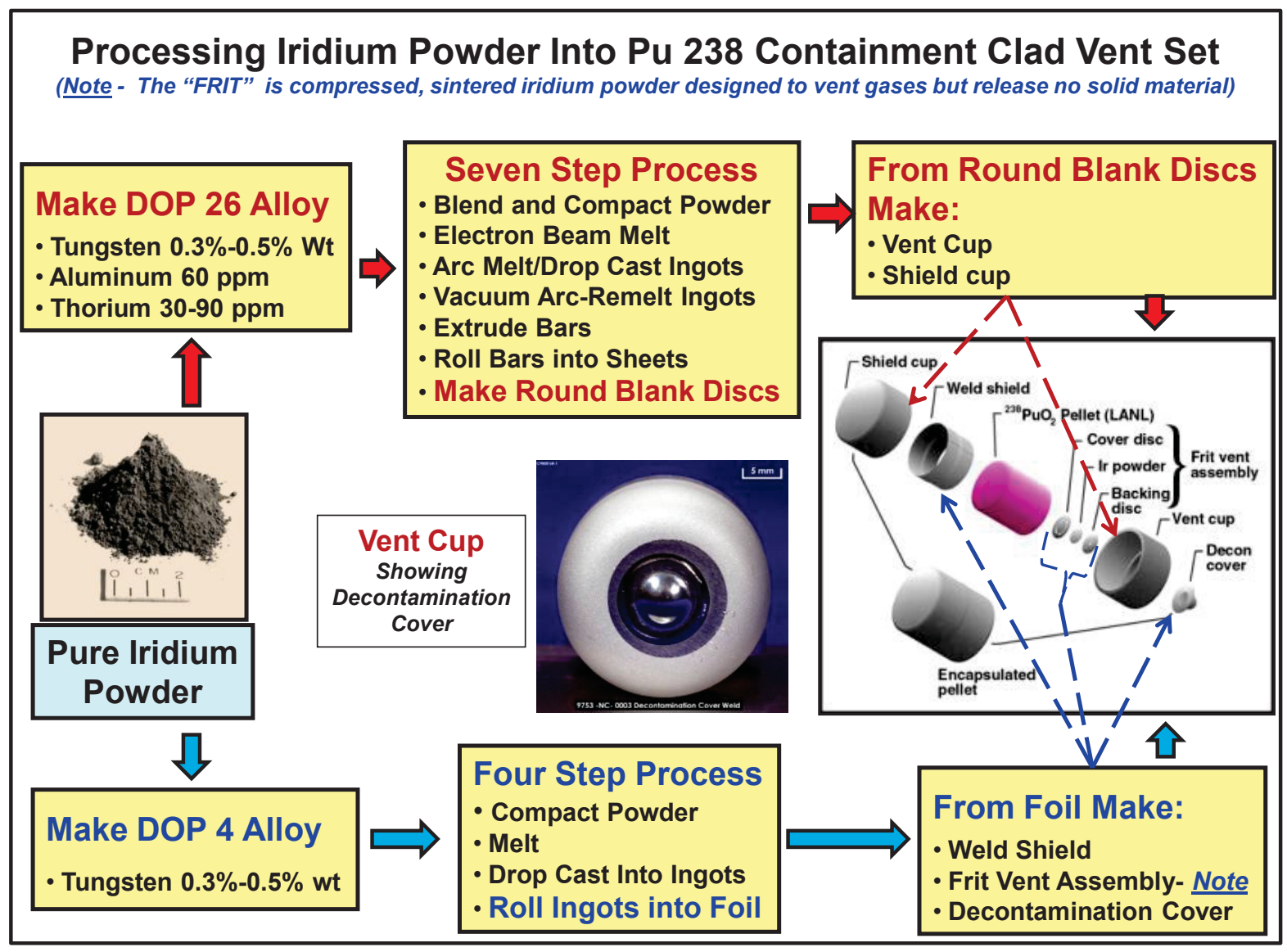

Figure 2-2. Iridium alloy development.

Iridium is a dense, high-strength metal with a very high melting temperature relative to other metals. ORNL has developed two alloys of iridium that provide the characteristics required. ORNL receives iridium in a pure powder form and creates the desired alloys in the laboratory. The alloys are processed into solid metal and then into the two forms needed: (1) round blank discs from one alloy and (2) thin foil from the other alloy.

The GPHS clad vent set is a very complex shell for the $\mathrm{Pu}^{238}$ pellet. It has seven specific parts made from the blank discs and foil. It is $\sim 1.2$ inches in diameter. It takes unique skills learned through extensive training and experience to be able to make such small parts with the required precision.

A unique feature of the GPHS clad vent set is the "frit" vent. One of the $\mathrm{Pu}^{238}$ decay products is helium gas. The helium gas can build up pressure inside the iridium clad if it is not vented. The frit vent is a filter made of sintered pure iridium powder that allows helium decay gas to pass but not any solid material. Figure 2-3 shows the Vent Clad Assembly focusing on the Frit Vent. 


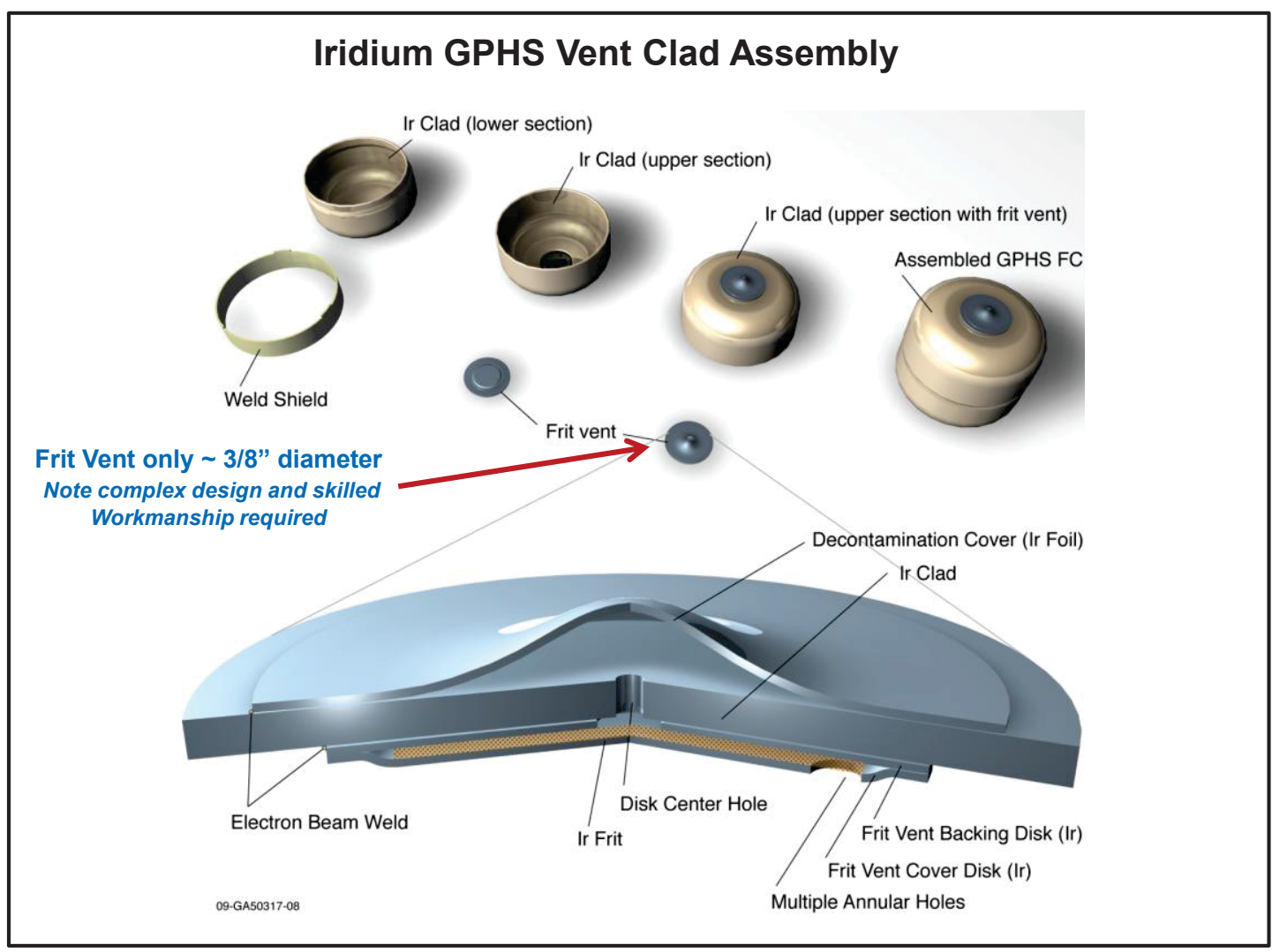

Figure 2-3. Frit vent on the vent clad assembly.

The manufacturing clad vent sets requires 45 pieces of special equipment and a highly skilled workforce.

Extensive training is required to maintain the skilled work force necessary at ORNL. Additional funding is required to recruit and train replacements for the skilled personnel who are approaching retirement age. Maintaining this capability reduces the risk of losing continuity of operations.

Processing iridium was developed at ORNL and is a national asset.

Nine of the major pieces of equipment needed are shown in Figure 2-4. These large units require an extensive preventive and corrective maintenance program that is stressing ORNL's current funding. 


\section{Nine Major Pieces of Equipment Used in Iridium GPHS Clad Vent Set Fabrication}

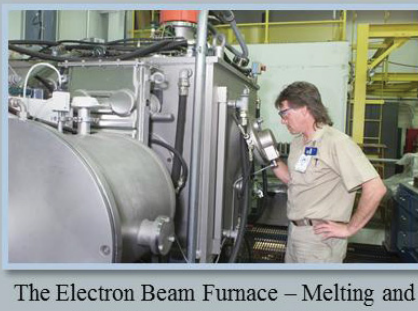
Purification of Iridium Alloy
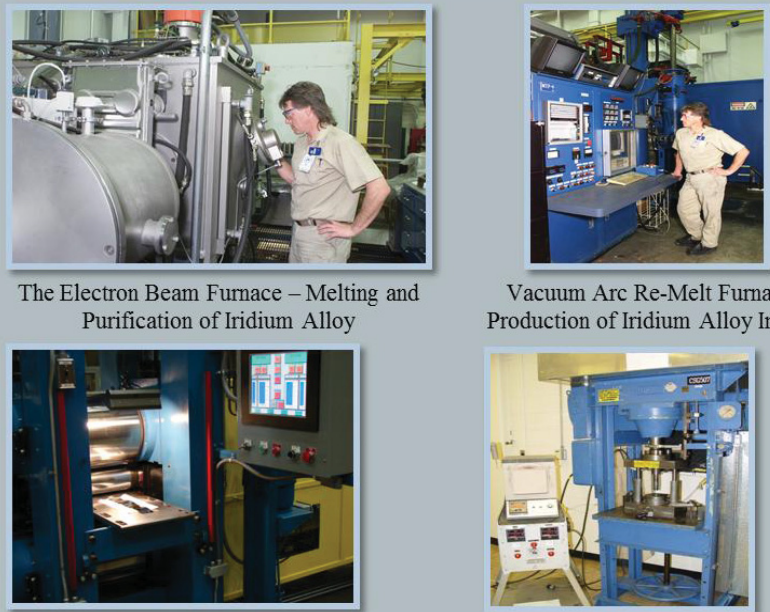

Vacuum Arc Re-Melt Furnace Production of Iridium Alloy Ingots

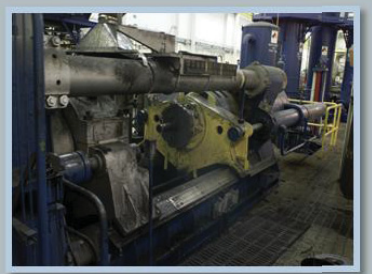

1200 Ton Extrusion Press Process Iridium Alloy Ingots
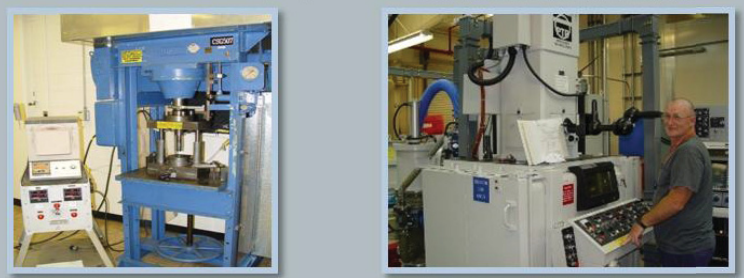

Precision Rolling Mill Reduce Iridium Alloy Sheet and Foil to Required Thickness

Hydraulic Press for Forming Fueled Clad Vent Cups

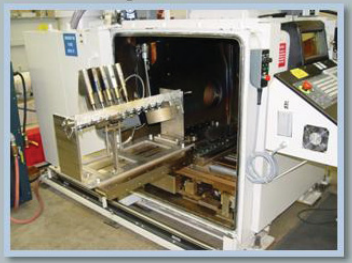

Ten Head Welding Positioner Electron Beam Welding of Clad Vent Set Components

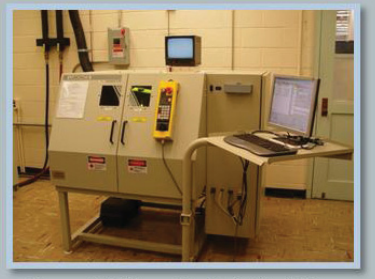

Laser Welder - Fueled Clad Vent Assembly Fabrication
Electron Beam Welder Used in Both Iridium Alloy Production and Clad Vent Set Fabrication

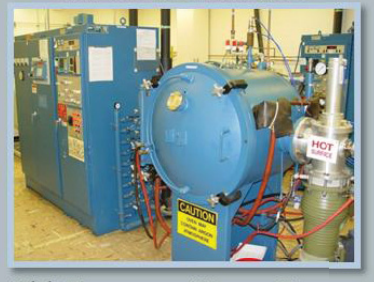

High-Temperature Vacuum Furnace Fueled Clad Vent Set Production

Figure 2-4. Nine major pieces of equipment used in Iridium GPHS clad vent set fabrication.

\subsection{Pt-Rh Clad Vent Set Production}

$\mathrm{Pu}^{238}$ pellet containment for LWRHUs uses the Pt-Rh alloy for the main parts and pressed and sintered pure platinum for the vent frit. The temperature and service requirements for the LWRHU fuel clads are not as stringent as the iridium alloy GPHS clad vent sets. Pt-Rh is easier to fabricate than iridium and it meets all the design requirements for LWRHU clad vent sets.

Figure 2-5 shows the parts of the LWRHU clad vent set and the complex production process. The completed LWRHU FC is only $1 / 4$ inch in diameter. 


\section{Making Pt-Rh Alloy LWRHU Clad Vent Set}

\footnotetext{
- Vent Cap, Clad Body, End Cap, and Shim are made from Platinum - Rhodium Alloy

- Frit made from pressed, sintered pure Platinum Powder (Frit allows gases to vent but releases no solid material)
}

\section{Complex, Multi-Step Metal Fabrication Processing:}

Process requires 48 precise steps by technicians with unique skills and training

- Clad Body 11 steps

- End Cap 12 steps

- Vent Cap 12 steps

- Shim

- Frit 9 steps 4 steps

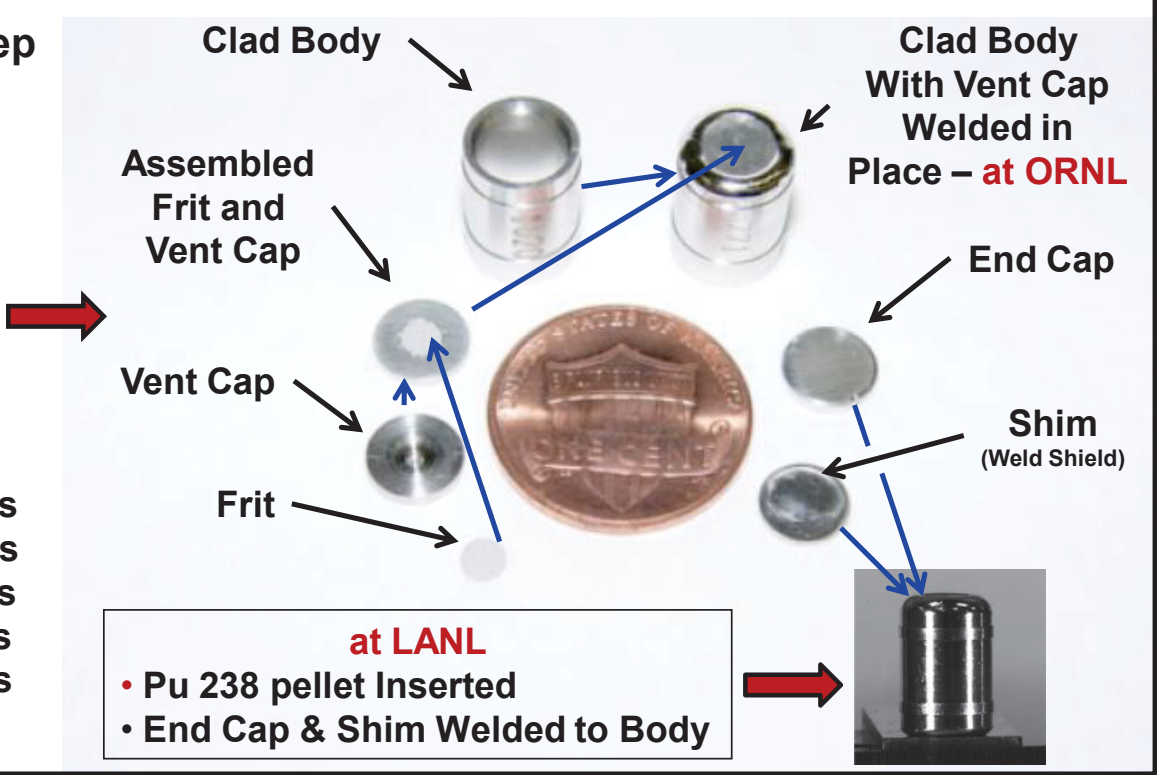

Figure 2-5. Parts and production process of the LWRHU clad vent set.

It requires highly skilled and trained technicians to manufacture such small parts to the exacting specifications required. The RHU clad vent set assembly is welded together at ORNL, except for the end cap and shim. It is shipped to LANL where the $\mathrm{Pu}^{238}$ pellet is inserted along with the shim and then the end cap is welded in place. The shim shields the $\mathrm{Pu}^{238}$ fuel when welding the end cap in place. The major pieces of equipment needed for manufacture of the clad vent sets are shown in Figure 2-6. 


\section{Major pieces of Equipment for Manufacture of LWRHU Clad Vent Sets}

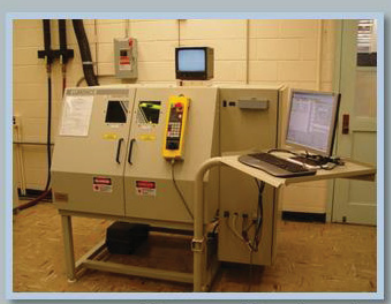

Laser Welder - Welds Frit and Vent Cap to RHU Clad Body

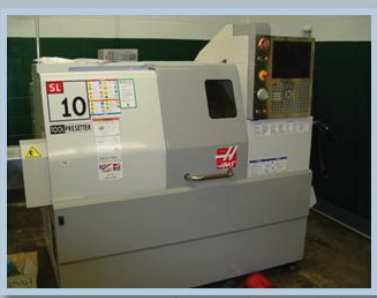

Haas SL-10 Lathe used to machine RHU Clad Bodies

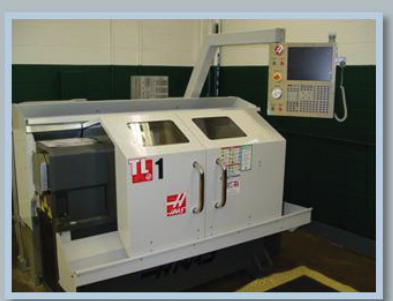

Haas TL-1 Lathe used to machine RHU Clad Caps

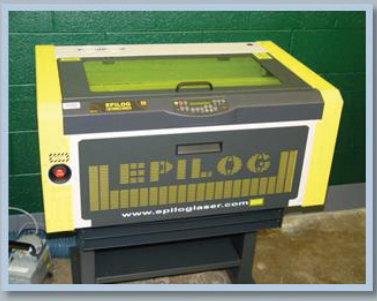

Epilog Laser marks identification numbers on RHU Clad Bodies

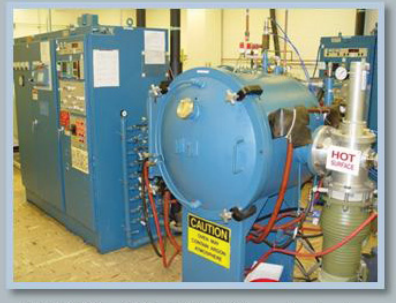

RHU Clad Vent Set Manufacturing High-Temperature Vacuum Furnace

Figure 2-6. Major pieces of equipment for manufacture of LWRHU clad vent sets.

\subsection{Procurement, Receipt Inspection, and Heat Treatment of Pyrolytic Graphite Insulator for LWRHU Assembly at LANL}

A completed LWRHU requires fueling the LWRHU clad vent set and closure welding of the clad body at LANL, as discussed above. Once fueling is complete, it is then inserted into two insulating shells at LANL to complete the LWRHU. The assembled LWRHU consists of an outer FWPF aeroshell and an inner Pyrolytic Graphite Insulator surrounding the LWRHU FC, as shown in Figure 2-7. ORNL establishes the specifications and procures the Pyrolytic Graphite Insulators from a contractor. ORNL conducts a QA inspection and a heat treatment of the Pyrolytic Graphite Insulators in a high-temperature vacuum furnace to bake out moisture and volatile impurities. After these processes, the Pyrolytic Graphite Insulators are shipped to LANL. In addition, the FWPF aeroshells are procured and managed similarly by INL and then shipped to LANL.

Figure 2-7. LWRHU assembly.

\subsection{Manufacture of CBCF Insulation Sets at ORNL}

CBCF insulation sleeves are used in the assembly of GPHS modules at INL. The process flow diagram included as Figure 2-8 shows the production process for the insulation sleeves. The final manufacturing of the GPHS modules and their loading into the MMRTGs or ASRGs at INL is described in detail in 
Chapter 4. At INL, two GPHS FCs (manufactured at LANL) are inserted into each insulator sleeve and capped with the discs, and then two insulator sleeve assemblies are inserted into the GPHS module, as shown in Figure 2-8.

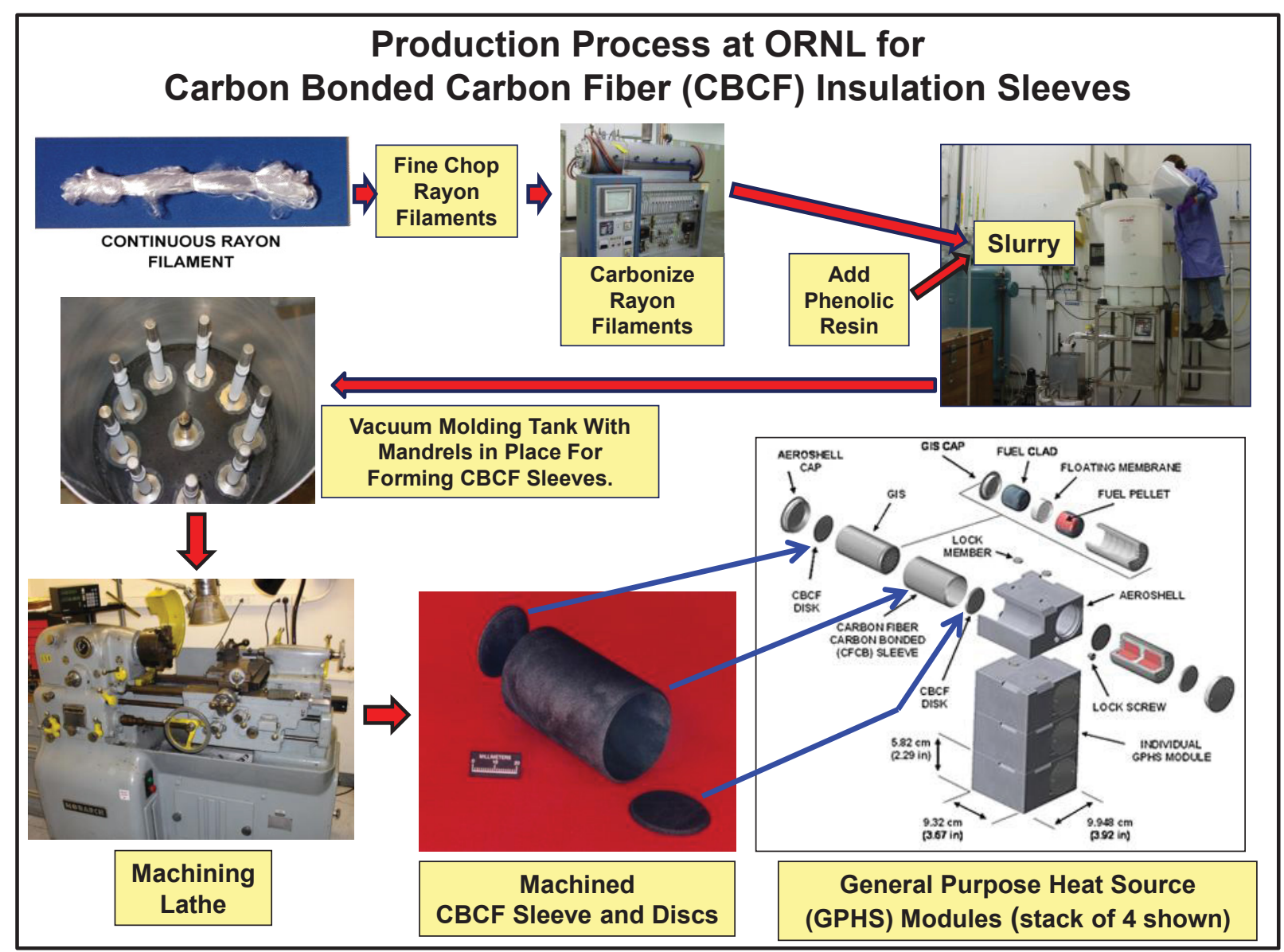

Figure 2-8. CBCF insulation sleeves production process at ORNL. 


\section{LOS ALAMOS NATIONAL LABORATORY (LANL)}

\subsection{Overview}

The plutonium-238 Oxide $\left(\mathrm{Pu}^{238} \mathrm{O}_{2}\right.$ processing facility for the production of radioisotope heat sources is located within Plutonium Facility-4 (PF-4) at Technical Area-55 (TA-55), as shown in Figure 3-1.

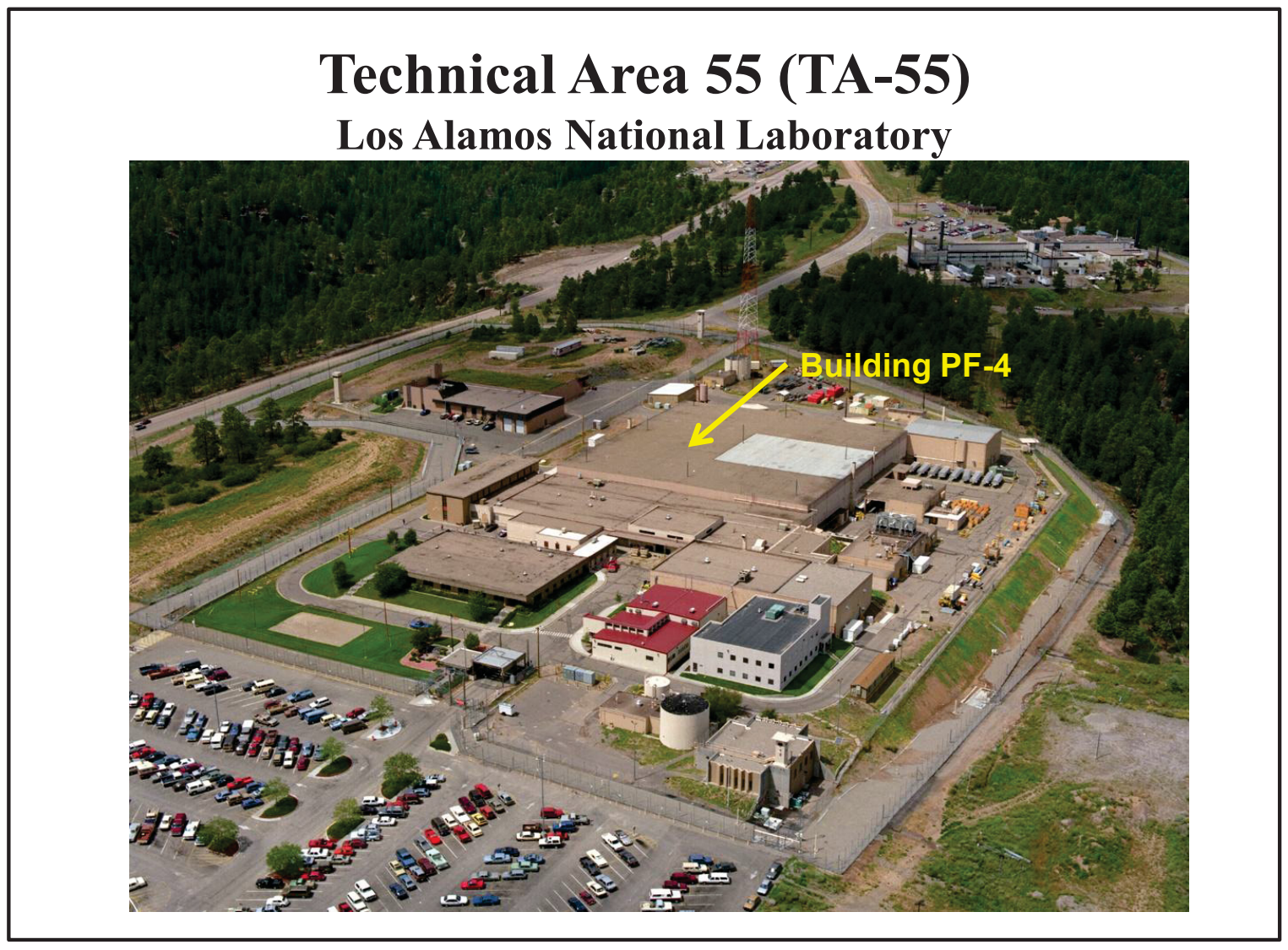

Figure 3-1. Building PF-4 at TA-55.

The $\mathrm{Pu}^{238}$ Facility:

- Occupies $12,000 \mathrm{ft}^{2}$ within PF-4

- Contains 78 gloveboxes

- Contains 61 pieces of special equipment

- Has a replacement plant value (RPV) estimated at $\$ 500$ million

- Includes a staff of 57 FTEs for program operations.

Approximately 40 matrixed staff from LANL provide infrastructure support. Additional staffing, materials, and equipment required to ramp up for a production campaign are fully funded by the user. 
GPHS FCs and LWRHU FCs are produced at LANL to support NASA missions. Production for national security missions is not addressed due to classification. GPHS FCs are shipped to INL where they are used to build MMRTGs and ASRGs. These units provide decades of electrical power for outer planet and deep space exploratory missions.

At LANL, LWRHU FCs are encased in an inner special insulator (provided by ORNL) and an outer protective aeroshell (provided by INL) to make a flight ready LWRHU (Figure 3-2). They are stored at LANL until shipped to the launch site. In the extremely low temperature environment of outer space, LWRHUs provide vital heating for various components, instruments, lubricants, and thruster fuels within the spacecraft.

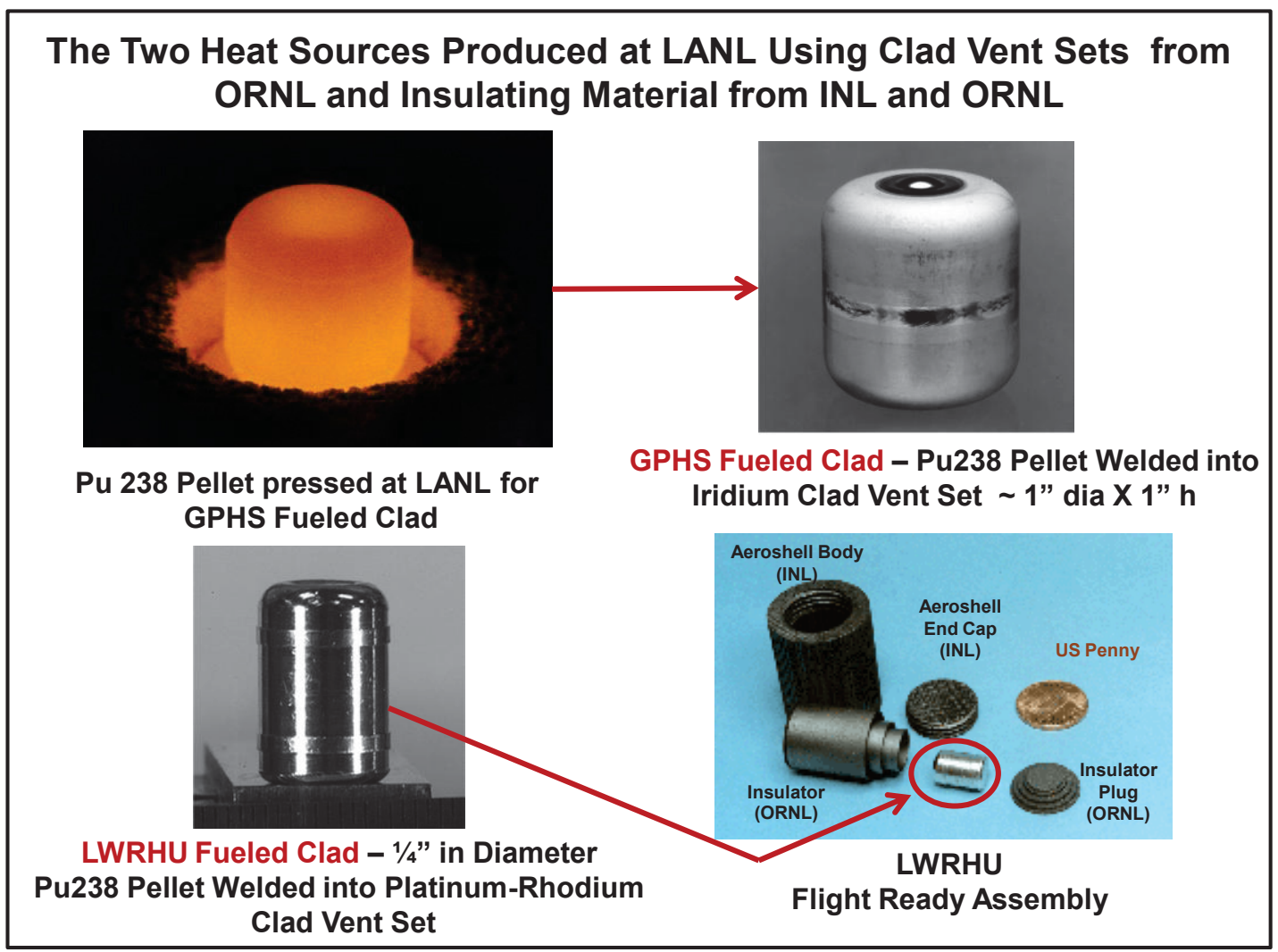

Figure 3-2. Heat sources produced at LANL using clad vent sets from ORNL.

By far, the major capital equipment investment at LANL is the 78 complex gloveboxes. All processing of $\mathrm{Pu}^{238} \mathrm{O}_{2}$ must be conducted in tightly sealed gloveboxes maintained under negative pressure to ensure no leaks of fuel into the work spaces. Special precautions and controls are required to ensure operators are not exposed to $\mathrm{Pu}^{238} \mathrm{O}_{2}$ powder or radiation from radioactive isotopes embedded as impurities in the fuel.

One of the eight rows of gloveboxes required for FC and RHU production is shown in Figure 3-3 as an example of the size and complexity of the glovebox installations. 


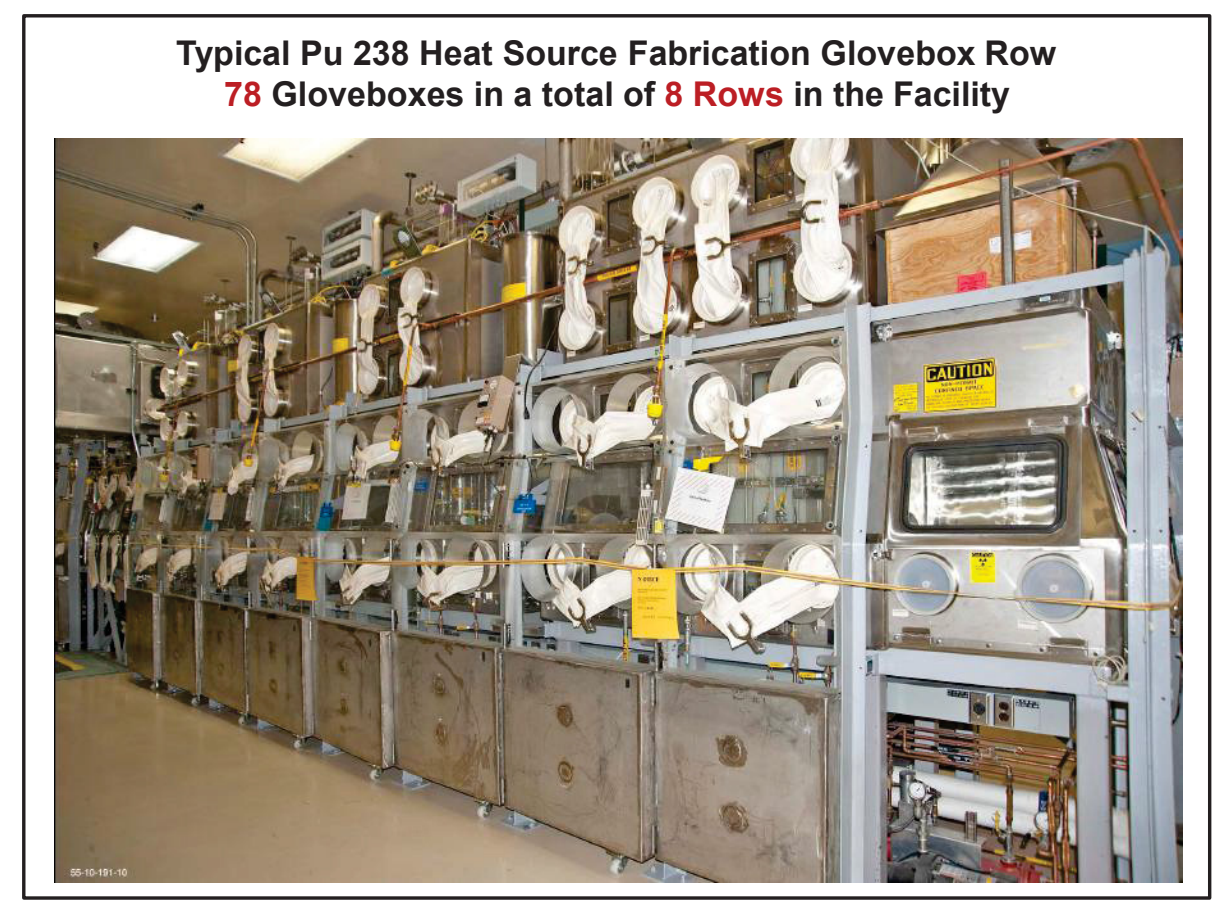

Figure 3-3. Complex gloveboxes at LANL.

There are 40 gloveboxes between 35 and 50 years old. For these older boxes, there are window seal integrity concerns due to embrittlement caused by age and radiolytic decomposition. These gloveboxes require replacement and are included in the facility revitalization plan.

This facility cannot be temporarily shut down and/or even be placed in a standby condition between production campaigns. The unique invasiveness of $\mathrm{Pu}^{238} 0_{2}$ in its powdered form causes significant contamination and equipment deterioration problems within the boxes if not constantly addressed. A vacuum must be maintained at all times throughout the glovebox system to ensure that contamination does not leak out. Thus, continuous servicing and maintenance on the gloveboxes and equipment are required. Also, continuous training and practice for the operators in making heat sources is essential. If operator skill and experience levels are not maintained, it would take at least 4 years to recruit and train the staffing necessary to manufacture heat sources and conduct a formal restart of operations. Complex operations at LANL are required to produce heat sources that meet mission requirements. This process has been developed over decades and is unique. There is no other known facility in the world that can make these heat sources.

$\mathrm{Pu}^{238} 0_{2}$ fuel undergoes a dissolution and precipitation process to remove contaminants and then is converted into a ceramic form, pressed into pellets, and encapsulated in special metal alloy clad vent sets, which are made at ORNL (see Chapter 1). This is a highly complex process requiring many skilled operators, as shown in Figure 3-4. 
Figure 3-4.

\section{LANL Process for Producing $\mathrm{Pu}^{238} \mathrm{O}_{2}$ GPHS Fueled Clads and LWRHUs}

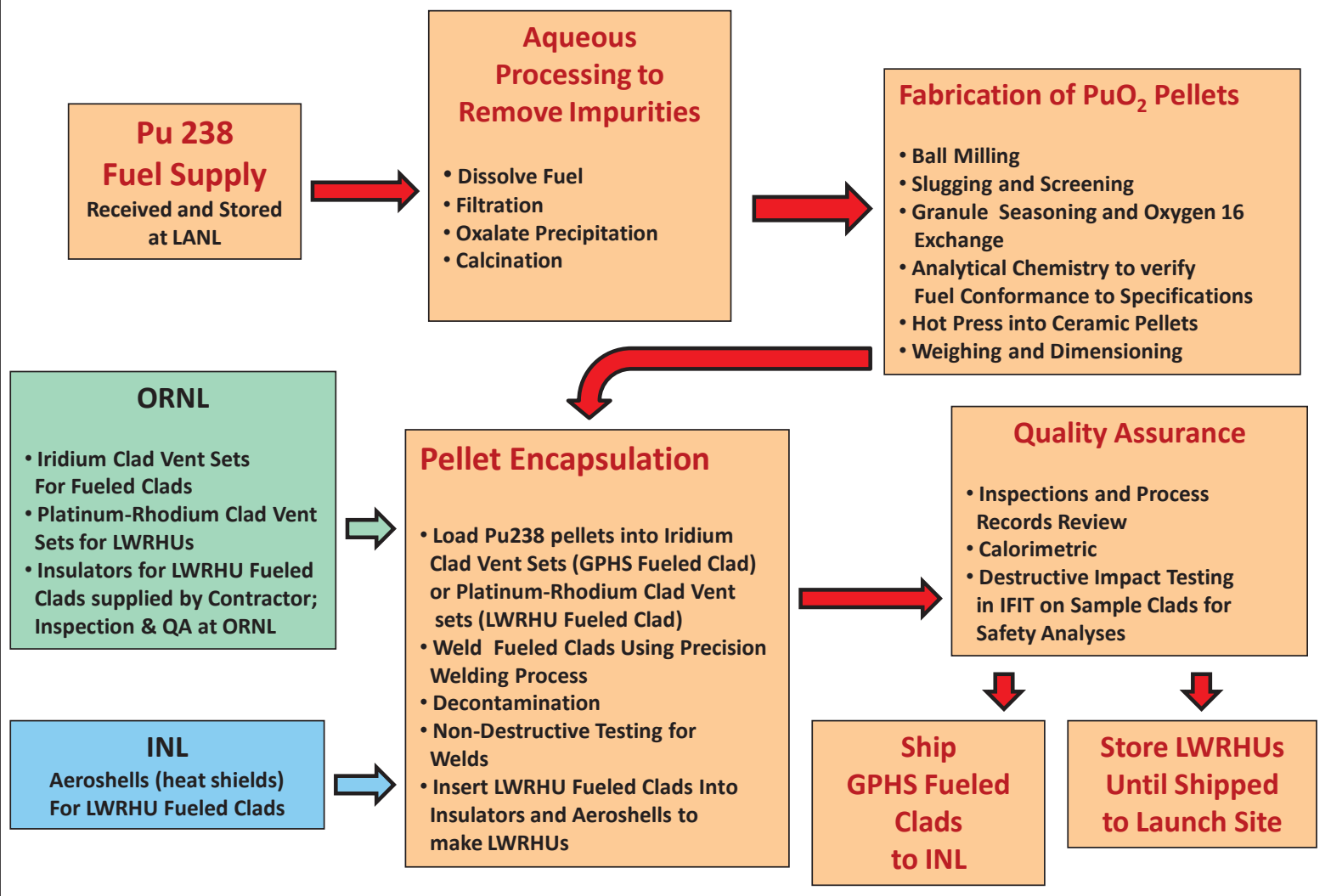

The production process outlined in Figure 3-4 is presented in more detail in the following sections.

\subsection{Aqueous Processing to Remove Impurities}

\subsubsection{Dissolving Fuel, Filtration, Oxalate Precipitation, and Calcination}

The first step in the process to manufacture a GPHS FC or LWRHU FC is to remove contaminates from the stored fuel. Fuel can become contaminated with non-actinides such as chromium, iron, nickel, silicon, manganese, and copper during production of $\mathrm{Pu}^{238}$ and when processing it into an oxide fuel source. In addition, decay of $\mathrm{Pu}^{238}$ (87-year half-life) begins immediately after production, and $99+\%$ of the decay product is Uranium-234 $\left(\mathrm{U}^{234}\right)$. The buildup of $\mathrm{U}^{234}$ plus the contaminants from $\mathrm{Pu}^{238}$ production all serve to decrease the heat density of the fuel.

To remove these contaminants, an aqueous dissolution and recovery process is used. Approximately 160 to 180 grams of unprocessed fuel is introduced. The fuel is dissolved in acid and then chemically treated to create a plutonium precipitate that is recovered through filtration while $\mathrm{U}^{234}$ and other contaminants remain in solution and are discarded as waste. A heating, or calcining, process is used to drive off any moisture and chemical residues from the precipitate and produce a $\mathrm{Pu}^{238} \mathrm{O}_{2}$ fuel. Nominally, approximately 
150 grams of fuel is precipitated out. The small percentage of fuel that remains in solution is recycled through subsequent aqueous recovery runs. The process, which is complex and labor intensive, is described in more detail in Figures 3-5 and 3-6.

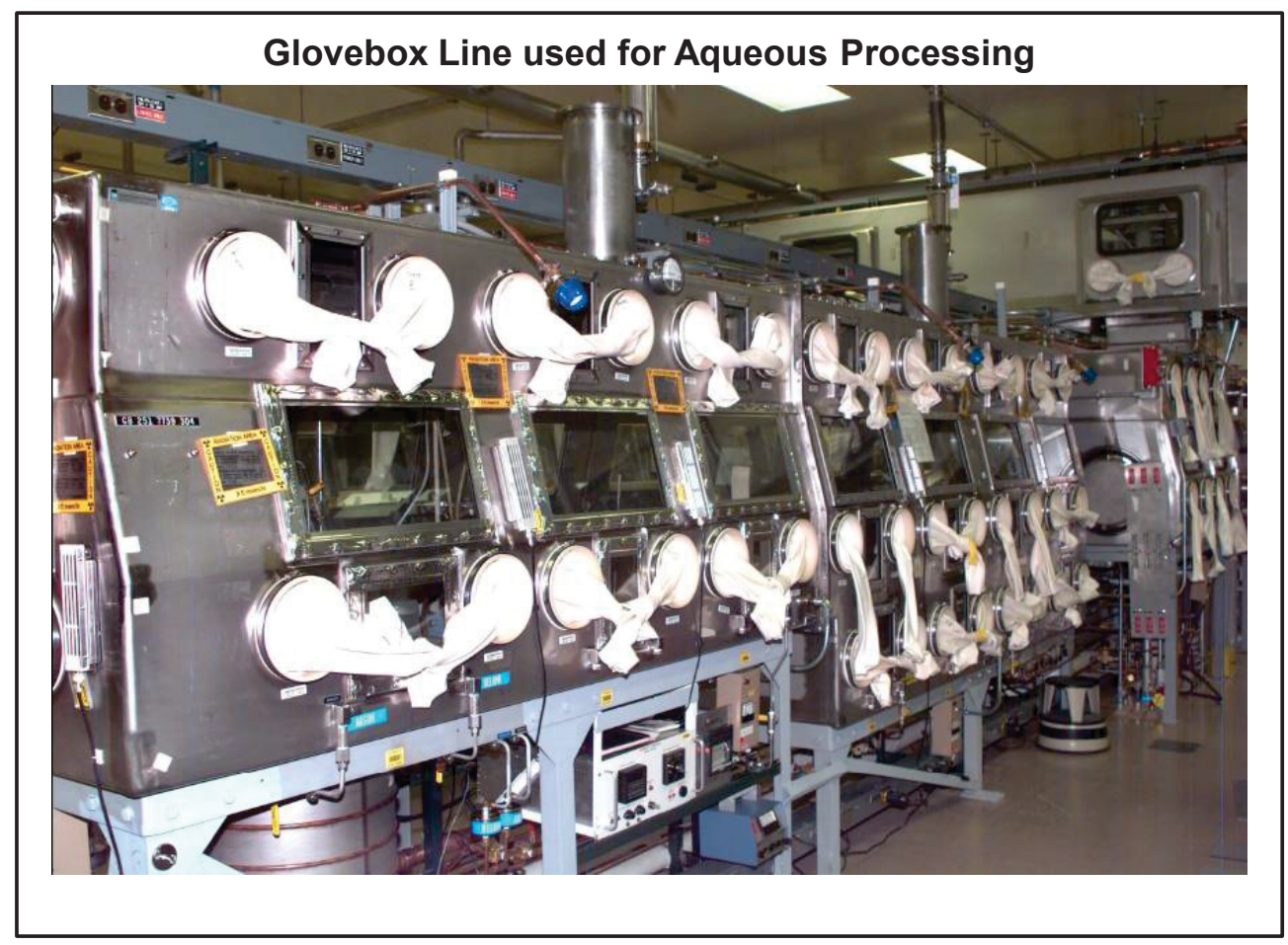

Figure 3-5. Glovebox line used for aqueous processing. 


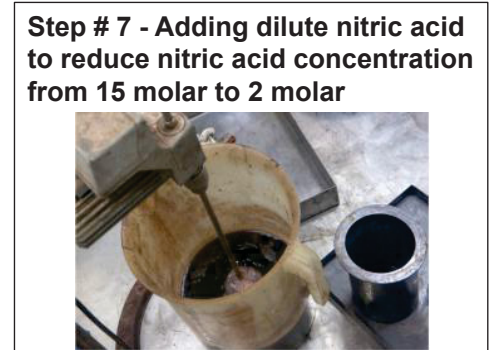

Step \# 10 - Adding oxalic acid to form Pu-oxalate precipitate, leaving U234 and most metal contaminants in solution as waste

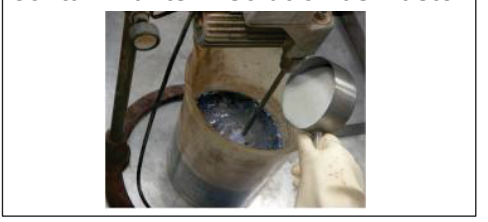

Step \# 11 - Filtering out the Pu-oxalate precipitate with $\mathrm{Pu}$ in +3 valance state

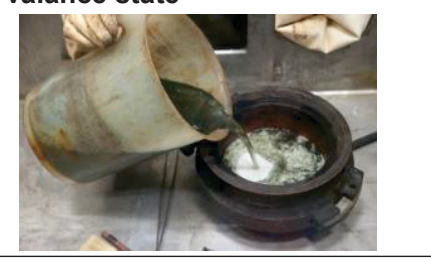

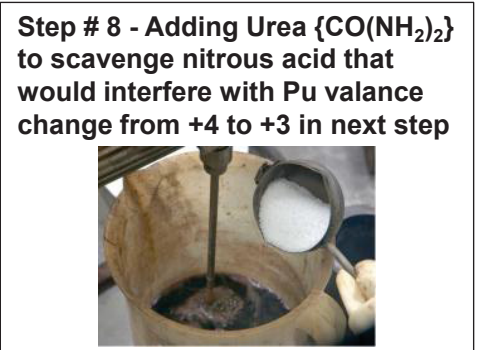

Step \# 9 - Adding hydroxylamine (HAN) to reduce $\mathrm{Pu}$ valence to +3 for precipitation (next step)

At +3:

$>$ more efficient removal of

impurities

$>$ maximizes

Pu238 recovery

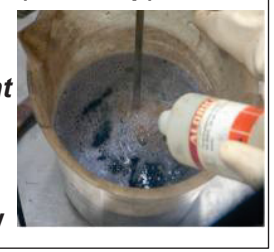

Step \# 12 - Oxalate precipitate placed in furnace to drive off $\mathrm{CO}_{2}$ and form solid $\mathrm{PuO}_{2}$ fuel that reverts to the +4 valance state

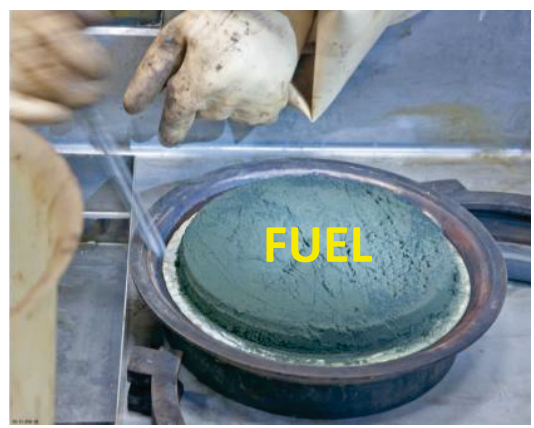

Figure 3-6. Aqueous recovery process.

\subsubsection{Disposition of Waste from Aqueous Processing}

Hazardous waste from aqueous processing, both chemical and nuclear, must be handled safely, accounted for, and disposed of in approved waste handling facilities (Figure 3-7). This requires a dedicated glovebox, special processing equipment, and skilled operators.

Figure 3-7. Disposal of hazardous waste from aqueous processing.

\subsubsection{Fuel Accountability after Aqueous Processing}

At the completion of aqueous processing, the fuel is then transferred in desired lot sizes into the heat source fabrication process. The lots are transported between stations in capped fuel storage and transfer containers. The oxide must be weighed between each major process operation for process and material control and accountability reasons (Figure 3-8). 


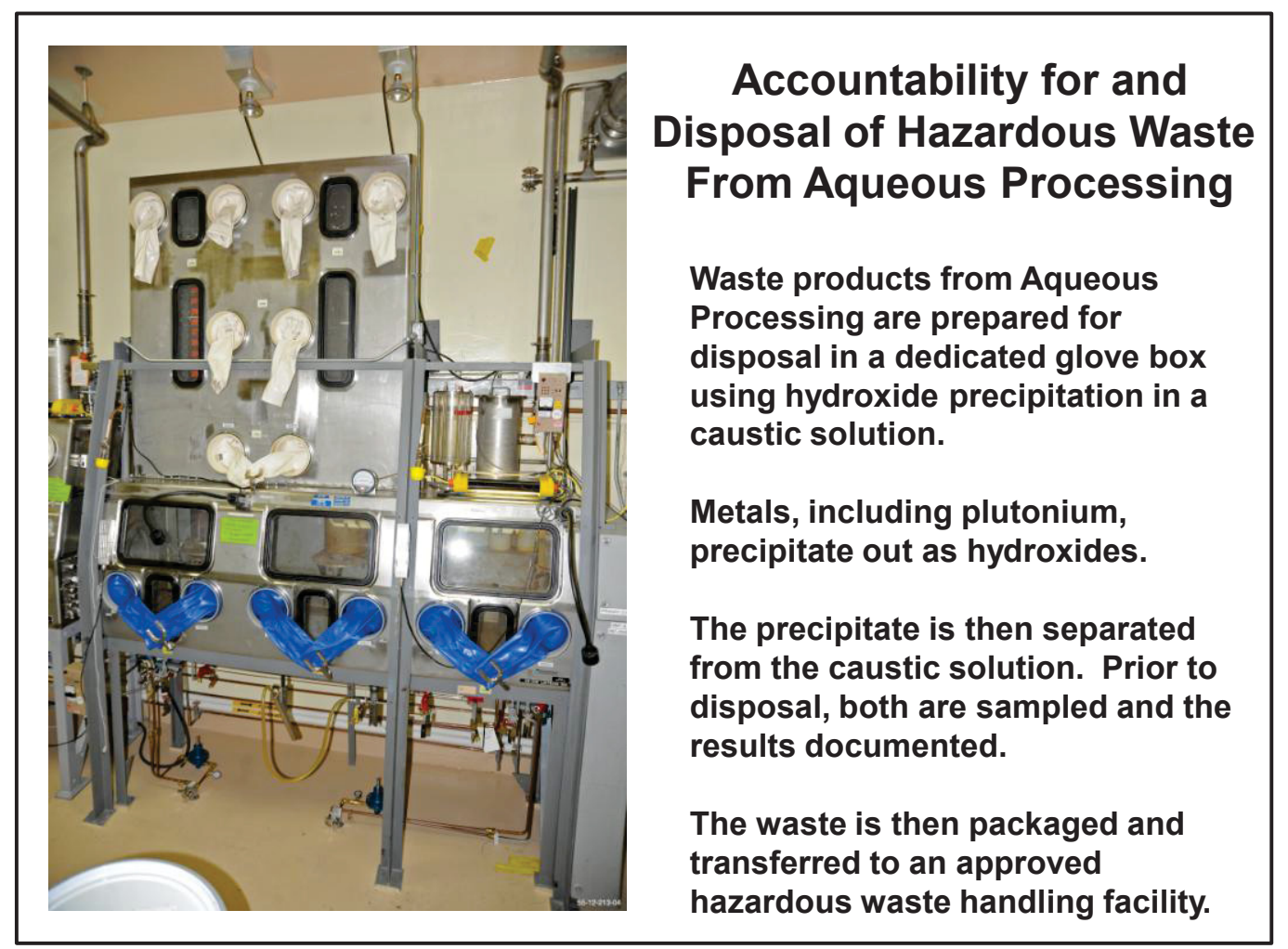

Figure 3-8. Weighing fuel between process steps for continuous accountability.

\subsection{Fabrication of $\mathrm{Pu}^{238} \mathrm{O}_{2}$ Pellets}

\subsubsection{Ball Milling, Slugging, and Screening}

The fuel powder from the aqueous recovery process is converted to granules of the desired size for hot pressing into heat source pellets. This is accomplished in steps by a process of ball milling, slugging, and screening using special equipment in two gloveboxes. These steps are discussed below.

Ball Milling: The first step is ball milling (Figure 3-9) the powder to produce the desired particle size and powder morphology. This is a normalizing step to eliminate differences in surface activities and powder packing from one lot of feed powder to the next. The as-received powder consists of two types of particles with a median diameter of approximately $2.7 \mu \mathrm{m}$. One type particle is rosette shaped and one is long and thin. The long, thin particles have been shown to have a low packing density, which interferes with achieving adequate bonding during hot pressing. Studies have shown that the fuel will be adequate for bonding during hot pressing if the powdered is ball milled to a median particle diameter of approximately $1 \mu \mathrm{m}$. 

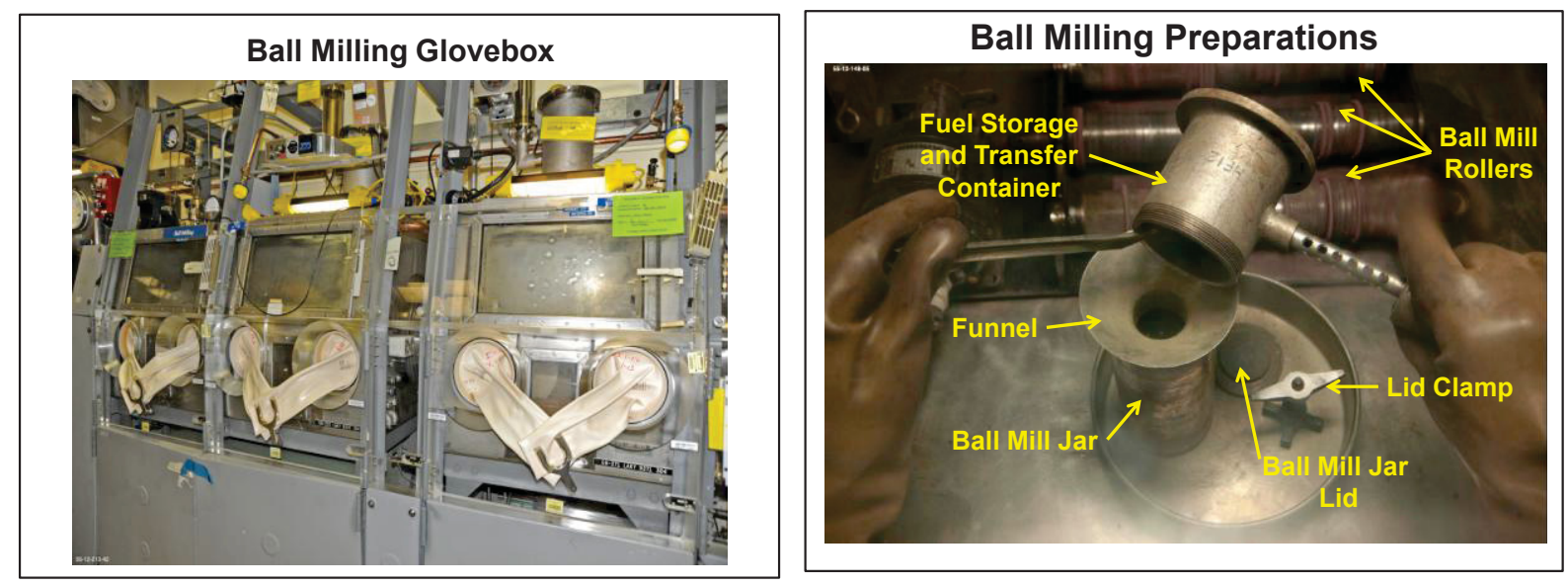

Figure 3-9. Ball milling glovebox and preparations.

The Ball mill jar, loaded with a fuel lot, is rolled for 8 hours (Figure 3-10). The jar contains 110 balls $5 / 8$-inch in diameter made of hardened steel. The powdered fuel does not adhere well to the hardened steel balls or the Ball Mill Jar. Thus, only about $1 \%$ of the powder is lost to waste during the ball milling process. The rolling action produces a suitably uniform powder with the desired particle size of approximately $1 \mu \mathrm{m}$.

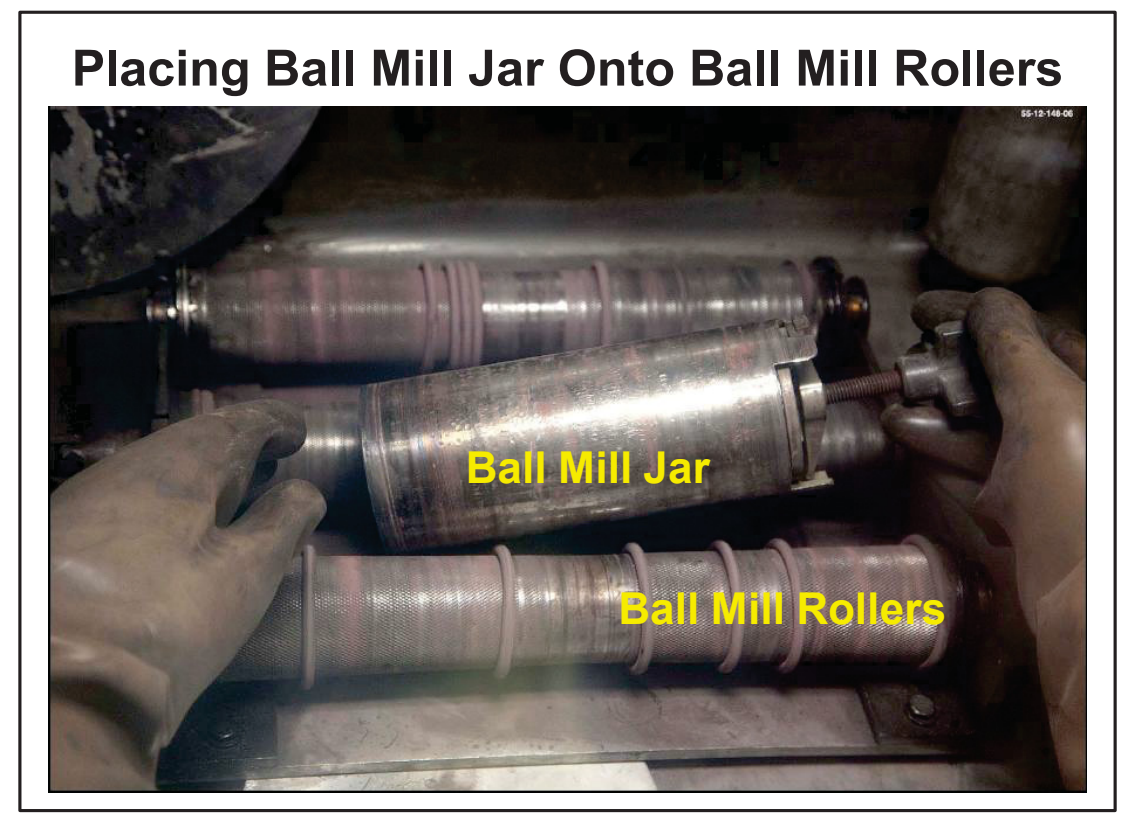

Figure 3-10. Ball Mill jar and rollers.

Slugging and Screening: Slugging (pelletizing) and screening (granulating) operations are performed (Figure 3-11) to convert the ball-milled fuel powder to granules of the desired size for hot pressing. 


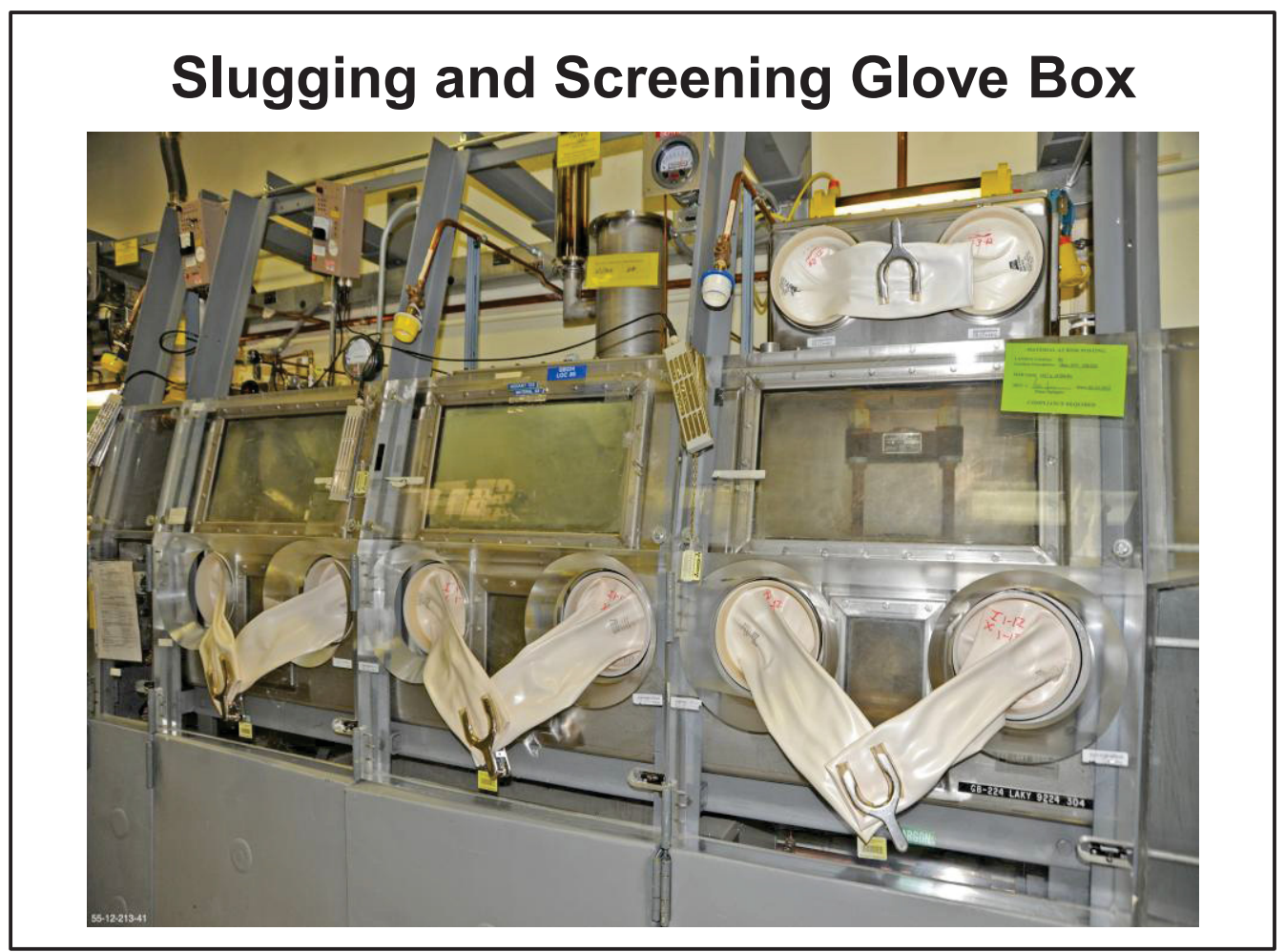

Figure 3-11. Slugging and screening glovebox.

Slugging: In a manufacturing process, a slug is defined as a lump of metal or ceramic material prepared for further processing. In the slugging operation at LANL, the fuel powder is collected from the Ball Mill, weighed, and transferred to the cold press die (Figure 3-12). This is conducted in 25-gram lots. The powder is then pressed in a hydraulic press to 400MPa to form a "green" (unsintered, non-heat treated) ceramic pellet or slug at $60 \%$ theoretical density, which then undergoes further processing into a finished ceramic heat source pellet with desired properties. 

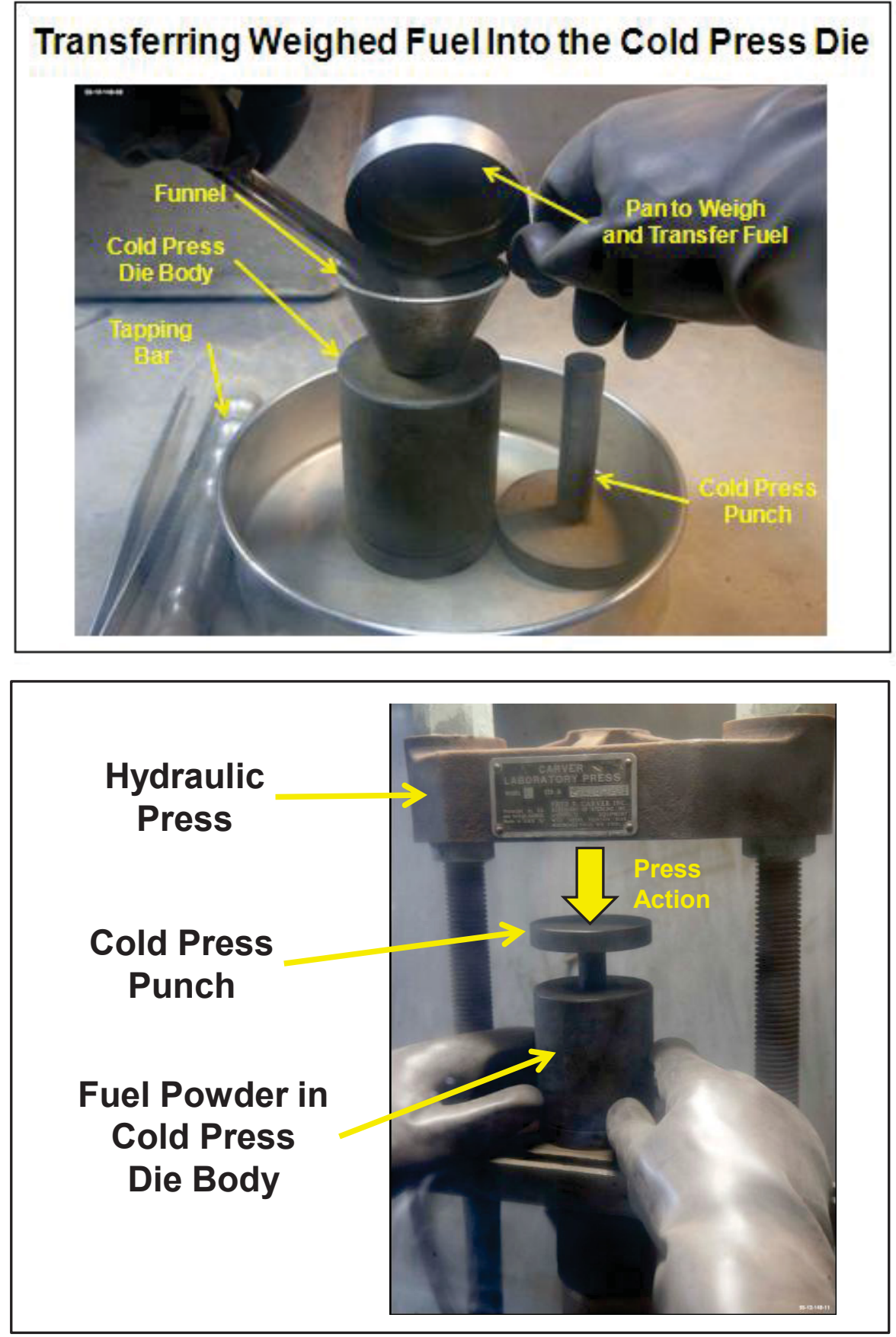

Figure 3-12. Transferring weighted fuel into the cold press die.

Screening: The 25-gram pellets (slugs) from the cold press process are broken up and screened to achieve uniform $<125 \mu \mathrm{m}$ (micron) size granules. The cold pressed ("slugged") fuel is manually broken up using hand held rollers on a flat sieve surface. There are three sieves and a catch pan. The first is the Coarse Sieve where the slugs are broken up into coarse granules that drop to the Uncertified Sieve (Figure 3-13). The Uncertified Sieve has a screen mesh of $<125 \mu \mathrm{m}$, but, because it is subjected to the direct stress of the rolling action, the screen mesh cannot retain certification with regards to granule size it will allow to pass. The Uncertified Sieve serves to protect the Certified Sieve below it. Rolling is not done on the Certified 
Sieve. Granules passing through the Uncertified Sieve are allowed to drop by gravity through the Certified Sieve without rolling to ensure final granule size is $<125 \mu \mathrm{m}$.

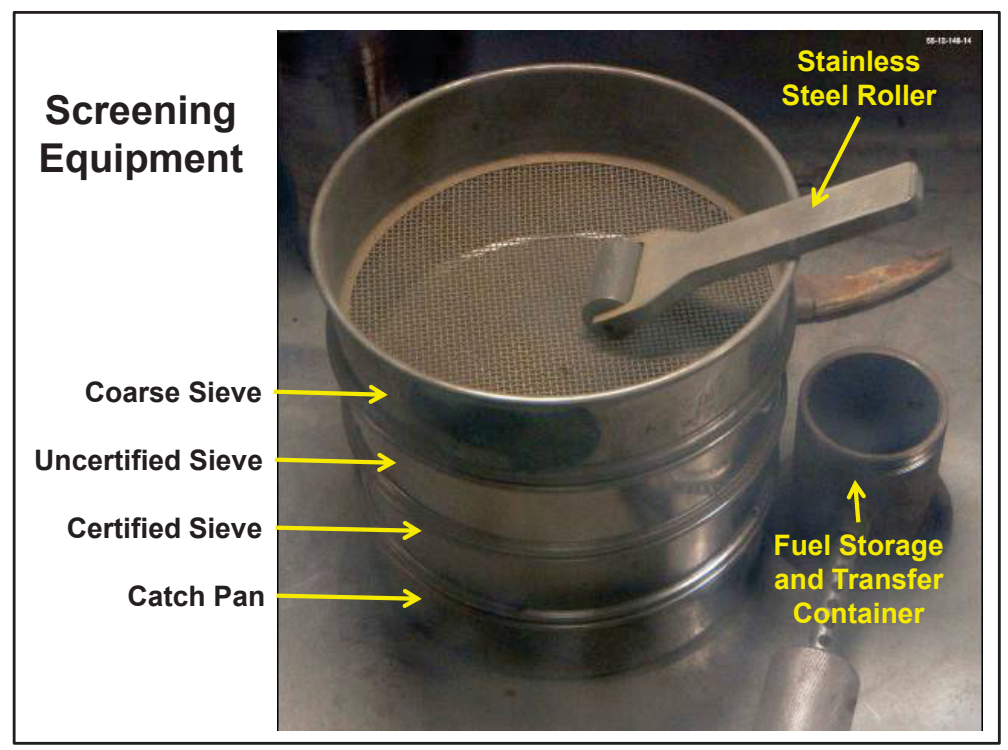

Figure 3-13. Screening equipment.

\subsubsection{Granule Seasoning and Oxygen 16 Exchange}

This is the most important processing step before pressing into a pellet. After the $<125 \mu \mathrm{m}$ granules are made, they are thermally seasoned in special high-temperature furnaces (Figure 3-14) to form reactive ("low fired") and nonreactive ("high fired") components of the ceramic "grog" feed mixture. There are two types of high temperature, horizontal, core, and shell furnaces used. The Centorr furnace has a capacity of 75 grams and is used for low fire only. The Astro furnace also has a capacity of 75 grams and can be used for both low fire and high fire. There are three Astro and two Centorr furnaces.

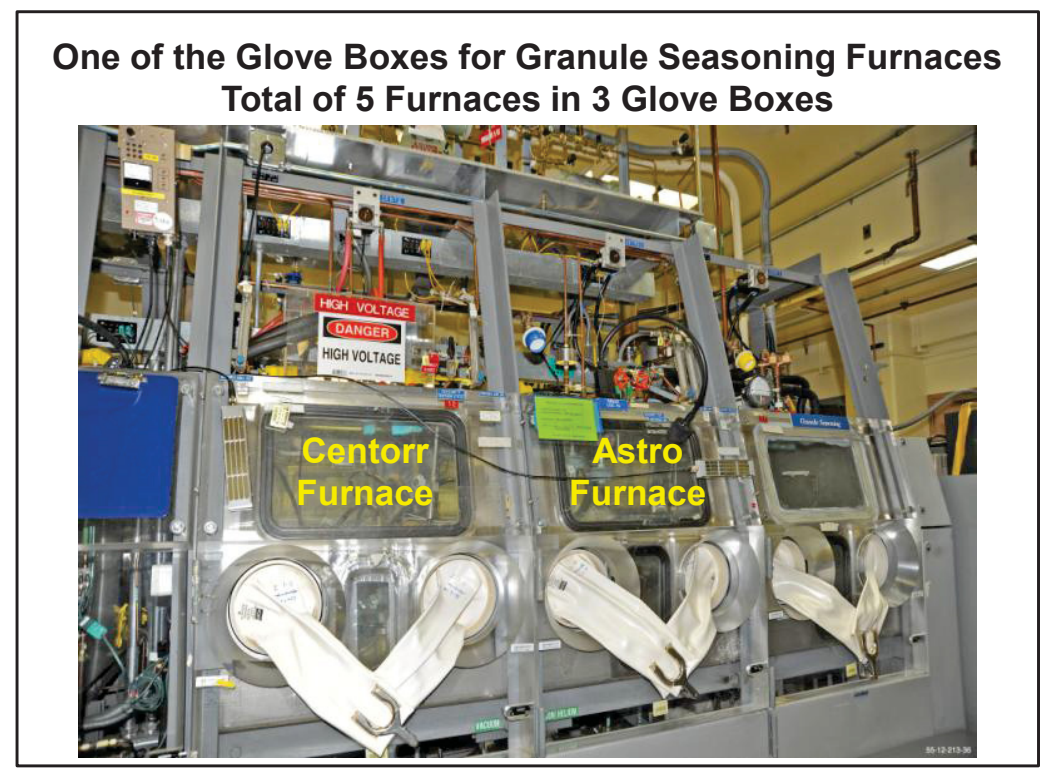

Figure 3-14. Granule seasoning furnaces. 
In this process, $60 \%$ of the green granules are designated as low fire and are seasoned for 6 hours at 1,100 degrees Celsius $\left({ }^{\circ} \mathrm{C}\right)$. The remaining $40 \%$ are designated as high fire and are seasoned for 6 hours at $1,600^{\circ} \mathrm{C}$. The low-fired granules still remain reactive enough to flow (i.e., shrink) around the non-reactive high-fired granules to form a homogeneous microstructure during the subsequent hot pressing operation to form heat source pellets.

In addition to seasoning the granules in preparation for hot pressing into pellets, the natural neutron emission rate (NER) for new $\mathrm{Pu}^{238} 0_{2}$ fuel is reduced. Atmospheric oxygen normally contains a small percentage of the stable isotopes oxygen-17 $\left(\mathrm{O}_{17}\right)$ and oxygen-18 $\left(\mathrm{O}_{18}\right)$. Thus, the oxygen in the $\mathrm{Pu}^{238} \mathrm{O}_{2}$ fuel introduced into the heat source production process contains that small percentage of $\mathrm{O}_{17}$ and $\mathrm{O}_{18}$. plutonium decays by emitting an alpha particle, and two protons and two neutrons bound together. When these alpha particles interact with $\mathrm{O}_{17}$ and $\mathrm{O}_{18}$, two new isotopes of Neon are produced and neutrons are emitted. For new fuel, significant NER exists that poses a radiation hazard to workers and could cause damage to sensitive instruments on board a spacecraft during the course of a mission. During the granule seasoning process, a significant percentage of the $\mathrm{O}_{17}$ and $\mathrm{O}_{18}$ isotopes in the fuel oxide are exchanged for $\mathrm{O}_{16}$ isotopes, which reduces the NER to an acceptable level. To accomplish this, there is an inflow into the furnace of a mixture of argon gas and a special water vapor that has only the $\mathrm{O}_{16}$ isotope in it, $\mathrm{H}_{2} \mathrm{O}_{16}$. As this gas and special water vapor mixture flows over the heated fuel, the exchange occurs. Figure 3-15 is a schematic of either type of furnace in glovebox, with flow of argon gas and a special water vapor that has only the $\mathrm{O}^{16}$ isotope in it, $\mathrm{H}_{2} \mathrm{O}_{16}$.

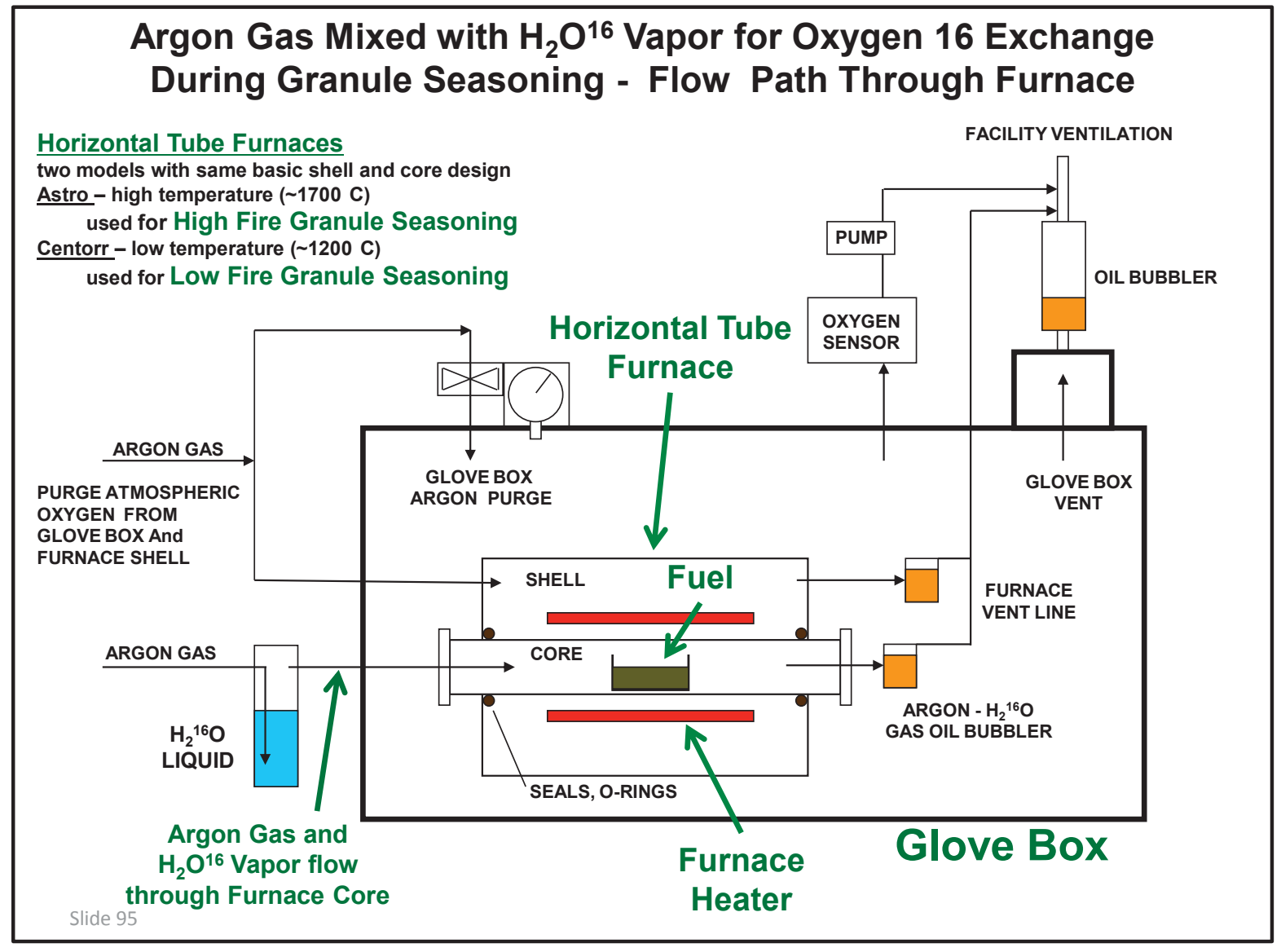

Figure 3-15. Flow path of argon gas mixed with $\mathrm{H}_{2} \mathrm{O}_{16}$ vapor for $\mathrm{O}_{16}$ exchange during granule seasoning. 
The fuel must be inserted into the furnaces in a precise manner in order to ensure all the fuel lot is exposed to the required temperature. The fuel is distributed evenly in a platinum "boat" using a small scoop to transfer the green fuel granules from the Storage and Transfer Container to the "boat." Platinum is used because the oxide fuel is not reactive with it. The loading of fuel into one of the furnaces is illustrated in Figures 3-16 through 3-19.

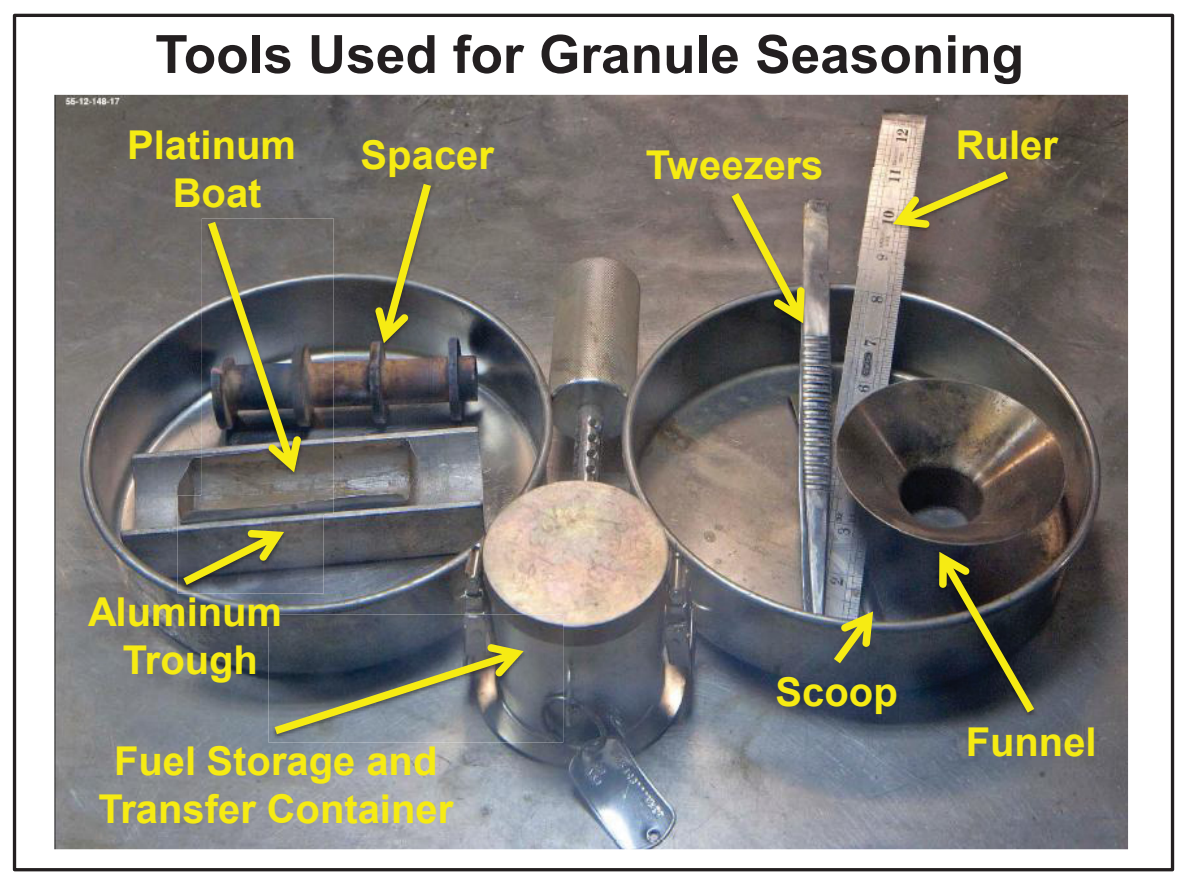

Figure 3-16. Tools used for granule seasoning.

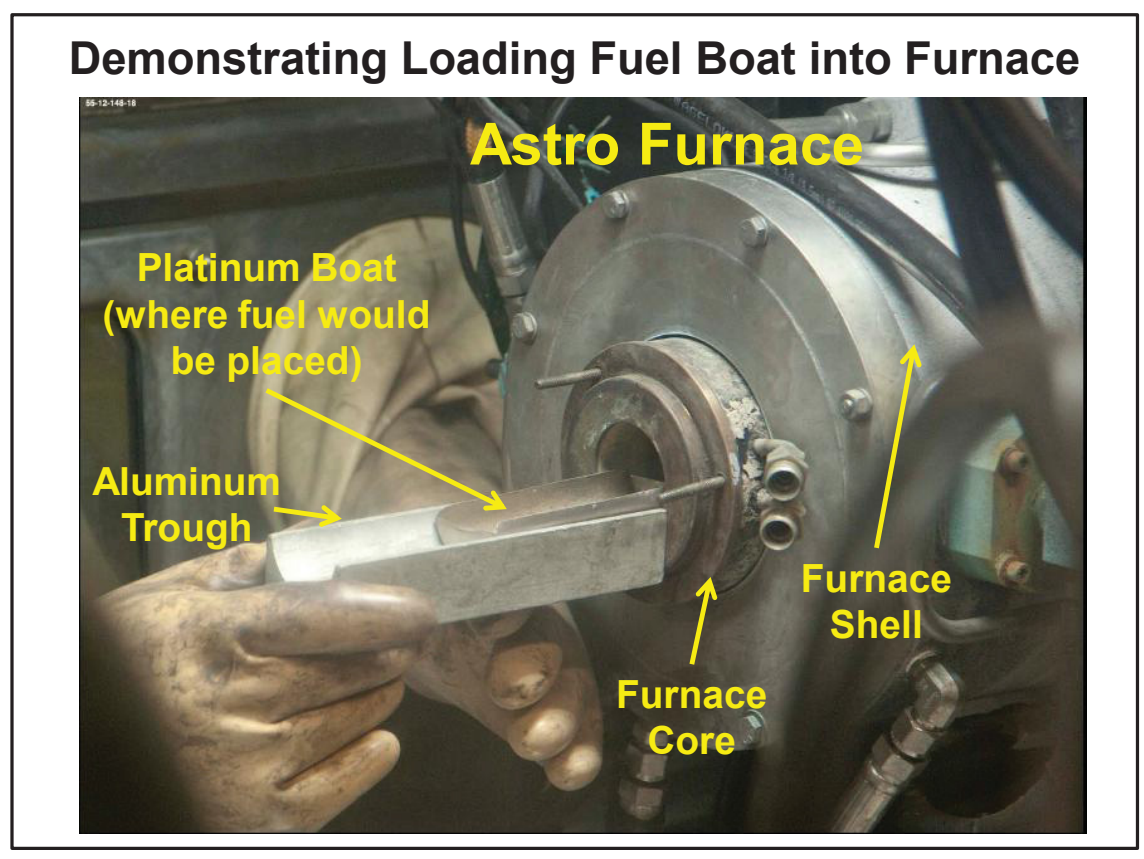

Figure 3-17. Loading of the fuel boat into the furnace. 


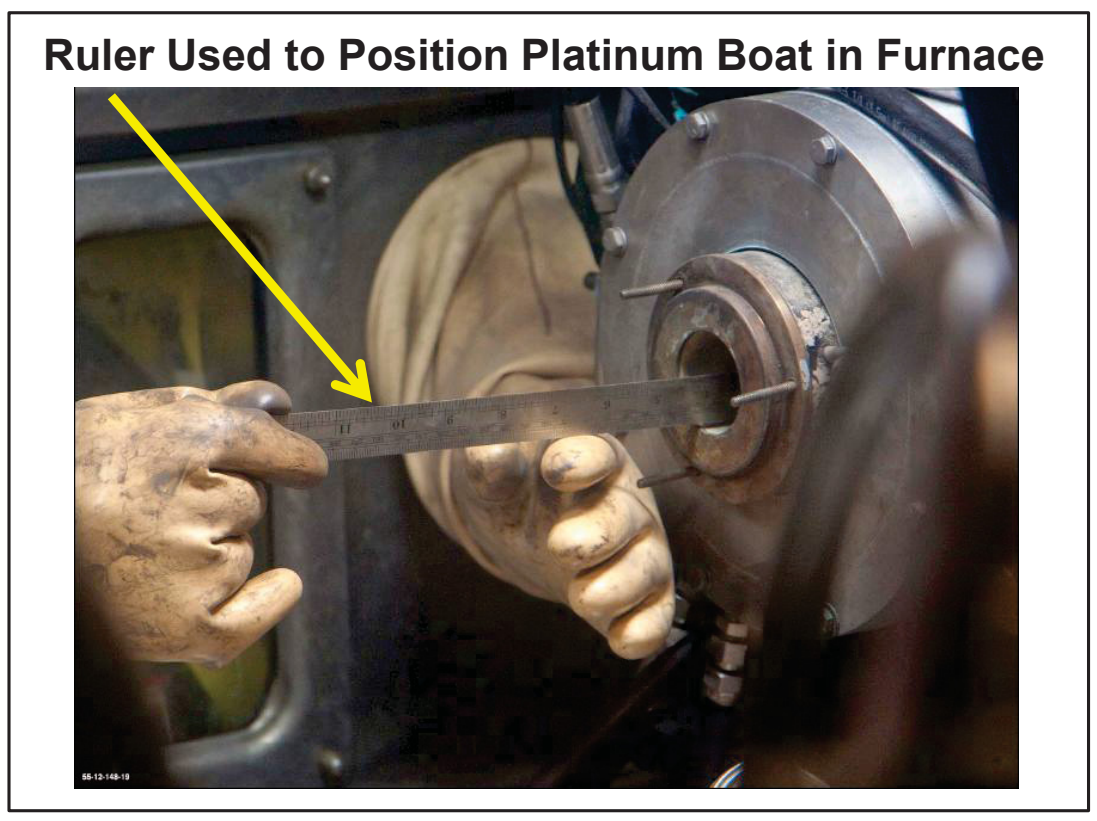

Figure 3-18. Ruler used to position platinum boat in the furnace.

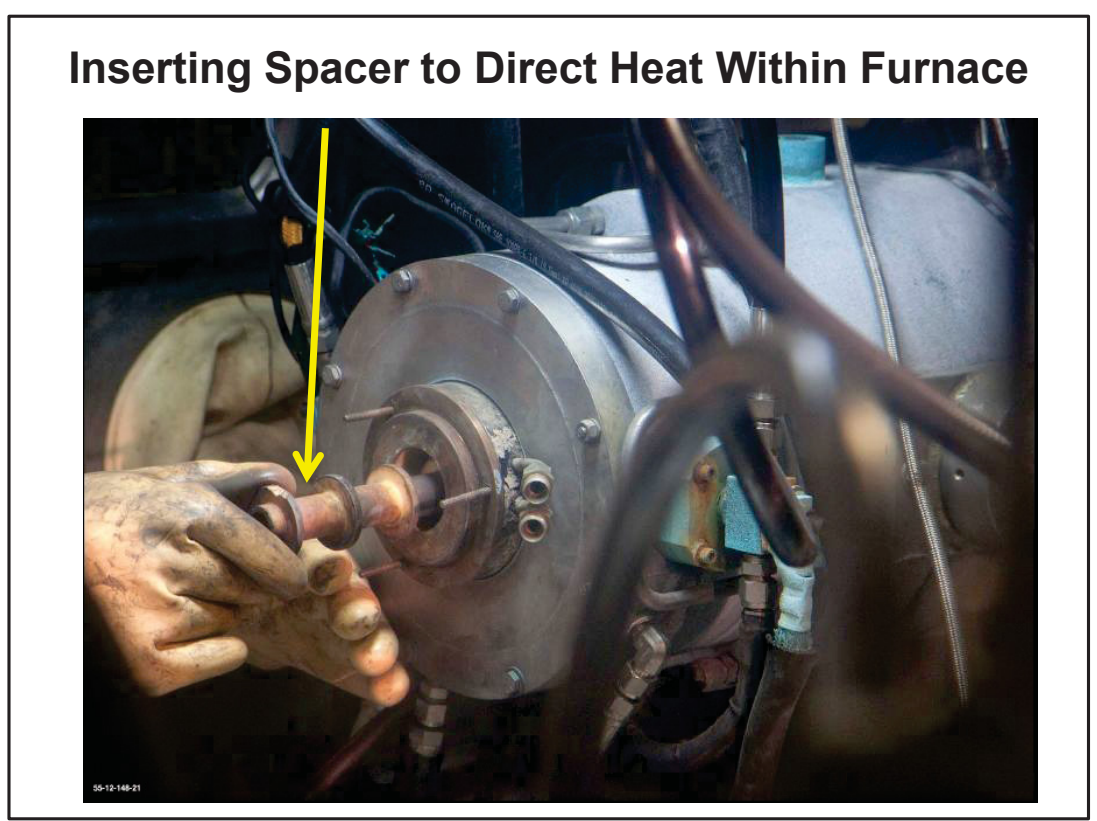

Figure 3-19. Inserting spacer to direct the heat within the furnace.

At the end of the cool down (after seasoning), the spacer and platinum boat are removed using a simple hook (not shown).

After seasoning, the granules are screened again through a $<212 \mu \mathrm{m}$ mesh. The seasoning process causes the high and low fire to conglomerate into particles that can be larger than 212 microns. The seasoned fuel is sieved to break up the conglomeration, and the size is adequate to achieve the desired granulation. 


\subsubsection{Analytical Chemistry}

During the production and processing of $\mathrm{Pu}^{238} \mathrm{O}_{2}$ fuel, impurities are introduced into the fuel that must be measured and accounted for (Figure 3-20). The effects of impurities have been extensively investigated since the early 1960s, and specifications for the amount of any impurity allowed have been developed.

\section{Analytical Chemistry Conducted to Determine Pu 238 Content and Levels of Impurities in $\mathrm{Pu}^{238} \mathrm{O}_{2}$ Fuel}

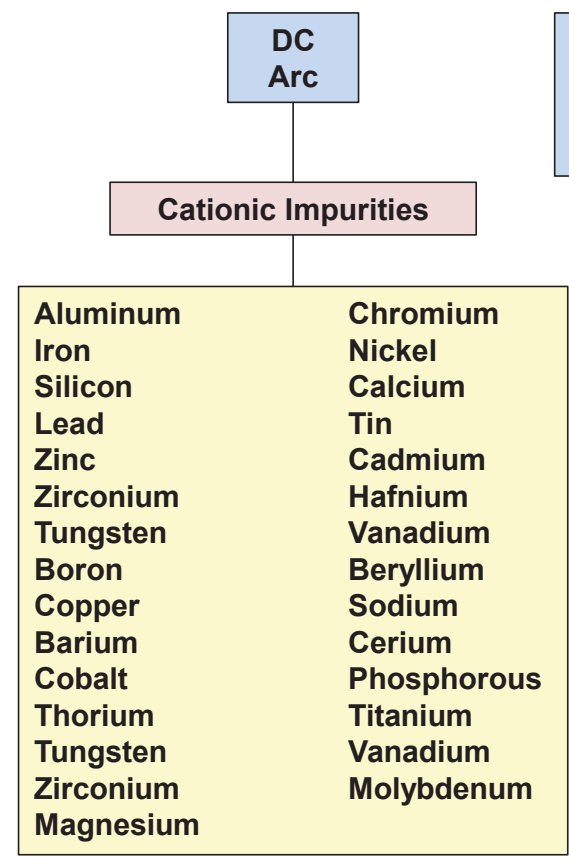

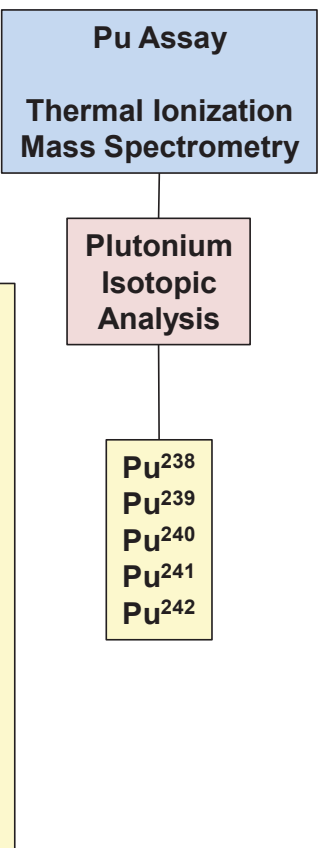

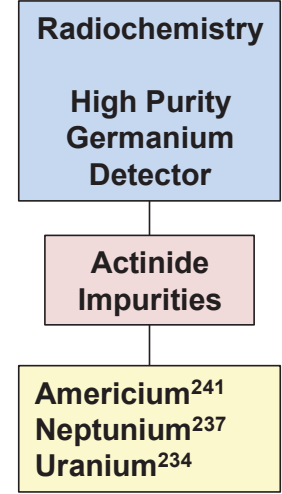

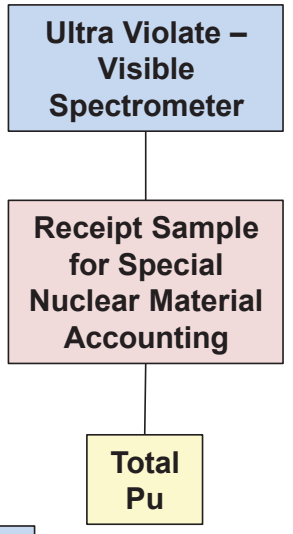

\section{Neutron}

Detector

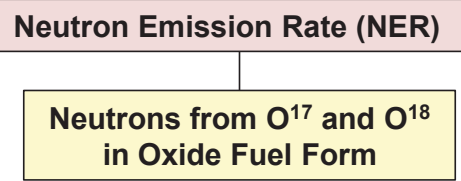

Figure 3-20. Analytical chemistry conducted to determine $\mathrm{Pu}^{238}$ content and levels of impurities in $\mathrm{Pu}^{238} 0_{2}$ fuel.

Impurities in the fuel can cause degradation of fuel or fuel clad performance in four basic ways:

1. Some impurities can cause the fuel to fragment into respirable fines $(<10 \mu \mathrm{m}$ in size) that can pose a hazard under accident conditions that breach the iridium clad

2. Some impurities can interact with the iridium clad material to reduce strength and ductility

3. Some impurity oxides can block the clad vent hole and not allow helium gas generated in the fuel to vent properly, which can cause swelling of the fuel and loss of clad integrity

4. Certain impurities can undergo alpha particle-neutron $(\alpha / n)$ reactions with the $\alpha$-particles from decay of $\mathrm{Pu}^{238}$, causing the fuel to have a NER that can be a radiation hazard to workers and can interfere with sensitive equipment on the spacecraft if above specifications.

Analysis of total plutonium content of the fuel (all isotopes) is conducted upon receipt for special nuclear material accountability. Samples for impurities and measurements of NER are taken before and after 
granule seasoning. Any out-of-specification measurements are reviewed by a QA committee, and appropriate actions are taken to resolve the issue. A primary concern is ensuring that fuel is not lost to waste due to an out of specification measurement, and one of several approved remedies can normally be employed.

Currently, all sample measurements except NER are conducted at the Chemistry and Metallurgy Research (CMR) Facility at LANL. This requires placing samples in special tantalum vials (Figure 3-21), seal welding the vials in the special Advanced Manufacturing Engineering Technologies (AMET) welder, and then placing them in special protective containers for transport to CMR. Normal sample size is 0.3 grams. The tantalum vials are inscribed with the fuel lot sample identification (ID) number for careful tracking.

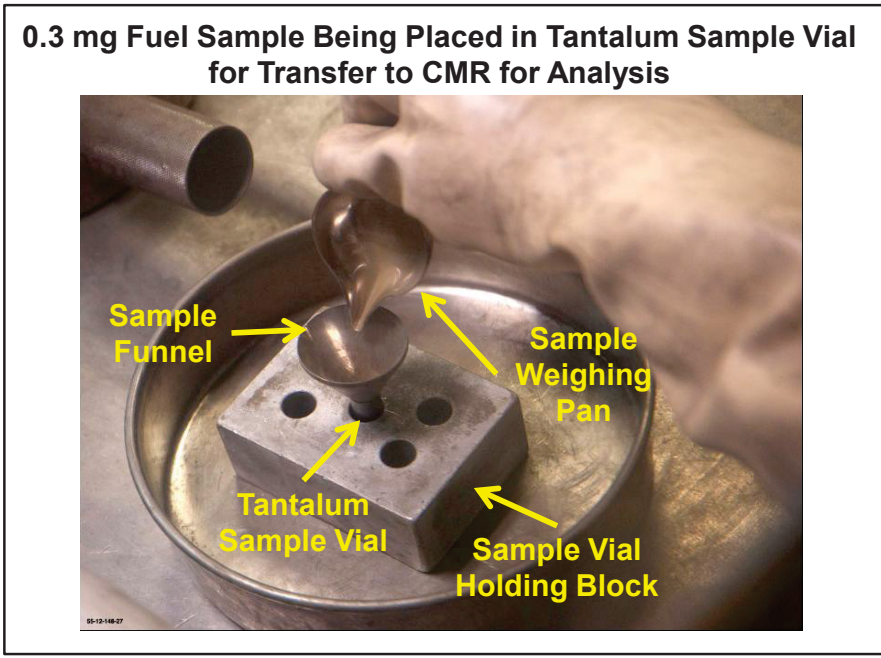

Figure 3-21. Tantalum sample vial.

Press-fit lids are placed onto the tantalum vials (Figure 3-22). The vials are sent for welding of the lids by the AMET welder using a sample vial transfer container that keeps the vials upright. The AMET welder glovebox and welding machine are shown in Figures 3-23 and 3-24, respectively.

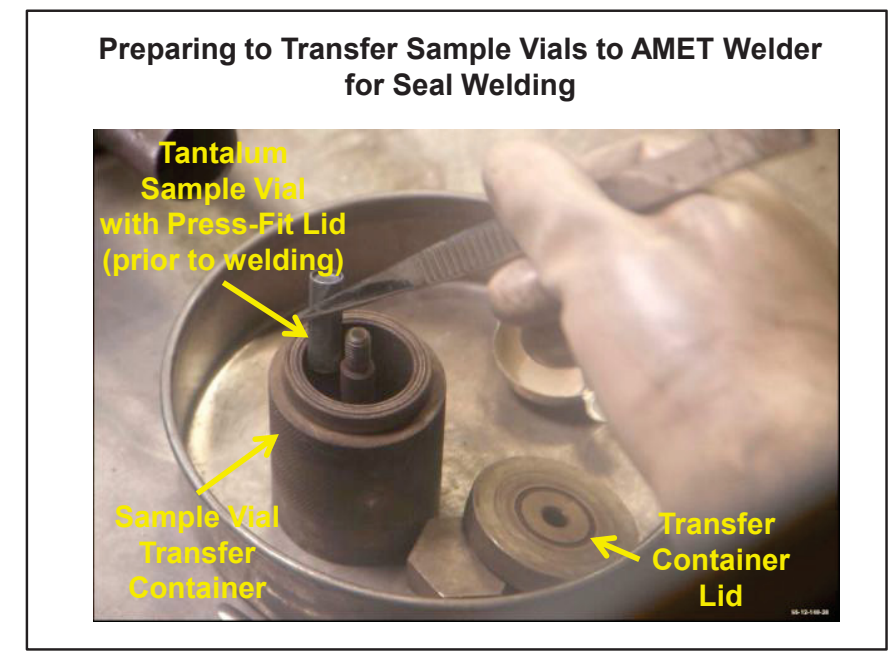

Figure 3-22. Tantalum sample vial with press-fit lid (prior to welding). 


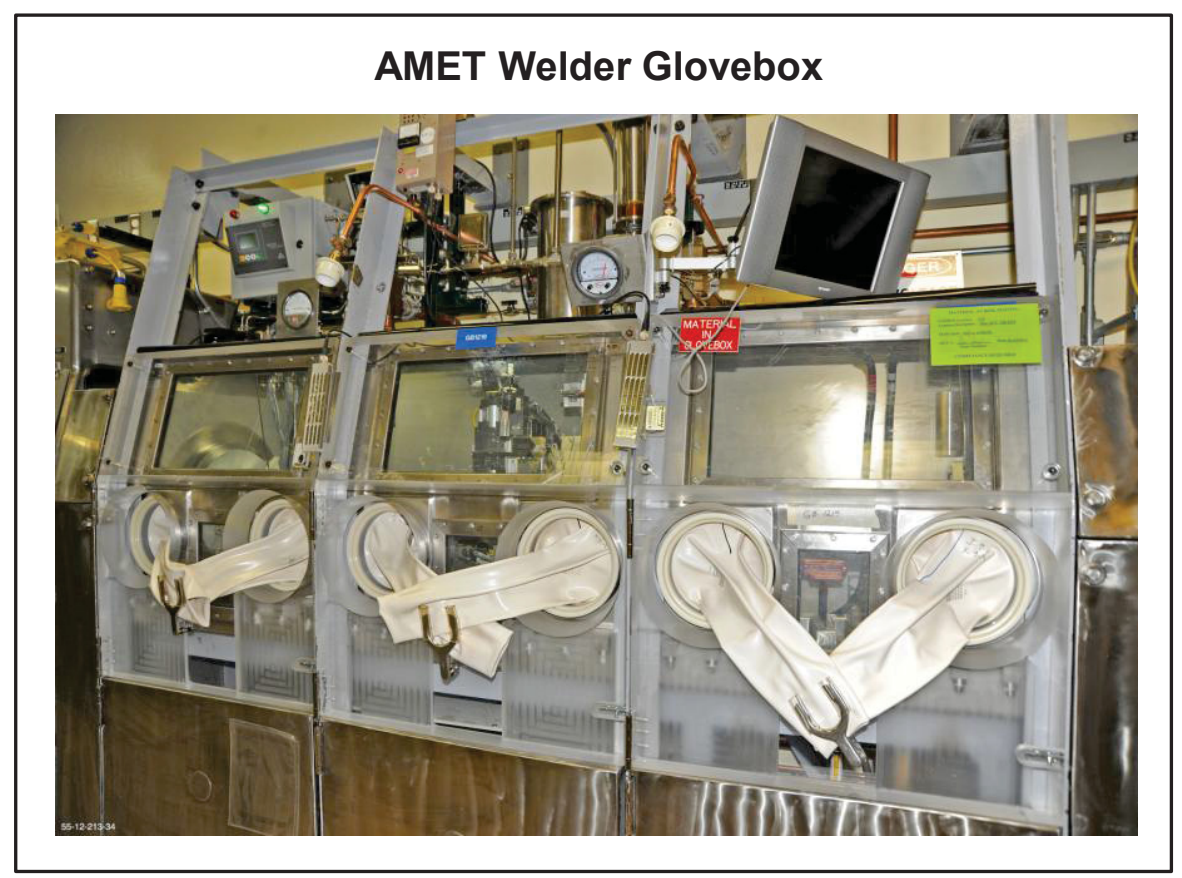

Figure 3-23. AMET welder glovebox.

\section{AMET Welding Machine in Glovebox}

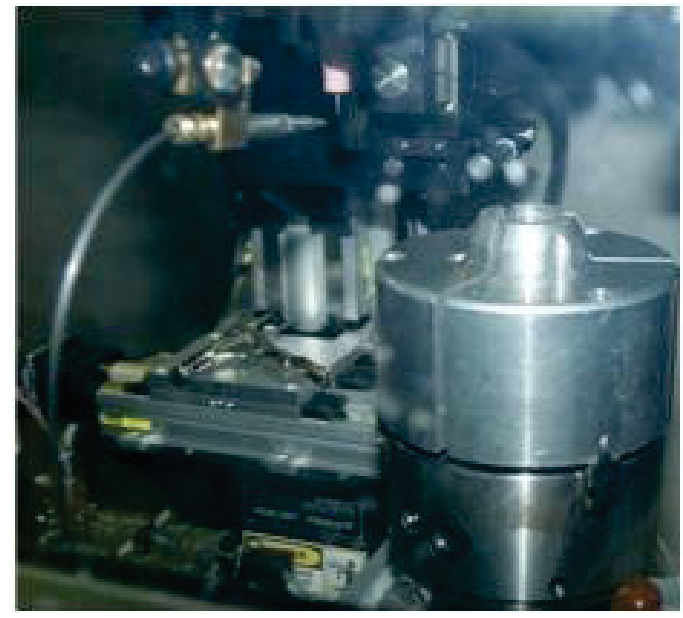

Figure 3-24. AMET welding machine in glovebox.

After seal welding the tantalum vial, it is placed in a plastic container for protection and then placed in a capped metal cylinder for transport to the CMR Facility by a two-person team to meet special nuclear material security requirements. Residue from the samples is returned to the $\mathrm{Pu}^{238}$ Facility.

The CMR Facility is scheduled for shutdown in Fiscal Year (FY) 2015. All analytical chemistry operations will be moved into the $\mathrm{Pu}^{238}$ Facility in $\mathrm{PF}-4$. A project to accomplish this is underway and will require new gloveboxes and analysis equipment (Figure 3-25). This is a major effort that is scheduled 
to be completed in FY 2015. The new requirement to perform analytical chemistry in PF-4 will require additional staffing and increase facility maintenance costs.

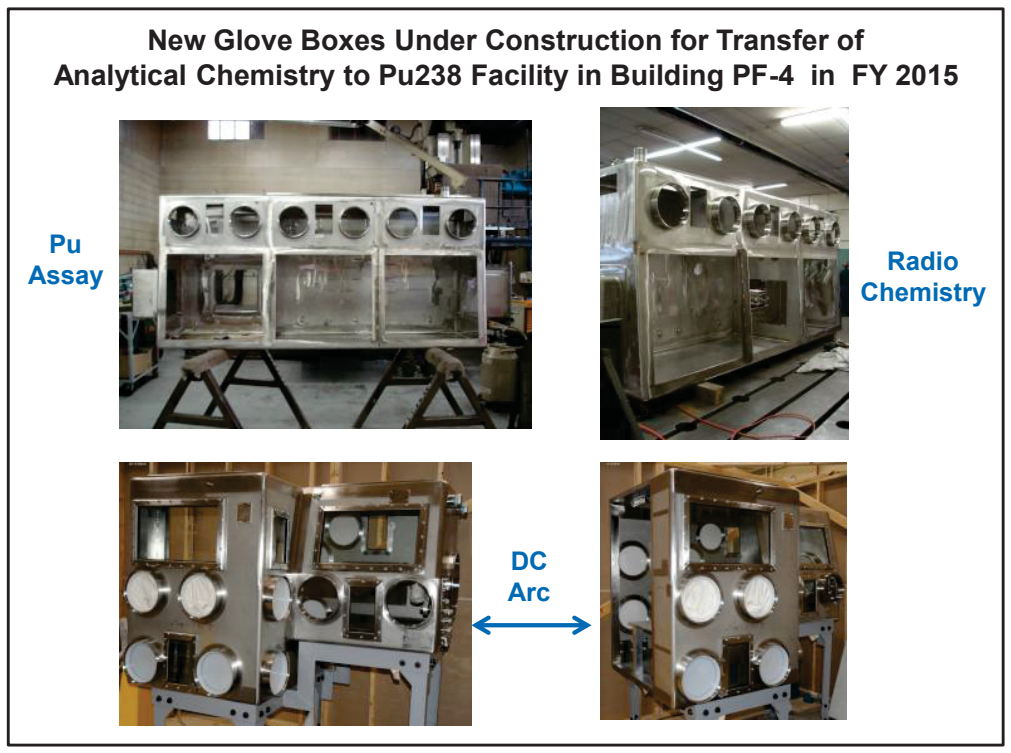

Figure 3-25. New gloveboxes under construction for $\mathrm{Pu}^{238}$ Facility.

\subsubsection{Hot Pressing Fuel into Ceramic Pellets}

The grog-type fuel is used to fabricate the GPHS fuel pellets by mixing the proper ratio of $<212 \mu \mathrm{m}$ granules seasoned at $1,100^{\circ} \mathrm{C}(60 \%$ by weight $)$ and $1,600^{\circ} \mathrm{C}(40 \%$ by weight) (Figure $3-26)$. The mixing is accomplished by putting the granules into a blending jar and rolling it without any grinding balls. After the mixing is complete, a graphite pressing die is loaded with approximately 150 grams of the granule mix.

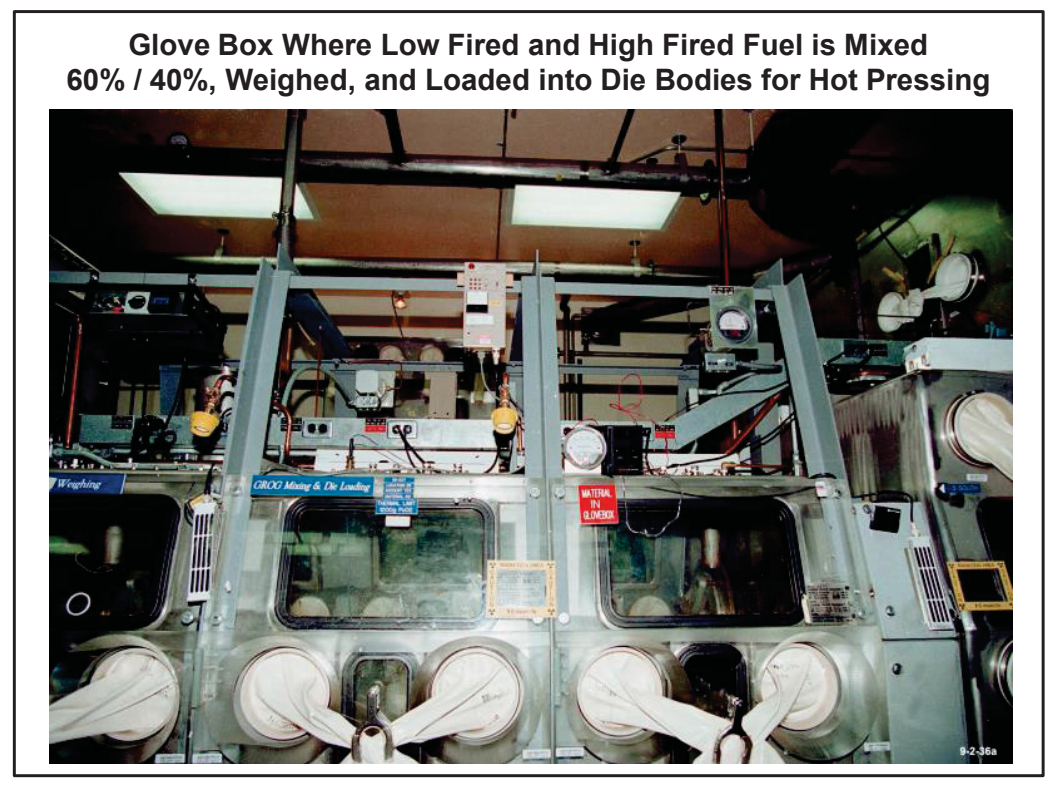

Figure 3-26. Glovebox where low fired and high fired fuel is mixed. 
Hot Pressing - The GPHS pellets are pressed in one of two hot presses. As Figures 3-27 and 3-28 indicate, the two hot presses are large and complex. They are the most complicated and costly pieces of equipment in the facility and require extensive maintenance. Much of the equipment and systems needed are located in the basement of PF-4 under where the hot press gloveboxes are located on the main floor. Each hot press has a motor-generator in the basement supplying high frequency air conditioning power to the induction heating coils through a complex control system that ensures precise temperature control during the pressing operation. The rams are operated by high pressure hydraulic systems in the basement that feed hydraulic pressure up through the main floor into the gloveboxes. These hydraulic systems also have control systems to achieve and maintain the precise pressure required. Cooling water also comes from systems in the basement up to the gloveboxes to cool the induction heating coil and the hot press base plate.

Each hot press can do one FC pellet or 16 RHU pellets at a time. The die is positioned between the hydraulic press upper and lower rams inside an induction heating coil. The pellets are pressed at $1,500^{\circ} \mathrm{C}$ at 2,750 pounds per square inch, gauge (psig) for 18 minutes followed by $1,500^{\circ} \mathrm{C}$ at $2,800 \mathrm{psig}$ for 9 minutes. The pellets are then sintered at $1,000^{\circ} \mathrm{C}$ for 6 hours followed by $1,527^{\circ} \mathrm{C}$ for another 6 hours. During pressing operations, a vacuum can is lowered to cover the coil and die and is sealed at the bottom so that a vacuum can be drawn and maintained while pellets are being pressed. After a suitable cooling period, the vacuum can is lifted and the die assembly is removed.

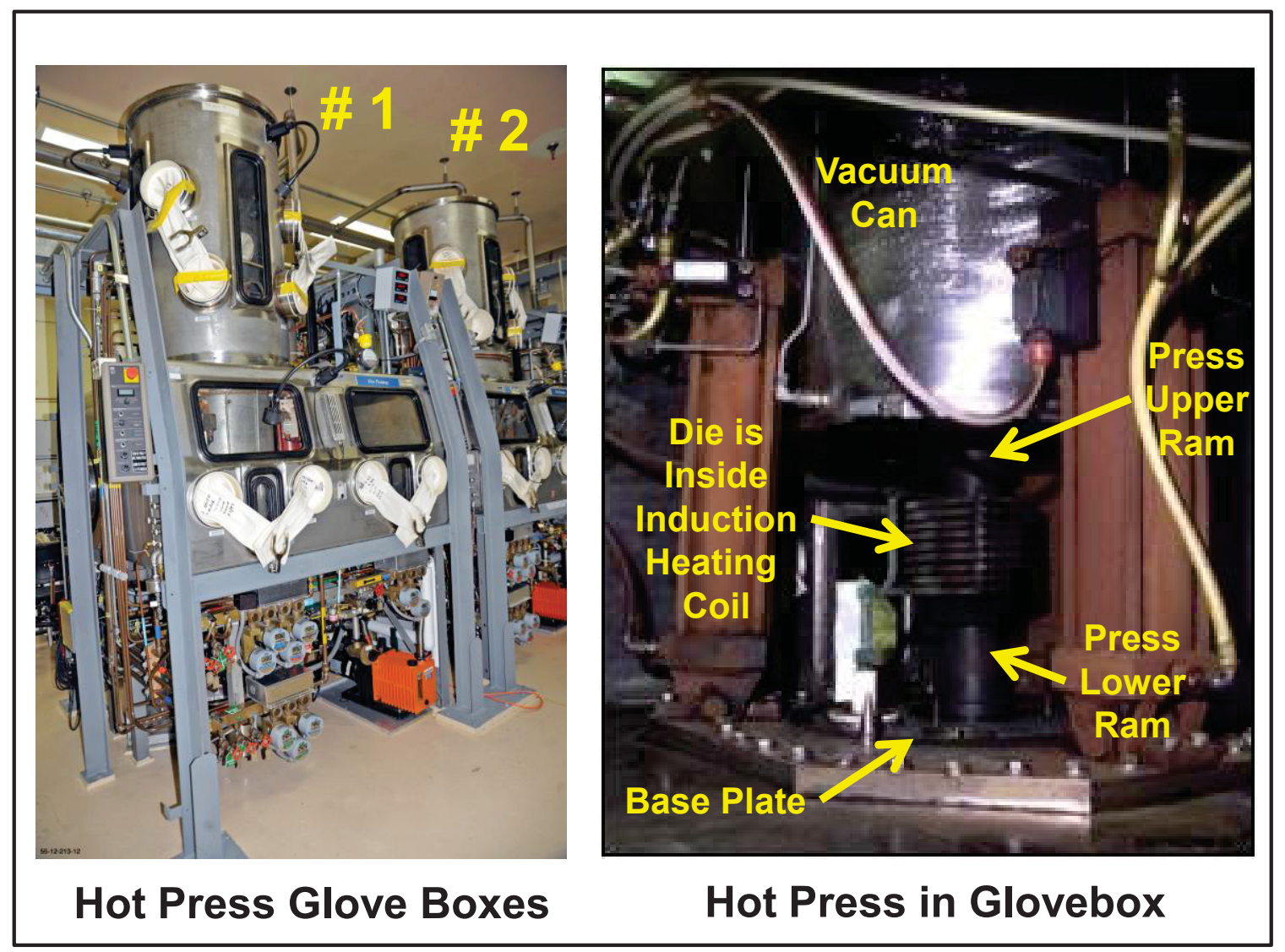

Figure 3-27. Hot press gloveboxes. 


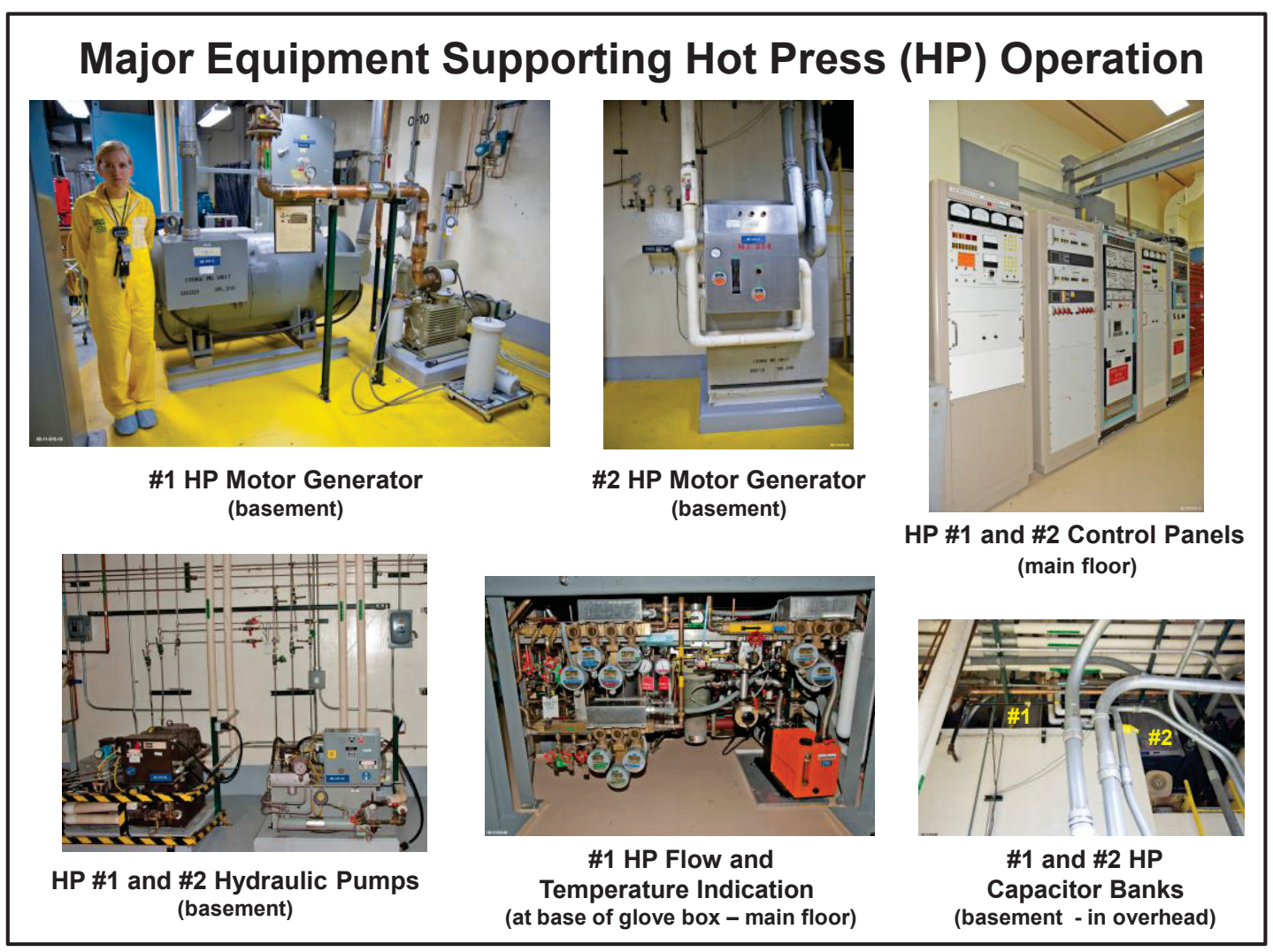

Figure 3-28. Major equipment supporting hot press operation.

\subsubsection{Weighing and Dimensioning}

The pellets are removed from the dies and the pellets are weighed and dimensioned to ensure they meet specifications. They are then released for encapsulation (Figure 3-29). LWRHU fuel pellets are produced in basically the same manner as the GPHS pellets.

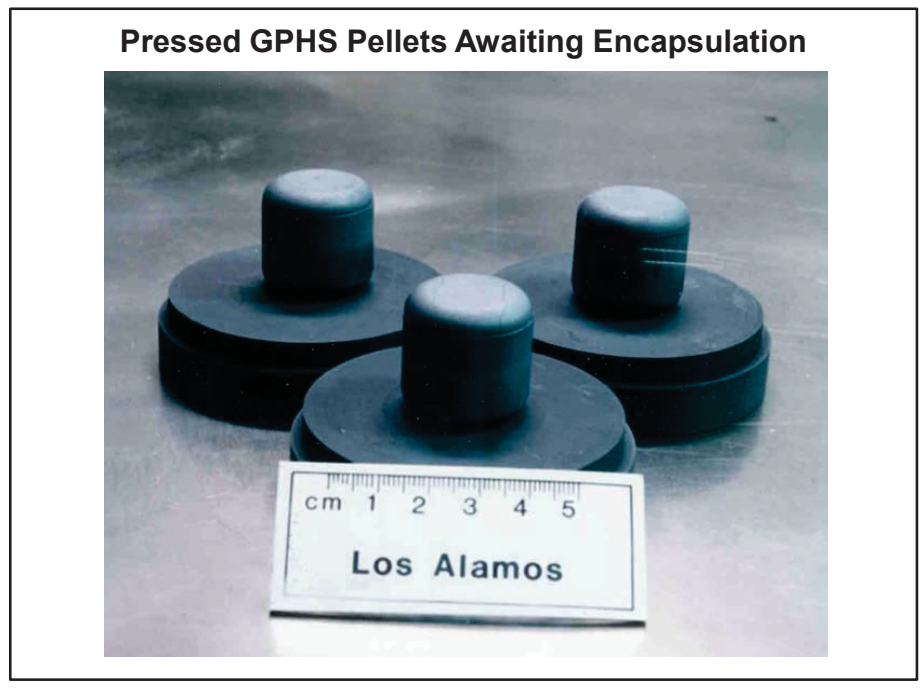

Figure 3-29. Pressed GPHS pellets awaiting encapsulation. 


\subsection{Pellet Encapsulation}

\subsubsection{Welding the Clad Vent Sets}

The GPHS fuel pellets are encapsulated in the iridium alloy clad vent sets that are made at ORNL. All the parts depicted in grey in Figure 3-30 are manufactured at ORNL. The process is described in detail in Section 2.

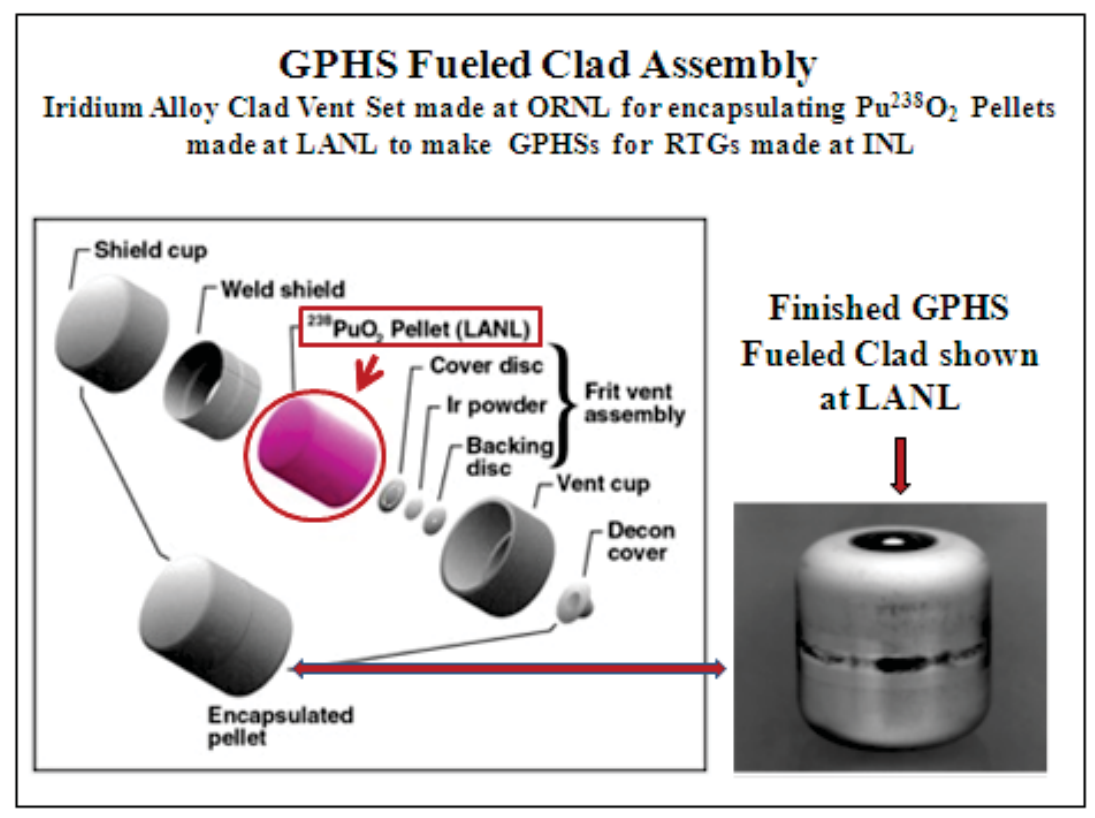

Figure 3-30. GPHS FC assembly.

GPHS encapsulation is accomplished using a precision welder located within a dedicated glovebox on the main floor (Figure 3-31).

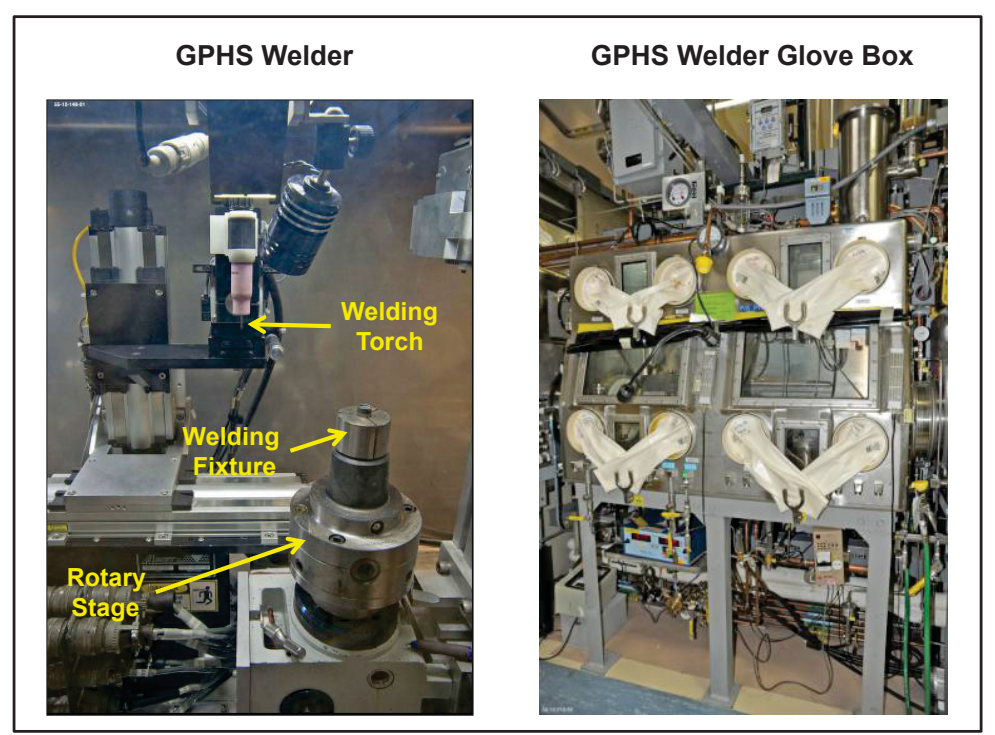

Figure 3-31. GPHS welder and welder glovebox. 
The LWRHU FCs are welded into the platinum-rhodium alloy clad vent sets also manufactured at ORNL. The components of the LWRHU clad vent set that are manufactured at ORNL are shown in Figure 3-32 (in grey), and the production process is described in detail in Section 2.

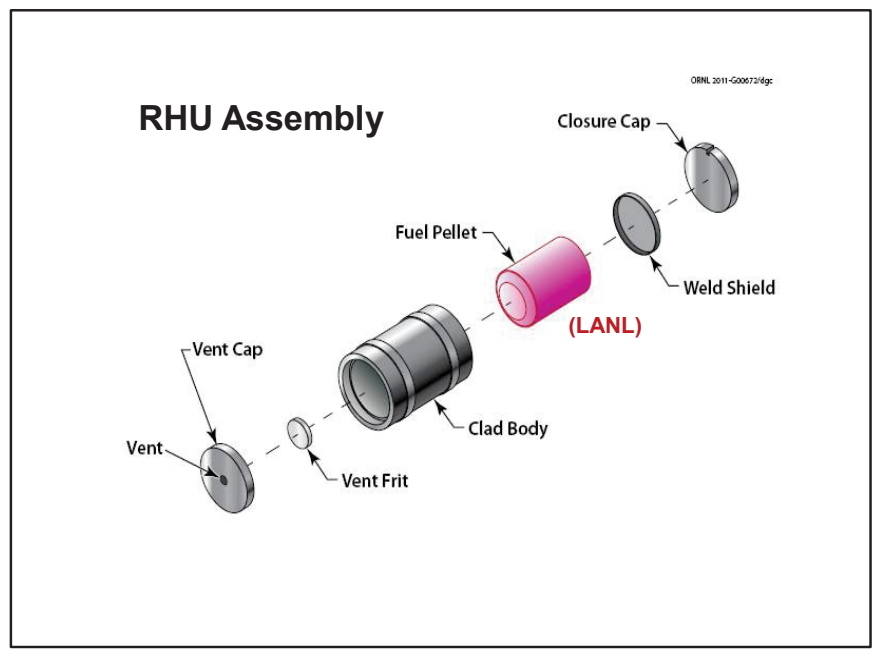

Figure 3-32. RHU assembly.

Encapsulation of the LWRHU is accomplished in the AMET welder shown in Section 3.3.3 above.

\subsubsection{Clad Weld Metallography}

During GPHS FC and LWRHU FC production campaigns, demonstration welds are periodically conducted to evaluate the weld quality being achieved by the welders. These are called simulant welds, and they are conducted on clad vent sets with no fuel in them. The welds are then subjected to metallographic examination (Figure 3-33).

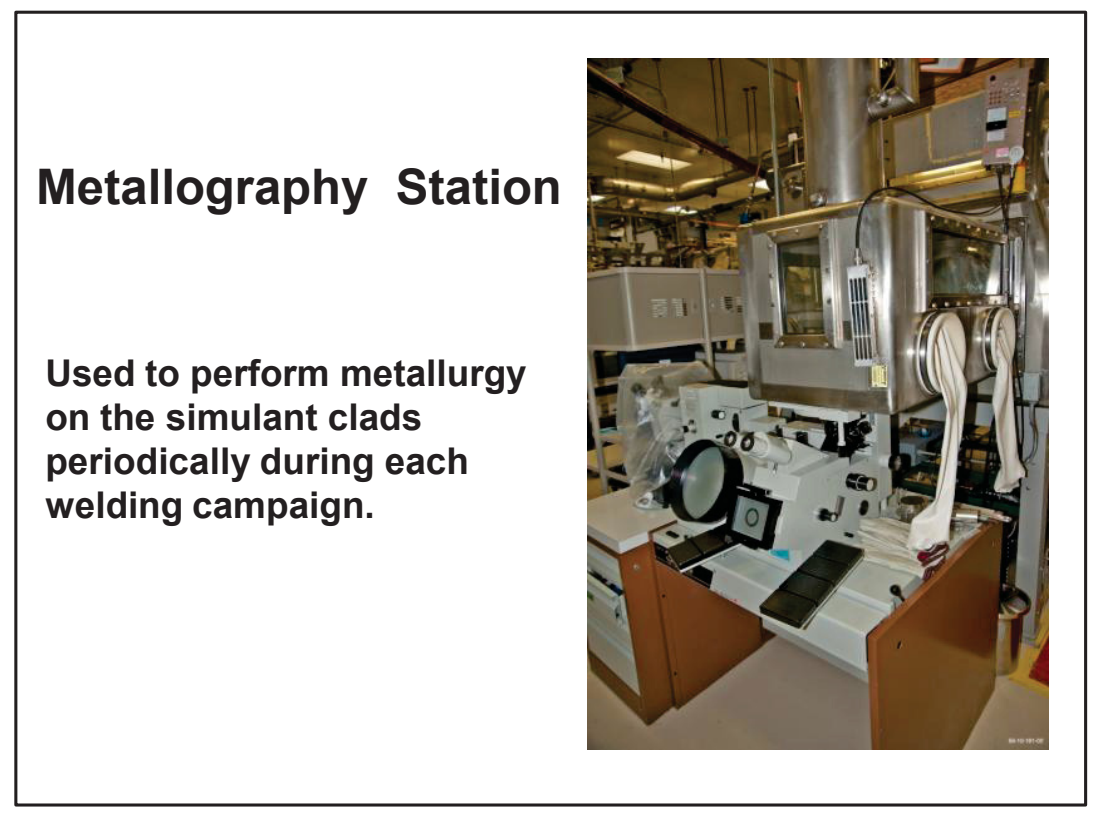

Figure 3-33. Metallography station. 


\subsubsection{Decontamination}

The completed GPHS and LWRHU fueled clads are next decontaminated in a special glovebox (Figure 3-34). This is a labor intensive, manual cleaning process that must be conducted by a trained operator. The clads are scrubbed using strong (hazardous) hydrofluoric acid and a demineralized water rinse. The cleaning takes approximately 2 hours. They are allowed to sit for 24 hours and then monitored for any residual contamination. If residual contamination is detected, the clads must be cleaned again and then checked after 24 hours. The process is repeated as many times as necessary until decontamination is achieved.

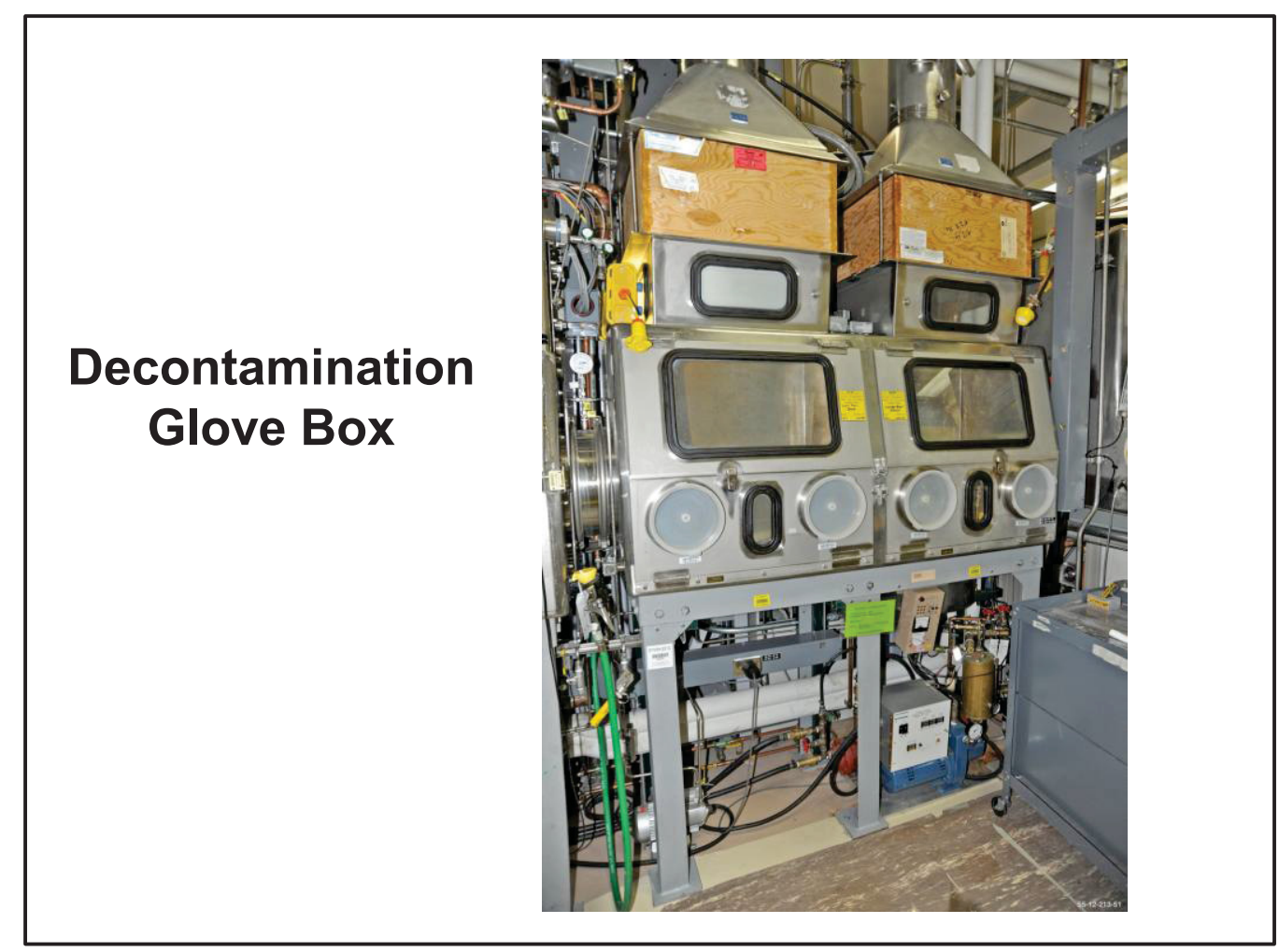

Figure 3-34. Decontamination glovebox.

\subsubsection{Non-Destructive Testing for FC Welds}

All GPHS and LWRHU FC welds are radiographed using a 6 million electron volt (MEV) x-ray machine. The unit is mounted on two special mobile tables (Figure 3-35) that can be positioned relative to each other as required for optimal results. 


\section{GPHS and RHU Radiography Equipment}
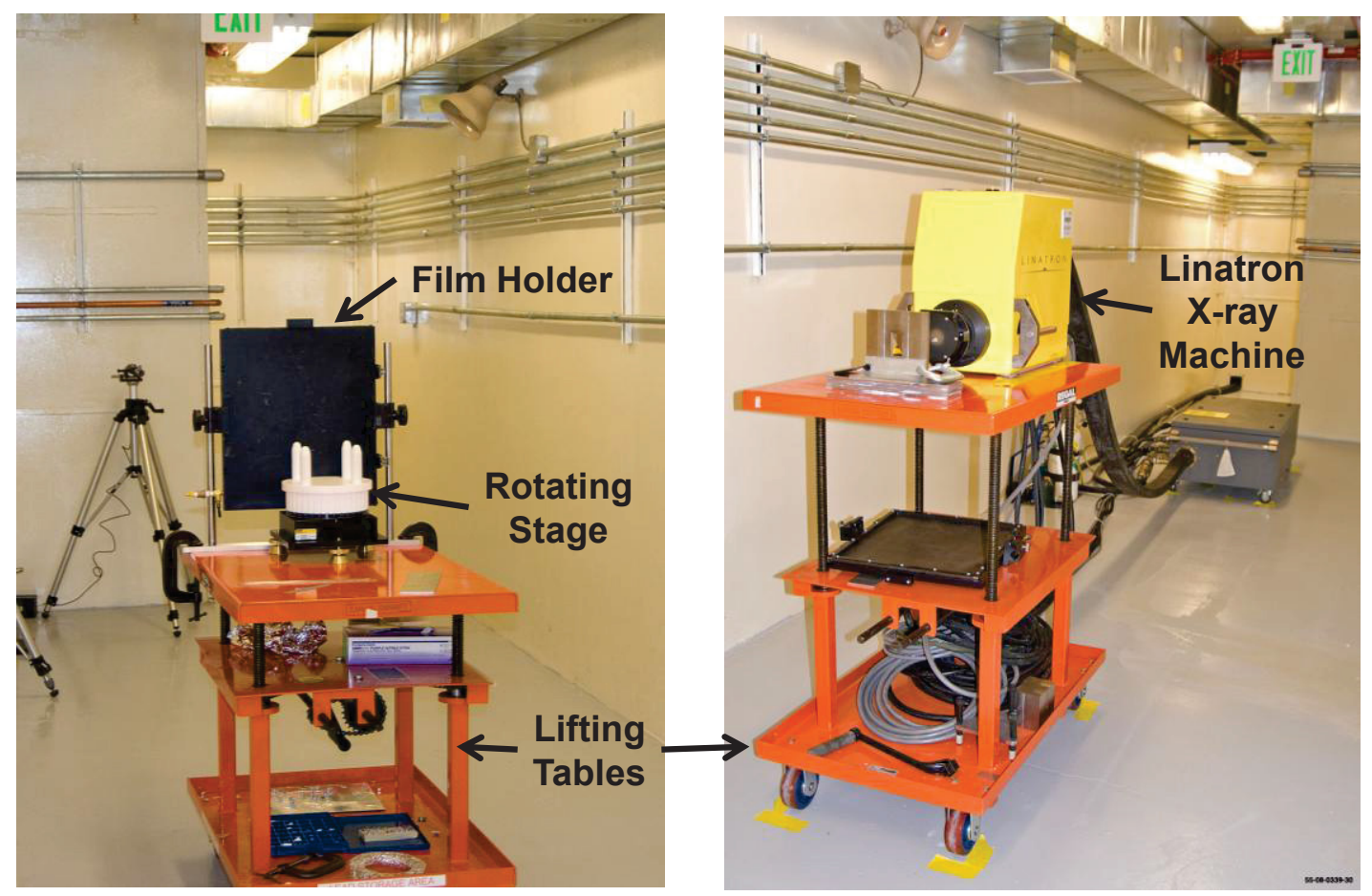

Figure 3-35. GPHS and RHU radiography equipment.

\subsubsection{Inserting LWRHU FCs into Insulators and Aeroshells to Make Flight Ready LWRHUs}

The RHUs are inserted into a Pyrolytic Graphite Insulator, which is then inserted into a FWPF aeroshell (heat shield) (Figure 3-36). The Insulator is procured by ORNL from a contractor, inspected for QA, and then shipped to LANL. The FWPF aeroshell is procured by INL from a contractor, inspected for QA, and then shipped to LANL. At LANL, flight ready LWRHU is assembled, undergoes final QA inspections, and is stored until shipped to the launch site. 


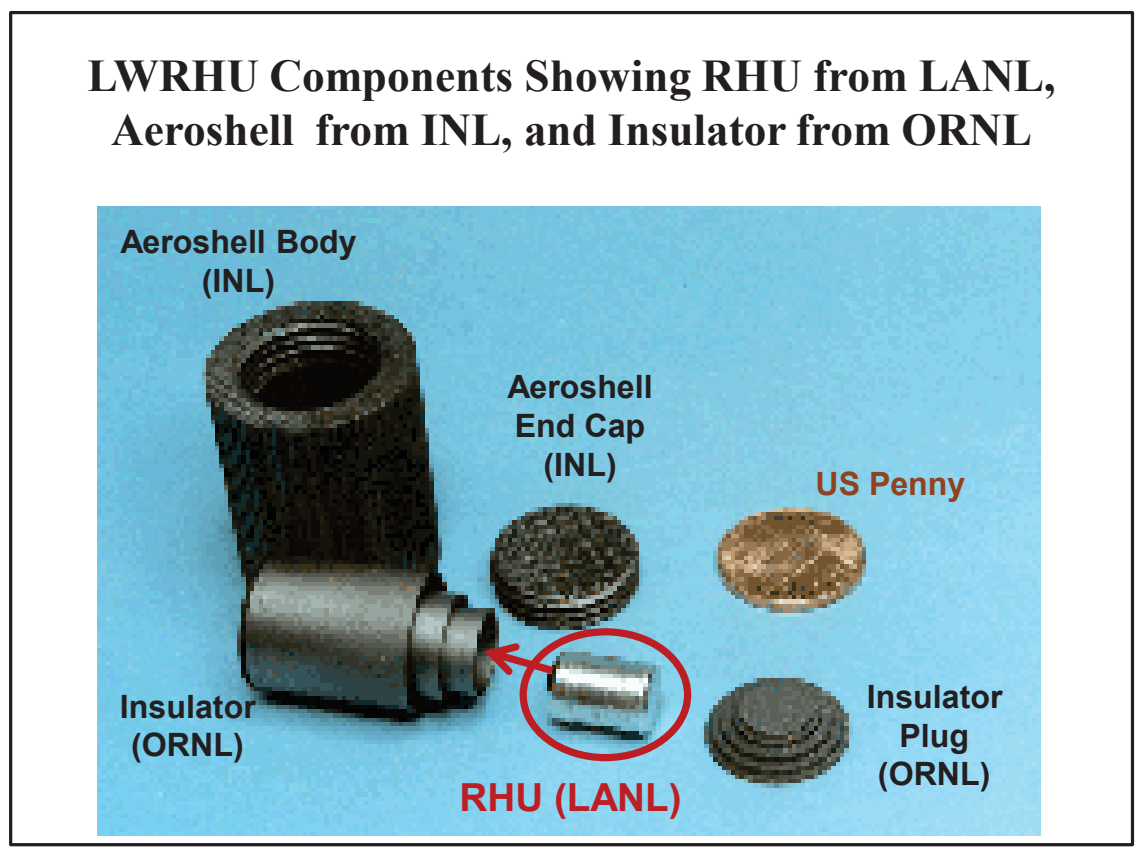

Figure 3-36. LWRHU components.

\subsection{Quality Assurance}

\subsubsection{Inspections and Process Records Review}

The completed GPHS FCs and LWRHUs undergo a thorough final inspection, which includes a review and certification of the process records. This is to ensure that each heat source meets the quality requirements. These records are filed for future reference. Heat sources that are determined to be "flight ready" undergo calorimetric testing to determine actual thermal power output at time of production. The GPHS FCs are then shipped to INL for MMRTG or ASRG production, and the LWRHUs are stored for shipment directly to the launch site, when required. Randomly selected heat sources are destructively tested, as described in Section 3.5.3. The results of these tests form a vital part of the QA database.

\subsubsection{Calorimetric Measurements of Thermal Power Output}

Each heat source is tested to determine its thermal power output (Figure 3-37). This is a vital data point for mission planning. It allows for calculations of MMRTG or ASRG actual power at the planned launch date, which is normally 2 to 4 years after production of the heat sources at LANL. 


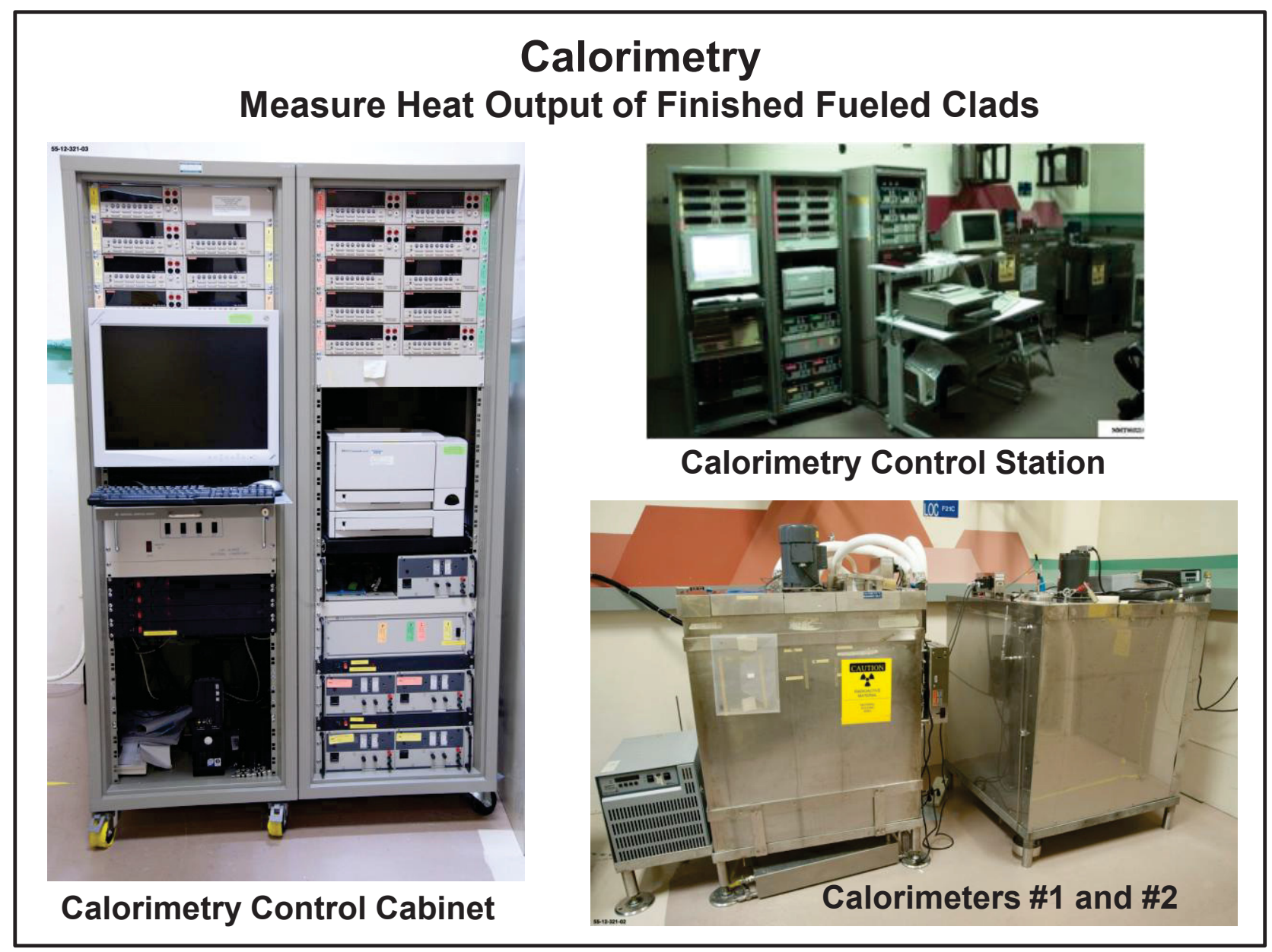

Figure 3-37. Calorimetry measurement equipment.

\subsubsection{Destructive Impact Testing on Selected FCs}

Isotope Fuels Impact Tester (IFIT) (Figure 3-38): DOE must ensure flight safety for fueled clads and advise the White House on launch safety issues. In order to test fueled clad and RHU integrity under launch or re-entry accident conditions and provide data necessary for safety analyses, a fueled clad/RHU impact testing program is maintained at the LANL facility (Figure 3-39).

In order to accomplish a comprehensive safety testing program, a complex and highly sophisticated testing capability, designated the IFIT (Figure 3-40), is operated and maintained at the LANL facility. GPHS and LWRHU FCs are impacted under very precise conditions replicating a launch or re-entry accident and then subjected to analysis to assess shell and weld integrity and containment of the $\mathrm{Pu}^{238}$ fuel. 


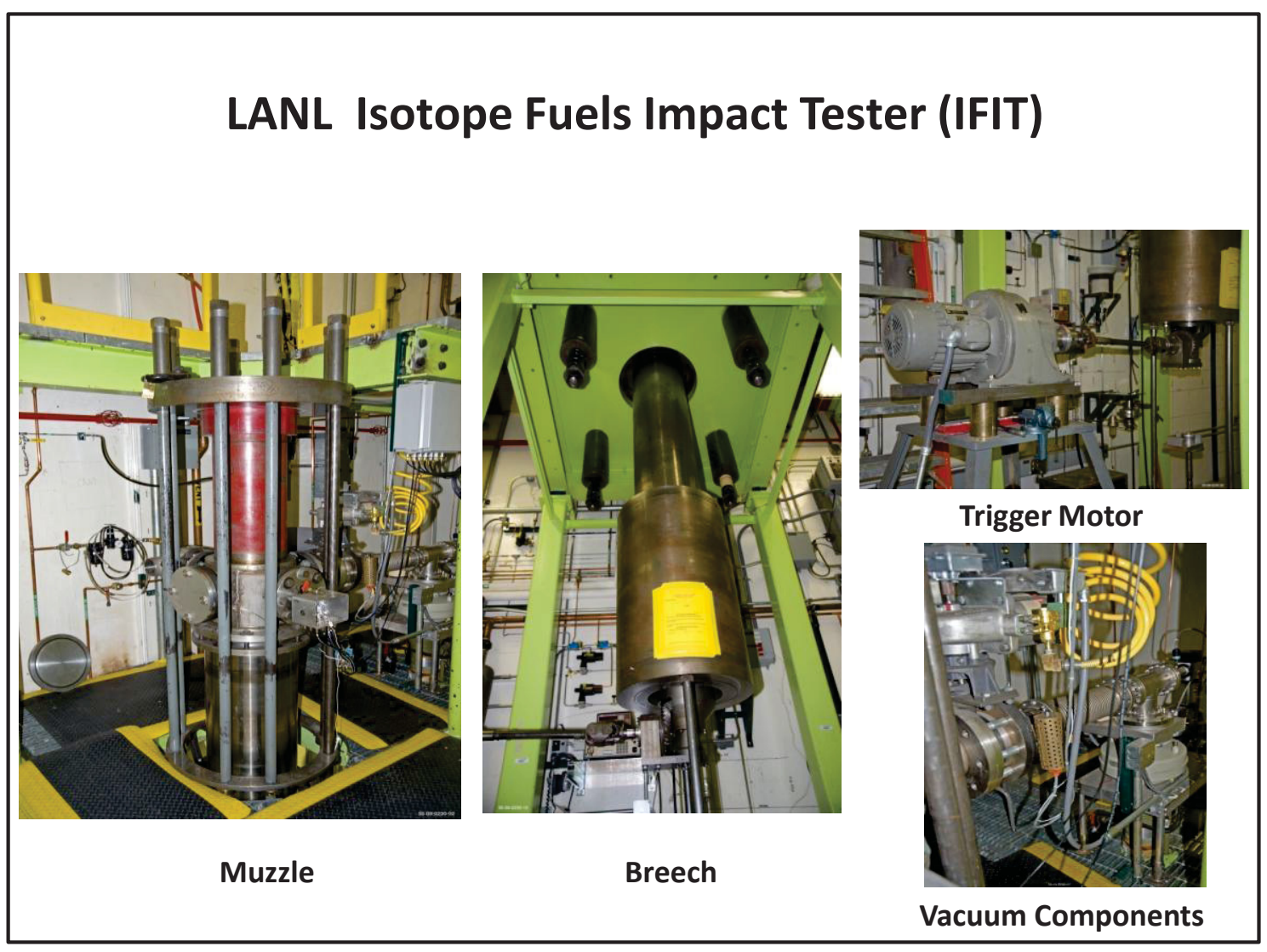

Figure 3-38. Isotope fuels impact tester.

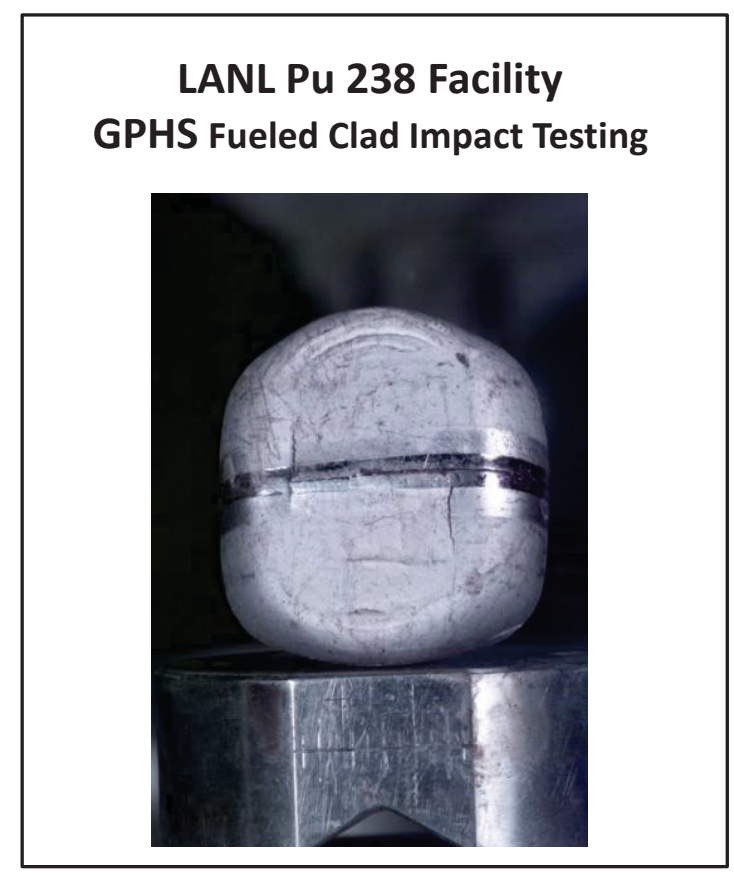

Figure 3-39. $\mathrm{Pu}^{238} \mathrm{GPHS}$ fueled clad impact testing. 


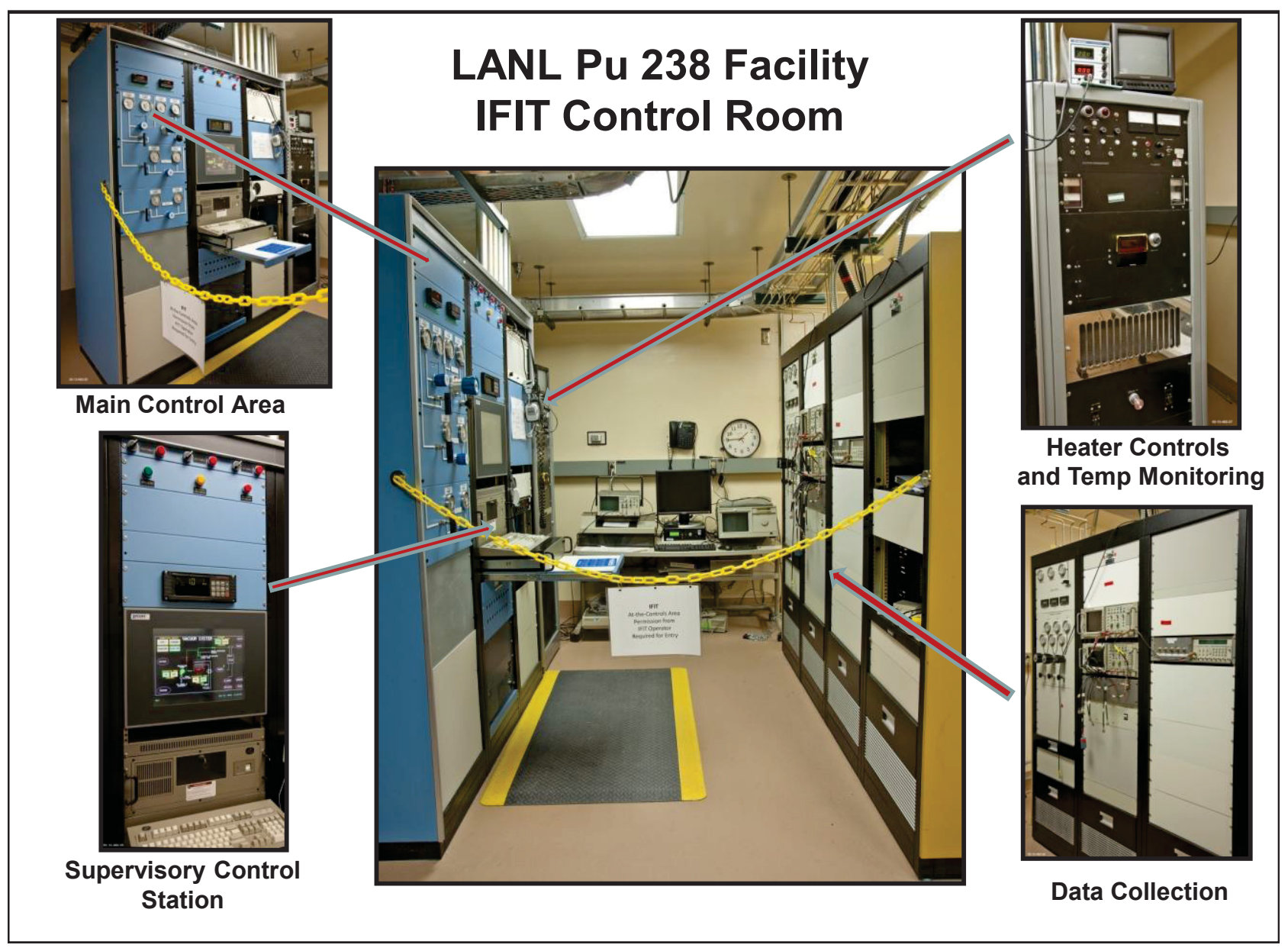

Figure $3-40 . \mathrm{Pu}^{238}$ Facility IFIT control room. 


\section{IDAHO NATIONAL LABORATORY (INL)}

\subsection{Overview}

\subsubsection{Facilities}

The RPS Program at INL is responsible for assembly, testing, storage, and transportation of RTGs of various designs for NASA's space exploration program and national security. National security missions will not be discussed due to classification.

The SDPS facilities at INL occupy three buildings:

1. Space and Security Power Systems Facility (SSPSF)

2. Engineering Development Laboratory (EDL)

3. Radioisotope Systems Training and Servicing Facility (RSTSF).

The SSPSF is the main production facility (Figure 4-1). It is comprised of two buildings on the Materials and Fuels Complex (MFC) campus, MFC-792 and MFC-792A. The MFC is one of three main nuclear energy research and applied engineering campuses at INL; the SSPSF is a nuclear facility. In the SSPSF, RPS are fueled, assembled, and tested. A detailed description of activities in this facility is included later in this chapter. 


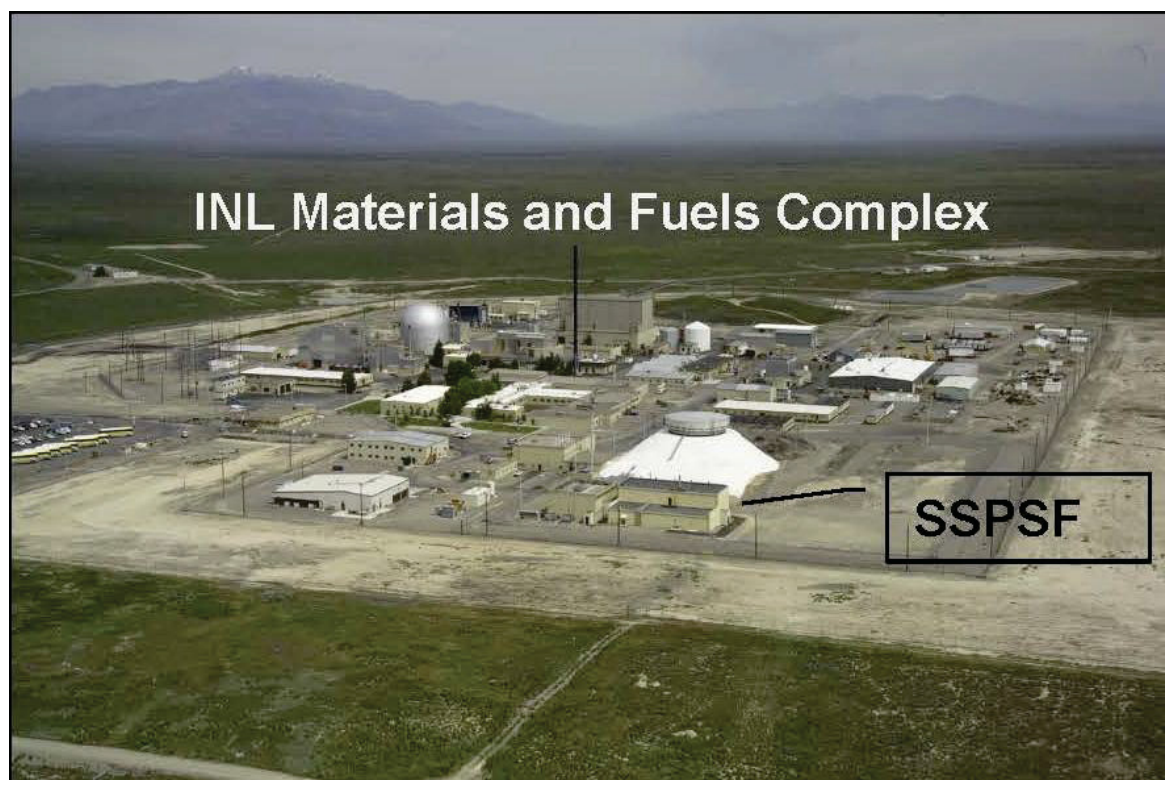

\section{Space and Security Power Systems Facility (SSPSF) Idaho National Laboratory (INL)}

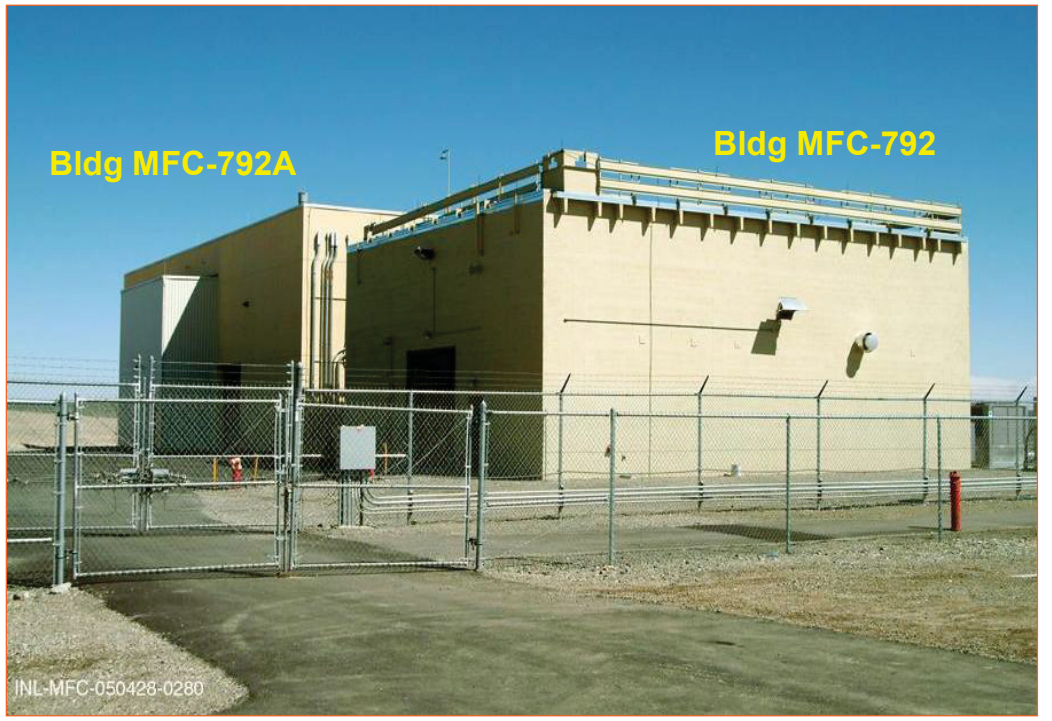

Figure 4-1. The SSPSF at INL.

The EDL Facility (Figure 4-2) provides support services and is also located at MFC in Building MFC-772. This facility conducts various non-radiological operations and provides a variety of support functions. The EDL, a non-nuclear facility, occupies most of Building 772. The EDL is used to fabricate, assemble, mockup, and test various research, development, and production equipment. The majority of work conducted in EDL is for the RPS Program. The facility includes equipment and gloveboxes for welding, including an electron-beam welder, furnaces for bake-out of graphite components, forming equipment for heat source hardware, and various machine tools. Some RPS equipment is stored in an EDL-managed storage building. 
The Radioisotope Training and Servicing Facility (Figure 4-2) also provides support services and is located on the Idaho Nuclear Technology and Engineering Center (INTEC) campus, Building B21-265. The Radioisotope Thermoelectric Generator Transportation System (RTGTS) (tractor trailer trucks), which moves the RTGs to user sites, and two types of shipping containers are stored in this facility. The facility also provides a training area for these systems.
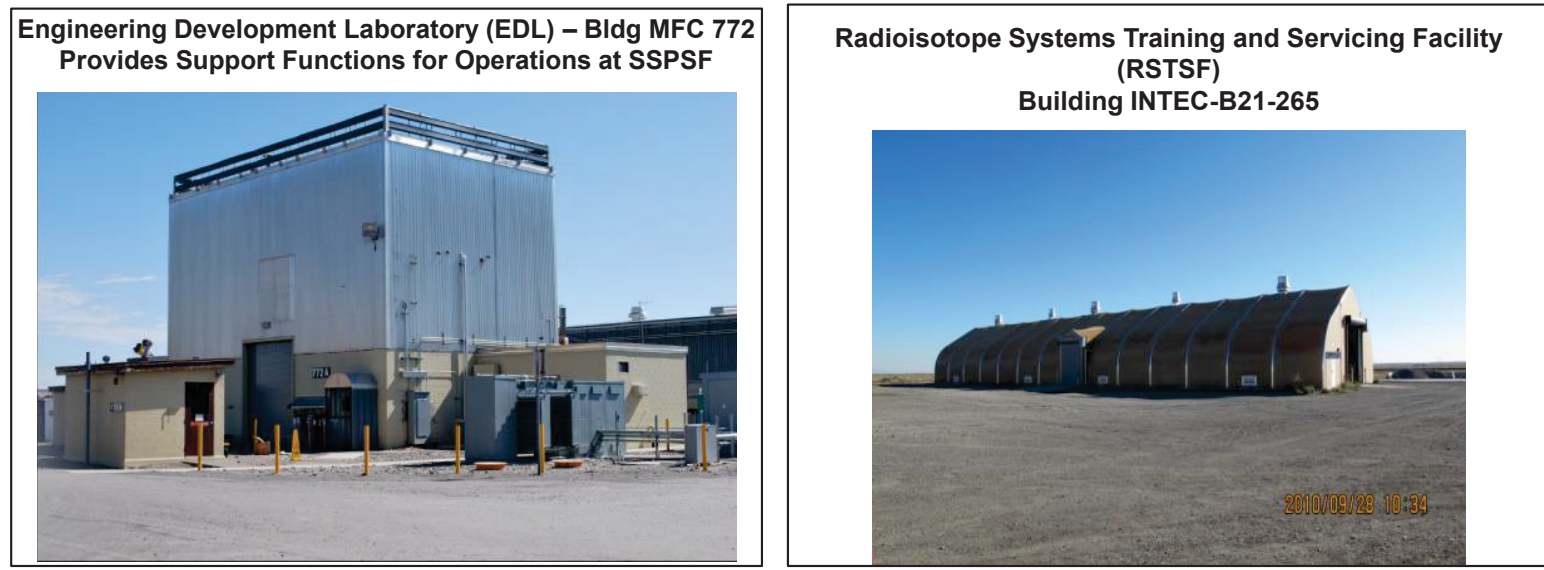

Figure 4-2. EDL and RSTSF at INL

The overall investment for these facilities is as follows:

- 30 major pieces of equipment

- Four large, complex gloveboxes

- Replacement value is estimated at over \$25 million

- Occupies $25,000 \mathrm{ft}^{2}$ in four buildings

- Staffed by 40 highly trained and skilled FTEs.

\subsubsection{Current Mission}

The current mission is to function as lead laboratory for the SDPS Program and to produce MMRTGs and ASRGs for NASA. MMRTGs are currently in production. The MMRTG shown in Figure 4-3 powered NASA's Mars Science Laboratory (MSL) launched in November 2011. Preparations are in progress for production of the first ASRG (Figure 4-3), which is planned to power NASA's Discovery 12 mission currently scheduled for 2016.

Figure 4-3. MMTRG and ASRG.

\subsubsection{Overview of Operations}

The process flow for production and delivery of radioisotope power supplies at INL is shown in Figure 4-4. 


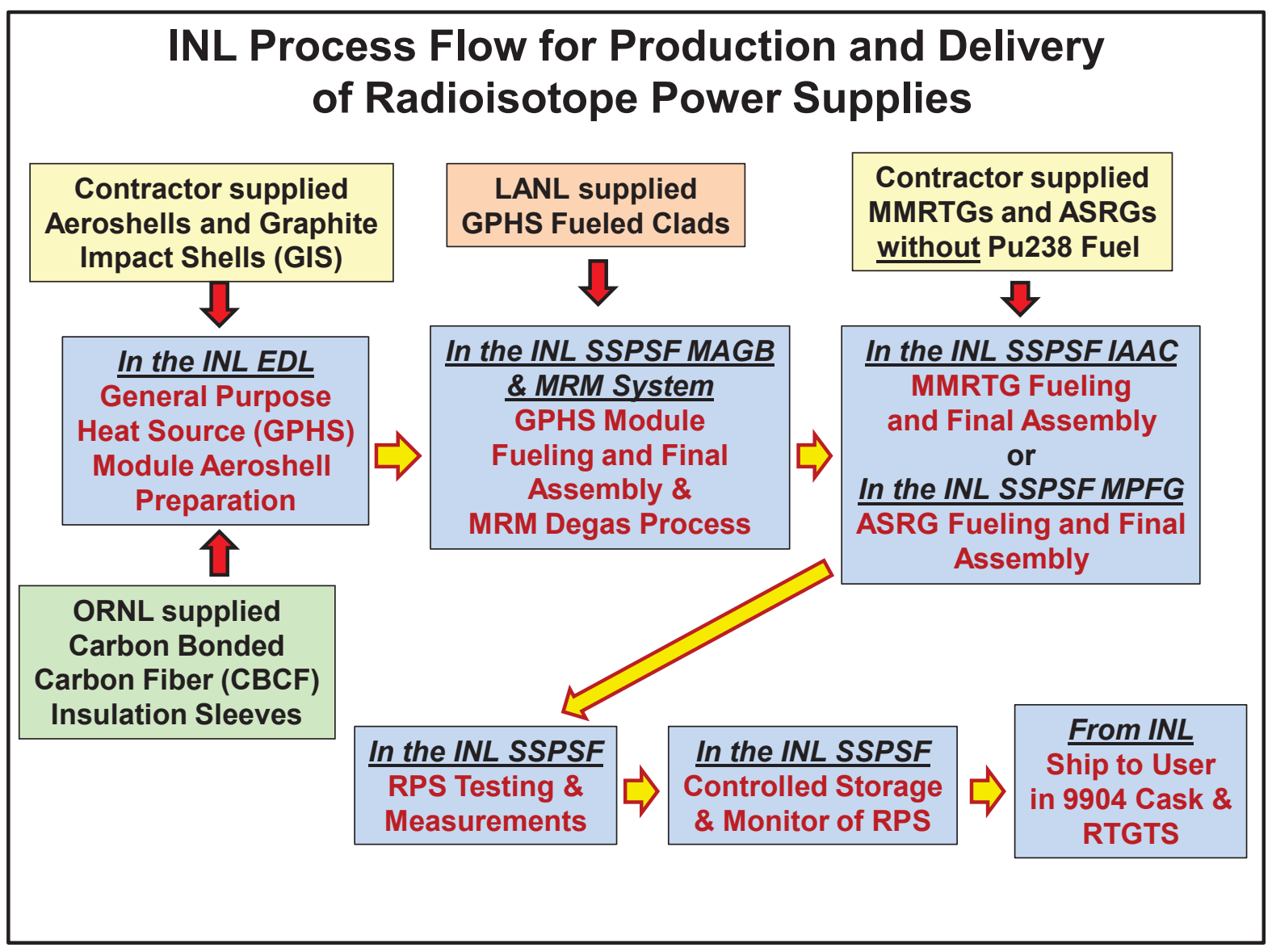

Figure 4-4. INL process flow for production and delivery of radioisotope power supplies.

\subsection{Preparation of GPHS Module Aeroshells in the EDL}

In the EDL, GPHS module aeroshells and graphite impact shells (GIS) are received from a contractor and the $\mathrm{CBCF}$ insulation sleeves are received from ORNL (Figure 4-5). Operations include:

- Inspection and QA checks

- Gluing of CBCF discs to the aeroshell caps

- Cutting lunes on the aeroshell caps

- Establishing the proper gap between the GIS and aeroshell caps

- Baking moisture and impurities out of $\mathrm{CBCF}$ and graphitic components.

The lune on the aeroshell cap accommodates a locking screw that retains the cap. 

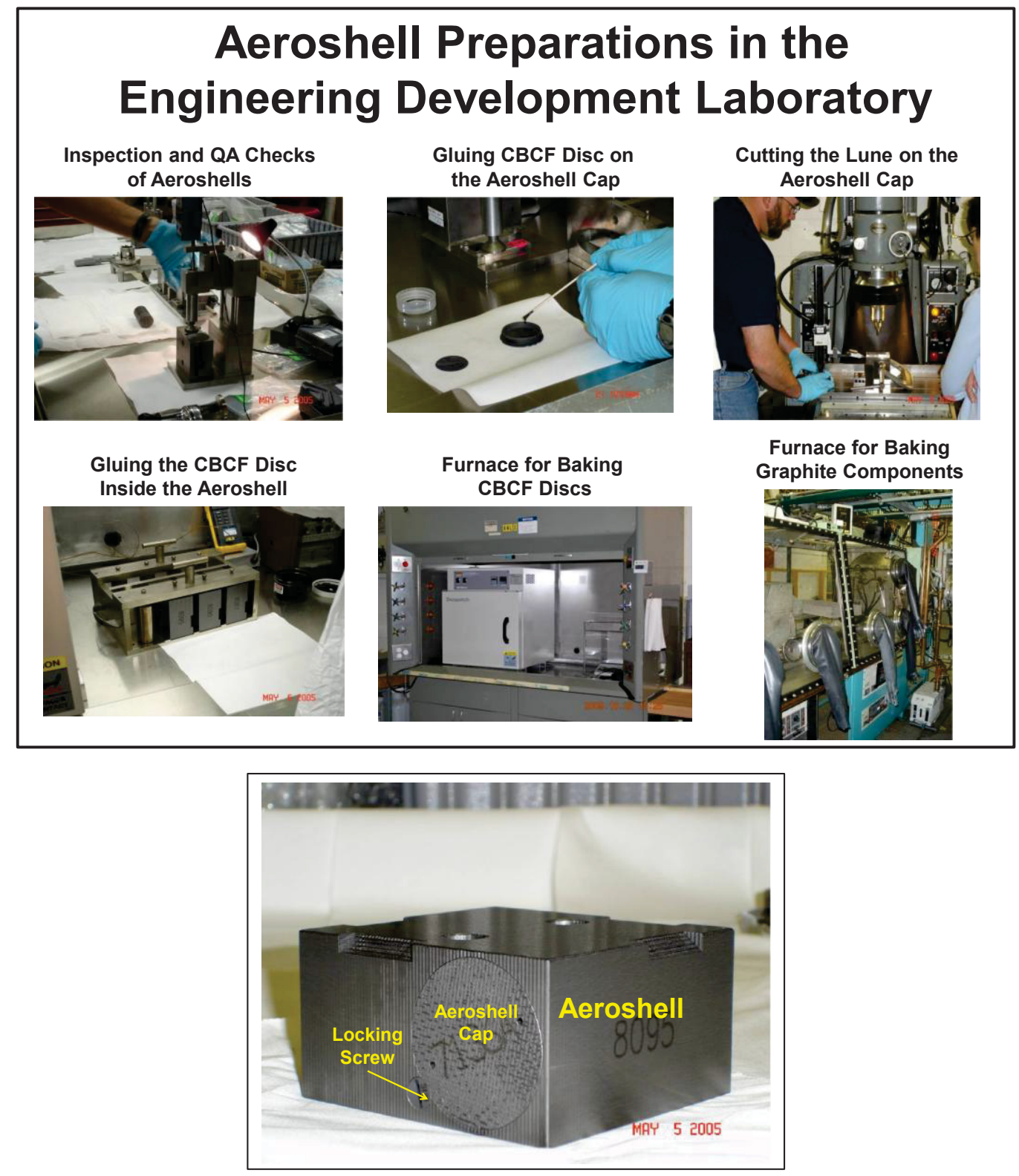

Figure 4-5. Aeroshell preparations in the EDL.

The prepared modules and the GISs are transferred to the SSPSF for fueling with the GPHS FCs and final assembly.

\subsection{Fueling and Assembly of RPSs at the SSPSF}

\subsubsection{SSPSF Facility}

MFC-792 is a non-nuclear, non-radiological facility that was originally constructed in 1971. The facility includes an office area, storage areas, and a facility monitoring system (FMS) to support the RTG assembly and testing operations performed inside of MFC-792A. 
MFC-792A annex is a hazard-category-2 non-reactor nuclear facility. It was built in 2004 and provides the following capabilities to support assembling of radioisotope power supplies:

1. Module Assembly Glovebox (MAGB) for assembly of GPHS aeroshell modules

2. Inert Atmosphere Assembly Chamber (IAAC) for assembly of MMRTGs

3. Vacuum/Inert atmosphere welding glovebox used for assembly of hardware for national security missions and for welding operations associated with the manufacture and sealing of special Model 9516 containers for shipping material containing $\mathrm{Pu}^{238}$

4. Multipurpose fueling glovebox for assembly of ASRGs.

\subsubsection{Production Material Requirements Provided from Off Site}

The following inputs are provided to the SSPSF from outside sources for its production work:

1. GPHS FCs $\left(\mathrm{Pu}^{238}\right.$ heat source for RTGs) are manufactured at LANL and shipped to INL (Figure 4-6) for assembly of GPHS modules

\section{Fuel Receipt}

- Fueled clads arrive in 9516 Type B cask from Los Alamos National Laboratory (up to $500 \mathrm{~W}_{\text {th }}$ per cask)

- Welded containment vessel and inner liners and product cans are opened mechanically
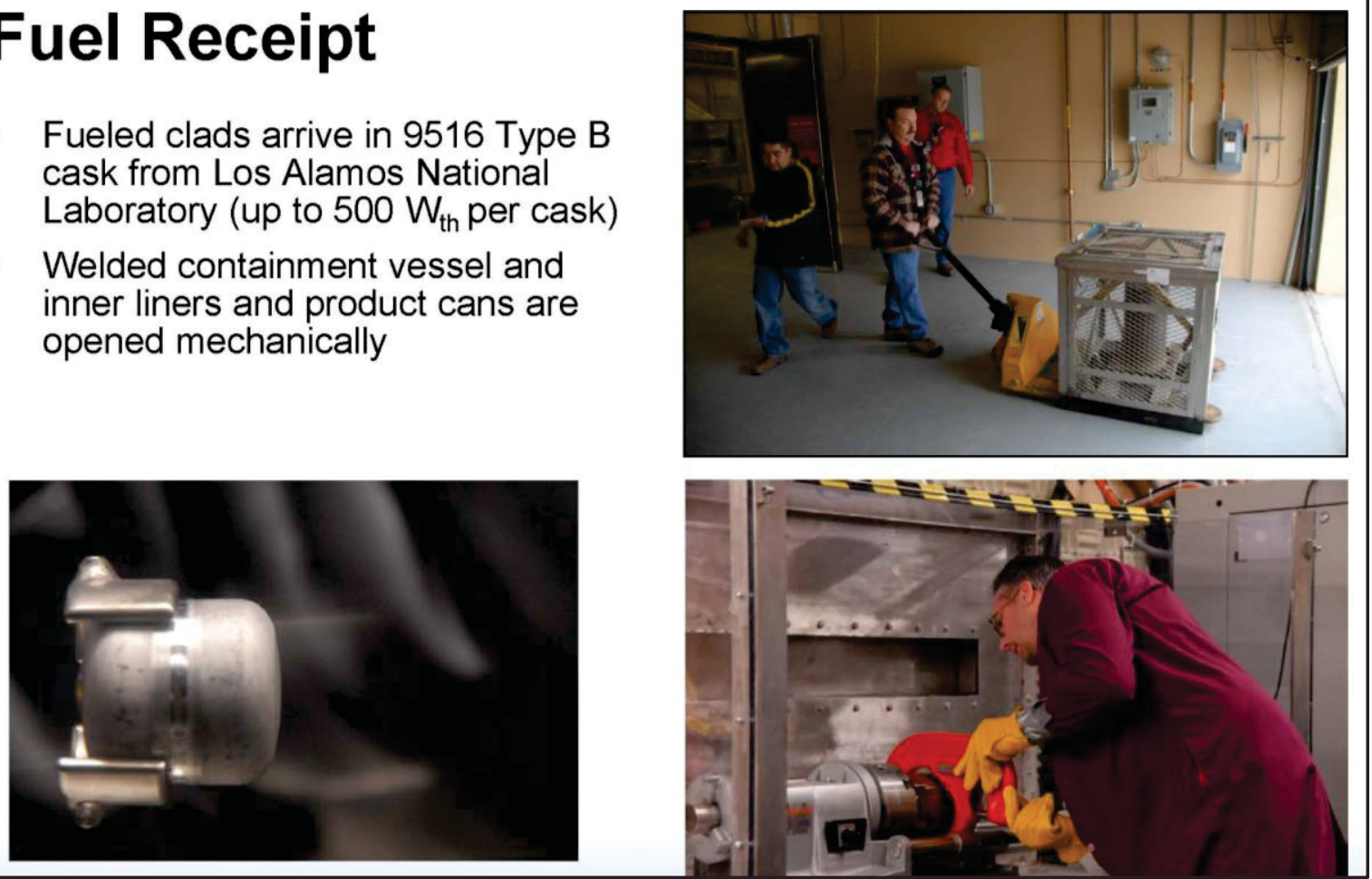

Figure 4-6. GPHS FC shipped to INL for assembly.

2. The MMRTGs and ASRGs without $\mathrm{Pu}^{238}$ fuel are provided by Design Agency Systems Integration Contractors

3. GIS provided by a contractor, are received and inspected at the EDL. These are used in assembly of the GPHS Modules. 


\subsubsection{First Operation - Assembling a GPHS Module}

In the SSPSF, final assembly of the GPHS module is accomplished in the MAGB (Figure 4-7).

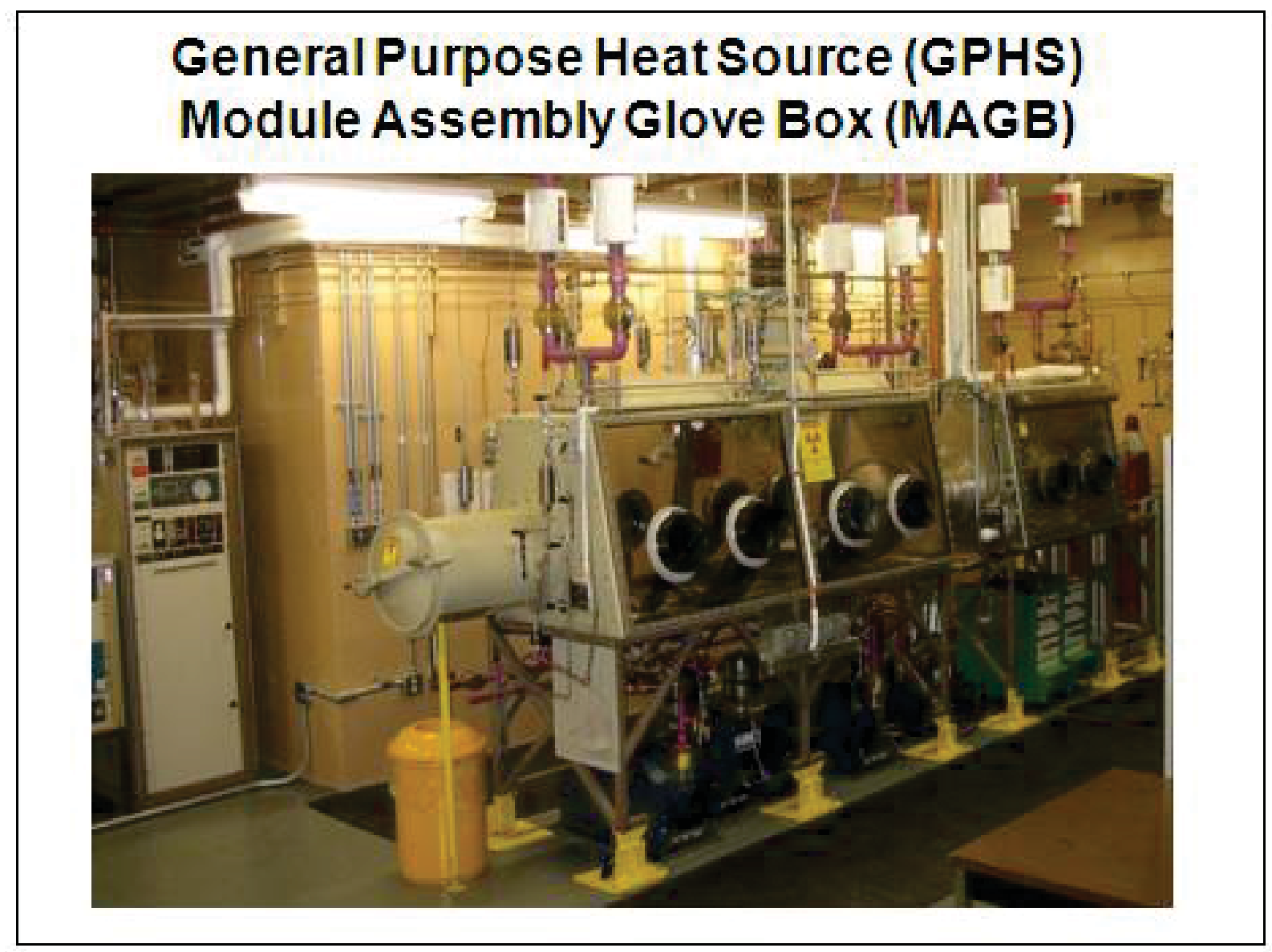

Figure 4-7. GPHS MAGB.

The prepared aeroshells and GIS are then transferred from the EDL. The $\mathrm{Pu}^{238}$ FCs manufactured at LANL are retrieved from storage in special, seal-welded Model 9516 Product Cans. The cans are unsealed and the $\mathrm{Pu}^{238} \mathrm{FCs}$ are inspected and staged for loading. Two FCs are inserted into each GIS and two loaded GIS are inserted into each aeroshell, one on each side. The aeroshell caps are screwed into place and secured with a locking screw. 


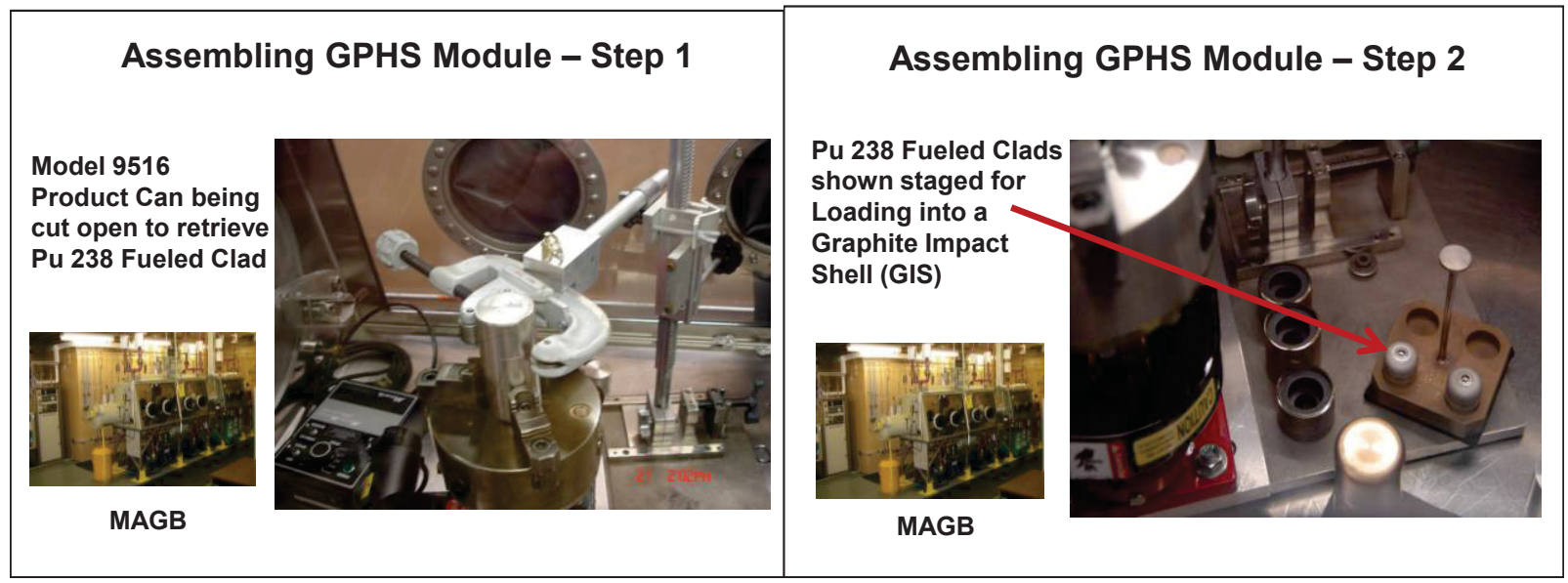

Figure 4-8. Steps to assembling a GPHS module.

\section{Assembling GPHS Module - Step 3}

2 Pu238 Fueled Clads are loaded into a Graphite Impact Shell (GIS)

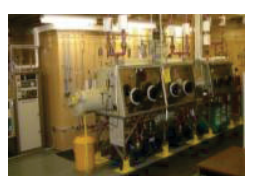

MAGB

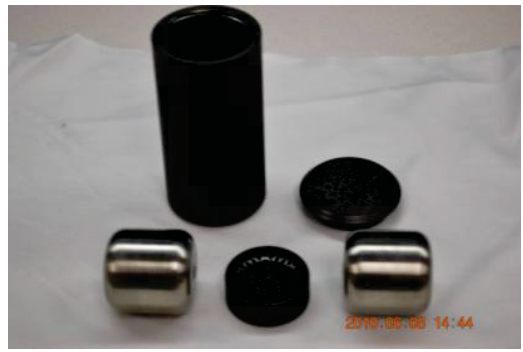

Assembling GPHS Module - Step 5

Assembled GPHS Fuel Module -4 Pu 238 Fueled Clads in FWPF Aeroshell

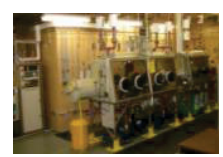

MAGB

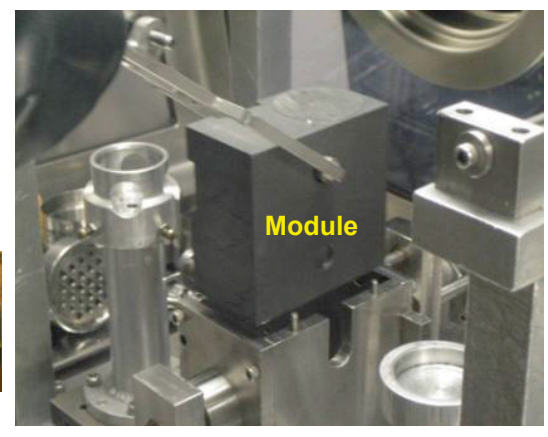

\section{Assembling GPHS Module - Step 4}

First GIS shown being loaded into Module second loaded from opposite side

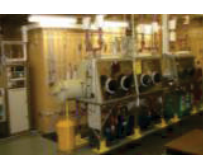

MAGB

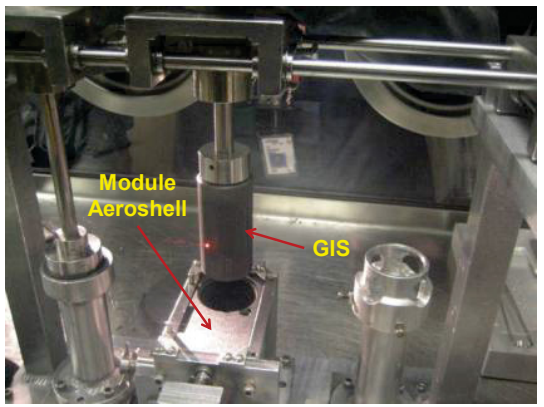

\section{Assembling GPHS Module - Step 6}

Completed Module placed in a Delta Seal container for temporary storage prior to "Module Reduction Monitoring"

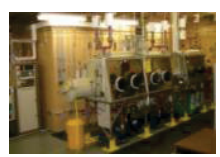

MAGB

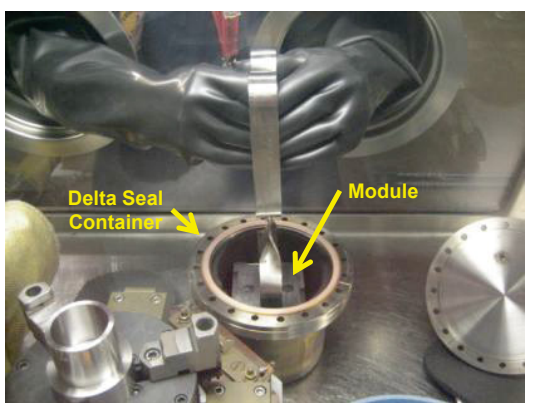




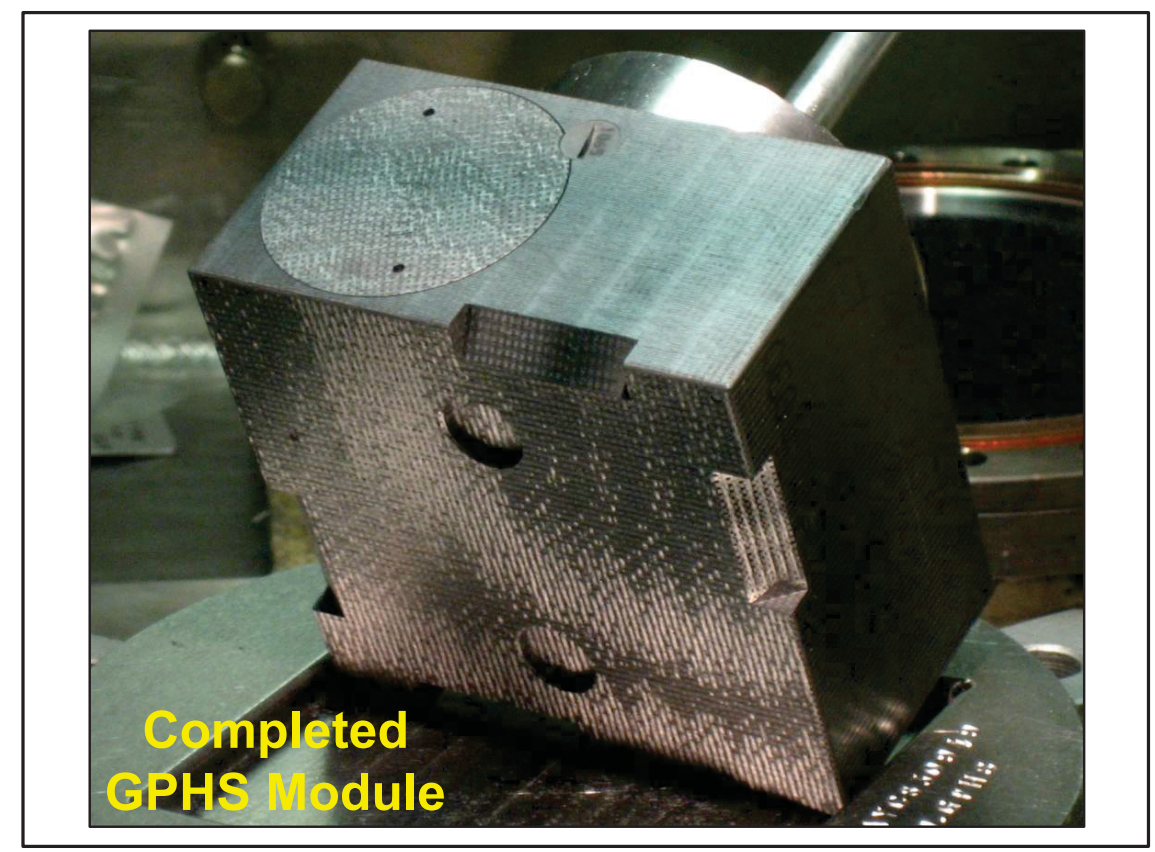

Figure 4-8. Steps to assembling a GPHS module (Continued).

\subsubsection{Module Reduction Process to Degas $\mathrm{O}_{2}, \mathrm{CO}$, and $\mathrm{CO}_{2}$}

After the number of modules sufficient for building an RPS have been assembled and stored in Delta seal containers, they are transferred to module reduction monitoring (MRM) containers, which are seal welded one at a time in the MAGB (Figure 4-9). They are then placed in the MRM system. The function of the MRM system is to control and monitor spontaneous reduction of the $\mathrm{Pu}^{238} \mathrm{O}_{2}$ in a newly fueled GPHS module to $\mathrm{Pu}^{238} \mathrm{O}_{1.98}$. Heat is applied to the MRM containers to get the temperature in the correct range for the reaction. Oxygen liberated from the chemical reduction comes out through the frit vent in the FC to interact with the graphite in the module to generate $\mathrm{CO}$ and $\mathrm{CO}_{2}$ gases, which are then vented out through the MRM container vent. In summary, the purpose of this procedure is to get the spontaneous reduction and liberation of oxygen over and done with and to let the $\mathrm{CO}$ and $\mathrm{CO}_{2}$ production run its course in a controlled condition with these gases vented out of the MRM container before loading the module into an RPS. This is necessary because $\mathrm{CO}$ and $\mathrm{CO}_{2}$ gases that are not vented off can reduce the thermoelectric performance of an assembled RPS.

The MRM reaction takes 4 to 6 weeks. However, the modules are kept in the MRM system until time for assembly of an RPS. This is done since taking the modules out of the MRM containers and returning them to Delta seal containers would likely invalidate the MRM process. 


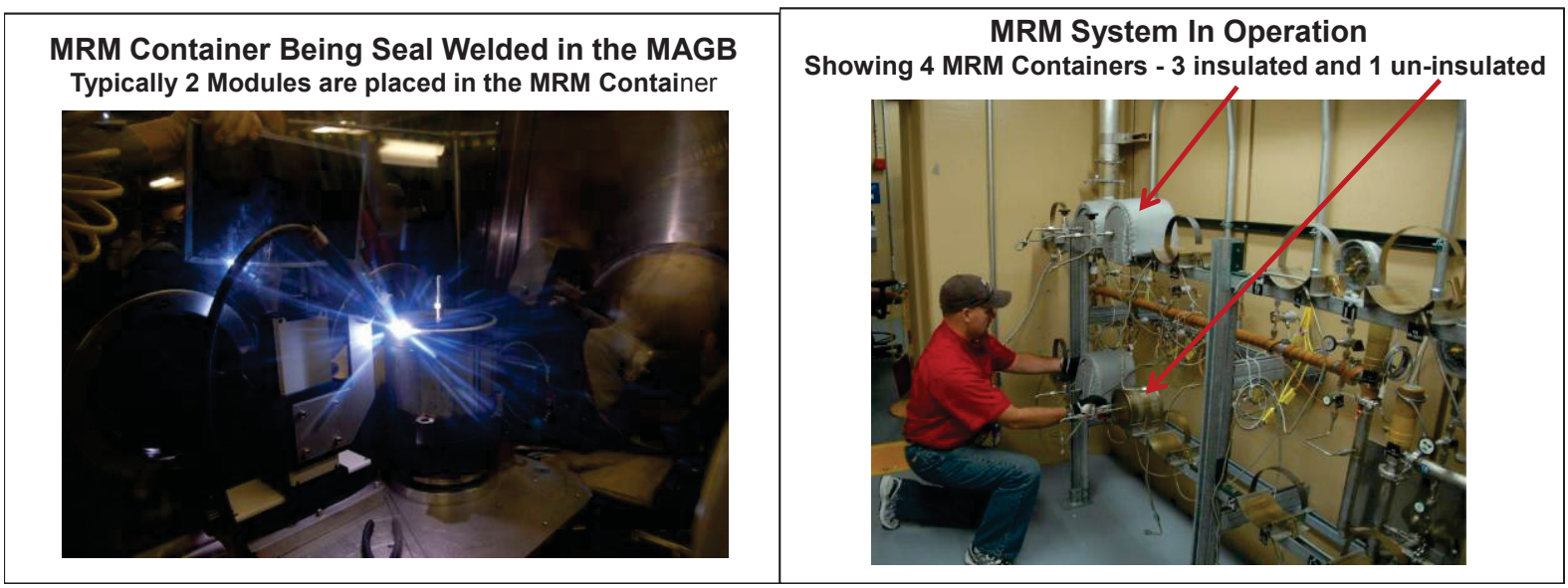

Figure 4-9. MRM container system.

\subsubsection{Second Operation - Fueling and Final Assembly of a MMRTG}

In the SSPSF, fueling and final assembly of a MMRTG is accomplished in the IAAC and adjacent decanning glovebox (Figure 4-10). The GPHS modules are taken out of their MRM containers in the decanning glovebox.

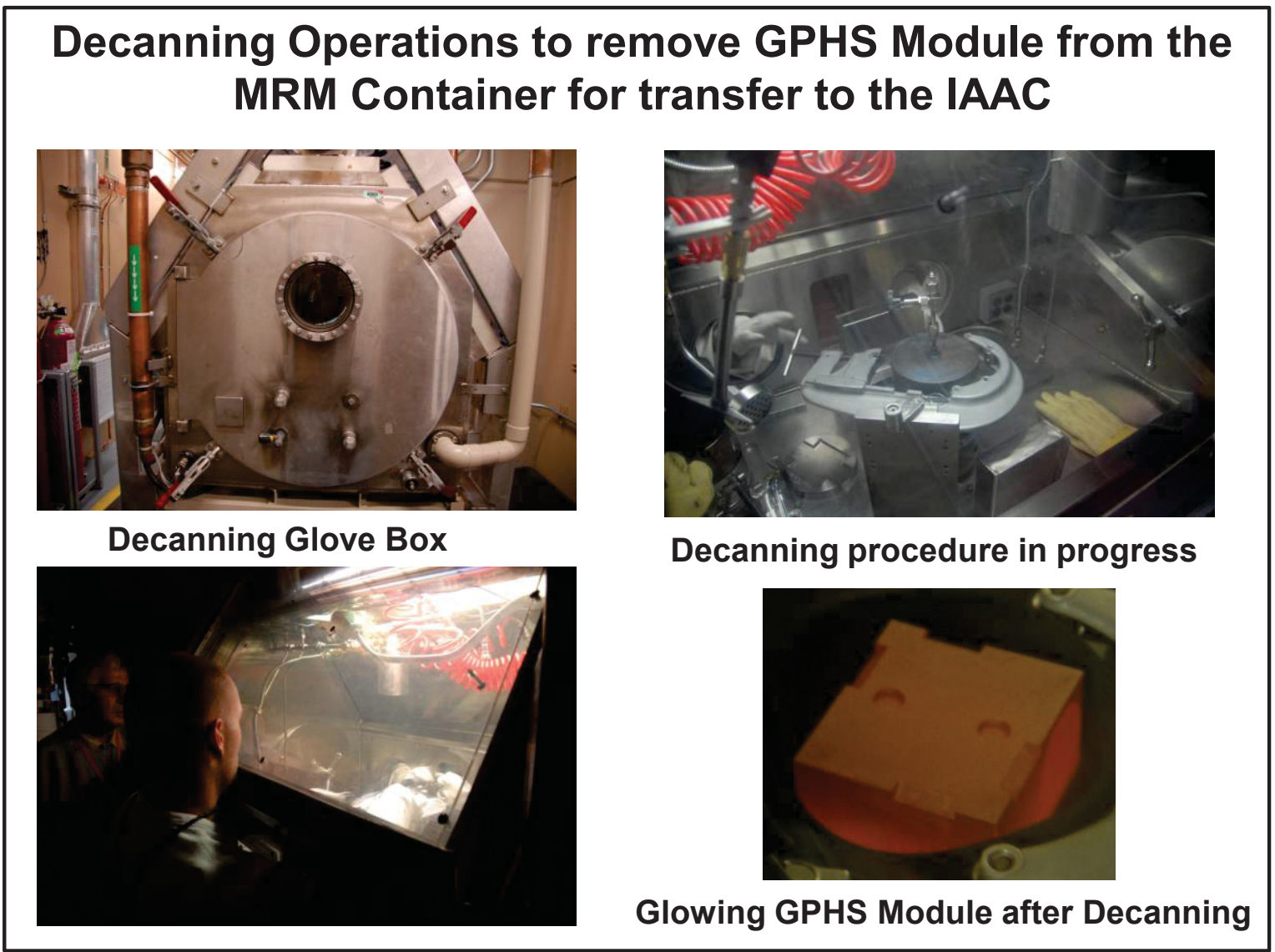

Figure 4-10. Decanning operations to remove GPHS module from the MRM container. 
The final fueling and assembly of a MMRTG is shown in the following sequence of steps (Figures 4-11 through 4-15). The entire assembly takes place in the IAAC. The inert atmosphere established in the IAAC before the GPHS modules are introduced prevents back leakage of oxygen into the $\mathrm{Pu}^{238}$ fuel clads, which could invalidate the MRM process.

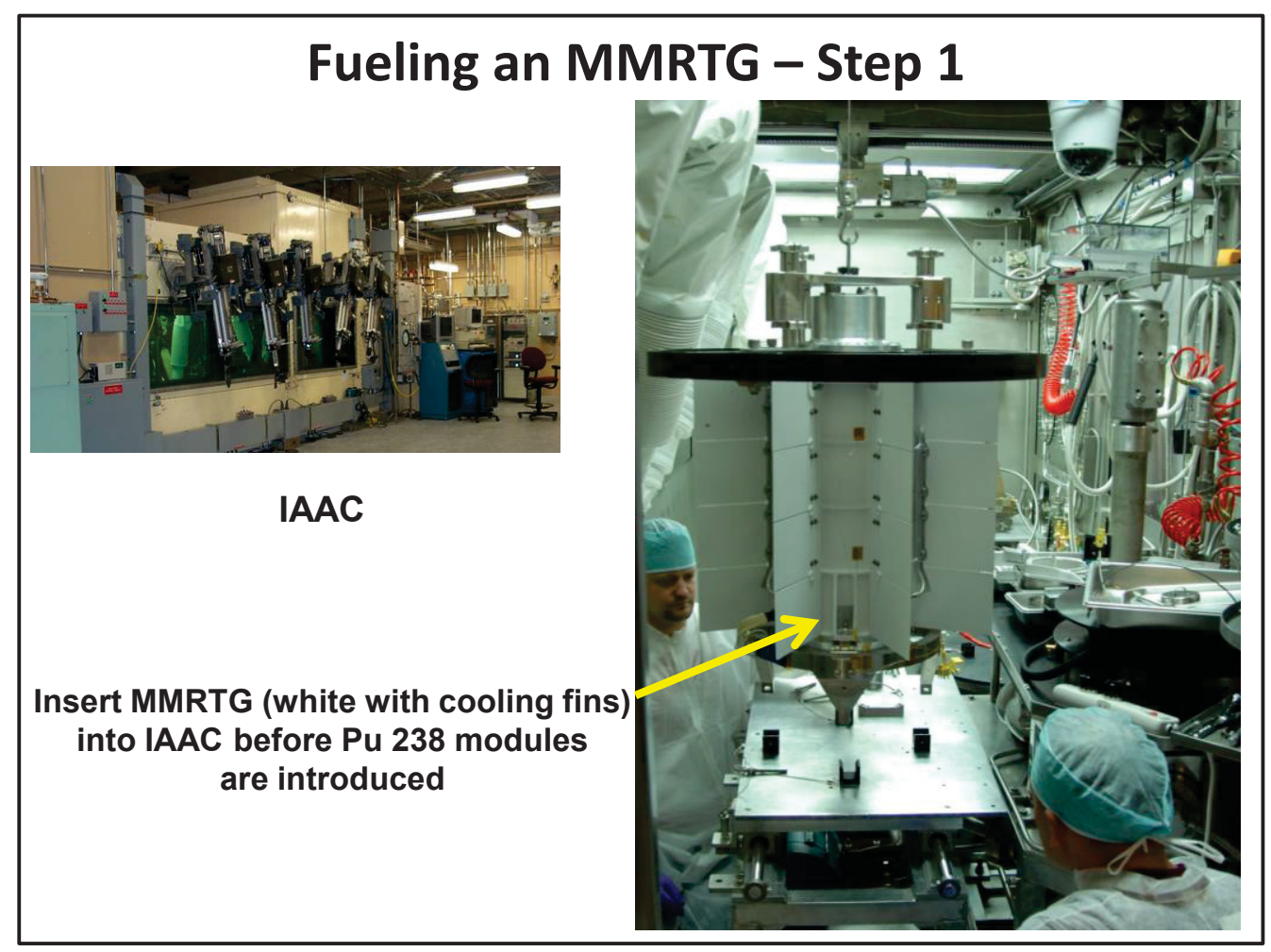

Figure 4-11. Fueling an MMRTG - Step 1. 


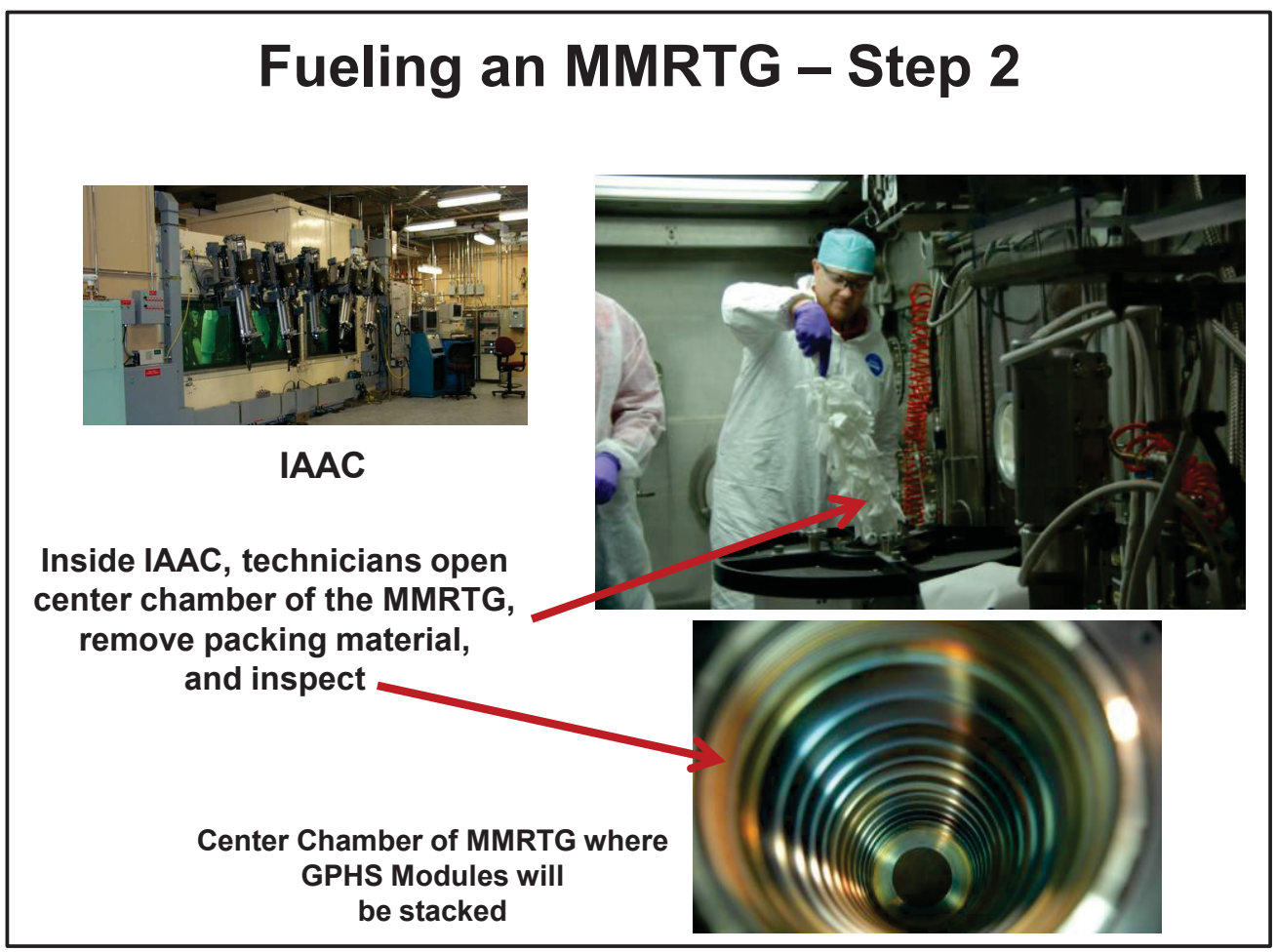

Figure 4-12. Fueling an MMRTG - Step 2.

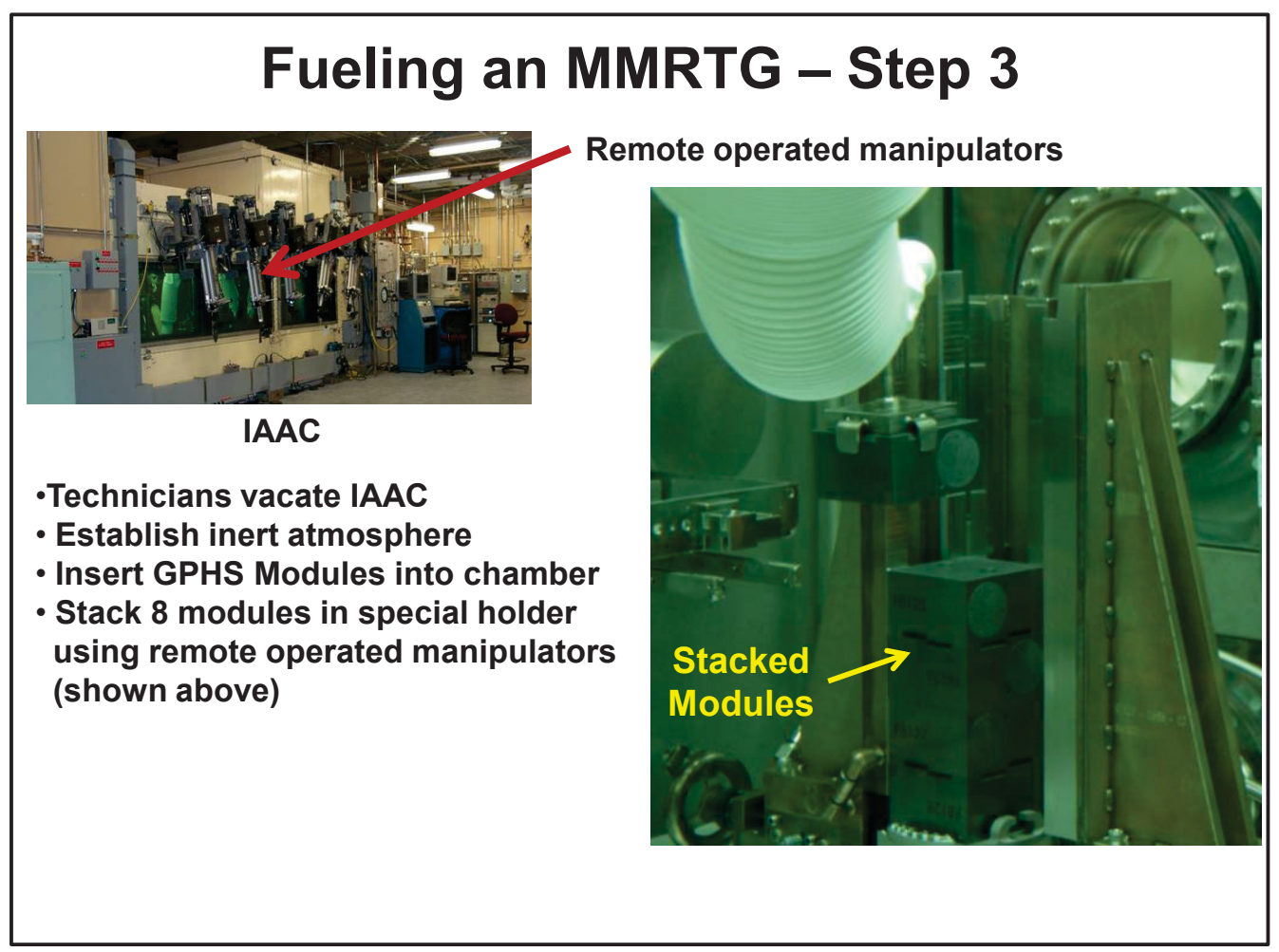

Figure 4-13. Fueling an MMRTG - Step 3. 


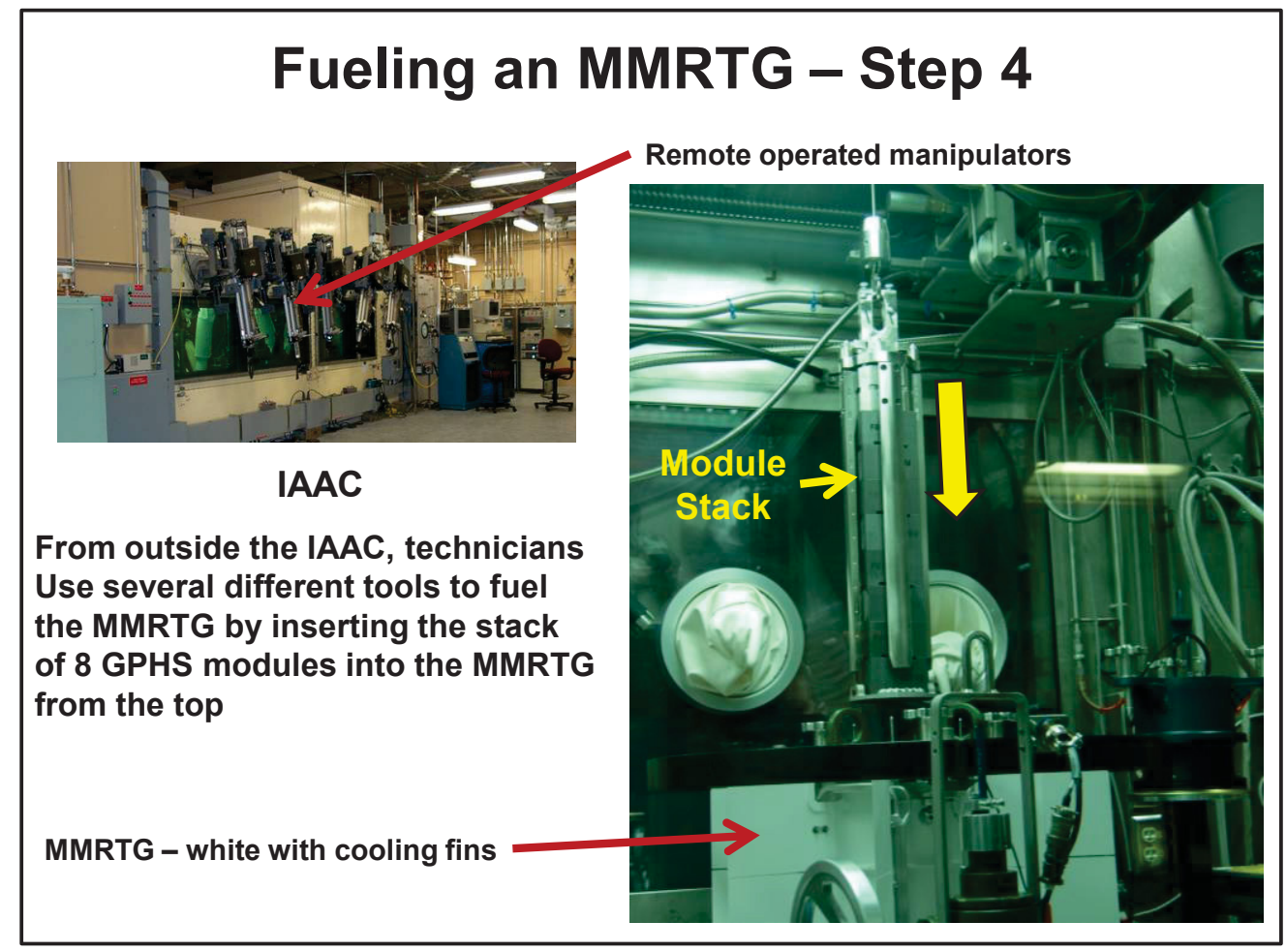

Figure 4-14. Fueling an MMRTG - Step 4.

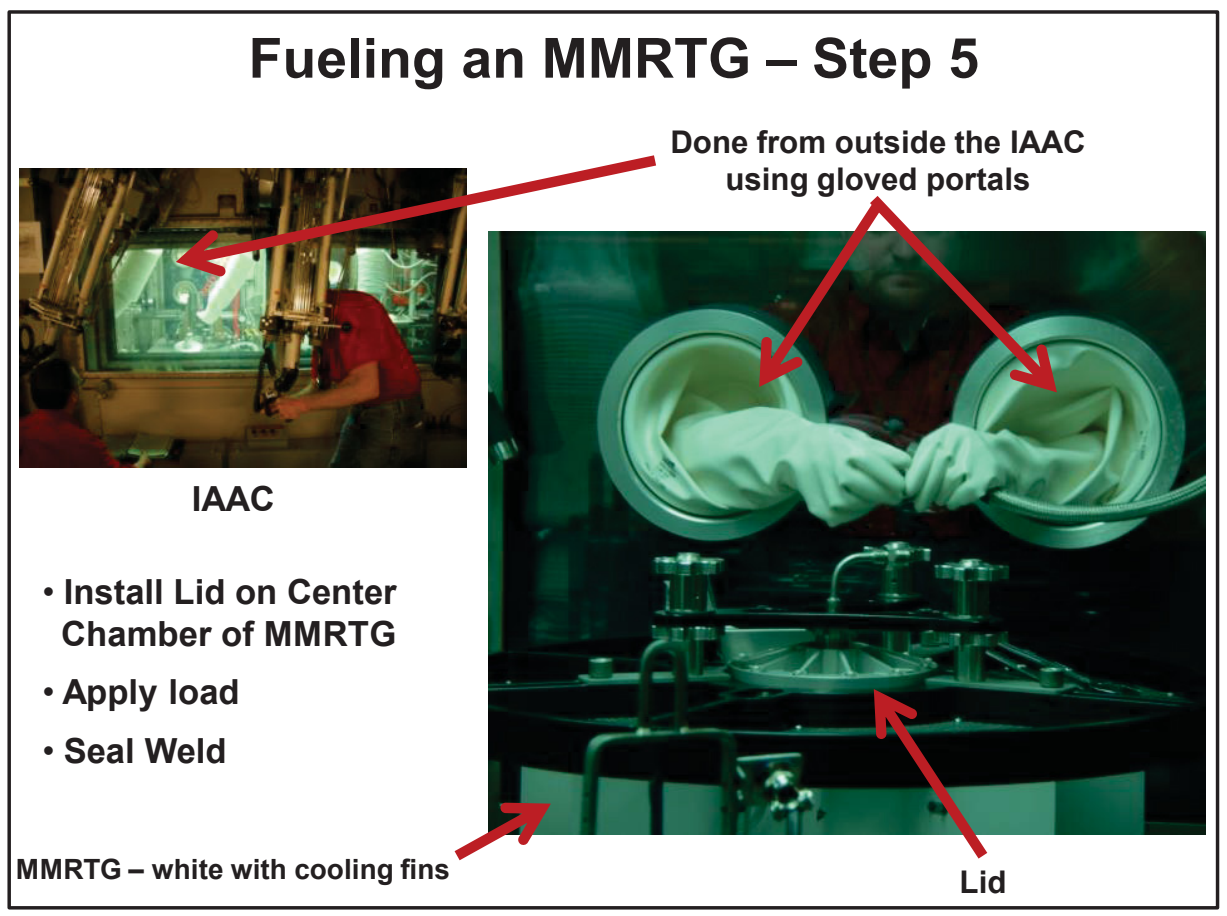

Figure 4-15. Fueling an MMRTG - Step 5. 


\section{RPS Closure and Seal Welding}

- Fueling lid Installed

- Pre-load applied with compression tool

- Helium gas exchanged in fueling cavity

- Seal plug weld

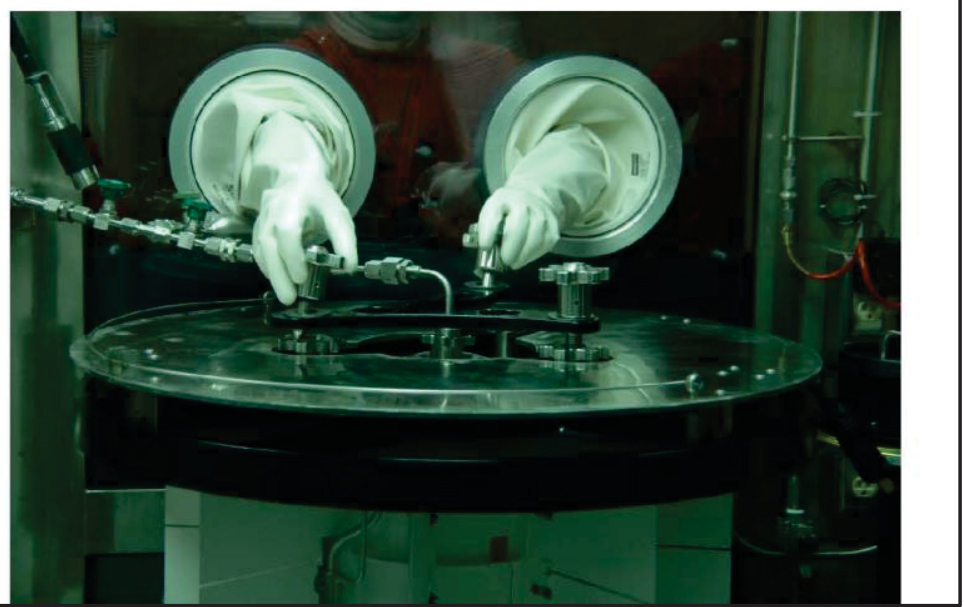

Figure 4-16. Final assembly of MMRTGs at the IAAC.

\subsection{MMRTG Testing and Measurements}

\subsubsection{Vibration and Shock Testing}

The vibration and shock testing of MMRTGs simulates the physical environment that will be encountered during launch. The MMRTG is mounted on the shaker equipment in the SSPSF (Figure 4-17). Once in place and all instrumentation connections have been made, the test is controlled remotely from a complex control panel capable of simulating a variety of conditions. 


\section{Vibration Testing}

- RPS mounted for vibration testing

- RPS subjected to proto-flight vibration test environments in the $\mathrm{X}, \mathrm{Y}$, and $\mathrm{Z}$ axis orientations

- Test objectives:

- Power output remains unchanged

- Frequency shifts of $<5 \%$ are seen in primary frequencies indicating that no components moved or displaced under load

- Before and after entire test sequence, ensure power circuit and instrumentation remain electrically isolated
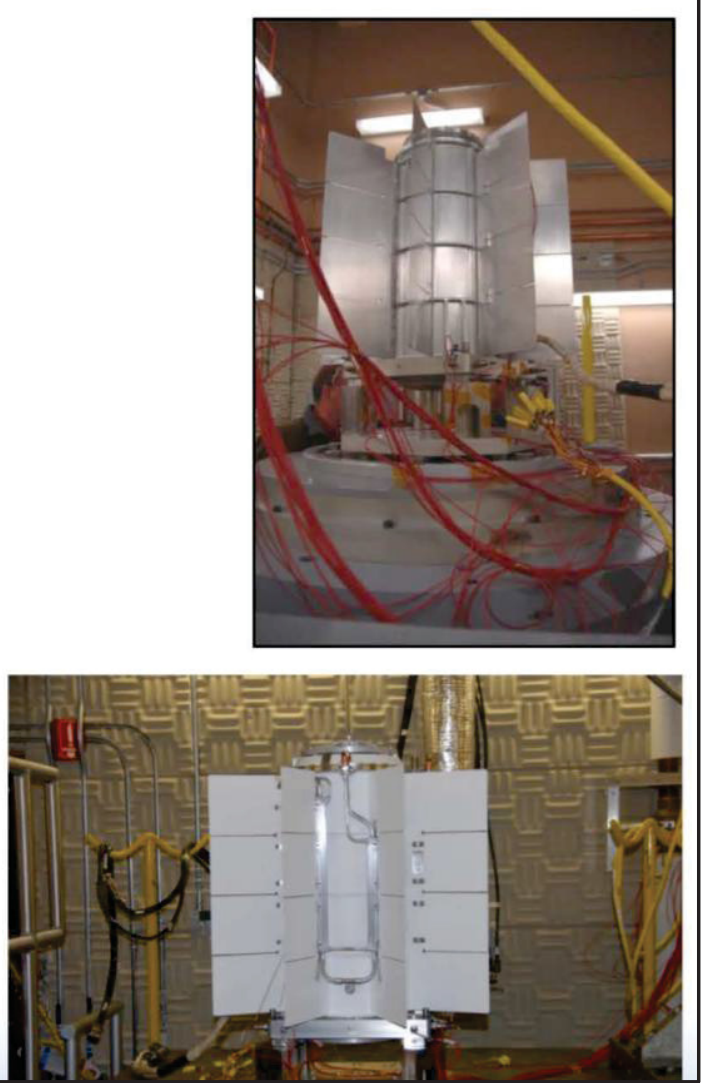

Figure 4-17. Vibration and shock testing table and facility.

\subsubsection{Thermal Vacuum Testing}

Thermal vacuum testing is performed using the thermal vacuum chamber (TVC) in the SSPSF (Figure 4-18). The TVC is designed to operate at high vacuum and low temperatures to determine the operating characteristics of an assembled MMRTG in a simulated space environment.

The cooling function has to date been provided by a simple water jacket on the outside of the chamber. The inside temperature has been a less than desired approximation of the conditions in space. This has required mathematical extrapolations of the data. A modification to the TVC is planned to incorporate a cryogenic liquid nitrogen shroud that will significantly improve cooling performance to provide a better approximation of the cold in space. This will reduce the extrapolation of data needed. 


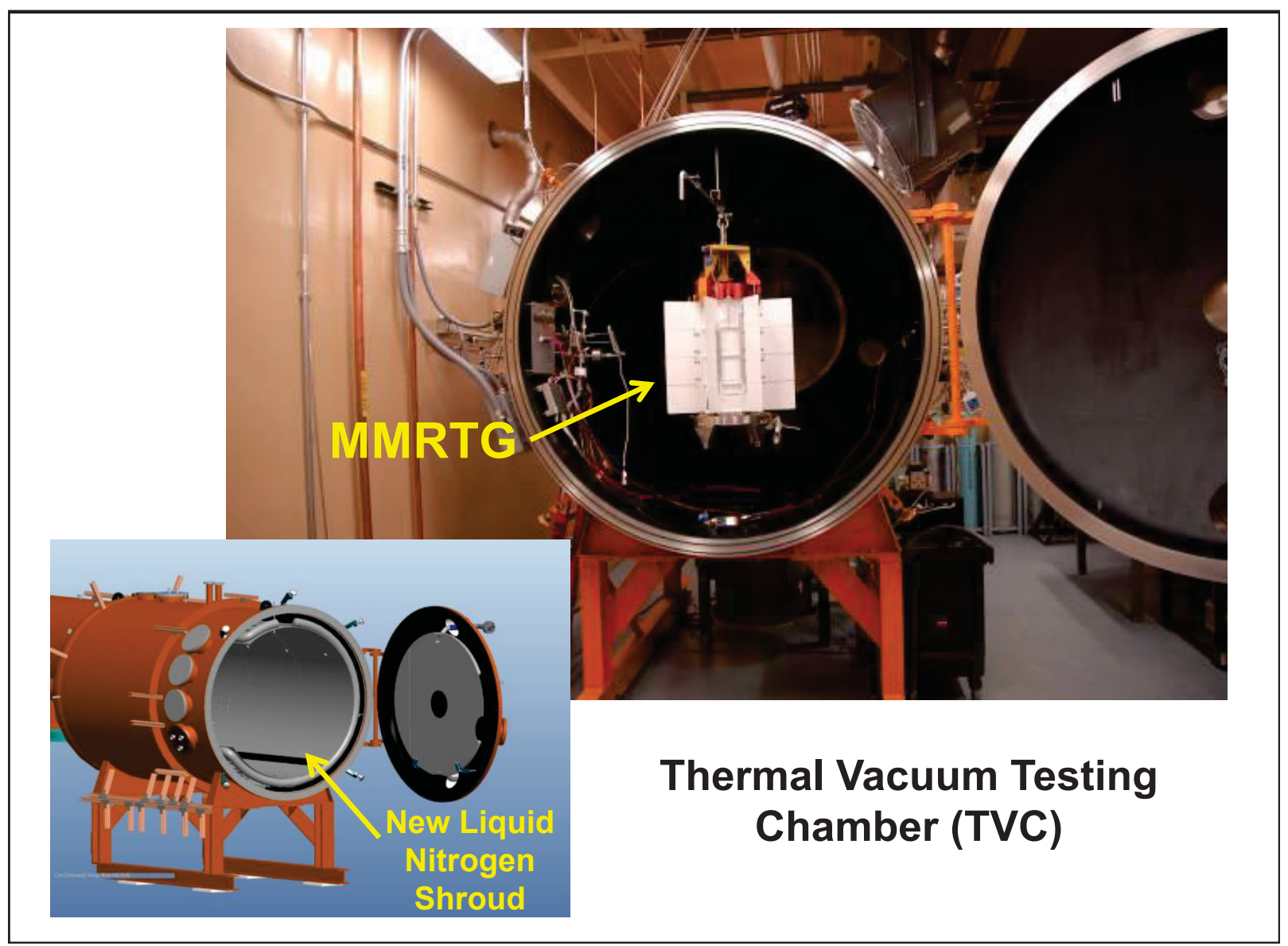

Figure 4-18. Thermal vacuum testing chamber.

\subsubsection{Magnetic Testing}

An inherent magnetic field associated with an RPS can interfere with the performance of sensitive instruments on the spacecraft. Magnetic measurements are conducted to detect and measure any magnetic field that may be present (Figure 4-19). If determined necessary by these measurements, the magnetic signature will be adjusted by energizing special coils placed around the RPS. This operation normally only requires a few seconds. 


\section{Magnetic Testing Facility}

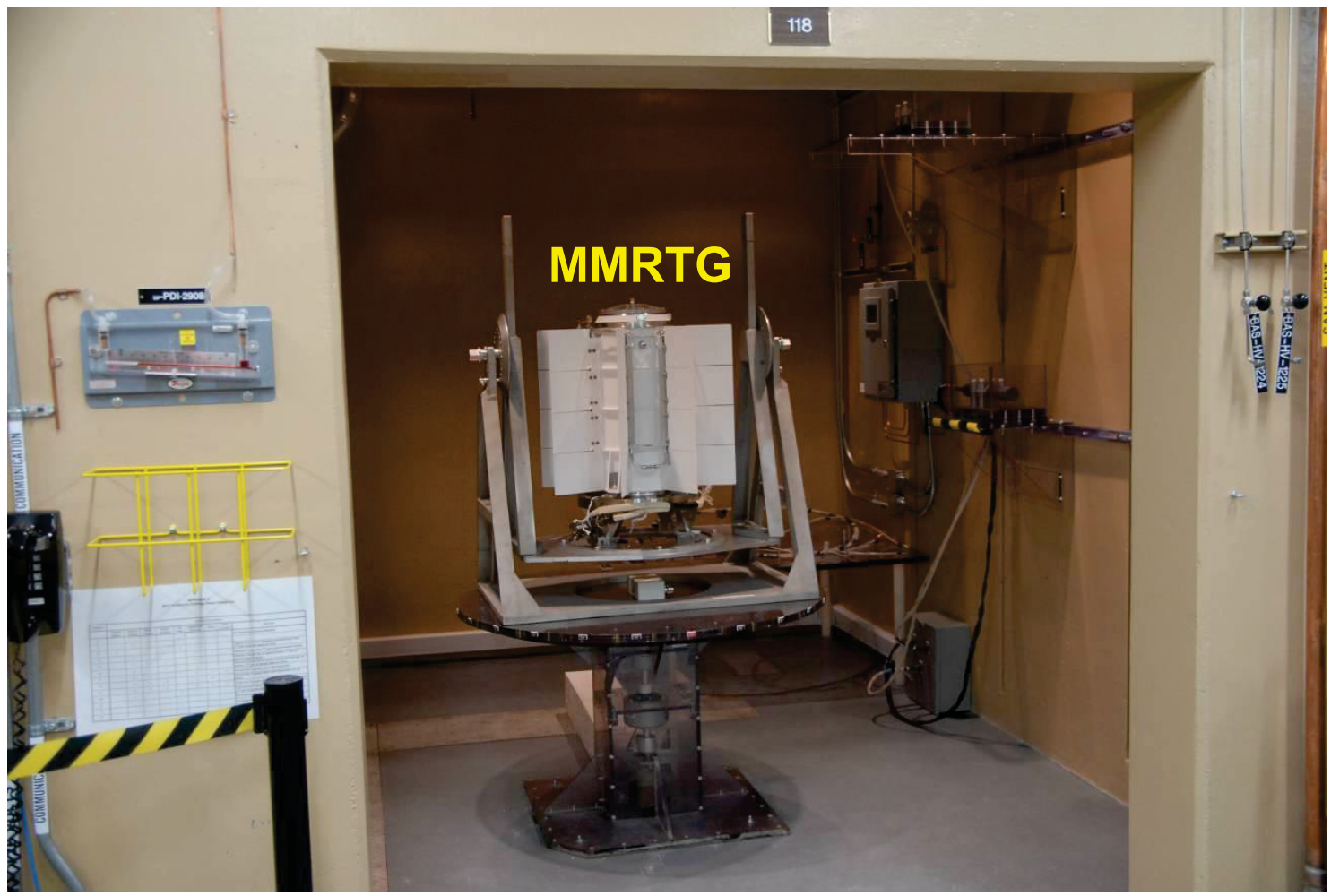

Figure 4-19. Magnetic testing facility.

\subsubsection{Mass Property Measurement}

The MMRTG Mass Property Measurement Facility (Figure 4-20) is located in the SSPSF. The mass property tests are used to determine the mass, center-of-gravity, and moment-of-inertia of the MMRTG. This is essential information needed by NASA engineers for calculating launch parameters and for planning precise maneuvering of the spacecraft during the mission. 


\section{Mass Property Measurement Facility}

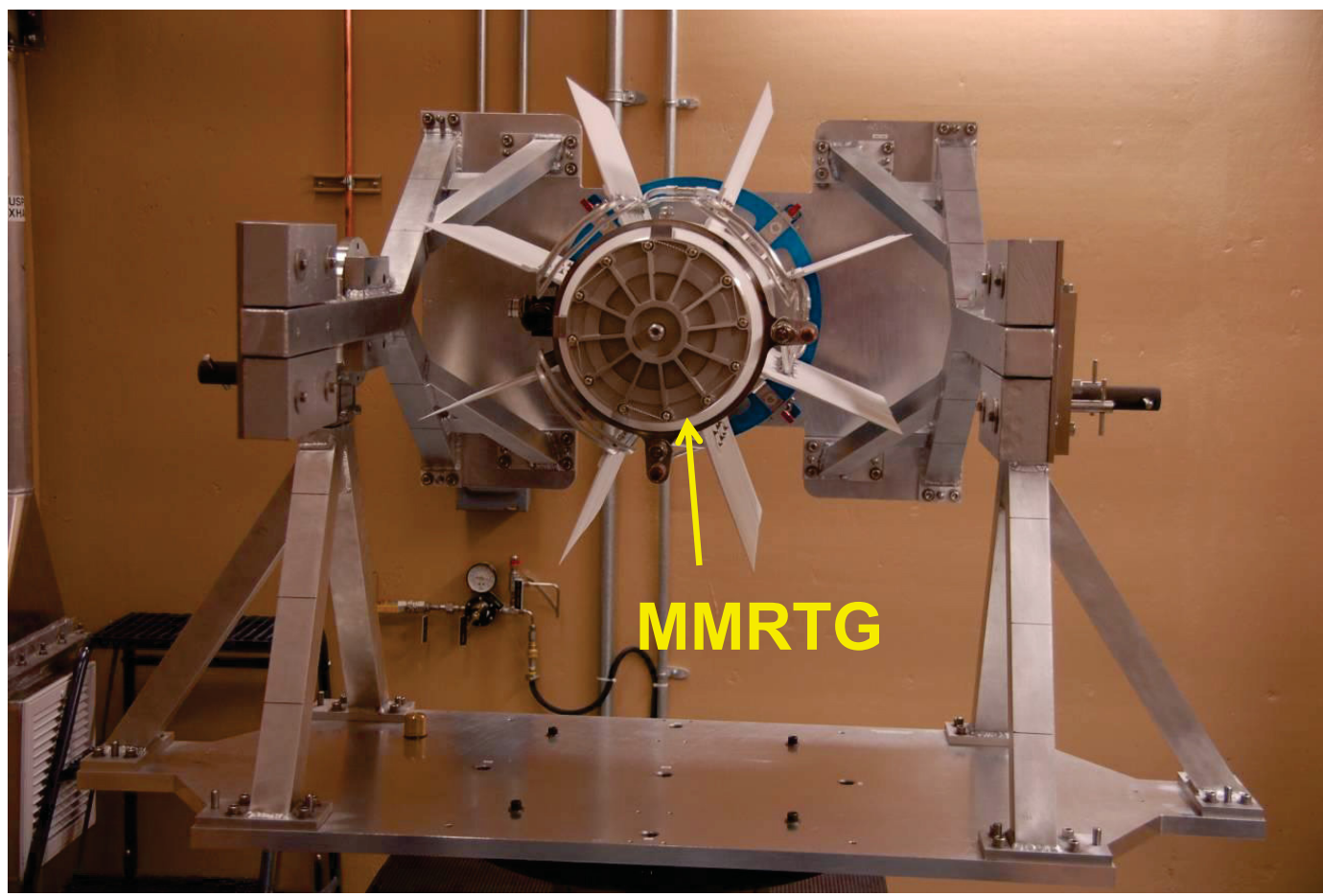

Figure 4-20. Mass Property Measurement Facility.

\subsection{Planned ASRG Fueling and Final Assembly}

The fueling and final assembly of the ASRGs will be conducted in the Multi-Purpose Fueling Glovebox (MPFG) (Figure 4-21) located in the SSPSF. It will support NASA's Discovery 12 mission planned for launch in 2016. This will be the first of NASA's missions using an ASRG. 


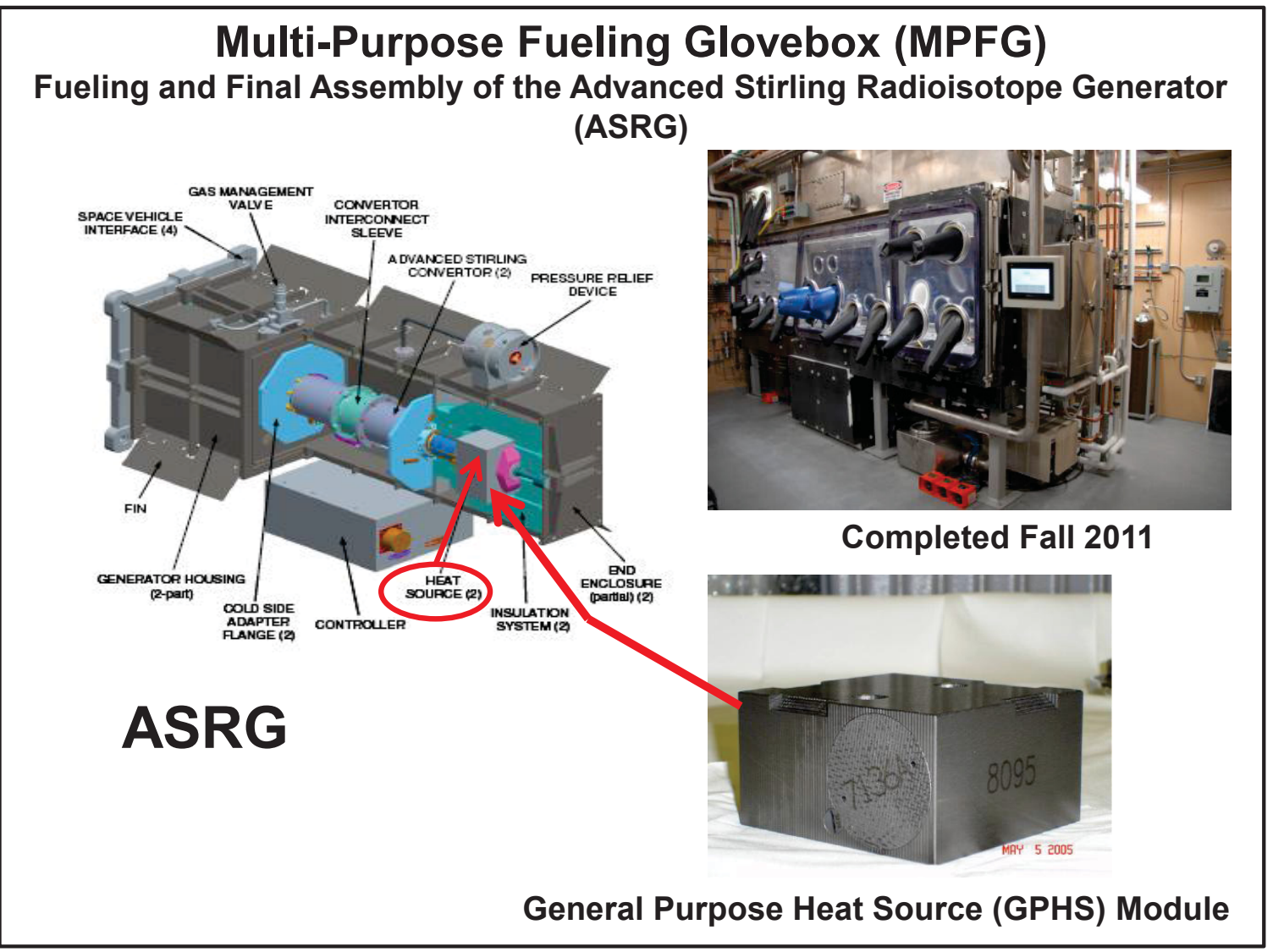

Figure 4-21. Fueling and final assembly of the ASRG in the MPFG.

\subsection{Welding of 9516 Product Cans for Shipping $\mathrm{Pu}^{238}$}

\subsubsection{Vacuum/Inert Atmosphere Welding Glovebox}

Welding associated with final construction and seal welding of 9516 product cans are conducted in the Vacuum/Inert Atmosphere Welding Glovebox (Figure 4-22) located in the SSPSF. 


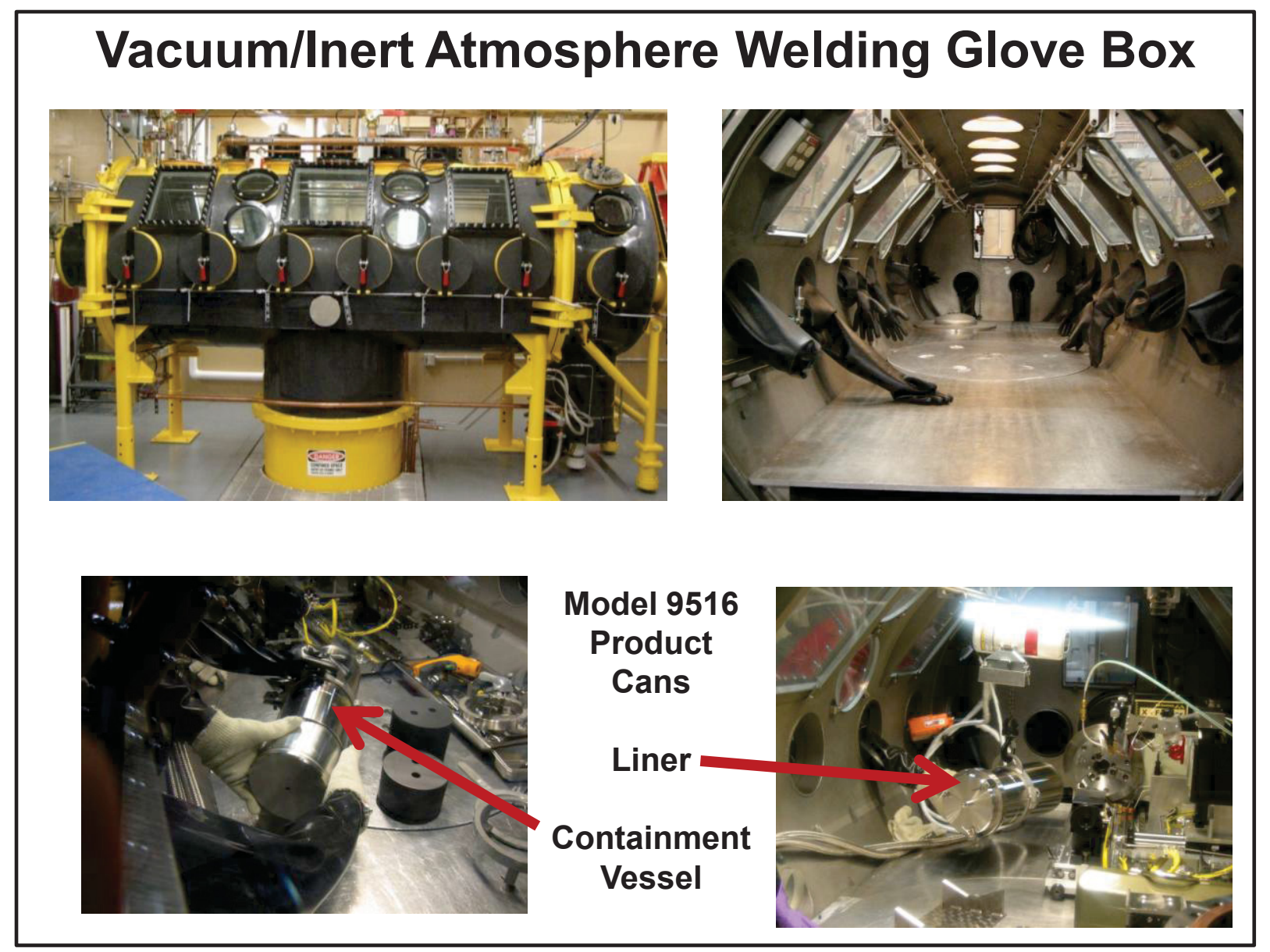

Figure 4-22. Vacuum/Inert Atmosphere Welding Glovebox.

\subsubsection{Model 9516 Product Cans}

Model 9516 product cans are used for shipping GPHS FCs between LANL and INL. The 9516 product cans are manufactured at INL. The cans meet Title 10, Code of Federal Regulations (CFR), Section 71 (10 CFR 71) requirements for shipping $\mathrm{Pu}^{238}$. The 9516 has two components: (1) a liner and (2) a containment vessel. Open containers are sent to LANL for their use in shipping GPHS FCs to INL and by the INL if GPHS FCs need to be returned to LANL. Prior to shipping of GPHS FCs, the 9516 product cans are seal welded either at LANL or in this glovebox at INL.

\subsubsection{Model 9516 Shipping Packages}

INL is the custodian of 20 Model 9516 shipping packages used to transport radioactive materials between facilities (i.e., INL, LANL, and Russia). This includes manufacturing, maintaining, inspecting, and shipping the package in accordance with 10 CFR 71 requirements. Additionally, INL maintains the Safety Analysis Report for Packaging (SARP).

The shipping package is shown in Figure 4-23. It consists of a steel frame and internal support structure in the shape of a cube with heavy wire mesh covering all sides. It is designed to hold one Model 9516 product can securely mounted in the interior. 


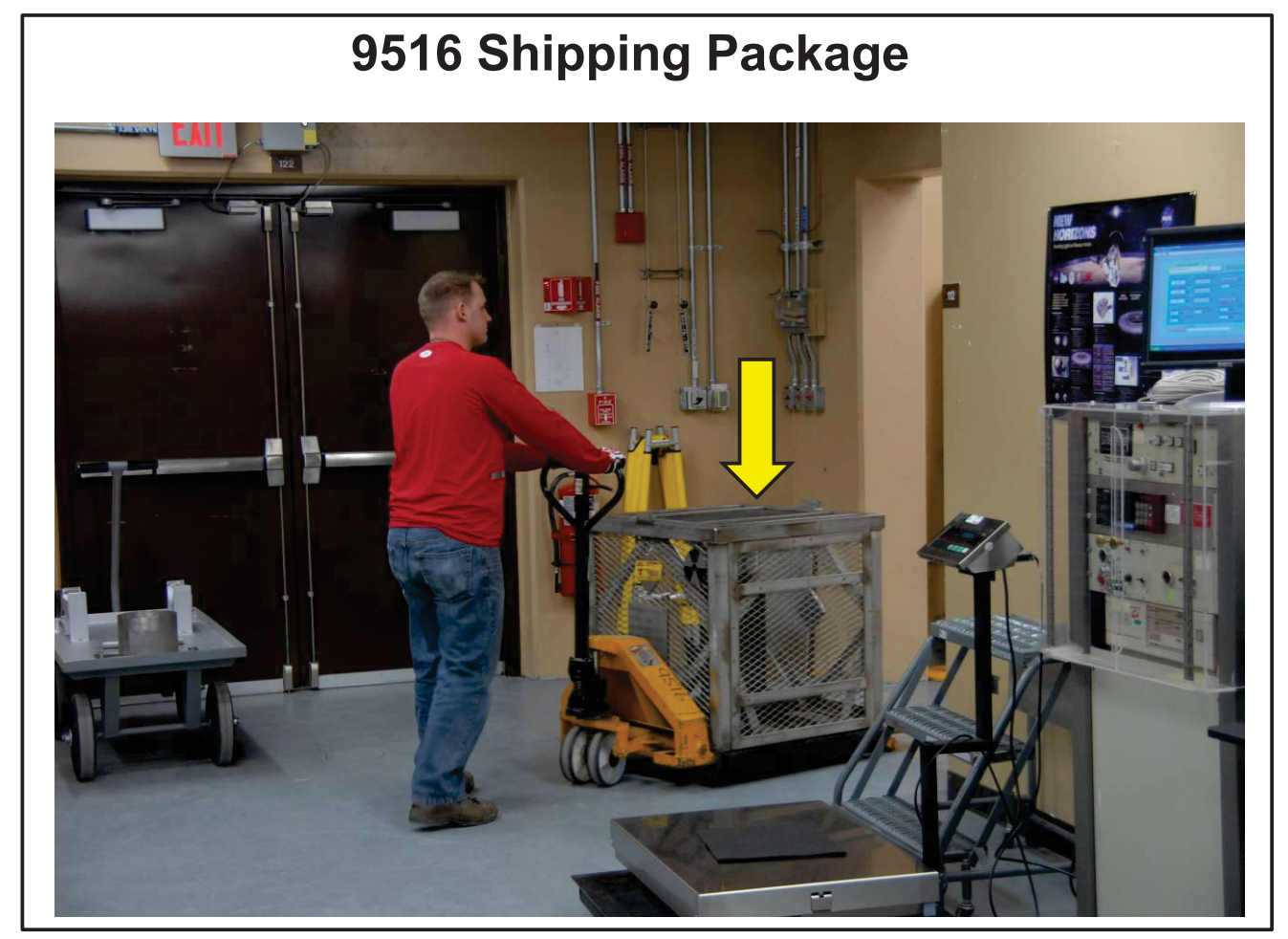

Figure 4-23. Model 9516 shipping package.

\subsection{Shipping of RPSs}

INL is custodian of three Model 9904 shipping packages (Figure 4-24) used to transport the RPS between INL and user sites. This includes maintaining, inspecting, and shipping the package in accordance with 10 CFR 71 requirements. Additionally, INL maintains the SARP, which currently meets the requirements. The cask provides shielding and redundant cooling systems.

The Model 9904 shipping packages are transported to the user sites. The INL is custodian of two RTGTSs used to transport Model 9904 shipping packages. Custodianship requires that all maintenance, inspection, and operations be conducted on the RTGTS, as required. The exclusive-use semitrailer and on-board support systems are necessary when transporting an RPS from INL to user sites. The semitrailer system is divided into five subsystems:

1. Semitrailer

2. Power supply

3. Instrumentation and data acquisition

4. Package temperature control

5. Package mounting.

The RTGTSs (Figure 4-25) and Model 9904 shipping packages are stored in Building INTEC-B21-265 (Figure 4-26), which provides a training area for this equipment. 


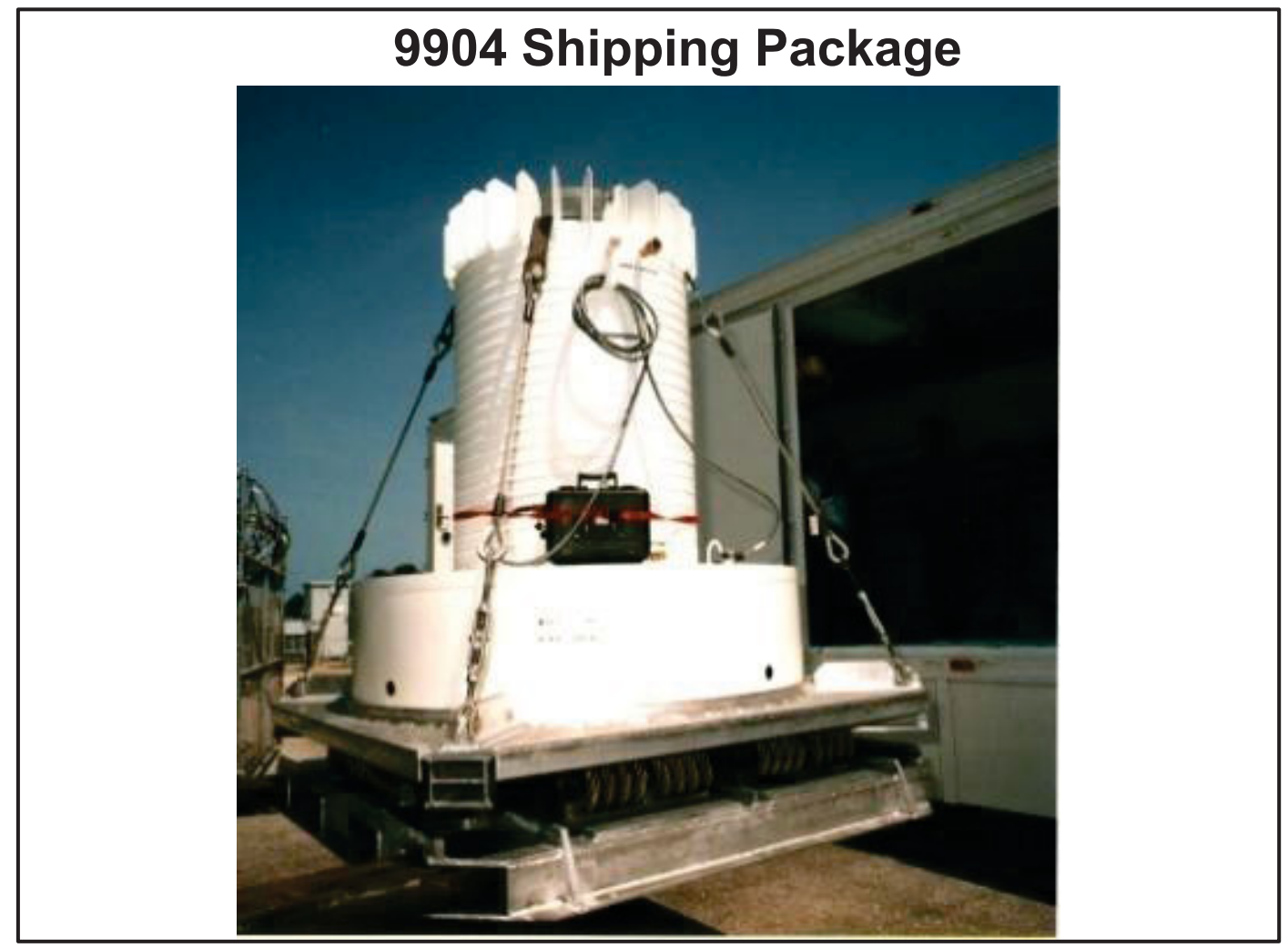

Figure 4-24. Model 9904 shipping package.

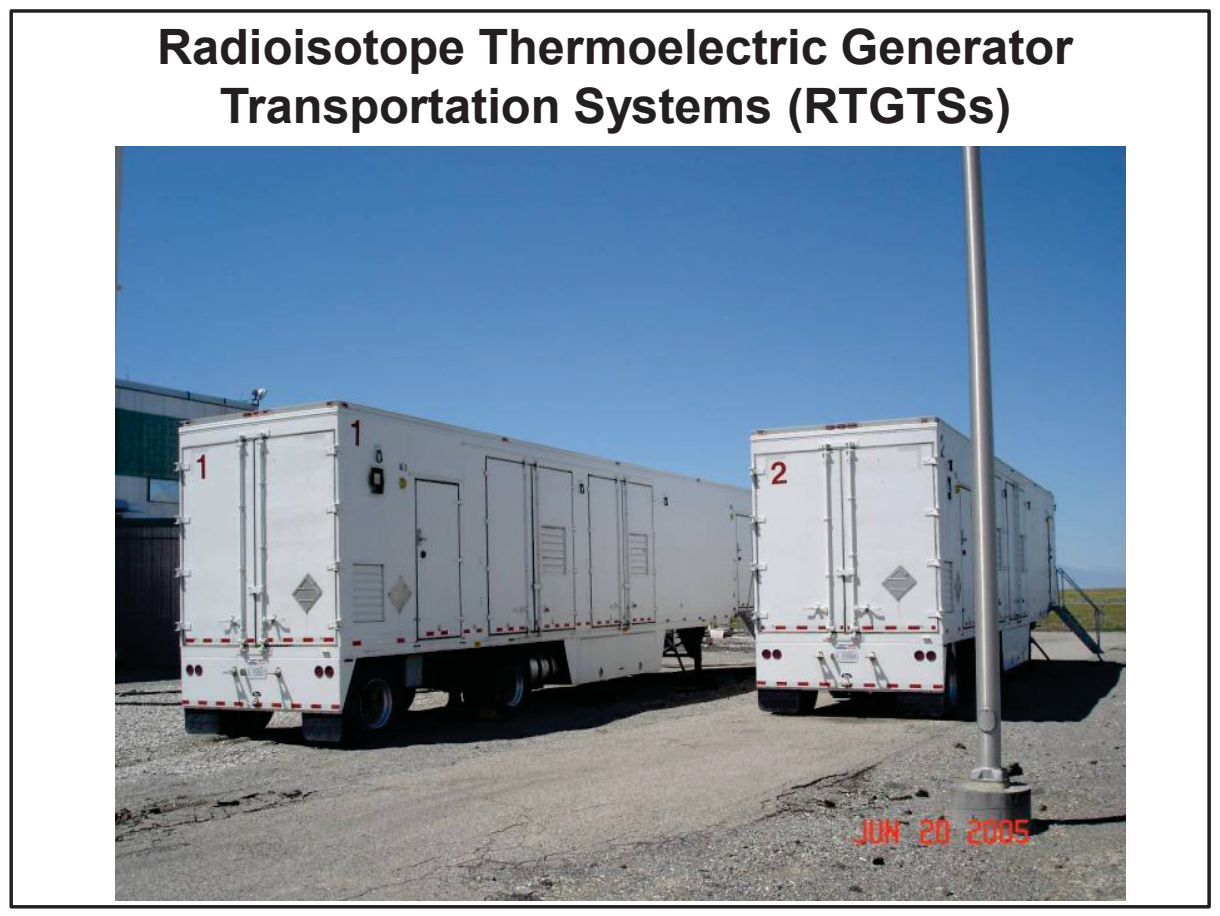

Figure 4-25. RTGTSs used to transport Model 9904 shipping packages. 

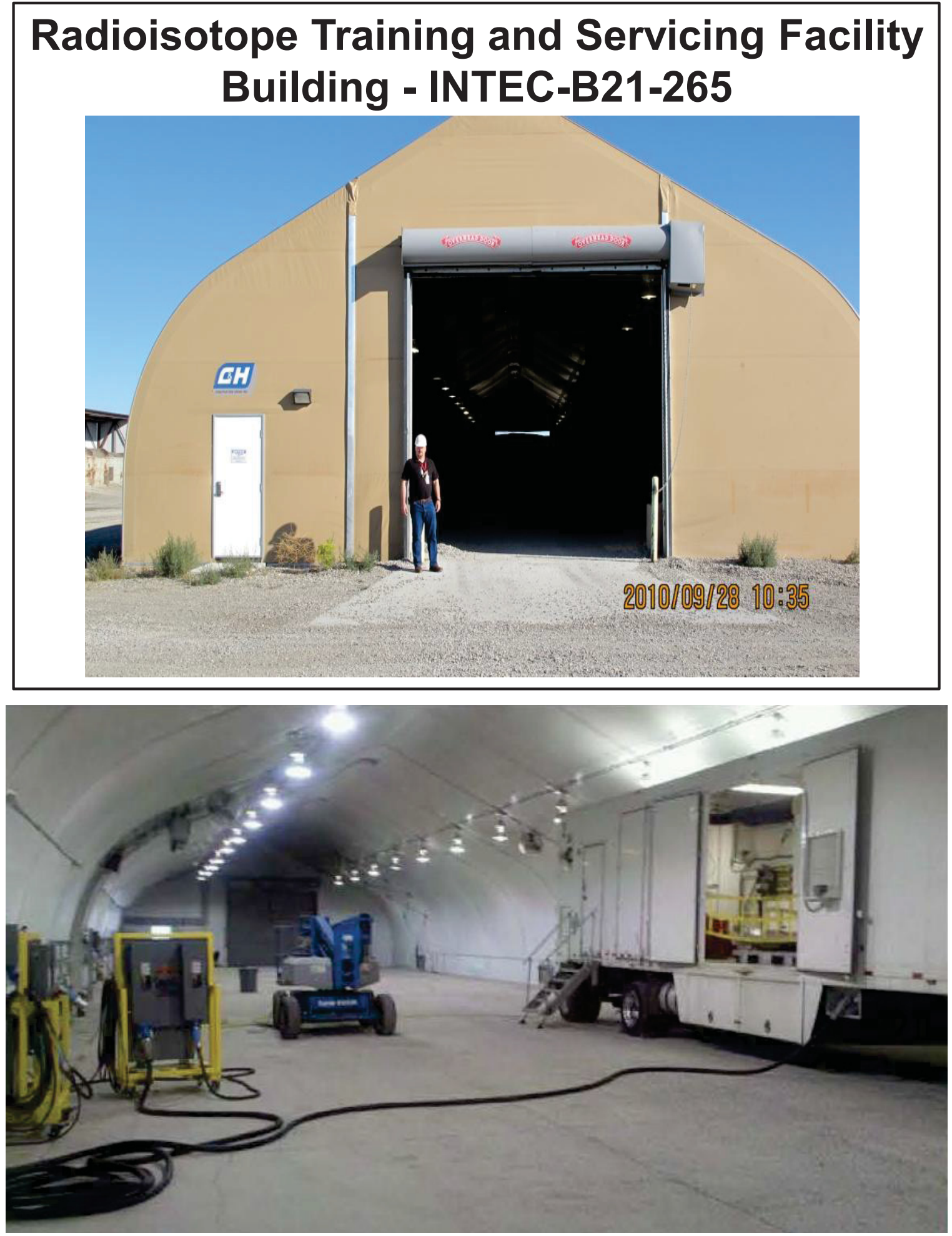

Figure 4-26. Building INTEC-B21-265. 


\section{KENNEDY SPACE CENTER OPERATIONS}

\subsection{Overview}

When a space mission using RTGs is planned by NASA, a team from the NE SDPS (NE-75) provides significant support for the launch operations at KSC. This team is made up of both federal staff members and contractor personnel, primarily from INL.

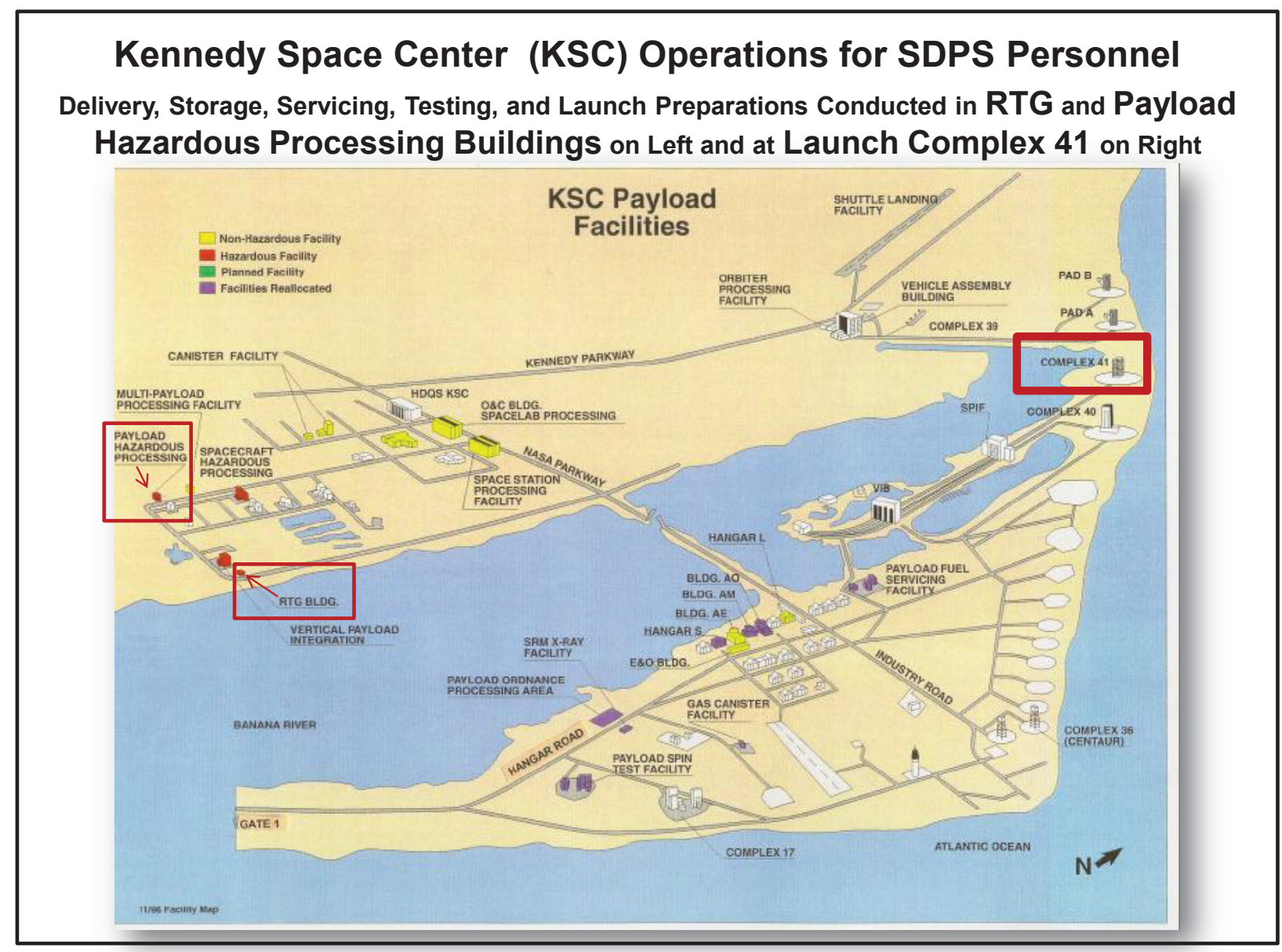

Figure 5-1. KSC operations for SDPS personnel.

\subsection{Activities Prior to Shipment to the KSC}

DOE continues to maintain ownership and safety responsibility for RTGs even after shipment to KSC and launch. It is necessary for the facilities and ground transportation plans at KSC to be compliant with the nuclear safety management requirements in 10 CFR 830, "Nuclear Safety Management." This requires, among other actions, that a Documented Safety Analysis (DSA) be written, reviewed, approved, and implemented by DOE. The writing of this DSA typically begins approximately 2 to 3 years prior to launch and should be approved approximately 8 to 12 months prior to launch to allow adequate time for implementation. This document thoroughly analyzes the safety of the nuclear material contained within the RTG unit by taking into consideration the specific environmental conditions present in the facilities 
and the planned actions to be performed with the RTG unit, which include any movements between facilities on the KSC site. All actions with the RTG unit are strictly regulated by written procedures, and any changes to those procedures are subject to an Unreviewed Safety Question (USQ) evaluation in accordance with 10 CFR 830.

An important activity that interacts with the DSA is a full dress rehearsal that occurs approximately 12 to 18 months prior to launch. This involves all parties that will handle the RTG unit during its time at KSC. This event is frequently "shadowed" by the team writing the DSA so that all activities and potential hazards are analyzed in the DSA. This rehearsal also allows for planning and establishment of an effective liaison between the various agencies involved, including NASA-KSC, United Launch Alliance (ULA), Jet Propulsion Laboratory (JPL), Applied Physics Laboratory (APL), and the DOE team.

\subsection{Shipment to the KSC}

Upon completion of the fueling and testing sequence and inclusion of the radioisotope power supply (RTG) unit as a certified payload in the Model 9904 shipping cask, it will be shipped to the KSC. Typical pre-launch arrival times vary but 4 to 6 months prior to launch allows adequate time for testing and other pre-launch activities. The Model 9904 shipping cask is designed to protect the RTG during transit from any hazards that might be encountered and to maintain the required storage conditions. It is instrumented for monitoring the status of the RTG at all times and provided environmental control. The RTG is transported from INL, where it was manufactured and stored, to the KSC on board a specially designed trailer called the RTGTS. The RTGS has independent, redundant electrical power supplies, instrumentation for monitoring the RTG, and a cooling water system to supply the Model 9904 cask. Once the RTG unit is present at KSC, it is unloaded from the 9904 cask and stored in the RTG Facility (RTGF) Figure 5-2), which has been set aside for that purpose.
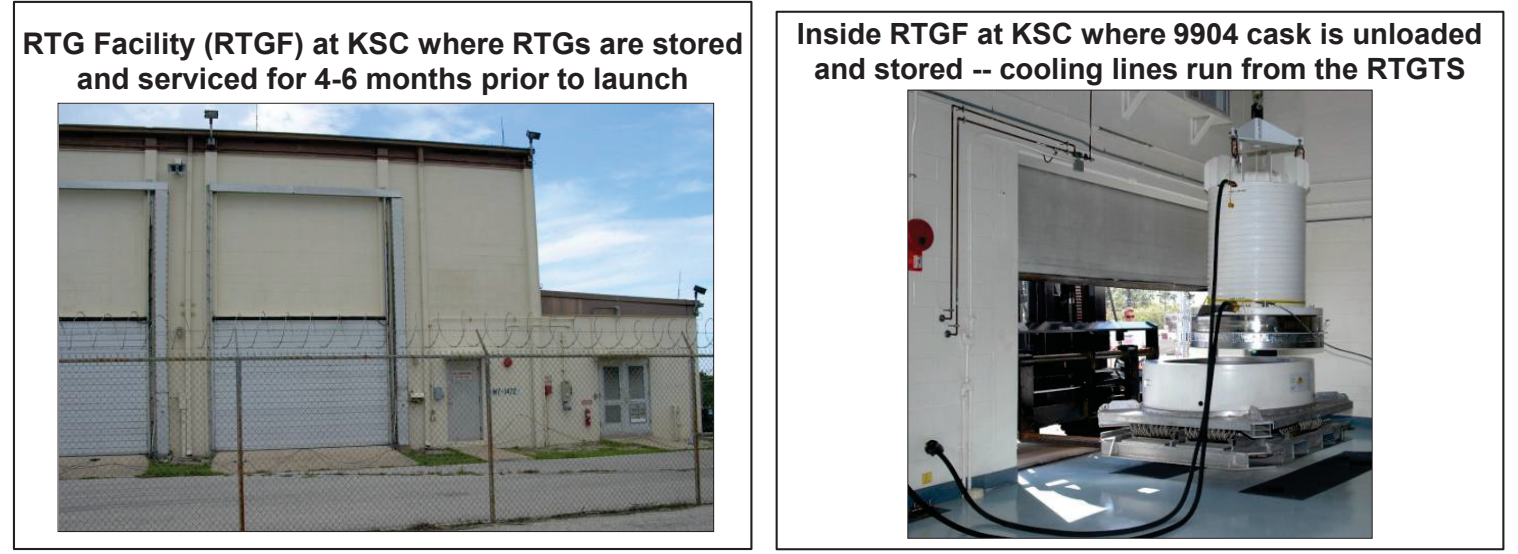

Figure 5-2. RTGF at KSC where RTGs are stored and serviced for 4 to 6 months prior to launch.

\subsection{Testing and Pre-launch Activities}

Between arrival at KSC and launch of the spacecraft, continuous support is required from the DOE launch team. This includes the following activities:

1. Maintaining the DSA so that all procedures are adequately reviewed and ready for use, 
2. Continuous monitoring of the status of the RTG,

3. Daily checks of the storage facility, and

4. Coordinating with organization managing the mission to address RTG specific questions and conduct required pre-launch tests at the Payload Hazardous Servicing Facility (PHSF).

\subsubsection{Wellness Check}

The wellness check (Figure 5-3) is a standard procedure that is undertaken as the first order of business at the RTGF. This check usually takes the form of a measurement or series of measurements of the output power and any other specific test desired for the particular RTG.

\section{Conducting Wellness Check in the RTGF at KSC}

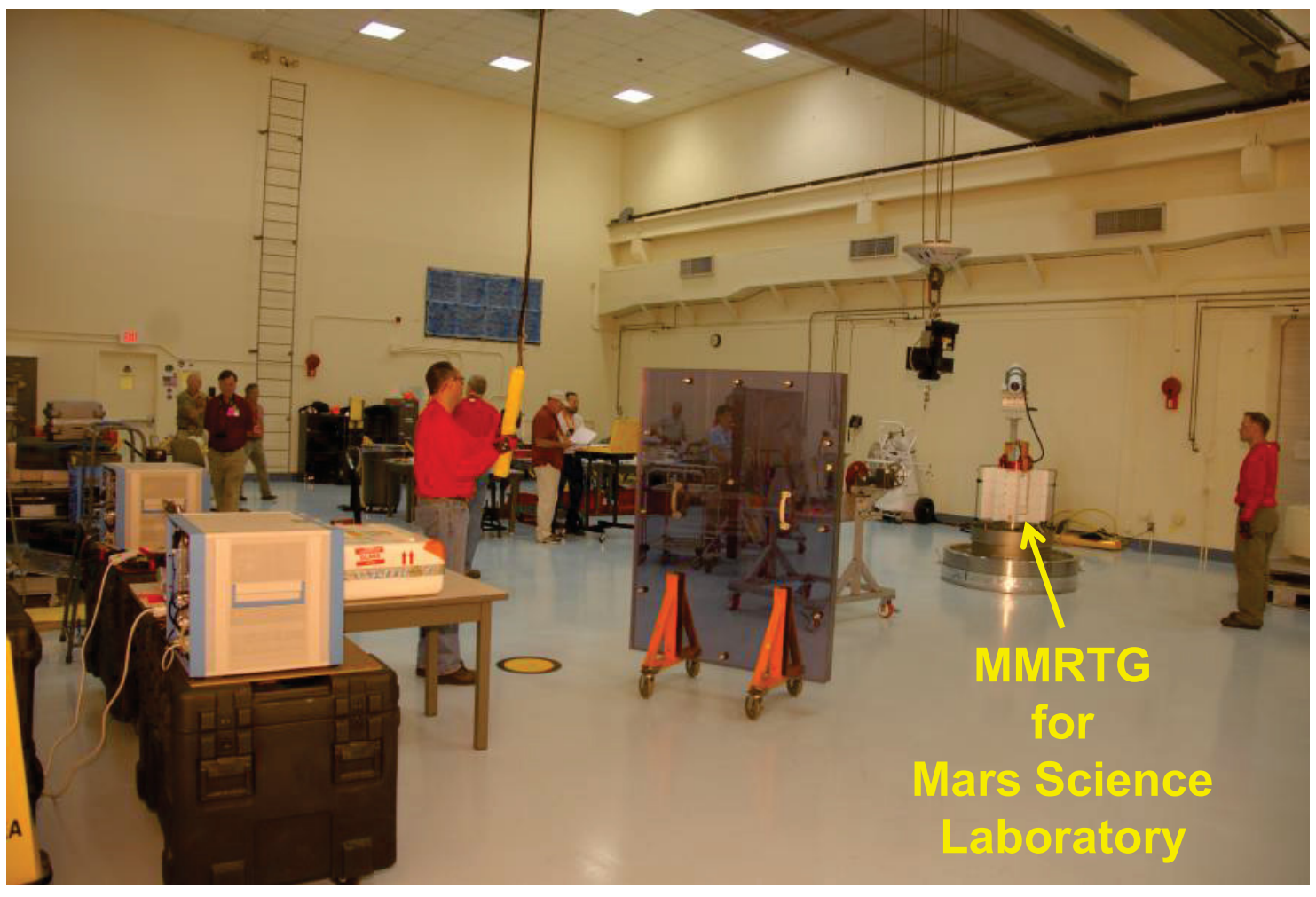

Figure 5-3. Wellness check activities at the KSC.

\subsubsection{Hot Fit Check}

In the hot fit check, the RTG is mated up with the space vehicle. This check is performed at the Payload Hazardous Servicing Facility (PHSF) (Figure 5-4). 


\section{Delivery of the RTG to the Payload Hazardous Servicing Facility (PHSF)}

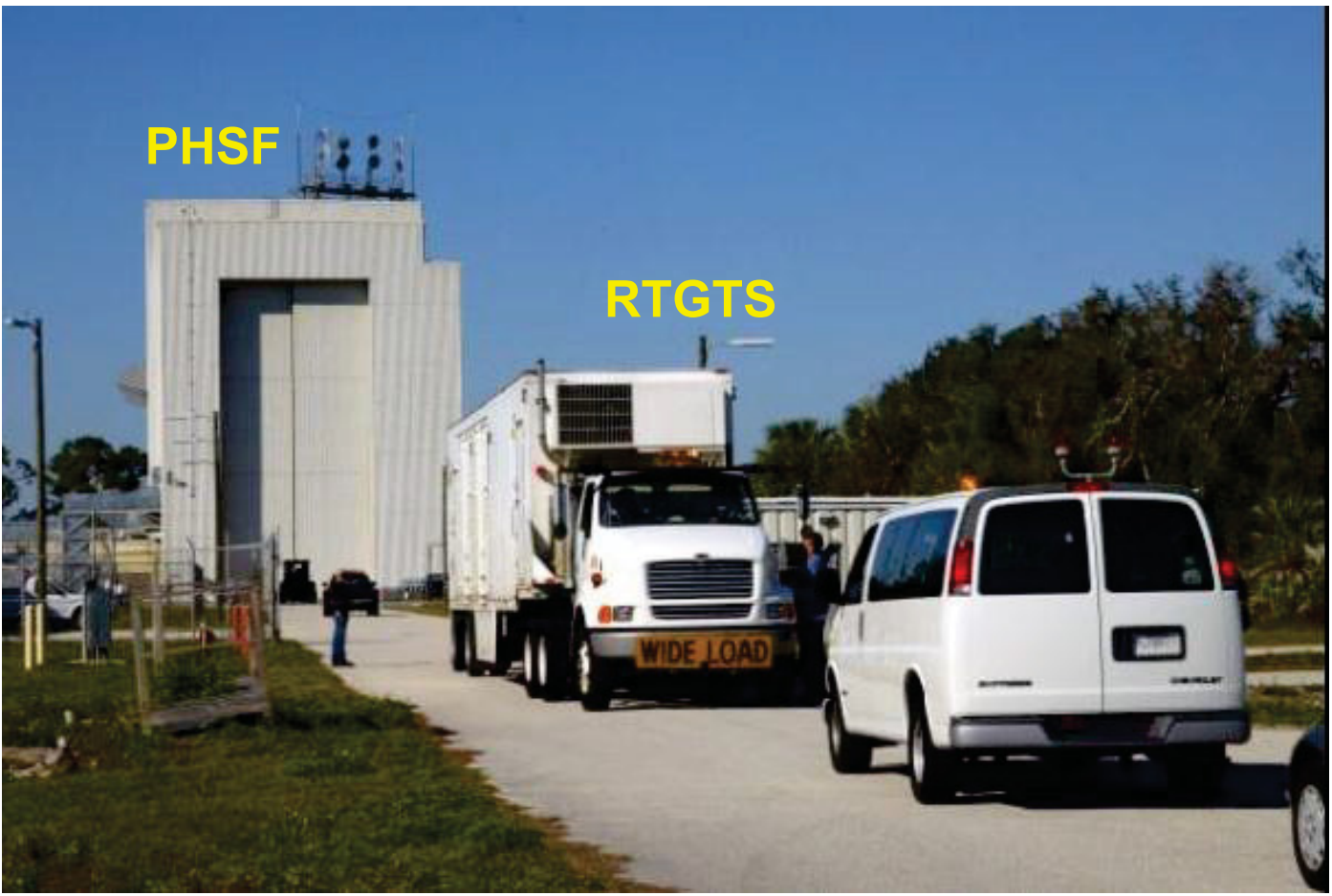

Figure 5-4. Delivery of the RTG to the PHSF.

This ensures that all equipment on the spacecraft that are to be powered by the RTG function as expected and that all procedures, tooling, and personnel are performing as required. Figures 5-5 through 5-7 highlight hot fit checks for the MMRTG used on the MSL, which was launched in November 2011. Figure 5-8 shows the hot fit check operations for the Pluto New Horizons mission launched in January 2006. During the hot fit checks, INL personnel are shown actively assisting the NASA team. 


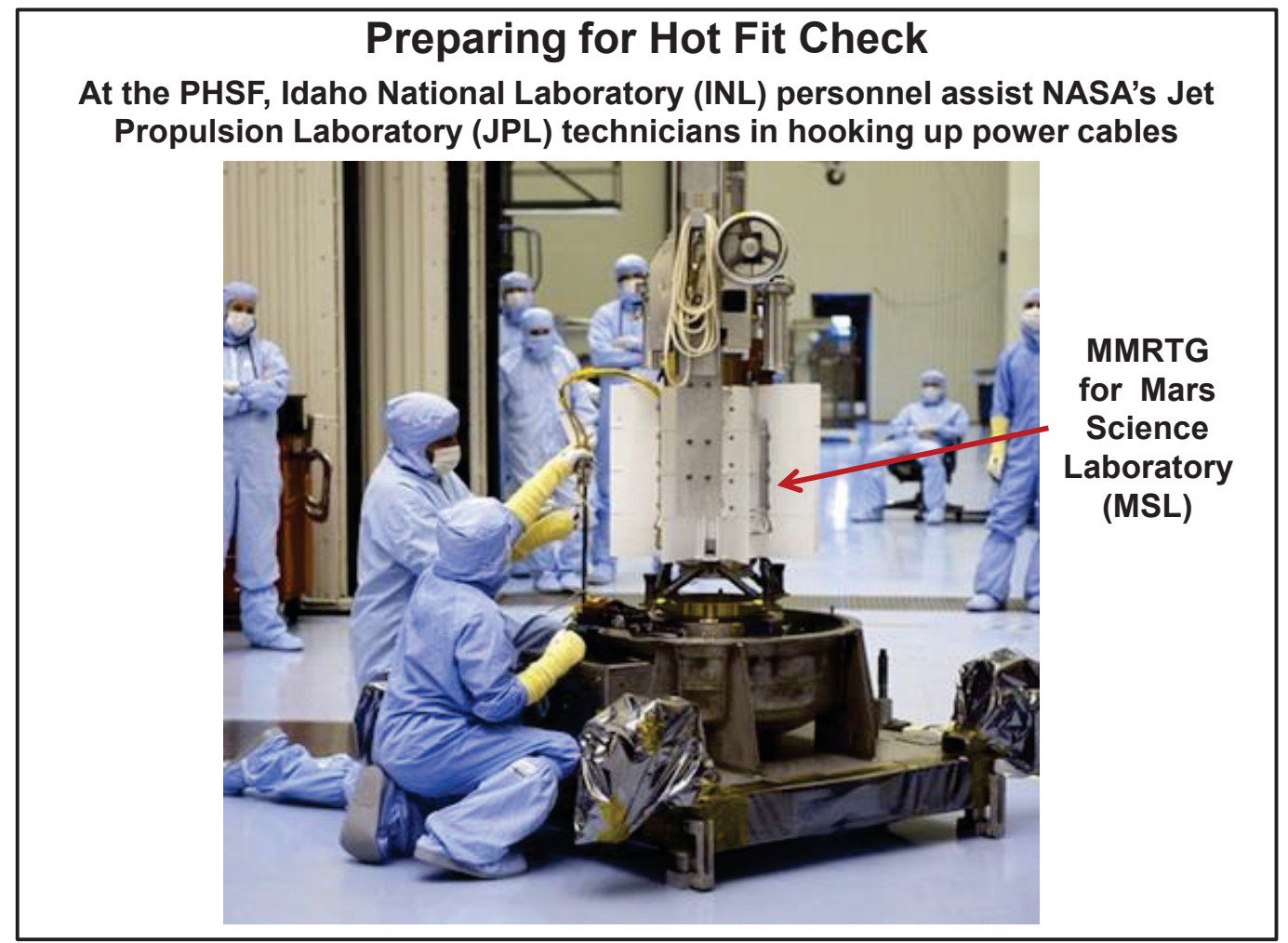

Figure 5-5. INL personnel assisting JPL technicians as they prepare for hot fit check.

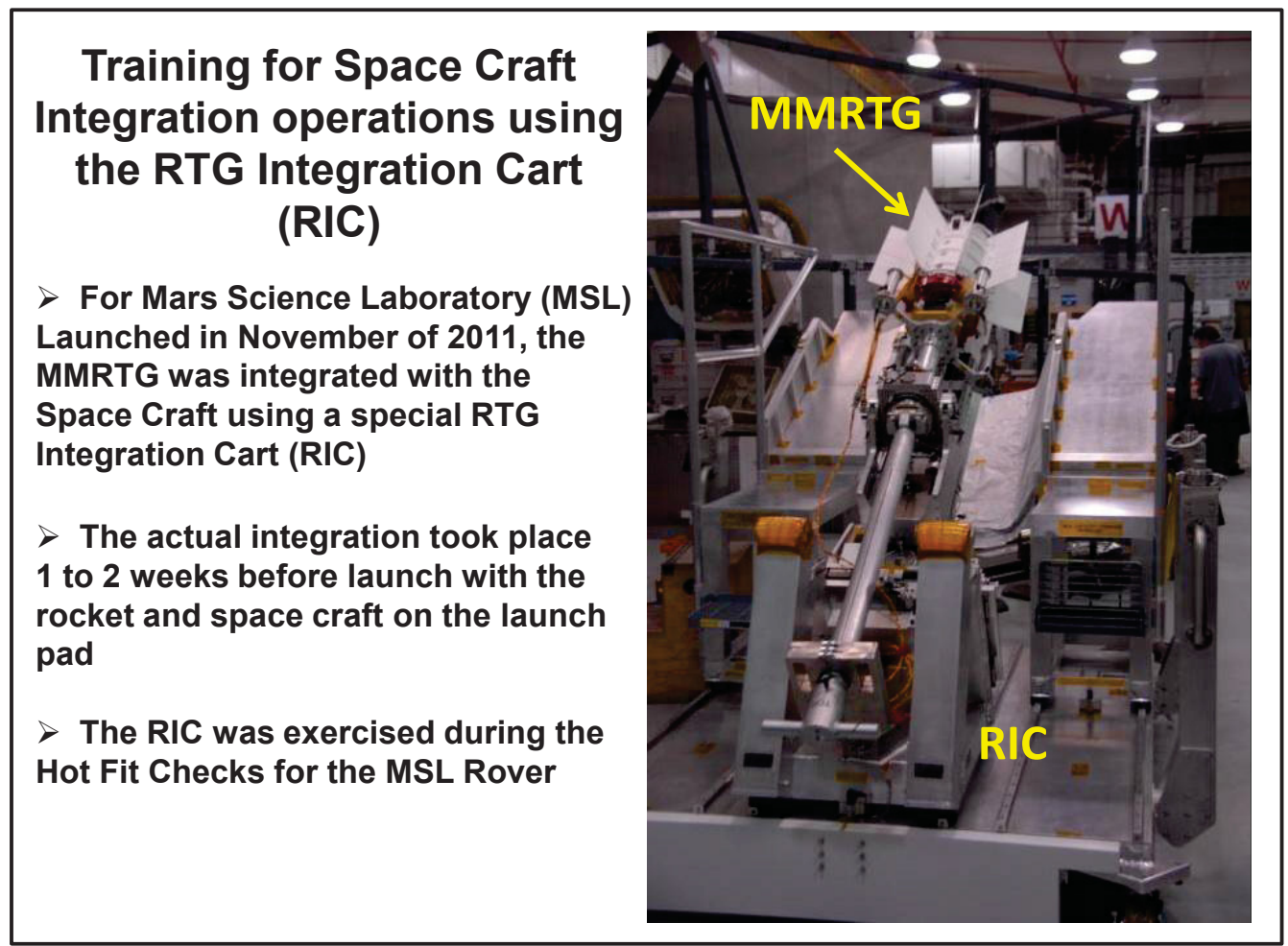

Figure 5-6. Training for spacecraft integration operations using the RIC. 


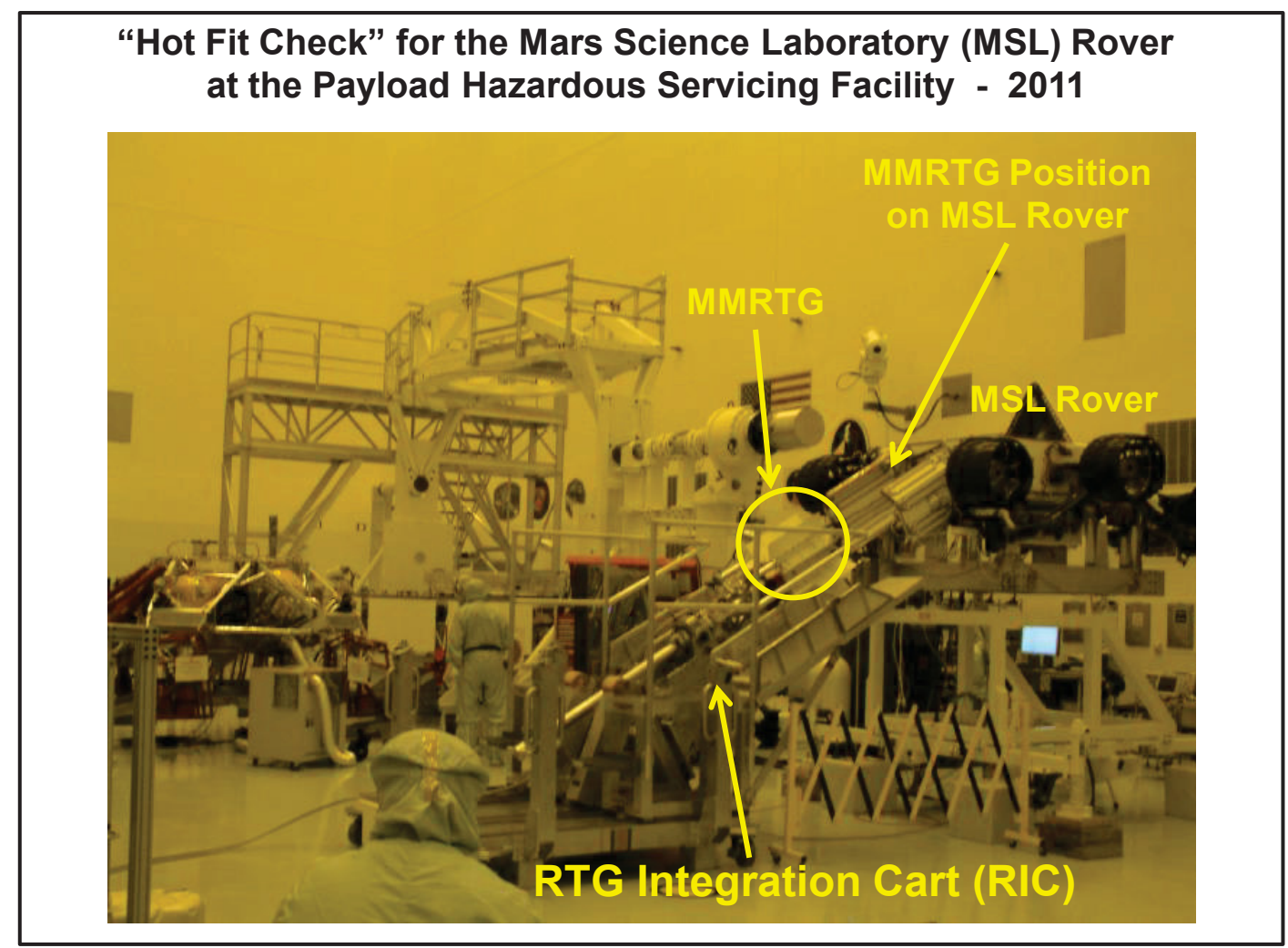

Figure 5-7. Hot fit check for the MSL rover at the PHSF.

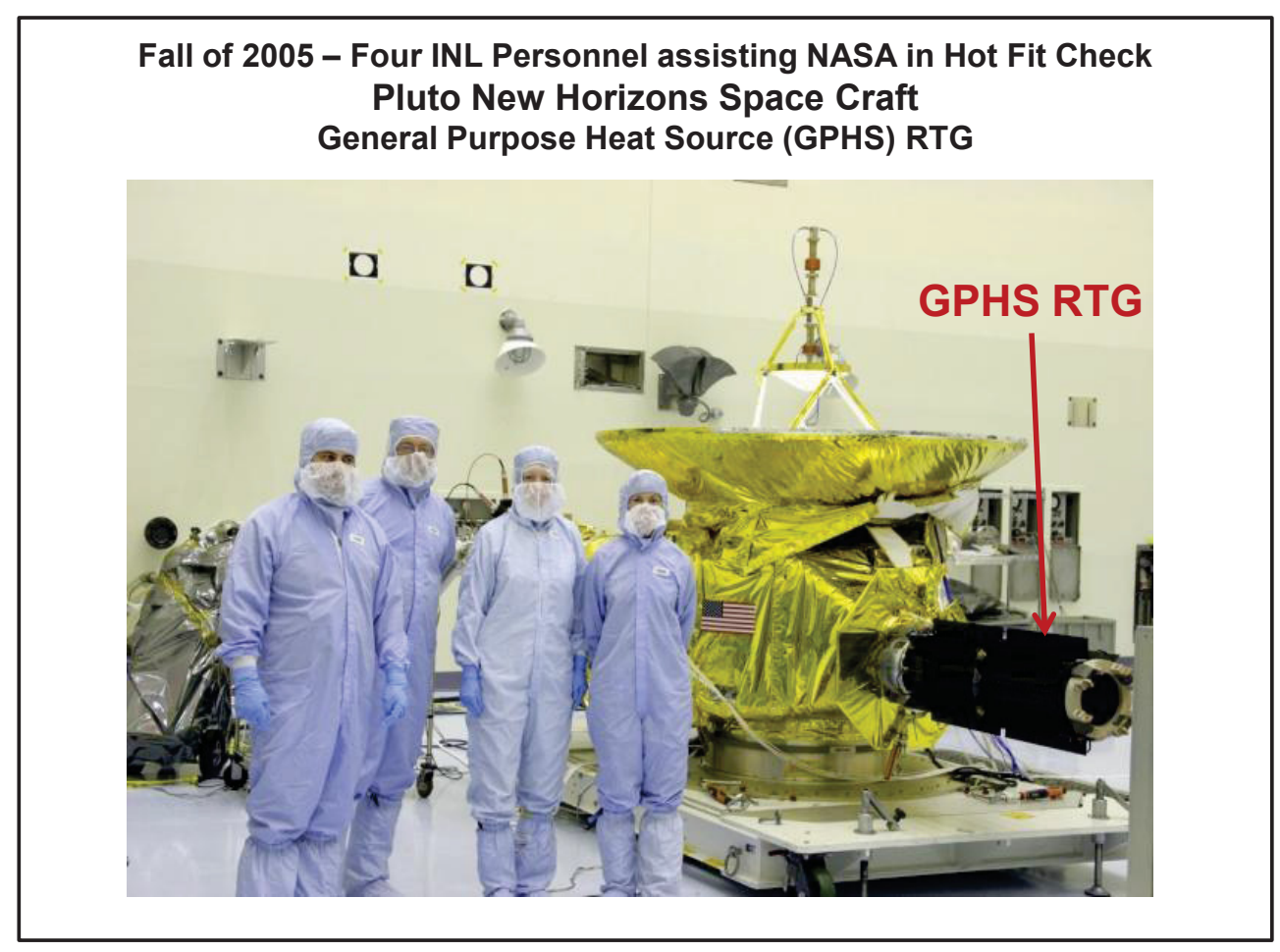

Figure 5-8. INL personnel assisting NASA in hot fit check for Pluto New Horizons spacecraft. 


\subsection{Final Integration with the Spacecraft}

The RTG is usually integrated with the spacecraft at the space launch complex (Figure 5-9), with the spacecraft fairing already seated on the rocket, through a hatch that is placed into the fairing.

\section{KSC Launch Complex - 41 \\ Vertical Integration Facility (VIF) to the left Launch Pad right center between lightning towers}

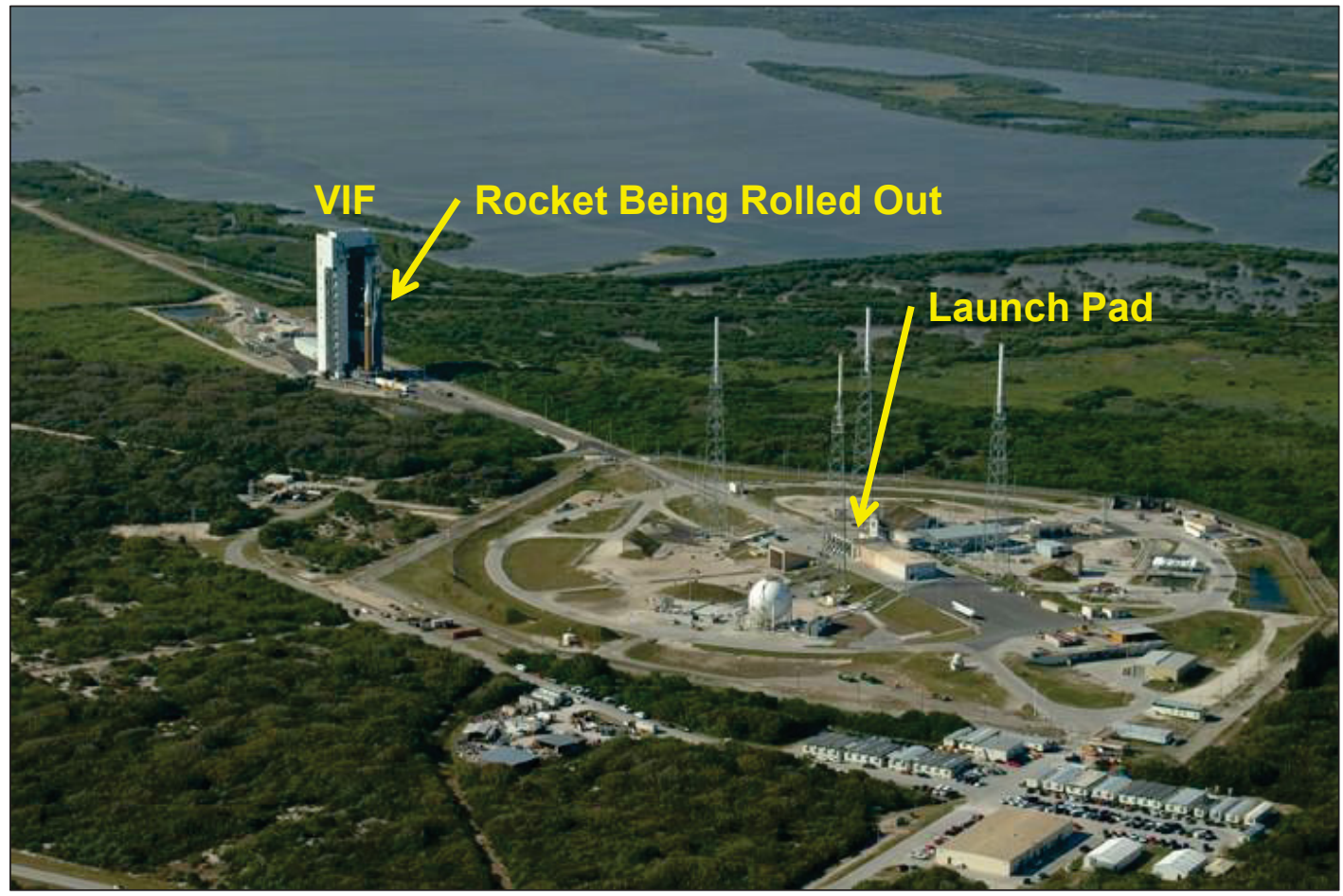

Figure 5-9. KSC launch complex.

The RTG is transported to the Vertical Integration Facility (VIF) at Launch Complex 41 (Figure 5-10) in a special protective enclosure called a Base Protective Cover Assembly, nicknamed the "Gorilla Cage." This takes place 1 to 2 weeks before launch. At the base of the VIF, the Base Protective Cover Assembly is attached to a crane and lifted to VIF Level 6 (Figure 5-11). On VIF Level 6, final checks are made (Figure 5-12) and the RTG is prepared for insertion into the spacecraft. It is then transferred to Level 5, where it is placed on the RTG Integration Cart (RIC) and inserted into the spacecraft through a hatch in the rocket nose fairing (Figure 5-16).

Final checks are made to ensure successful integration with the spacecraft and that all systems are functioning as required. At this point, the safety analysis for the launch is activated and final launch preparation activities are initiated. NE-75 staff members and INL contractor personnel are actively involved supporting the final launch preparations. 
Delivery of MMRTG for MSL to the Vehicle Integration Facility (VIF) Launch Complex 41

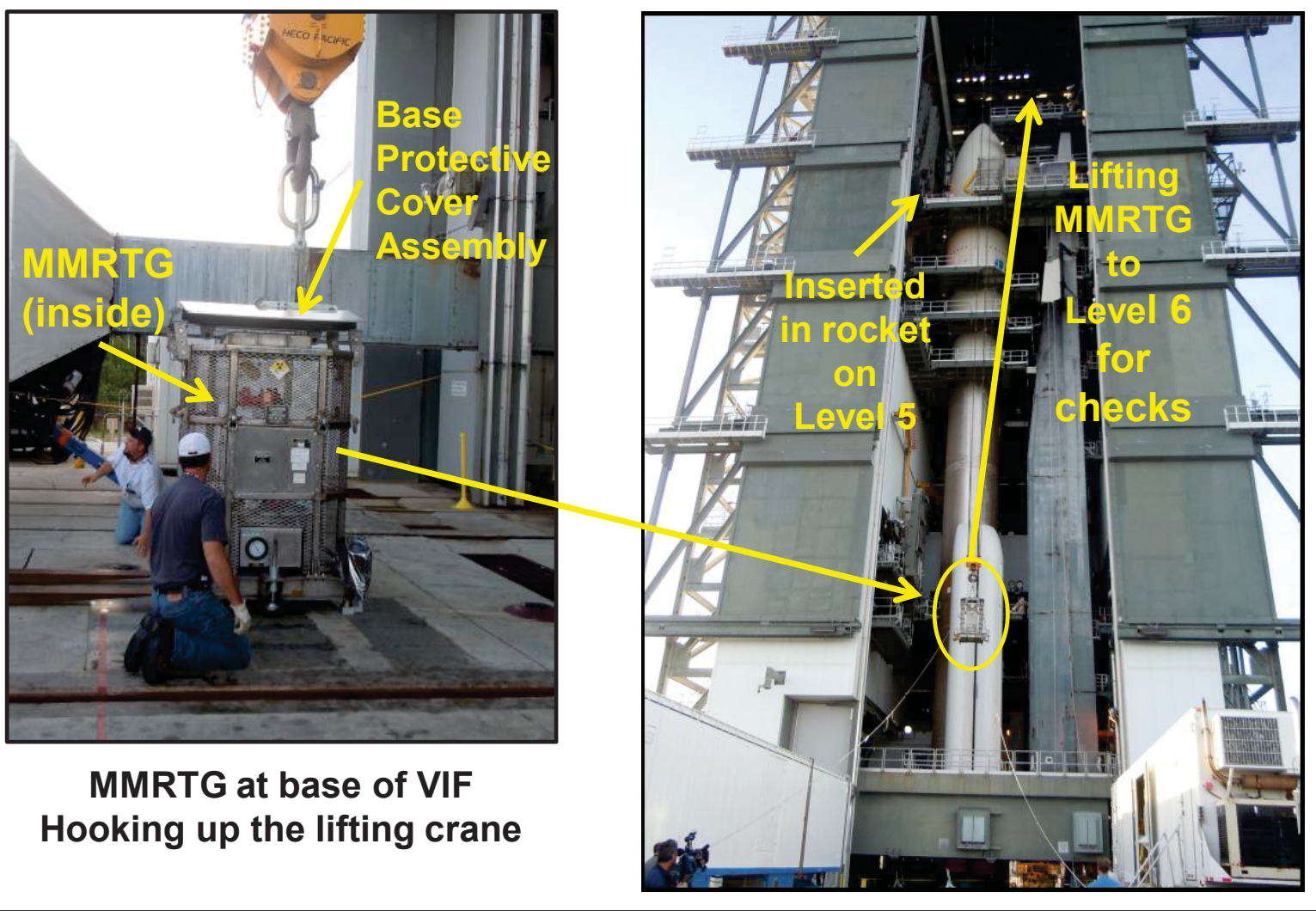

Figure 5-10. Delivery of MMRTG for MSL to the VIF Launch Complex 41. 


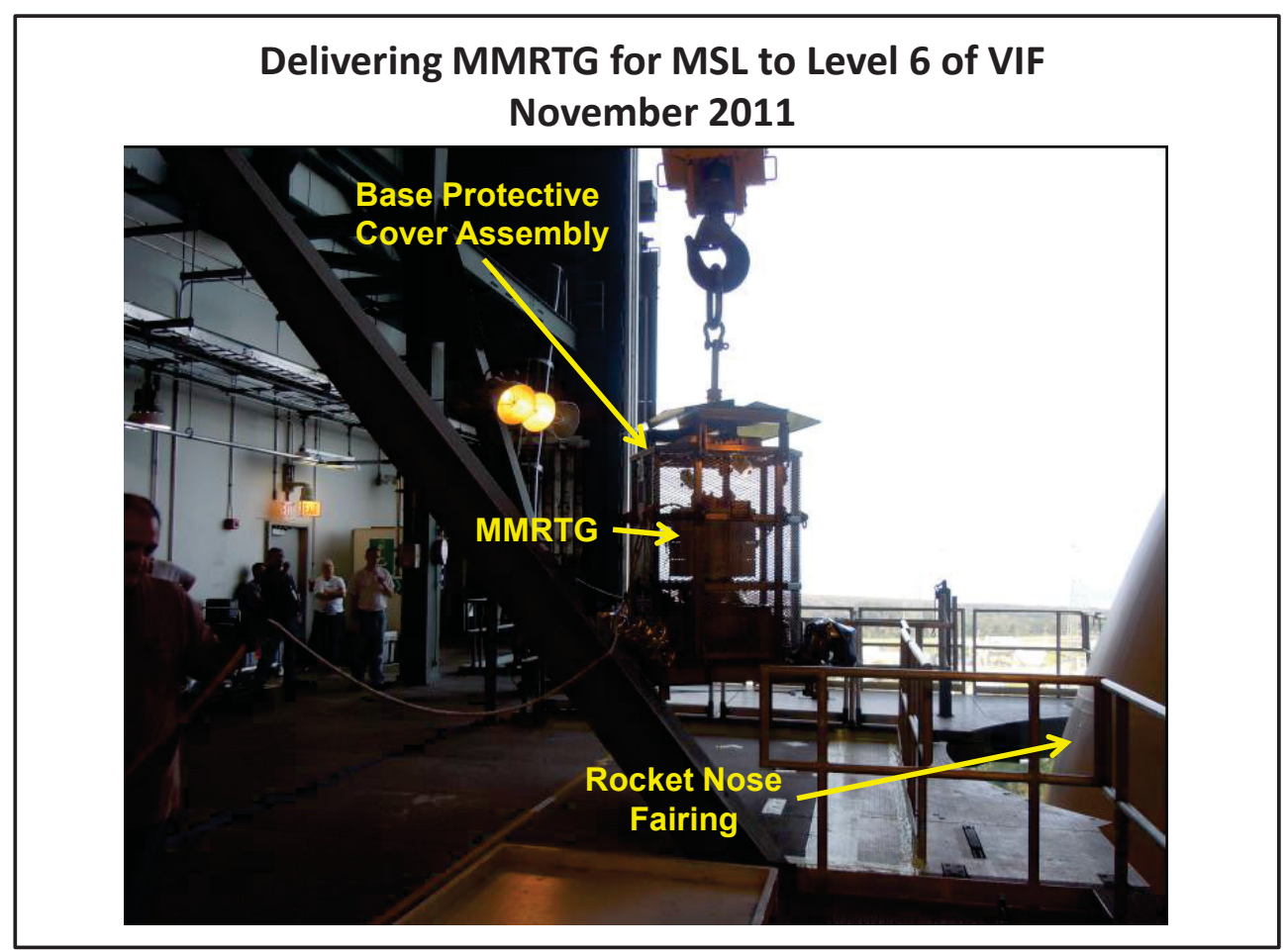

Figure 5-11. Delivery of MMRTG to Level 6 of VIF.

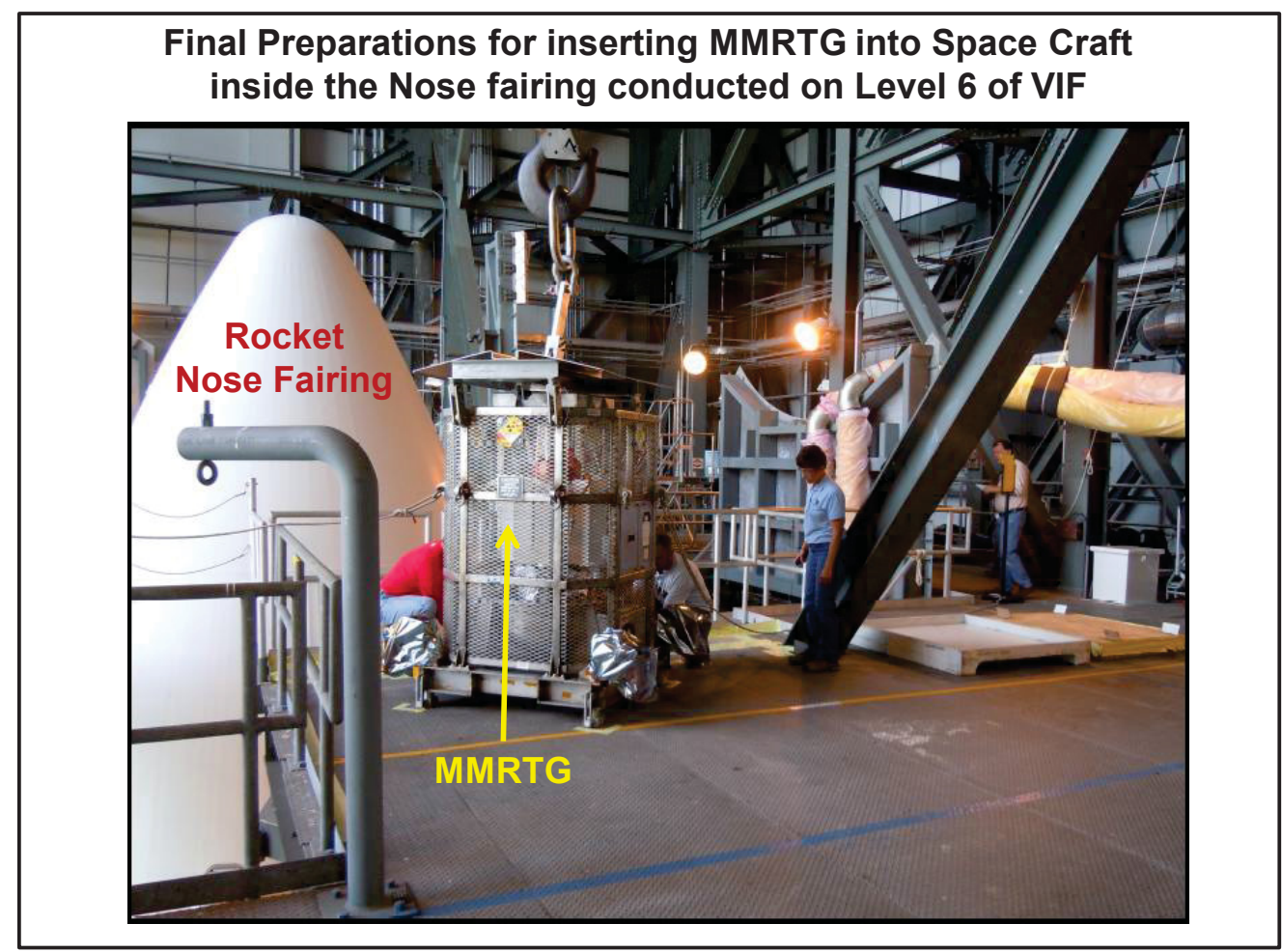

Figure 5-12. Final preparations for inserting MMRTG into spacecraft inside the noise fairing conducted on Level 6 of VIF. 


\section{On Level 5 of VIF, the MMRTG being placed on the MSL Rover using the} RTG Integration Cart (RIC) through hatch on the rocket nose fairing November 2011

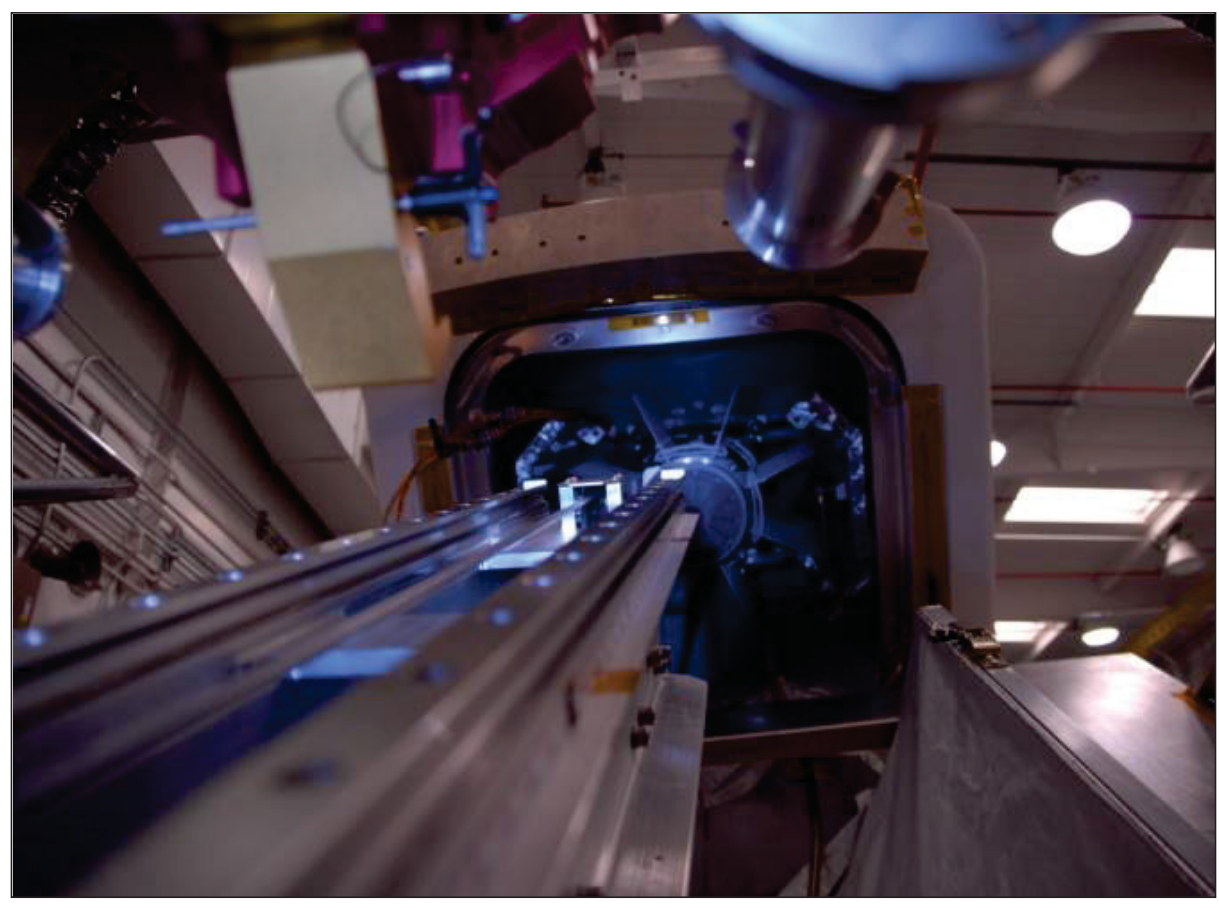

Figure 5-13. MMRTG being placed on the MSL rover using the RIC through rocket nose hatch on Level 5 of the VIF. 


\subsection{Recent Launches of NASA Missions Powered by RTGs}

Figures 5-14 and 5-15 illustrate the two most recent launches of NASA missions powered by RTGs.

\section{Pluto New Horizons Launch - January 19, 2006}

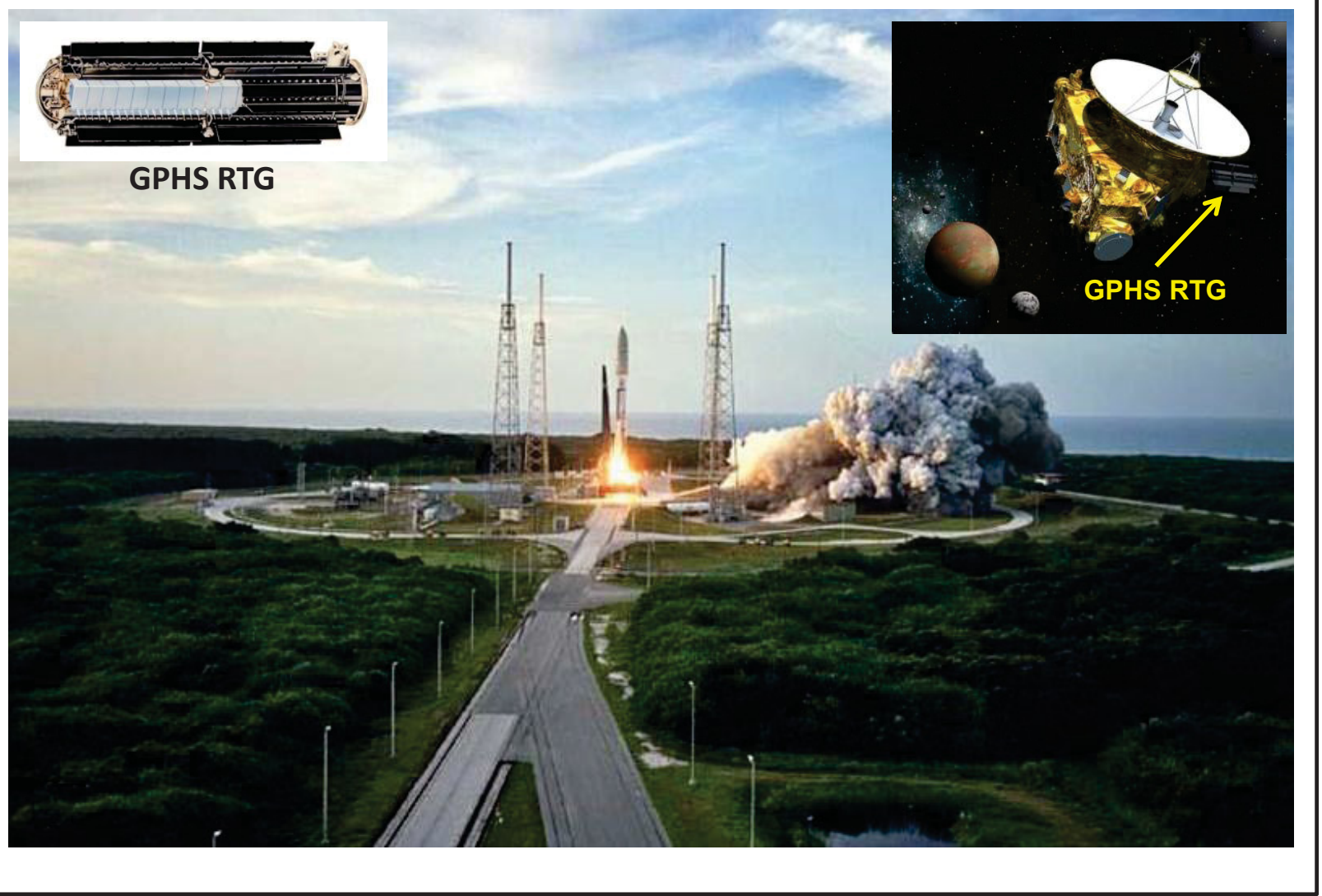

Figure 5-14. Pluto New Horizons launch - January 19, 2006. 


\section{Mars Science Laboratory Launch November 26, 2011}

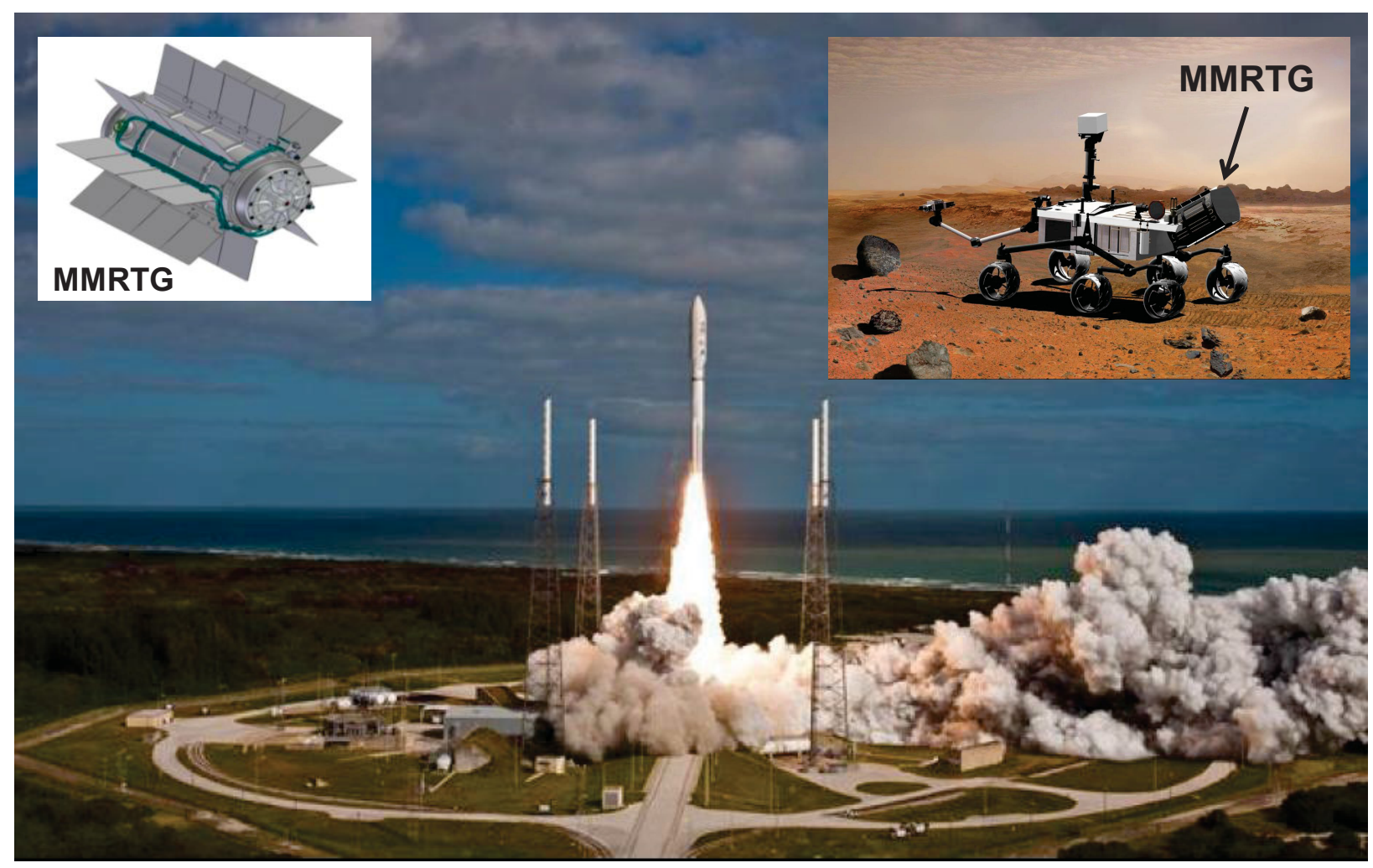

Figure 5-15. MSL launch - November 26, 2011. 


\section{REFERENCES}

10 CFR 71, 2000, Code of Federal Regulations, Title 10, "Energy," Part 71, "Packaging and Transportation of Radioactive Materials," Office of the Federal Register.

10 CFR 830, 2000, Code of Federal Regulations, Title 10, “Energy," Part 830, "Nuclear Safety Management," Office of the Federal Register. 